\title{
The role of Forests in Climate Change Mitigation:
}

A discursive institutional analysis of REDD+ MRV

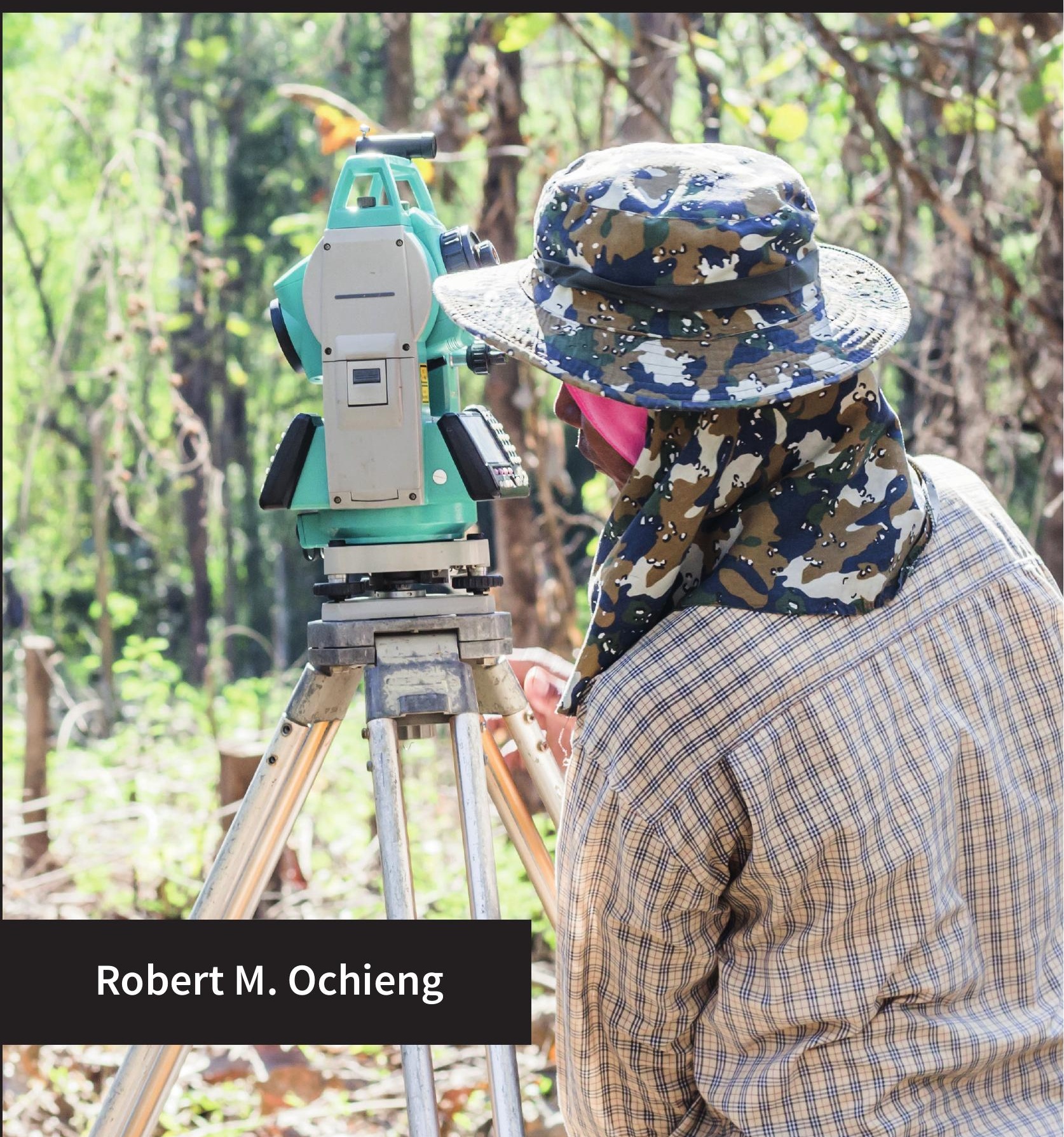


The role of forests in climate change mitigation: A discursiveinstitutional analysis of REDD+ MRV 


\section{Thesis committee}

\section{Promotors}

Prof. Dr B.J.M. Arts

Professor of Forest and Nature Conservation Policy

Wageningen University and Research

Prof. Dr M. Herold

Professor of Geo-information Science and Remote Sensing

Wageningen University and Research

\section{Co-promotors}

Dr I.J. Visseren-Hamakers

Associate professor, Department of Environmental Science and Policy

George Mason University, Virginia, USA

Prof. Dr Maria Brockhaus

Professor of International Forest Policy

University of Helsinki, Finland

\section{Other members}

Prof. Dr J.P.M. van Tatenhove, Wageningen University and Research

Prof. Dr.G.M.J. Mohren, Wageningen University and Research

Prof. Dr L. Giessen, University of Göttingen, Germany

Dr A. Gupta, Wageningen University \& Research,

This research was conducted under the auspices of the Wageningen School of Social Sciences (WASS) 


\title{
The role of forests in climate change mitigation: A discursive-institutional analysis of REDD+ MRV
}

\author{
Robert M. Ochieng
}

\section{Thesis}

submitted in fulfilment of the requirements for the degree of doctor at Wageningen University

by the authority of the Rector Magnificus

Prof. Dr A.P.J. Mol

in the presence of the

Thesis Committee appointed by the Academic Board

to be defended in public

on Tuesday 30 May 2017

at 4 p.m. in the Aula. 
Robert M. Ochieng The role of forests in climate change mitigation: A discursive-institutional analysis of REDD+ MRV,

172 pages.

$\mathrm{PhD}$ thesis, Wageningen University, Wageningen, the Netherlands (2017)

With references, with summaries in English, and Dutch

ISBN: 978-94-6343-171-2

DOI: $10.18174 / 412210$ 


\section{Table of Contents}

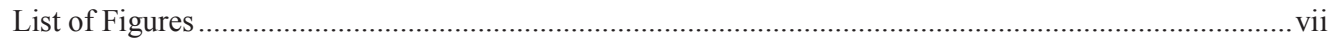

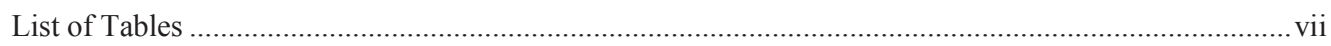

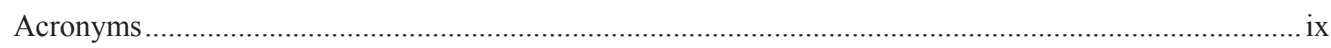

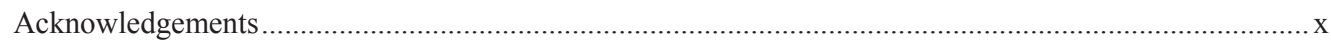

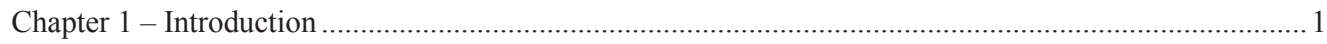

1.1. REDD+ and new demands for forest monitoring in developing countries ................................. 1

1.2. Scholarship on forest monitoring for REDD+ and emerging research gaps ................................. 4

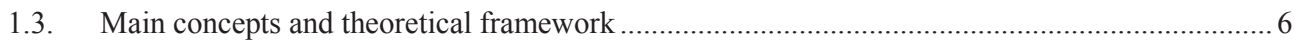

1.3.1. Regime theory and the concept of institutional effectiveness .......................................... 7

1.3.2. Discursive Institutionalism: A theory of discourses and institutions ................................. 9

1.3.3. Institutionalization and institutional change: the policy arrangement approach ................. 12

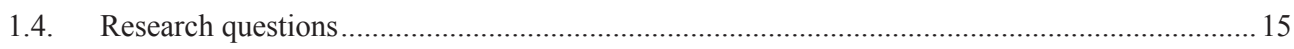

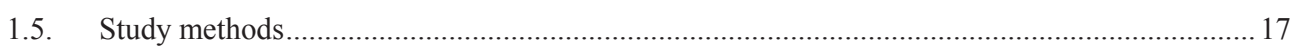

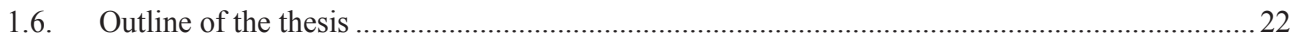

Chapter 2 - Institutional Effectiveness of REDD+ MRV: countries progress in implementing technical

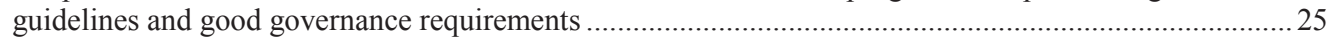

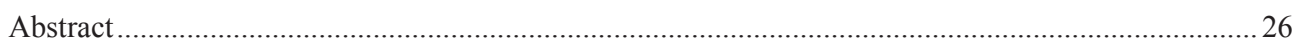

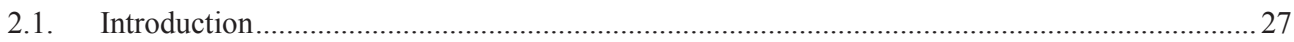

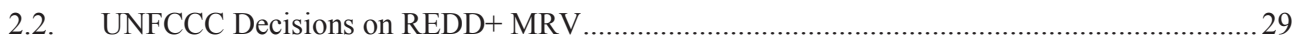

2.3. 'Institutions' and UNFCCC Guidelines on REDD+ MRV ......................................................... 30

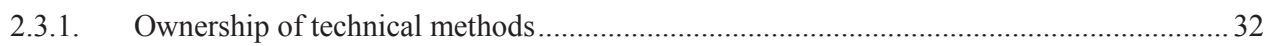

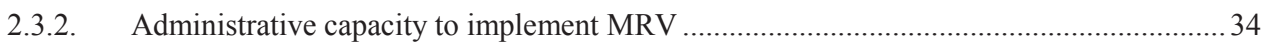

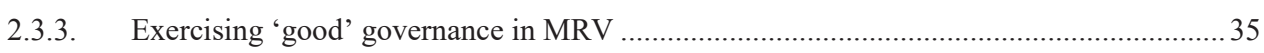

2.4. REDD+ countries progress in implementing technical guidelines and good governance

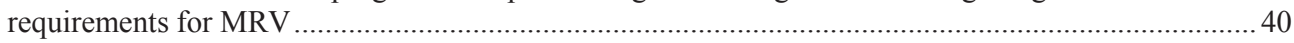

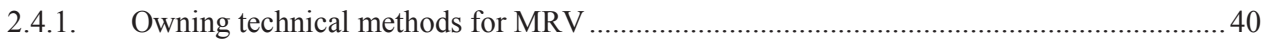

2.4.2. Developing administrative capacity to implement REDD+ MRV ..................................... 41

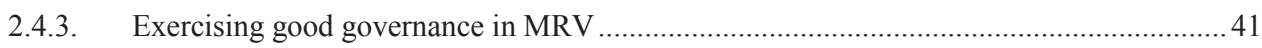

2.4.4. Countries' overall progress in implementing UNFCCC technical and good governance

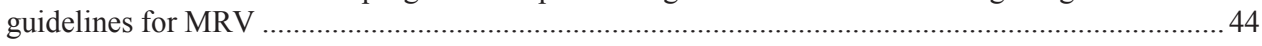

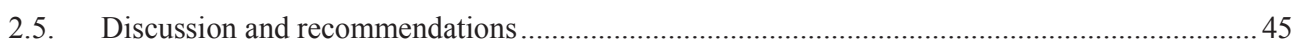

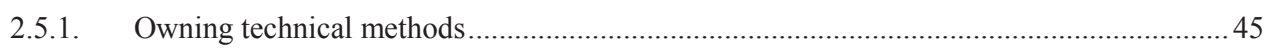

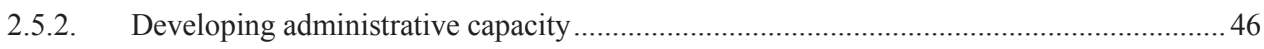

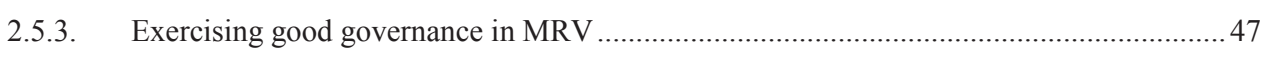

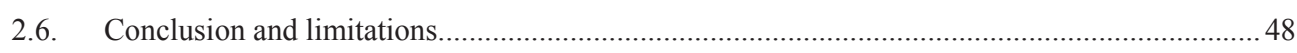


Chapter 3 - Historical development of institutional arrangements for forest monitoring and REDD+ MRV

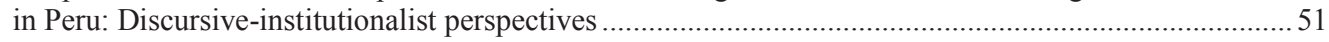

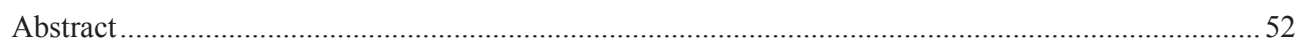

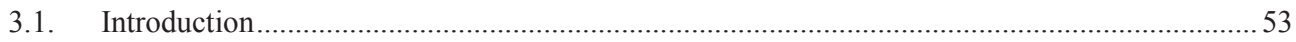

3.2. Discursive Institutionalism and the Policy Arrangement Approach ...........................................5 54

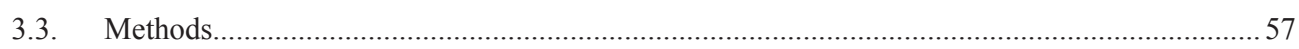

3.4. Evolution of institutional arrangements for forest assessments in Peru..................................... 58

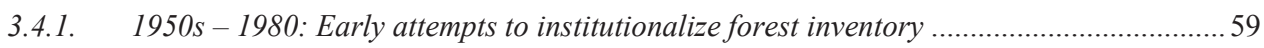

3.4.2. $1980 \mathrm{~s}$ - early 2000s: Broadening the scope of forest assessments ..................................... 60

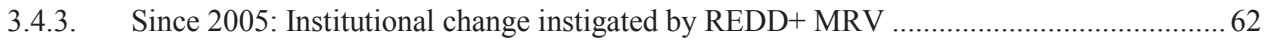

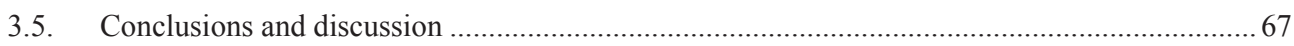

Chapter 4 - Institutionalization of REDD+ MRV in Indonesia, Peru and Tanzania: Progress and

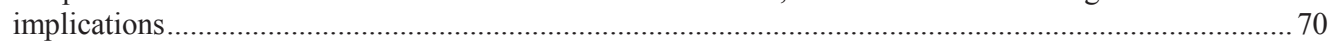

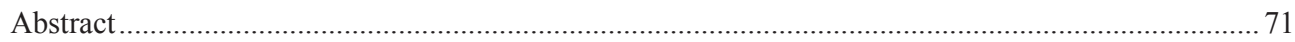

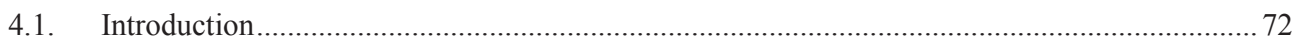

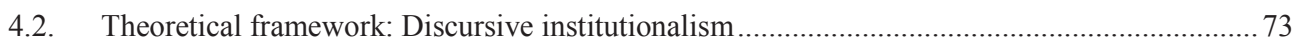

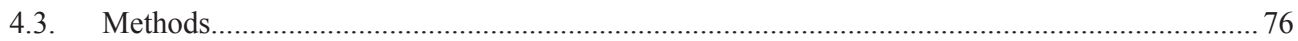

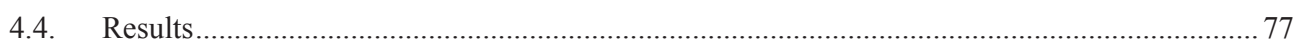

4.4.1. Institutionalization of MRV in Indonesia, Peru and Tanzania ............................................ 77

4.4.2. Exploring reasons for differences in institutionalization of MRV across countries ........... 85

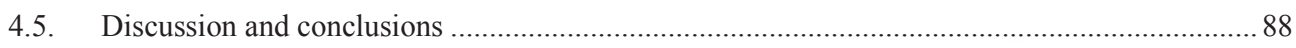

Chapter 5 - Does discourse matter in institutionalization? The case of REDD+ MRV in Indonesia, Peru

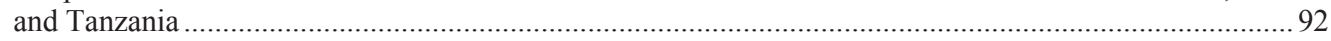

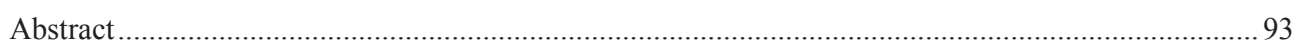

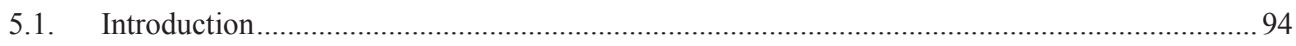

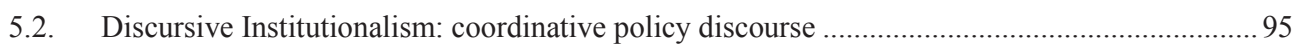

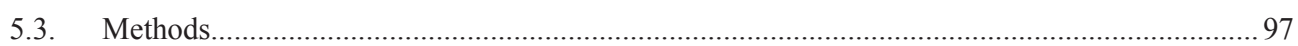

5.4. Discursive politics of MRV policymaking: actors, ideas and institutionalization ....................... 98

5.4.1. Inclusive and enabling $M R V$ discourse in Indonesia ...................................................... 98

5.4.2. Inclusive and facilitative MRV discourse in Tanzania ..................................................... 103

5.4.3. Exclusionary and constraining MRV discourse in Peru ............................................... 108

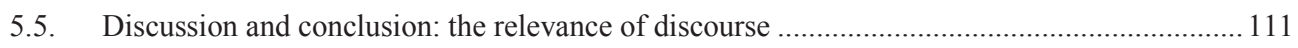

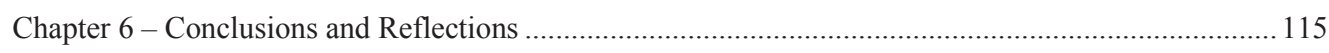

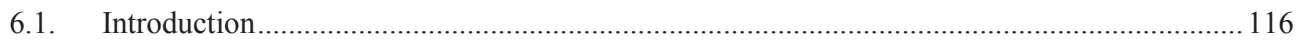

6.2. Varying institutional effectiveness of REDD+ MRV across 13 countries................................ 117

6.3. Shallow institutionalization of REDD+ MRV in Peru............................................................ 119

6.4. Varying degrees of institutionalization of MRV in Indonesia, Peru and Tanzania ................... 122 


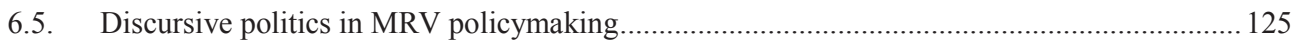

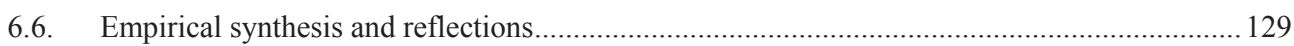

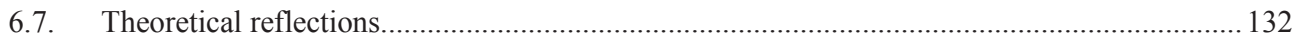

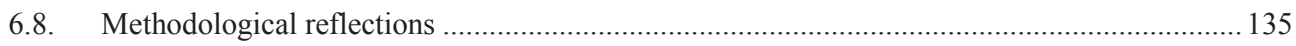

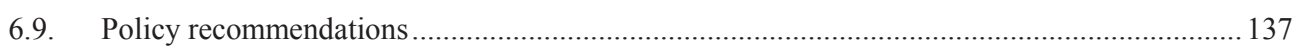

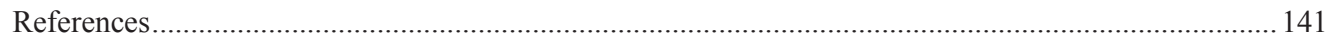

Summary - The role of forests in climate change mitigation: A discursive-institutional analysis of

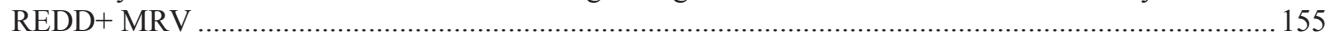

Samenvatting - De rol van bossen in de strijd tegen klimaatverandering: een discursief-institutionele

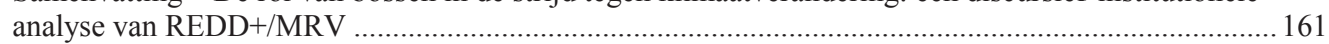

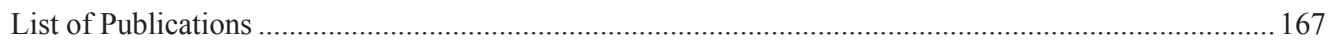

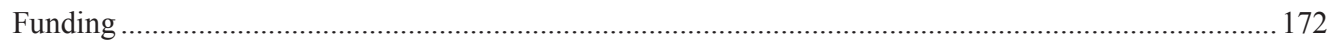

\section{List of Figures}

Figure 1.1: A nested case of institutional effectiveness and institutionalization of REDD+ MRV in

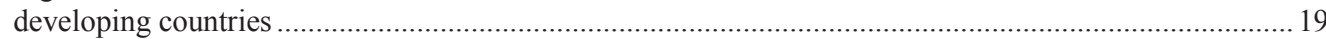

Figure 4.1: Historical development of institutional arrangements for forest measurement in Peru ........... 75

\section{List of Tables}

Table 1.1: Forest, Deforestation and REDD+ Facts: Indonesia, Peru and Tanzania ................................20

Table 1.2: Number of respondents by category and country .................................................................22

Table 2.1: Framework for assessing REDD+ countries progress in implementing technical guidelines and

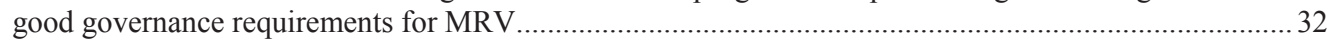

Table 2.2: Framework for assessing REDD+ countries' progress in implementing UNFCCC technical guidelines and good governance requirements for MRV ........................................................................ 37

Table 2.3: Progress in owning technical methods for MRV ................................................................. 40

Table 2.4: Countries' progress in developing administrative capacity for MRV ..................................... 41

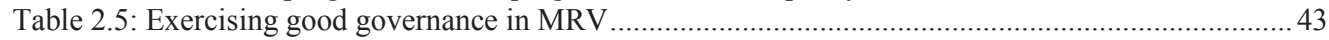

Table 2.6: Countries' aggregate score on each dimension of and overall effectiveness of REDD+ MRV 45

Table 3.1: Framework for assessing extent of institutional change (Adapted from Wiering and Arts, 2006)

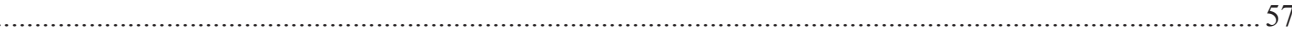

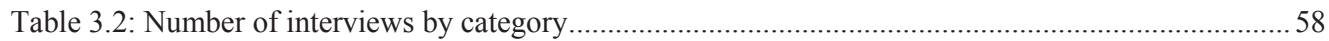

Table 3.3: Historical development of institutional arrangements for forest measurement in Peru............... 66

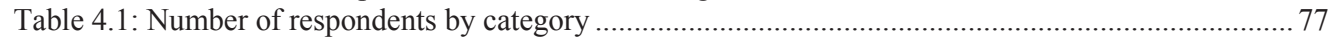

Table 4.2: Summary of institutionalization of REDD+ MRV in Indonesia, Peru and Tanzania ................. 84

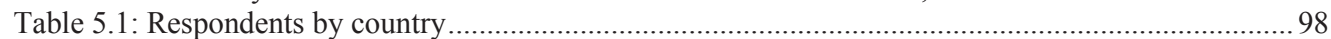

Table 6.1: Summary of countries' institutional effectiveness ..................................................................... 118

Table 6.2: Depth of institutional change instigated by different international discourses on forests ....... 121

Table 6.3: Summary of extent of institutionalization of REDD+ MRV in Indonesia, Peru and Tanzania

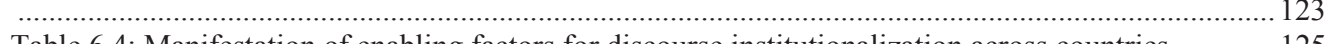

Table 6.4: Manifestation of enabling factors for discourse institutionalization across countries .............. 125

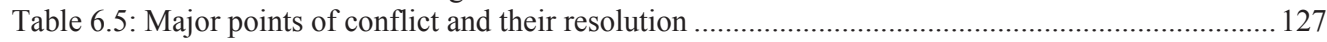




\section{Acronyms}

CIFOR: Centre for International Forestry Research

COP: $\quad$ Conference of the Parties

DG: Directorate General

DI: $\quad$ Discursive Institutionalism

DRC: $\quad$ Democratic Republic of Congo

EF: $\quad$ Emission Factor

FAO: $\quad$ Food and Agricultural Organization of the United Nations

FCPF: $\quad$ Forest Carbon Partnership Facility of the World Bank

FDG: $\quad$ Focus Group Discussion

FIP: $\quad$ Forest Investment Programme of the World Bank

GCS: $\quad$ Global Comparative Study on REDD+

GHG: Greenhouse Gas

INCAS: Indonesian National Carbon Accounting System

INDC: $\quad$ Intended Nationally Determined Contributions

IPCC: Intergovernmental Panel on Climate Change

IRA-UDSM: Institute of Resource Assessment, University of Das es Salaam

LULUCF: $\quad$ Land Use, Land Use Change and Forestry

MINAM: $\quad$ Ministry of Environment, Republic of Peru

MoEF: $\quad$ Ministry of Environment and Forestry, Republic of Indonesia

MoU: $\quad$ Memorandum of Understanding

MRV: $\quad$ Monitoring, Reporting and Verification

NAFORMA: National Forest Monitoring and Assessment, Tanzania

NCMC: $\quad$ National Carbon Monitoring Centre of the United Republic of Tanzania

NFI: $\quad$ National Forest Inventory

NFMA: $\quad$ National Forest Monitoring and Assessment

NFMS: National Forest Monitoring System

NGO: Non-Governmental Organization

NICFI: $\quad$ Norwegian International Climate and Forest Initiative

PAA: $\quad$ Policy Arrangement Approach

PNG: $\quad$ Papua New Guinea

REDD+: $\quad$ Reducing Emission from Deforestation and forest Degradation in Developing Countries; and the role of conservation, sustainable management of forests and enhancement of carbon stocks in developing countries

RS: $\quad$ Remote Sensing

SBSTA: $\quad$ Subsidiary Body for Scientific and Technological Advise

SERFOR: Forest Service of the Republic of Peru

TFS: $\quad$ Tanzania Forest Service

UN REDD: United Nations Programme on Reducing Emissions from Deforestation and Forest Degradation

UNFCCC: United Nations Framework Convention on Climate Change

VPO-DoE: Vice President's Office, Department of Environment 


\section{Acknowledgements}

Many people contributed to the success of this $\mathrm{PhD}$ research and I would like to acknowledge their contributions. First, this $\mathrm{PhD}$ research has been made possible through financial support and scholarship from the Centre for International Forestry Research (CIFOR) and their inspiring research project Global Comparative Study on REDD+. I am grateful to CIFOR for the scholarship. Second, I would also like to thank my mentors through this PhD journey. Thank you Bas for accepting me as one of your PhDs, and for your constructive comments and feedback. Ingrid, thank you for believing in my capacity to complete a PhD. Thank you also for providing the constructive criticism and inspiration needed to accomplish a $\mathrm{PhD}$. Maria, I am very grateful for the many opportunities you created for me to share my ideas and learn from others. I am also grateful for your constructive comments and inputs in all the chapters of the dissertation. Martin, thank you for accepting me as one of your PhDs, and for your contributions to the dissertation.

Third, this study was conducted at the great Wageningen University and Research (WUR). I want to thank the WUR for providing a conducive and challenging learning environment. It has been a pleasure being at the Forest and Nature Conservation Policy Group (FNP). I would like to thank the entire FNP fraternity (Professors, Assistant Professors, Lecturers) for their hospitality. I am especially grateful to Thomas for being a supportive and fun office-mate, and to Cinthia, Joana, Alex, Margreet and Albertina for the many discussions we had over concepts and theories. I am also grateful to Carla and Audrey for their support with administrative matters.

Fourth, the field work for this PhD was conducted in Indonesia, Peru and Tanzania. I am grateful for the inputs and expertise shared by interviewees and experts in all the countries that are too many to mention here. However, I would like to thank the following people for helping me during my fieldwork. In Peru, sincere appreciation goes to Prof. Victor Berrena, Prof. Carlos Vargas, Prof. Carlos Llerena, Prof. Emeritus Jorge Malleux and Angel Armas for their insights on the Peruvian forestry sector. Special gratitude to Prof. Barrena for personally making the necessary calls and connections to secure interview appointments. Thanks are also due to Rocio Malleux and her team at the 'Forest Observation Room', and especially Alejandra Zamora. In Indonesia, sincere thanks goes to Tom Harvey, Dr. Bellinda Margono, Dr. Haruni Krisnawati, Dr. Agus Sari and Dr. Taufiq. I am also grateful to the CIFOR GCS Module I team for their 
support. I am especially grateful to Christine Wairata, Efrian Muharrom, Cynthia Maharani, Bimo Dwisatrio and Rahayu Koesnadi for facilitating field logistics. In Tanzania, sincere gratitude goes to Nurdin Chamuya, Faustine Ninga, Prof. Rodgers Malimbwi and Dr. Eliakimu Zahabu for both their insights and making the necessary connections to secure interview appointments. I would also like to thank my field assistants Lody Junio and Sonya Dewi (Indonesia); Elizabeth Romero (Peru); and Athmani Rama and Petty Paul (Tanzania) for helping with the interviews and translations.

Fifth, back in Kenya, I have been blessed by people who have mentored and encouraged me in my academic and professional life. Prof. Donald Ogweno, I am grateful for the opportunities you created for me to learn and gain experience. Thank you also Donald for teaching several means to earn a living. Dr. Evans Kituyi, I am grateful for your mentorship, partnership and friendship. Dr. Harrison Kojwang, I am thankful for the many consultancy opportunities you accorded me. Dr. Joshua Cheboiwo, I am grateful to for the opportunity to work and learn from KEFRILondiani projects. Friends are like jewels and I would like to thank my friend Kephas Okach and his wife Margaret for their friendship. I am also grateful for the friendship and encouragement of Willis Ombai, Fred Ayuke, Vincent Oluoch, Geoffrey Ogutu, Steve Ichami, Caroline Lumosi, Faith Mutavi, Hellen Kimanthi, Marjanneke Vijge, Evi Andriyani, Febrina Desrianti, Robert Okayo, and all Kenyans in WUR.

Finally, I would like to thank my family for their love, friendship and unwavering support. Mama Grace and Mzee Nelson, thank you for the gift of life. Sincere thanks to my dear grandma, Mama Debora Akumu, for the sound up-bringing during my early childhood. Dear Lydia, thank you for taking care of our family and children while I have been away. Thank you beautiful, also for your love, affection and friendship. Trina and Jamie, I love you more than you can imagine. I hope one day you will read this dissertation to not only appreciate why I was always away, but also to inspire you in your own academic and professional careers.

\section{Robert M. Ochieng}

Wageningen, May 2017 
Chapter 1 - Introduction 


\subsection{REDD+ and new demands for forest monitoring in developing countries}

Deforestation and forest degradation is the second largest source of carbon dioxide emissions, after fossil fuels (IPCC, 2014). Estimates indicate that up to $20 \%$ of total net anthropogenic carbon emissions come from land use and land-use change, especially deforestation and forest degradation (Denman et al., 2007; Holly and Martin, 2007; Schrope, 2009). Most of this deforestation and forest degradation occurs in tropical developing countries (FAO, 2015; IPCC, 2014). Although the rate of global deforestation has slowed by $50 \%$ over the last five years, the world is still losing its forests at an annual rate of 7.6 million ha with adverse consequences for humanity, the climate and biodiversity (FAO, 2015). Thus, reducing emissions from deforestation and forest degradation in developing countries $\left(\operatorname{REDD}+^{1}\right)$ has been negotiated and adopted within the United Nations Framework Convention on Climate Change (UNFCCC) as one of the strategies to mitigate climate change (UNFCCC, 2014a, b). Proponents argue that limiting global warming to under $1.5^{\circ} \mathrm{C}$ cannot be achieved without REDD+ (Angelsen et al., 2009; IPCC, 2014). Experts assert that REDD + provides a carbon-effective, cost-efficient, and equitable mechanism for reducing emissions from deforestation and forest degradation while improving local livelihoods and enhancing biodiversity conservation (IPCC, 2014; Metz et al., 2007; Santilli et al., 2005; Stern, 2007).

The UNFCCC has outlined a three-phased approach to implementing REDD+ (Angelsen et al., 2012; UNFCCC, 2010, 2014a). Phase I - the 'readiness' phase - involves developing national strategies, policies and measures, accounting frameworks and capacity building. Phase II - the 'implementation' phase - involves implementation of national strategies, policies and measures, technology development and results-based demonstration activities. Phase III - the 'results-based payment' phase - involves payments for fully measured, reported and verified emission reductions. In getting 'ready' and 'implementing' REDD+, the UNFCCC identifies four elements that REDD+ countries must establish (UNFCCC, 2010). The first is development of national REDD + strategies and action plans. This entails detailed assessment of a country's situation with respect to deforestation and forest degradation, relevant governance issues, and a proposition of

\footnotetext{
${ }^{1}$ REDD+ in full is: Reducing Emission from Deforestation and forest Degradation in Developing Countries; and the role of conservation, sustainable management of forests and enhancement of carbon stocks in developing countries.
} 
policies and measures to realize REDD+. The second is setting of forest reference emission levels. This is a baseline of emissions against which any future emission reductions would be monitored. The third is development of a national monitoring, reporting and verification (MRV) system to monitor, account for and internationally report on any changes in carbon emissions as a basis for payments. The last is development of REDD+ safeguards to ensure that REDD+ activities do not compromise the livelihood of forest dependent communities and contribute to biodiversity conservation.

UNFCCC negotiations on REDD+ were concluded at the $21^{\text {st }}$ Conference of the Parties in 2015, and many tropical developing countries identify REDD+ as one of their Intended Nationally Determined Contributions (INDCs) to climate change mitigation as part of the Paris Climate Agreement. Since 2008 several developing countries (henceforth REDD+ countries) have been involved in REDD+ 'readiness' and demonstration activities (Angelsen et al., 2012), although only a few have moved to the 'implementation' phase (Korhonen-Kurki et al., 2013). Simultaneously, several bi- and multi-lateral agencies were launched to support REDD+ countries in their readiness and demonstration activities. Prominent among these are the Forest Carbon Partnership Facility and the Forest Investment Program of the World Bank, the UN REDD Program, and the Norwegian International Forest and Climate Change Initiative.

As REDD + is based on the idea that developed countries could pay developing countries for reducing emissions from deforestation and forest degradation, developing a robust and transparent national forest monitoring system to monitor, report and verify (MRV) impacts is one of the critical elements to be established during the readiness and implementation phases (Meridian Institute, 2009; UNFCCC, 2010, 2014b). This is especially so because without an MRV system, REDD+ countries cannot estimate and report on their emission reductions and thereby receive results-based payments. This dissertation therefore deals with the extent to which the concept of monitoring, reporting and verifying (MRV) REDD+ outcomes has been institutionalized in developing countries.

Although the concept of MRV is new, the concept of forest monitoring is not. Since the advent of professional forestry in the $17^{\text {th }}$ Century (Westoby, 1989; Wiersum, 1995; Wiersum et al., 2012), 
forest monitoring has been part and parcel of forest management, and has been implemented in different forms in many European countries. Systematic national forest monitoring however, began only in the early $19^{\text {th }}$ Century. The practice of forest monitoring was later exported to the European colonies, and has since been taken over and conducted by post-colonial governments in many developing countries (FAO, 1993; Freitas et al., 2010; Lei et al., 2010; McRoberts and Tomppo, 2007; Tomppo et al., 2010a). From an earlier focus on assessment of timber stocks, the practice has evolved to include assessments of other forest variables than timber (Mohren et al., 2012) such as 'extent of forests' and 'forest health and vitality'. Despite this evolution, national forest monitoring has remained largely timber-oriented, and a 'closed' system with little participation of actors outside the state forestry bureaucracy.

The emergence of UNFCCC's decisions on REDD+ in general and MRV in particular has however introduced new ideas and demands for forest monitoring in developing countries. REDD+ countries are not only required to monitor, report and verify REDD+ impacts but also to establish National Forest Monitoring Systems (NFMS) to perform MRV (UNFCCC, 2009, 2010). The established NFMS are required to (1) use a combination of remote sensing and ground-based methods, (2) provide estimates that are transparent, accountable and publicly available, and (3) involve non-state actors including indigenous and forest communities (UNFCCC, 2009). These demands can be read as calls for change in the institutional arrangements for forest monitoring in developing countries for three reasons. First, while forest monitoring has largely been concerned with assessment of timber stocks (Mohren et al., 2012), MRV requires assessment of an additional forest variable: forest carbon stocks and their changes.

Second, the UNFCCC encourages REDD+ countries to engage indigenous and local communities in forest monitoring (UNFCCC, 2009), and to provide forest carbon estimates that are transparent and accountable. Additionally, although forest monitoring has been the exclusive domain of state forestry officials, the requirement to use both remote sensing and ground-based methods presupposes involvement of other state agencies, since remote sensing is traditionally vested in non-forestry agencies. This implies the need to ensure broader participation, transparency and accountability in forest monitoring for REDD+. Given that participation, transparency and accountability constitute key principles of 'good' governance (Kishor and Rosenbaum, 2012; 
Secco et al., 2013), it can be argued that these demands call for 'good' governance in national forest monitoring and carbon accounting for REDD+. Third, the UNFCCC specifies the technologies and methodologies for measuring forest area and area changes, and for estimating forest carbon emissions (IPCC, 2003, 2006; UNFCCC, 2009). Taken together, these demands call for changes in the scope and objectives of forest monitoring, the constellation of actors involved, and the technologies that may be used. In other words, these demands call for changes in the 'what', 'who' and 'how' of national forest monitoring (cf. Gupta et al., 2014).

\subsection{Scholarship on forest monitoring for REDD+ and emerging research gaps}

The UNFCCC decisions on forest monitoring for REDD+ have elicited considerable research. Many researchers (De Sy et al., 2012; Grainger and Obersteiner, 2011; Herold, 2009; Herold and Johns, 2007; Herold and Skutsch, 2011; Palmer Fry, 2011; Pratihast et al., 2013; Romijn et al., 2012; Skutsch and McCall, 2010) have examined the technical capacity of REDD+ countries to monitor REDD+ impacts. These researchers have concluded that most REDD+ countries not only have low technical capacity but also weak institutional capacity to monitor REDD+ impacts. Although this research has provided useful insights, three issues remain under-researched.

First, despite the conclusion that REDD+ countries have low technical and weak institutional capacity, subsequent research has mainly been concerned with developing new technologies for monitoring deforestation and forest degradation (e.g. Asner et al., 2009; GOFC-GOLD, 2010, 2013; Hansen et al., 2013; Hansen et al., 2008; Pratihast et al., 2012; Verbesselt et al., 2012). The extent to which existing institutional arrangements for forest monitoring in developing countries fulfil the technical and governance requirements imposed by REDD+ remain under studied. As Grainger and Obersteiner (2011) also observe, the few studies that have attempted to examine whether REDD+ countries fulfil UNFCCC's requirements for MRV (e.g. Romijn et al., 2012; Romijn et al., 2015) have concentrated on technical aspects only, leaving out institutional and governance aspects. This dissertation addresses this research gap by examining REDD+ countries' progress in meeting technical and governance requirements for MRV. It does so by firstly drawing on regime literature to conceptualize the UNFCCC and its decisions on REDD+ MRV as institution, and secondly by applying the concept of institutional effectiveness to assess the extent to which REDD+ countries meet the mentioned requirements. 
Second, and as argued above, the UNFCCC decisions call for changes in institutional arrangements for forest monitoring in REDD+ countries. Following the Policy Arrangement Approach (Arts and van Tatenhove, 2006; Liefferink, 2006b, see below), institutional arrangements for forest monitoring can be considered to comprise the scope and objectives of forest monitoring, the constellation of actors involved, resources used, as well as rules governing forest monitoring. To date, our knowledge of how institutional arrangements for forest monitoring in developing countries have developed and evolved, and how their evolution has been shaped by international processes such as the UNFCCC decisions on REDD+ MRV, is limited in two ways. We not only lack a clear understanding of the scope and objectives, the actors involved, the resources used and the rules governing forest monitoring in various tropical countries, but also a historical account of how these have evolved over time in light of the changing societal demands on forests. The dissertation addresses this gap in two steps. First, using the case of Peru, it examines how institutional arrangements for forest monitoring have historically developed and evolved, and how their evolution has been shaped by international processes, especially REDD+ MRV. Second, it examines and compares the extent to which the concept of MRV and its associated ideas have institutionalized in Indonesia, Peru and Tanzania, and explains differences from a discursiveinstitutionalist perspective.

Third, the vast majority of scholarship on MRV remains highly technical (see also arguments by Gupta et al., 2014; Vijge, 2016). This is so because in most scholarly debates (e.g. Asner et al., 2009; GOFC-GOLD, 2013; Hansen et al., 2013; Hansen et al., 2008; Herold, 2009; Herold and Johns, 2007; Herold et al., 2011; Herold and Skutsch, 2011; Romijn et al., 2012; Romijn et al., 2015) forest monitoring for REDD+ is considered a highly technical, value-free and apolitical activity. However, building on the work of others (Gupta et al., 2012; Gupta et al., 2014; Kowler and Larson, 2016; Vijge, 2016; Visseren-Hamakers et al., 2012), this dissertation argues that the concept of forest monitoring, and MRV in particular, is largely political. Decisions on what is to be monitored and reported, the appropriate actors to be involved, and the technologies to be used, whether at the international and national level, are made through political processes (Kowler and Larson, 2016; Lövbrand and Stripple, 2011; Vijge, 2016; Wertz-Kanounnikoff and McNeill, 2012). These political processes involve argumentation and contestation among policy actors on 
the key problems that MRV should address, the goals that it should achieve, and the best policy options to achieve those goals (cf. Brockhaus and Di Gregorio, 2014; Brockhaus et al., 2014). Scholarship on the political processes involved in developing policies to implement MRV remains scarce. And while such scholarship calls for the use of social scientific perspectives, and especially political theories, application of these theories to the analysis of MRV is limited (for exceptions see Gupta et al., 2014; Korhonen-Kurki et al., 2013; Kowler and Larson, 2016). Thus, in additional to examining how institutional arrangements for forest monitoring have developed and evolved, and how these have been shaped by international processes such as the UNFCCC decisions on REDD+ MRV, the thesis also advances scholarship on MRV by investigating and highlighting the political processes involved in developing policies to implement MRV, and how such processes enable or constrain institutionalization. In addressing the gaps identified above, the dissertation aims to meet three objectives:

1. To examine the institutional effectiveness of REDD+ MRV in selected developing countries;

2. To examine the extent to which the concept of REDD+ MRV and associated ideas have materialized in new institutional arrangements for forest monitoring in developing countries, and how this can be explained from a discursive-institutionalist perspective;

3. To examine how discursive processes of policymaking and the argumentation and contestation inherent in such processes enable or constrain institutionalization of MRV in selected countries.

\subsection{Main concepts and theoretical framework}

To meet the three objectives of the study, the dissertation builds on neo-institutional theory and uses two schools of thought: regime theory and discursive institutionalism. First, it uses regime theory to conceptualize the UNFCCC and its decisions on REDD+ MRV as an international institution. Thus conceptualized, the thesis draws on the concept of institutional effectiveness to assess the extent of implementation of technical and governance requirements for MRV in 13 REDD+ countries. Second, the thesis uses discursive institutionalism and the policy arrangement approach for an in-depth assessment of the extent to which the concept of MRV and associated ideas have become institutionalized in selected countries, and the discursive processes through 
which such institutionalization occurs. Taken together, these approaches allow for examining and comparing institutional effectiveness of REDD+ MRV, in other words the extent of institutionalization of MRV in selected countries, the political processes involved in developing policies to implement MRV, and how these processes enable or constrain institutionalization.

\subsubsection{Regime theory and the concept of institutional effectiveness}

Neo-institutionalist theories emphasize the role of institutions in shaping, guiding and constraining human action and agency. The basic tenet is that actors, in making their decisions and choosing their action trajectories - whether as individuals or collectives - follow institutionalized values, norms and rules (Hall and Taylor, 1996; March and Olsen, 1983; March and Olsen, 1998). This literature also recognizes that institutions operate at different levels of governance (Scott, 2001; Scott, 2014; Young, 1980). We can therefore distinguish those institutions that operate at the international level from those that operate at the national and local levels. Institutions operating at the international level are often referred to as international institutions (or regimes), and often govern the actions and behaviour of members of the international system (Rittberger, 1993b; Rittberger and Mayer, 1993; Young, 1980). Members of the international system predominantly comprise states, although other actors such as non-governmental organizations and the business community are also increasingly involved (Arts, 1998, 2000; Visseren-Hamakers, 2013).

Regime theories are essentially theories of International Relations, and are concerned with conceptualizing and explaining the formation, persistence and transformation of international institutions. Although international institutions can be conceptualized from different schools of thought, including realism and neoliberalism (see Arts, 2000 for a review), this thesis aligns itself with the cognitivist school of international relations (Haas, 1982; Hasenclever et al., 1996, 1997). Although this school of thought accepts institutionalism - that is the assumption that relations and cooperation among states are governed by institutions - just as all other schools of thought in regime theory do, it conceives of these institutions in a more dynamic way. Cognitivists accept the consensus definition of international institutions as the internationally agreed-upon principles, norms, rules and decision-making procedures around which states' expectations converge in a given issue area of international cooperation (Krasner, 1982; Rittberger, 1993a). However, for cognitivists, these institutions do not over-determine states' actions and behaviour. Rather, they 
see international institutions as created, maintained and changed by members of the international system (Haas, 1982; Haas et al., 1993; Hasenclever et al., 1996, 1997; Kratochwil and Ruggie, 1986), and emphasize the role of states' ideas and interactions in driving institutional change and transformation.

Regime theorists study climate change as one of the issue areas of international cooperation (Victor, 2006). UN member states negotiated and adopted the United National Framework Convention (UNFCCC) in 1992 to foster international cooperation on climate change. The institution of the UNFCCC is regularly discussed and modified by the Parties, especially through and during the so-called conference of the parties where Parties negotiate the specific provisions of the convention. In accepting the cognitivist school of thought of international institutions, I consider the UNFCCC and its various decisions including those on REDD+ MRV as an international institution that aims to structure actions of Parties and achieve international cooperation on the issue area of climate change. But I also see the construction and modification of the institution of the UNFCCC as driven by Parties' shared understanding of the climate change problematique.

Although research on international institutions has mainly been concerned with conceptualizing how such institutions emerge, persist and change over time, some work in this literature examines how the effectiveness - defined as problem-solving capacity - of international institutions can be measured (e.g. Breitmeier et al., 2011; Haas et al., 1993; Sprinz, 2000; Underdal, 1992; Young, 2011). Although scholars have developed different frameworks for conceptualizing and assessing effectiveness of international institutions (Helm and Sprinz, 2000; Smouts, 2008; Sprinz, 2000; Underdal, 1992; Young and Levy, 1999), this dissertation uses the framework proposed by Young and Levy (1999) since it is more comprehensive and examines effectiveness from different dimensions. These authors identify five dimensions along which institutional effectiveness can be evaluated. The (1) problem-solving dimension examines the degree to which the international institution has alleviated the problem that led to its creation. The (2) legal dimension examines the degree to which the contractual obligations of the institution are complied with by the state parties. The (3) economic dimension incorporates elements of the legal approach but adds economic efficiency criteria. The (4) normative dimension examines effectiveness in terms of normative 
principles such as fairness, stewardship, and participation, and the (5) political dimension examines changes in the behaviour and interests of the actors (Young and Levy, 1999, p. 4-7). The thesis blends aspects of the legal, normative and political dimensions to develop criteria and indicators for examining the extent to which selected REDD+ countries are adapting existing national forest monitoring practices and institutions to comply with and implement the technical guidelines and good governance requirements for REDD+ MRV.

\subsubsection{Discursive Institutionalism: A theory of discourses and institutions}

The literature on international institutions in general and institutional effectiveness in particular recognizes that while such institutions are negotiated and agreed upon at the international level, their specific provisions must be translated into national policies and institutions in order to be effective. Haas et al. (1993), for instance, observes that after such international institutions have been agreed upon, the burden of actions shifts to national responses. This observation calls on regime scholars to examine how national institutions change in response to international ones. The authors note that implementing provisions of international institutions at the national level usually involves developing the political and administrative capacity of national institutions of concerned countries. Furthermore, such internationally agreed institutions bring with them new ideas and concepts, which must similarly be translated into national policy processes and institutions. Along this line, I argued in section 1.1. that the UNFCCC decisions on REDD+ MRV have introduced new ideas on forest monitoring in developing countries. For an in-depth assessment of how the concept of MRV and associated ideas are being implemented in specific REDD+ country contexts, and the policy processes by which such implementation occurs, I use discursive institutionalism and the policy arrangement approach as analytical tools.

Discursive institutionalism (DI) is a relatively new strand of neo-institutional theory that emphasizes the constitutive role of ideas and discourses in politics, policymaking and institutional change (Hay, 2006; Schmidt, 2002, 2008). This discursive institutionalist approach is mostly advanced by Vivien Schmidt (Schmidt, 2001, 2002, 2008; Schmidt, 2010). Its basic tenet is that (new) ideas, and the discourses through which they are generated and exchanged during policymaking and public deliberation, may undermine or reinforce existing institutions, and thereby cause institutional change or stagnation (Arts and Buizer, 2009; Schmidt, 2008). I 
therefore find it a suitable analytical framework to conceptualize how the concept of MRV and associated ideas have shaped and been institutionalized in national institutional arrangements for forest monitoring in specific countries. As an analytical framework, DI distinguishes discourses and institutions (Arts and Buizer, 2009), and can be considered an attempt to bridge discourse and neo-institutional theories (Arts, 2012).

In general, DI as advanced by Vivien Schmidt (Schmidt, 2008; Schmidt, 2010) conceptualizes discourse in two ways: (1) as the shared and at the same time contested ideas about policymaking; and (2) as the interactive processes by which these ideas are exchanged, deliberated and legitimated during policymaking and public deliberations. In the words of Schmidt, this double conceptualization of discourse enables us to 'simultaneously indicate the ideas represented in the discourse (which may come in a variety of forms as well as content) and the interactive processes by which ideas are conveyed' (Schmidt, 2008, p. 309) during policymaking and public deliberations. Three types of ideas may be represented in a policymaking process: policy, programmatic and philosophical ideas (Mehta, 2011; Schmidt, 2008). Policy ideas are the strategies or solutions proposed by different policy actors to achieve given public aims. Programmatic ideas encompass the definition of the policy problem at hand and the policy aims to be achieved (Mehta, 2011; Schmidt, 2008; Schmidt and Radaelli, 2004; see also Wiering and Arts, 2006). Philosophical ideas are the taken-for-granted underlying norms and values in a given policy domain that are rarely contested, except in times of crisis (Campbell, 1998; Campbell, 2004; Mehta, 2011; Schmidt, 2008).

For Schmidt, the interactive part of discourse comes in two forms: communicative and coordinative discourse (Schmidt, 2008; Schmidt, 2010). The latter involves discussions and policy construction among policy actors, whether at the national or international level. This coordinative discourse comprises the individuals and groups involved in the generation, exchange, elaboration, and development of policy ideas. They may be civil servants, elected officials, experts, diplomats, organized interest groups, activists, etc. who seek to coordinate agreement among themselves on the best policies to achieve given public aims. In the case of national level implementation of MRV, this coordinative discourse comprises arenas where strategies to implement MRV are being discussed and developed. Different constituencies, including national and sub-national 
government agencies, non-governmental organizations (NGOs), academic and research institutes, private actors, and local communities may be represented in this MRV coordinative policy discourse.

Communicative political discourse, on the other hand, involves discussions between political actors and the general public (Schmidt, 2008). In this type of discourse, political and policy actors communicate and justify the policy options generated in the coordinative policy discourse to the general public, and the public may accept or sanction such policies in a number of ways. In the case of MRV, communicative discourse may comprise individuals and groups involved in MRV policy development communicating and justifying the policies chosen to implement MRV to different constituencies (read publics), such as project developers and communities implementing REDD + as well as NGOs engaged in sustainable forest management and related issues that may have a stake in REDD+ in general and MRV in particular. These constituencies may accept the developed MRV strategies by adopting them, or they may sanction them through petitions or protests.

In both coordinative and communicative policy processes, discursive institutionalists and Schmidt in particular conceive of actors as 'sentient'; i.e. thinking and speaking. Being 'sentient', these agents are conceived to possess both 'background ideational abilities' and 'foreground discursive abilities', which respectively enable them to re-think and generate new ideas about the institutions within which they act, and to communicate and deliberate their ideas about these institutions in critical ways (Schmidt, 2010). Schmidt (2008) conceives of 'background ideational abilities' as actors' internal capacity to create and maintain institutions and as comprising human capacities, dispositions, and knowhow. This concept thus relates to actors' internal (cognitive) abilities to generate new or reconceptualise ideas about existing institutions. But how then do the newly generated or re-conceptualized ideas enable institutional change? For Schmidt, this is where agents' 'foreground discursive abilities' come in. These abilities encompass 'people's capacity to think outside the institutions in which they continue to act, to talk about such institutions in a critical way, to communicate and deliberate about them, to persuade themselves as well as others to change their minds about their institutions, and to take action to change them, whether by building 'discursive coalitions' for reform against entrenched interests in the coordinative policy 
sphere, or informing and orienting the public in the communicative political sphere' (Schmidt, 2010, p. 16). Thus, both 'background ideational abilities' and 'foreground discursive abilities' bestow actors the agency to make and change institutions.

The concept of 'foreground discursive abilities' is similar to the concept of Habermas' (1996) 'communicative action', Dryzek's (2000) 'deliberative democracy', and Risse's (2000) 'argumentative rationality'. It relates to the interactive conception of discourse wherein actors share, deliberate, contest and argue about their policy, programmatic, and philosophical ideas about given public issues. It is through these processes of deliberation, argumentation, persuasion and contestation that institutions are changed or maintained. For discursive-institutionalists, and indeed cognitivists in general, these processes of deliberation, argumentation, contestation and persuasion constitute politics. Thus, politics involves the exchange, contestation and deliberation of policy, programmatic (and sometimes) philosophical ideas among policy actors, and the communication and justification of the chosen policies to the wider public. Such coordination and communication can take place at the international level when state parties negotiate the formation, change and transformation of international institutions. But they can also take place at the national level, when policy actors deliberate and exchange ideas on how to implement provisions of particular international institutions that they have signed. DI therefore defines politics in an unusual manner, namely not so much as conflicts about 'who gets what, when and where' (Lasswell, 1950), but rather as the exchange, deliberation, argumentation, contestation and persuasion among policy actors on the best policies to address given problems (Dryzek, 2000; Hajer, 2006; Hajer and Versteeg, 2005; Hajer, 1995; Schmidt, 2008; Schmidt, 2010).

\subsubsection{Institutionalization and institutional change: the policy arrangement approach}

Although DI provides a novel theoretical framework to conceptualize the relationship between discourses and institutions, the framework is wrought with a number of conceptual ambiguities. In order to make the DI framework amenable to my purpose of analysing how the concept of MRV and associated ideas have shaped and materialized into national institutional arrangements for forest monitoring in specific countries, I will criticise and modify it as follows. First, Schmidt (2010) defines institutions as 'simultaneously structures and constructs internal to agents' 
(Schmidt, 2008, p. 305), be they states or individuals. Although this definition of institutions is in principle similar to definition of institutions in regime literature (see above), as it recognizes the role of actors' ideas in constituting institutions, it is in my view problematic. Specifically, I find this definition incomprehensive and unspecific.

Second, discursive institutionalists in general and Schmidt in particular consider ideas and the interactive processes of policymaking and public deliberations as one of the triggers of institutional change. While I agree with the author and her colleagues that ideas and discourses are a basis for institutional change, in my view she does not explicate what this 'institutional change' entails, although she and colleagues provide several examples (e.g. Schmidt, 2001, 2002; Schmidt, 2006, 2013). Schmidt and other discursive institutionalists also hold that discourses and ideas, when successful, may institutionalize, but they do not elucidate what 'institutionalization' actually entails. Inspired by Leroy and Arts (2006), I consider institutionalization as not only manifested in enactment of rules to anchor given (policy) ideas in 'rules of the game', but also in the mobilization of new/ additional resources to implement these rules. Such resources, as Scott (2014) highlights, include both human and material resources. This means institutionalization involves not only mobilization and allocation of additional material resources (e.g. budgets, technologies, etc.) but also mobilization of (new) actors to implement the rules. To comprehensively conceptualize institutional arrangements, and grasp the mechanism by which institutionalization occurs, and what institutional change entails, I use the policy arrangement approach (PAA). This approach has been used by many others (Arts and Buizer, 2009; Buijs et al., 2014; den Besten et al., 2014) to operationalize institutional arrangements.

Like DI, the PAA tries to connect ideas and discourses to institutions (Arts and Buizer, 2009; Wiering and Arts, 2006). The PAA was originally developed to conceptualize and study the substance and organization of concrete policy domains. The approach defines a policy arrangement as the way in which a given policy domain is temporarily shaped in terms of discourses, actors, resources, and rules (Arts and van Tatenhove, 2006; Liefferink, 2006a; Wiering and Arts, 2006). In the PAA, discourses (and content-focused rules) constitute the substance of a policy domain, while actors, resources and organizational, process-related rules constitute the organization of the domain (Wiering and Arts, 2006). Discourses - as the substance of a policy domain - is defined 
in PAA as the 'dominant interpretative schemes, ranging from formal policy concepts and texts to popular story lines, by which meaning is given to a policy domain' (Arts and Tatenhove, 2004, p. 343). This definition of discourse in the PAA is similar to DI's conceptualization of discourses as the shared and the same time contested ideas about policymaking, as already elucidated above. The substance of a policy arrangement can therefore be further specified by distinguishing the three types of ideas (policy, programmatic and philosophical) discussed above.

Actors are the stakeholders involved in policymaking and implementation. From a regime perspective, they may be states and diplomats involved in coordinating formation and transformation of international institutions. Domestically, they could be policy makers, think tanks, bureaucrats, interest groups, etc. involved in coordinative and communicative policy construction as discussed above. These actors interact with one another during policymaking and deliberations and may form coalitions to advocate common ideas and or contest competing ones. This may lead to formation of discourse coalitions around common ideas, as theorized in discourse theory (e.g. Hajer, 2006; Hajer, 1995). Resources, next, comprise of the tools, technologies, budgets and skills that actors can mobilize to achieve common policy aims. Rules, finally, are the laws and procedures. While laws are the codes enacted to implement selected policy ideas, procedures are routines that delineate division of roles and authority between the actors (Arnouts et al., 2012; Wiering and Arts, 2006) with regard to implementation of the adopted policies.

Following the PAA, I conceive of national institutional arrangements for forest monitoring as encompassing policy discourses, actors, resources and rules. Thus, I use the PAA to conceptualize the institutionalization of MRV as the translation of MRV and associated ideas into national policy discourses (e.g. new or revised scope and objectives, and strategies), mobilization of new actors and additional resources, and enactment of new rules to anchor forest monitoring in law and formalize the roles of the different actors. To gauge the extent to which MRV has been institutionalized in different countries, I follow Wiering and Arts (2006) and distinguish between 'shallow' and 'deep' institutionalization. I conceive of shallow institutionalization as translation of MRV into new policy discourses, often expressed in speeches and statements to the wider public or in 'expert' debates, and deep institutionalization as translation of MRV into not only policy 
discourses, but also mobilization of new actors and additional resources and enactment of new rules.

I recognize however, that such translation and solidification of MRV into new institutional arrangements take place through interactive processes of policymaking - discourse - as Schmidt convincingly argues. Although the PAA tries to grasp the dynamics of policymaking as the interplay of day-to-day interactions among actors on the one hand, and as the macro-processes of social and political change on the other (Arts and van Tatenhove, 2006), I am of the opinion that these aspects are best covered by the concept of discourse as elucidated in DI. As the PAA acknowledges, policy innovation, which is defined as the renewal of policymaking in day to day interactions, is largely driven by actors' desire to do things differently. In my opinion, this desire to do things differently is driven by actors 'background ideational abilities', and day-to-day interactions can be best captured by the concept of 'foreground discursive abilities'. I therefore use the concept of discourse to study the actors involved in MRV policy discussions in the respective countries, the ideas they introduced or contested in these discussions, and how argumentation and contestation among them enabled or constrained institutionalization.

\subsection{Research questions}

To examine the institutional effectiveness of REDD+ MRV, how the concept of REDD+ MRV has shaped and materialized in new institutional arrangements for forest monitoring in developing countries, and how discursive processes of policymaking impact the extent of institutionalization, the dissertation addresses four research questions:

\section{What is the institutional effectiveness of REDD+ MRV in terms of its implementation} in REDD+-eligible countries? The emergence of the UNFCCC decisions on REDD+ MRV raises the questions of how the provisions of such decisions perform at the national level; that is, how state parties affected by these decisions implement them. This question uses the concept of institutional effectiveness - a measure of performance of international institutions - from regime literature to examine how UNFCCC technical guidelines and 
governance requirements for REDD+ MRV are being implemented in 13 developing countries across the tropics.

2. How have institutional arrangements for forest monitoring in developing countries developed and evolved, and how and to what extent has their evolution been shaped by international ideas and discourses on forests, especially REDD+ MRV? To answer this question, the research focuses on the case of Peru to examine how ideas and concepts that emerge from international processes shape national level institutional arrangements for forest monitoring. It draws on discursive institutionalism, which theorizes the nexus between discourses and institutions, to examine how and the extent to which the concept of MRV and associated ideas have materialized in new institutions for forest monitoring in Peru.

3. How and to what extent has the concept of MRV institutionalized in new or reformed institutional arrangements for forest monitoring in Indonesia, Peru and Tanzania, and how can differences in extent of institutionalization across the countries be explained? This research question builds on the claims of discursive institutionalism to compare the extent of institutionalization of REDD+ MRV in Indonesia, Peru and Tanzania, and explains any differences by examining theoretical factors for institutionalization and their manifestations in each country.

4. How has discursive politics enabled or constrained institutionalization of MRV in Indonesia, Peru and Tanzania? To answer this research question, I use the concept of discourse - understood as the interactive process of policymaking - to examine the actors involved in MRV policy development in Indonesia, Peru and Tanzania, and how argumentation and contestation among them have facilitated or constrained institutionalization.

The first research question addresses the first objective of the dissertation, the next two address the second objective, while the last addresses the third objective. By addressing these questions, this dissertation contributes to on-going debates on forest monitoring in general and REDD+ MRV 
in particular in three ways. First it advances assessment of REDD+ countries' capacity for forest monitoring, reporting and verification by adding an institutional dimension. This is significant because, as argued in section 1.2. and also acknowledged by others (Grainger and Obersteiner, 2011; Korhonen-Kurki et al., 2013), existing assessments largely concentrate on the technical dimensions of MRV. Second, and more theoretically, the thesis advances discursive institutionalist scholarship by showing empirically how processes of institutionalization and institutional change can be conceptualized and grasped by means of the policy arrangement approach (PAA). Although other scholars have used the PAA to operationalize discursive institutionalism (e.g. Arts and Buizer, 2009; Buijs et al., 2014; den Besten et al., 2014), they have not specified what idea and discourse institutionalization entails. The dissertation advances the work of these authors by bringing clarity to what idea and discourse institutionalization and institutional change entails. In doing so, the thesis contributes to answering Schmidt (2010) call on DI scholars to show empirically how, when, where and why ideas and discourses matter for institutional change.

Thirdly, the thesis advances scholarship on forest monitoring for REDD+ by drawing attention to the policy and political processes involved in developing institutional arrangements for forest monitoring in REDD+ countries. Although other scholars have acknowledged that REDD+ MRV is not only a technical issue but also a political one (Gupta et al., 2012; Gupta et al., 2014; Vijge, 2016; Visseren-Hamakers et al., 2012), analysis of political processes involved in developing policies to implement MRV is underrepresented in the current literature on REDD+ MRV. Overall, the thesis contributes to scholarship on forest monitoring in general and MRV in particular by introducing a new theoretical lens, namely discursive institutionalism and the policy arrangement approach to the analysis of MRV. Additionally, the findings and recommendations presented in the empirical chapters and the conclusions of the thesis may guide national and international policy makers and stakeholders on how to design policies to institutionalize REDD+ MRV, as well as how national REDD+ MRV policy processes could be (re)organized in a manner that enables inclusivity and hence broad-based acceptance of proposed approaches.

\subsection{Study methods}

The research presented in thesis was conducted within the ambit of the Global Comparative Study on REDD+ (GCS) led by the Centre for International Forestry Research (CIFOR). The GCS is 
being conducted in 13 countries across Africa, Asia and Latin America. The present study was designed as a nested case study, in which a sub-sample of cases is selected from a large sample of cases (Lotz-Sisitka and Raven, 2004), and was conducted in two phases. Phase I was designed as a cross-sectional case study and involved a survey of the institutional effectiveness of REDD+ MRV in all the 13 GCS countries: Bolivia, Brazil, Peru, Burkina Faso, Cameroon, Democratic Republic of Congo (DRC), Mozambique, Tanzania, Indonesia, Laos, Nepal, Papua New Guinea (PNG) and Vietnam. These countries were chosen for the GCS because they represent the major forest-rich tropical countries that have committed to implementing REDD+, and are responsible for majority of the emissions from deforestation and forest degradation (Korhonen-Kurki et al., 2014).

Data for this phase was obtained solely from secondary sources. A review of the regime and institutional effectiveness literature was carried out to develop a framework for assessing institutional effectiveness of REDD+ MRV. Further review of documents of the UNFCCC, including its Subsidiary Body for Scientific and Technological Advice (SBSTA), and the Intergovernmental Panel on Climate Change (IPCC) was done to provide details on the specific technical and governance requirements for MRV. This literature review enabled the development of criteria and indicators for assessing institutional effectiveness of REDD+ MRV. Subsequently, analysis of relevant national documents including Readiness Preparation Proposals, UN REDD National Program Documents, National REDD+ Strategies and Action Plans, MRV Framework Documents, CIFOR Country Profiles, Norwegian International Climate and Forest Initiative Evaluation Reports, etc. of the 13 countries was undertaken to elicit information on countries' progress in implementing the identified indicators of institutional effectiveness.

Phase 2 of the study involved in-depth examination and analysis of how and to what extent UNFCCC decisions on MRV have shaped and institutionalized in a sub-set of the GCS countries, namely Indonesia, Peru and Tanzania. Thus, the second phase involved sampling from within the 13 country cases (Figure 1.1). This phase was designed as an exploratory comparative case study (Flyvbjerg, 2006; Johnson and Onwuegbuzie, 2004; Yin, 1994). The three selected countries constituted the cases, while development and evolution of institutional arrangements for forest monitoring in response to international processes on forests, extent of institutionalization of MRV 
across countries, and discursive processes of MRV policy development and their effect on institutionalization, constituted the phenomena. The purpose of the comparative design was to allow cross-country comparison and learning (George and Bennett, 2005), which is a major goal of the GCS.

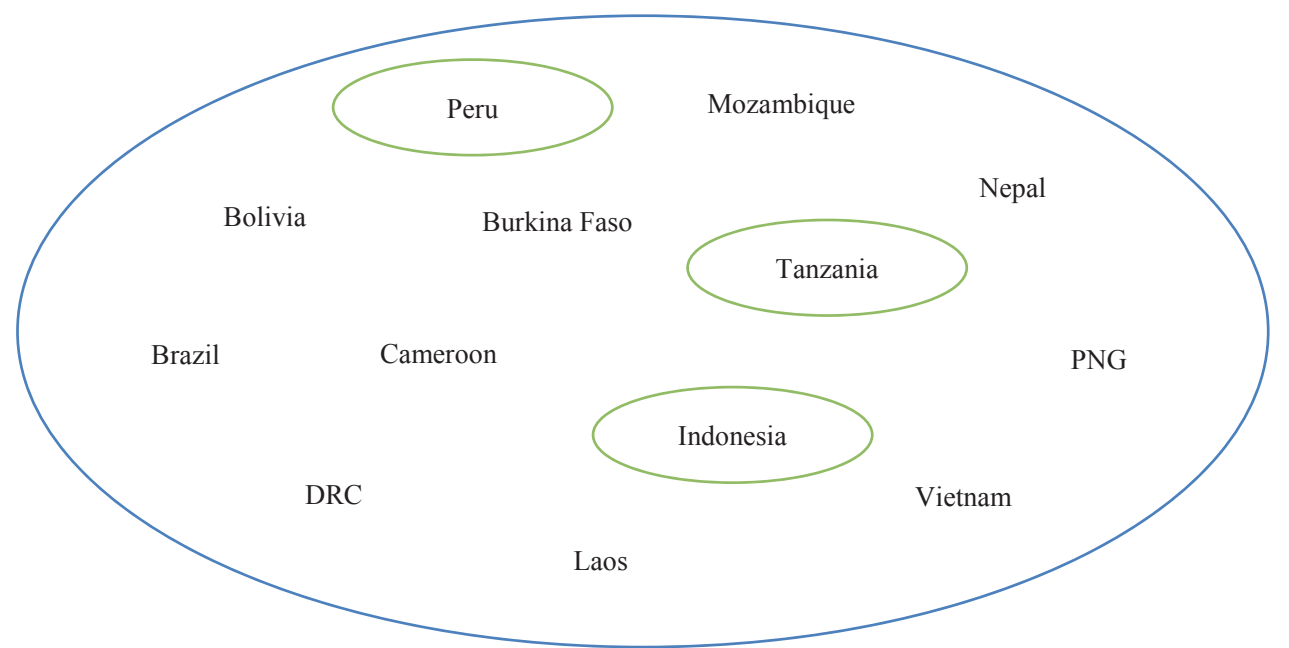

Figure 1.1: A nested case of institutional effectiveness and institutionalization of REDD+ MRV in developing countries

Indonesia, Peru and Tanzania were selected as country cases for in-depth study for several reasons. First, as Table 1.1 shows, these countries started their REDD+ processes in different time periods. Indonesia and Tanzania joined and have been receiving technical and financial support from the World Bank's Forest Carbon Facility (FCPF) and the UN REDD program from as early as 2009. Moreover, both countries have been receiving financial support from the Norwegian International Forest and Climate Initiative since 2009, including on issues regarding the establishment of forest measurement systems for REDD+ (MRV). Both countries could therefore be expected to be well advanced in implementing the different REDD+ elements, including MRV. Their 'maturity' in REDD + implementation would also allow for retrospective investigation of the discursive processes of MRV policy development. Peru, on the other hand, started engaging in REDD+ only recently. For example, Peru signed a Letter of Intent with Norway only in 2014, while the other two countries did so over five years ago. Also, studies show that government engagement in REDD+ in Peru began only after 2012 (Piu and Menton, 2014a; RoP, 2014), while both the 
Indonesian and Tanzanian governments started national-level REDD+ processes at a relatively early stage. Second, despite the early engagement of Indonesia and Tanzania in REDD+, as compared to Peru, several evaluations (Korhonen-Kurki et al., 2013; LTS International, 2013; Minang et al., 2014; Romijn et al., 2012; Romijn et al., 2015) suggest that the three countries are at different stages in developing technical and institutional capacity to conduct forest monitoring for REDD+. As such, they offer interesting contrasting cases to analyse and compare.

Table 1.1: Forest, Deforestation and REDD+ Facts: Indonesia, Peru and Tanzania

\begin{tabular}{|c|c|c|c|}
\hline Forest and REDD+ Facts & Indonesia & Peru & Tanzania \\
\hline Extent of Forest (Million ha) & 91.010 & 73.973 & 46.060 \\
\hline Forest as percentage of land cover & $53 \%$ & $57.8 \%$ & $52 \%$ \\
\hline $\begin{array}{l}\text { Average annual deforestation rate } \\
(\%)\end{array}$ & -1.1 & -0.2 & -0.8 \\
\hline Forest Transition Phase & Early transition & Pre-transition & Early transition \\
\hline Forest cover and deforestation & $\begin{array}{l}\text { High forest cover, high } \\
\text { deforestation }\end{array}$ & $\begin{array}{l}\text { High forest cover, } \\
\text { low deforestation }\end{array}$ & $\begin{array}{l}\text { High forest cover, } \\
\text { high deforestation }\end{array}$ \\
\hline Engagement in Forest Carbon & Yes, grant signed June & Cooperation & Yes, but not grant \\
\hline Partnership Facility (FCPF) & 2011 & $\begin{array}{l}\text { Agreement signed } \\
\text { May-August } 2014\end{array}$ & Holder \\
\hline Engagement in the FCPF Carbon & Emission Reduction & Emission Reduction & Not participant \\
\hline Fund & $\begin{array}{l}\text { Idea Note submitted } \\
\text { Sept. } 2014 \\
\text { Letter of Intent yet to be } \\
\text { signed }\end{array}$ & $\begin{array}{l}\text { Idea Noted submitted } \\
\text { Sept. } 2014 \\
\text { Letter of Intent } \\
\text { signed March } 2016\end{array}$ & \\
\hline Engagement in UN REDD Program & $\begin{array}{l}\text { Signed 2009, } \\
\text { implemented 2010-2013 }\end{array}$ & $\begin{array}{l}\text { Signed } 2016, \\
\text { implementation } \\
2016-2018\end{array}$ & $\begin{array}{l}\text { Approved 2010, } \\
\text { implemented 2010- } \\
2013\end{array}$ \\
\hline $\begin{array}{l}\text { Engagement in Forest Investment } \\
\text { Program (FIP) }\end{array}$ & $\begin{array}{l}\text { Yes, Investment Plan } \\
\text { approved Nov. } 2012\end{array}$ & $\begin{array}{l}\text { Yes, Investment Plan } \\
\text { endorsed Oct. } 2013\end{array}$ & Not participant \\
\hline $\begin{array}{l}\text { Readiness Preparation Proposal (R- } \\
\text { PP) }\end{array}$ & Submitted May 2009 & Submitted Dec. 2013 & Submitted Oct. 2010 \\
\hline REDD+ Strategy/ Action Plan & Published 2012 & Published 2016 & Published 2013 \\
\hline MRV Strategy/ Action plan in place & Published 2012 & $\begin{array}{l}\text { Draft yet to be } \\
\text { published }\end{array}$ & $\begin{array}{l}\text { Published } 2013 \text { as } \\
\text { part of REDD+ } \\
\text { Strategy }\end{array}$ \\
\hline Bilateral Agreement with Norway & Signed May 2010 & Signed Sept. 2014 & Signed April 2008 \\
\hline National Forest Inventories & Since 1989 & Since 2011 & Since 2009 \\
\hline
\end{tabular}

Third, although all the three countries have a forest cover of over 50\% (FAO, 2015), they have varying rates of deforestation. Indonesia and Tanzania have an average annual deforestation rate of $-1.1 \%$ and $-0.8 \%$ respectively, which are well above the $-0.22 \%$ threshold for low deforestation. Both countries can therefore be classified as high forest cover, high deforestation countries. By contrast, Peru has a deforestation rate of $-0.2 \%$ (FAO, 2015), which is below the $-0.22 \%$ threshold. Peru can thus be classified as a high forest cover, low deforestation country. In terms of 
the forest transition curve (Mather, 1992) - a measure of the status of deforestation and forest degradation in a given country - Peru is in the pre-transition phase, while Indonesia and Tanzania are in the early transition phase (Hosonuma et al., 2012). The three countries are therefore not only representative of the three tropical regions of Africa, Asia and Latin America, but also of countries at different phases of forest transition. Furthermore, Indonesia and Peru are among the most forestrich tropical countries, and both have the $2^{\text {nd }}$ largest tropical forests in their respective continents (FAO, 2015). Although Tanzania has less forests compared to other African countries, such as those of the Congo Basin, it faces a relatively higher deforestation rate (estimated at 372,000 ha/ year, FAO (2015)) compared to these and other African countries. It can therefore be considered as representative of African countries where threats of deforestation and degradation are highest and where remedial measures are most urgent.

Data for this phase of the study was obtained from primary and secondary sources. Primary data were obtained through 34 interviews in Indonesia, 23 interviews in Tanzania, and 42 interviews and two focus group discussions (FGDs) in Peru. In each country, interviews and FDGs were conducted with representatives of various forestry-related state agencies, local and international non-governmental organizations (NGOs), foreign government agencies, local community organizations, research and educational institutes, and independent forestry professionals (Table 1.2). These representatives were selected because they have been involved in forest monitoring and/or in REDD+ MRV discussions in the respective countries, and were selected purposefully from relevant contacts found in the reviewed national documents (Creswell, 2014; Kumar, 2005; Punch, 2005). After establishing initial contacts in the respective countries, subsequent interviewees were identified using the snowball sampling method (Punch, 2005).

Field work was conducted between October and December 2015, and August and September 2015 in Indonesia and Tanzania respectively. In Peru, field work was conducted between May and June 2014, followed by follow-up interviews with a subset of the interviewees in September 2016. The majority of the interviews were conducted in person (i.e. face to face) but a few were conducted through Skype and telephone, and lasted between 45 and 90 minutes. Although the interviews were conducted in English, for some respondents in Indonesia and Peru these were translated into the national language with the help of an interpreter. Secondary data were obtained through analyses 
of relevant national REDD+ policy documents as described for phase one, and other scientific and grey literature. The mixture of secondary and primary data, and sourcing of information from different categories of interviewees and FDG participants as well as follow-up interviews enabled triangulation of the obtained dataset. Since the study employed a case study design, statistical tests were not undertaken. Rather, data from the interviews, FDGs, observations, and document analysis were analysed by systematically coding, comparing, interpreting along the theoretical concepts as introduced and operationalized in section 1.3. above.

Table 1.2: Number of respondents by category and country

\begin{tabular}{lllll}
\hline Category of respondent & Indonesia & Peru & Tanzania & Total \\
\hline National/ sub-national government agencies & 12 & 22 & 8 & 42 \\
Non-governmental organizations & 8 & 9 & 5 & 22 \\
Intergovernmental organizations & 9 & 3 & 2 & 14 \\
Private actors (Consultants, academics) & 5 & 8 & 8 & 21 \\
Total & 34 & 42 & 23 & 99 \\
\hline
\end{tabular}

\subsection{Outline of the thesis}

This chapter has introduced the research presented in this dissertation by delineating the topic of the study, its objectives and research questions, theoretical framework and the study methods. This final section of the chapter presents an outline of the subsequent empirical (chapters 2-5) and concluding chapter (chapter 6) of the dissertation. Chapters 2 and 3 have been published as peerreviewed journal articles. Chapter 4 has been accepted for publication with moderate revision, while Chapter 5 has been submitted for publication to a peer-reviewed journal.

Chapter 2 engages with the first research question by examining the institutional effectiveness of REDD+ MRV in the 13 GCS countries. It draws on regime literature to conceptualize the UNFCCC and its decisions on REDD+ MRV as an international institution. It uses the concept of institutional effectiveness from regime literature and delves into the IPCC methodological guidelines for Land Use, Land Use Change and Forestry (LULUCF), and good governance literature to develop three dimensions of institutional effectiveness of REDD+ MRV: 'owning technical methods for MRV', 'developing administrative competence' to implement MRV, and 'inculcating good governance' in MRV systems. The chapter shows that most countries score high 
on 'owning technical methods', but relatively low in 'developing requisite administrative capacity' and 'inculcating good governance' in their MRV systems.

Chapter 3 engages with the second research question. Specifically, it uses the case of Peru to examine how and to what extent global ideas and discourses on forests, especially REDD+MRV, have shaped institutional arrangements for forest monitoring. It draws on discursive institutionalism and the policy arrangement approach to craft a framework for examining the extent to which REDD+ MRV and other global discourses have shaped national institutional arrangements for forest monitoring in Peru. It shows that REDD+ MRV has expanded the scope and objectives of forest assessments in Peru, inspired the mobilization of new actors and resources, and spawned the development of new rules to govern forest monitoring. However, these institutional changes are not yet 'deep', since the new rules for forest inventories have not yet been formally adopted, and the institutes envisaged to implement forest monitoring have not been established.

Chapter 4 engages with the third research question to provide an in-depth assessment of how the concept of MRV has been institutionalized in new policy arrangement in Indonesia, Peru and Tanzania. It draws on insights from discursive institutionalism and the policy arrangement approach to develop the analytical categories of 'shallow', 'shallow-intermediate', 'deepintermediate' and 'deep' institutionalization. The chapter shows that in all three countries, MRV has institutionalized in new or revised aims, scope and strategies for forest monitoring, and the development of new agencies, mobilization of new actors and resources, and development of new rules. However, the extent of institutionalization of MRV varies across the countries, with Indonesia experiencing 'deep' institutionalization, Peru 'shallow-intermediate', and Tanzania 'intermediate-deep' institutionalization. The chapter explains the differences in extent of institutionalization by reflecting on the theoretical factors for discourse institutionalization and their manifestation in each country, and concludes by drawing lessons to inform institutionalization of MRV in other countries.

Chapter 5 engages with the fourth research question. Specifically, it draws on discursive institutionalism to examine how the discursive politics of MRV policymaking has enabled or 
constrained institutionalization of REDD+ MRV in Indonesia, Peru and Tanzania. It shows that in Indonesia and Tanzania, where there is a broad-based national discourse on MRV, and where policy actors agree on the strategies to implement MRV and the role of different actors in forest monitoring, there is relatively 'deeper' institutionalization compared to Peru, where such discourse and agreement are lacking. The chapter concludes by showing how the discursive process facilitated institutionalization of MRV REDD+ MRV in Indonesia and Tanzania, and constrained the same in Peru.

Chapter 6 presents the conclusions on the study. It draws on the empirical chapters to answer the research questions. The chapter concludes that majority of the analysed countries has achieved at least a 'moderate' institutional effectiveness for MRV. Further, it concludes that the concept of REDD+ MRV has materialized in reformed institutional arrangements for forest monitoring in Indonesia, Peru and Tanzania. The chapter also concludes that forest monitoring for REDD+ is not only a technical activity, but is also political. It notes that decisions on what exactly is to monitored and reported, by whom, and with what methods are determined through political negotiations, and that how this political process is managed determines whether MRV is institutionalized or not. The chapter also reflects on the key theoretical concepts used in the study and the study methods. It ends by outlining several policy recommendations. 
Chapter 2 - Institutional Effectiveness of REDD+ MRV: countries

progress in implementing technical guidelines and good governance requirements

Published as: Ochieng, R.M., Visseren-Hamakers, I.J., Arts, B., Brockhaus, M. \& Herold, M., 2016. Institutional effectiveness of REDD+ MRV: Countries progress in implementing technical guidelines and good governance requirements. Environmental Science \& Policy 61, 42-52. 


\begin{abstract}
The UNFCCC requires REDD+ countries wishing to receive results-based payments to measure, report and verify (MRV) REDD+ impacts; and outlines technical guidelines and good governance requirements for MRV. This article examines institutional effectiveness of REDD+ MRV by assessing countries' progress in implementing these technical guidelines and good governance requirements, from three dimensions. Ownership of technical methods examines whether countries own technical methods for forest area and area change measuring, and for estimating forest carbon stocks; and whether national MRV systems cover all forests, land uses and carbon pools. Administrative capacity examines development of administrative competence to implement MRV. Good governance examines whether countries espouses norms of good governance in their MRV systems. We apply these dimensions to assess and compare progress in 13 REDD + countries, based on a review of national and international documents. Findings show that REDD + countries have high to very high ownership of technical methods. However, majority ranks only low to moderate on administrative capacity and good governance. This means that although countries have started developing technical methods for MRV, they are yet to develop the competence necessary to administer MRV and to inculcate good governance in MRV. The article explain the scores and suggest ways of improving implementation of REDD+MRV.
\end{abstract}

Keywords: REDD+ Countries; MRV; technical methods; administrative capacity; good governance. 


\subsection{Introduction}

At the $19^{\text {th }}$ Conference of the Parties (COP) to the United Nations Framework Convention on Climate Change (UNFCCC) in 2013, Parties agreed on a set of decisions to advance implementation of Reducing Emissions from Deforestation and forest Degradation in Developing countries; and the role of conservation, sustainable management of forests and enhancement of forest carbon stocks in developing countries (REDD+). The agreements encompassed decisions on methodologies for setting forest reference emission levels and modalities for measuring, reporting and verification (MRV) (UNFCCC, 2014b), which have been major contentious issues in REDD+ negotiations. On MRV, the agreements re-affirmed past COP decisions, namely that REDD+ countries wishing to receive results-based payments should measure, report and verify REDD+ carbon impacts and establish National Forest Monitoring Systems (NFMS) to perform MRV (UNFCCC, 2009, 2010).

Earlier at COP 16, the UNFCCC had outlined a three-phased approach to implementing REDD+ (UNFCCC, 2010): A readiness phase that involves development of national strategies, policies, accounting frameworks and capacity building; an implementation phase that involves implementation of national strategies and policies, technology development and results-based demonstration activities; and a results-based payment phase that involves payments for measured, reported and verified REDD + carbon impacts. Since 2008, several REDD + countries have been implementing REDD+ readiness and demonstration activities (Angelsen et al., 2012). Developing a robust and transparent NFMS to conduct MRV is a major activity in the readiness and implementation phases (Meridian Institute, 2009). As REDD+ was concluded at COP21 and features prominently in many of the submitted INDCs from tropical countries, it is very timely to assess countries' progress in implementing the UNFCCC decisions on REDD+ MRV.

Although several studies have examined the capacity of REDD+ countries to measure, report and verify REDD+ impacts (Grainger and Obersteiner, 2011; Herold, 2009; Herold and Johns, 2007; Herold and Skutsch, 2011; Palmer Fry, 2011; Pratihast et al., 2013; Romijn et al., 2012; Skutsch and McCall, 2010), these studies are limited with regard to the actual institutional effectiveness of REDD+ MRV in three ways. First, these studies examine whether REDD+ countries have the technologies in place to implement MRV but are silent on whether REDD+ countries actually own these technologies and whether they have the administrative capacity to implement MRV. Second, studies that examined REDD+ countries' technical capacity for 
MRV used global datasets such as the Food and Agricultural Organization's Forestry Resource Assessment Country Reports. Since it takes two-to-three years between data collection and publication of these datasets (Romijn et al., 2012), the information they contain do not reflect capacity building in MRV that countries have undertaken since 2008. Third, besides outlining technical methods for MRV, the UNFCCC has also outlined 'good' governance requirements for REDD+ MRV. However, as Korhonen-Kurki et al. (2013) rightly observe, studies on good governance aspects of MRV remain scanty. This article addresses these gaps by examining the 'institutional effectiveness' of REDD+ MRV decisions by assessing and comparing REDD+ countries' progress in implementing technical guidelines and good governance requirements for MRV. It does this by examining countries' progress regarding (1) 'ownership of technical methods' for MRV, (2) developing 'administrative capacity' to implement MRV, and (3) exercising 'good governance' in MRV.

The article proceeds as follows. Section two briefly outlines the UNFCCC decisions on modalities for REDD+ MRV. Section three introduces the concept of 'institutions' and serves to conceptualize the UNFCCC and its decisions on guidelines for REDD+ MRV as 'institutions'. Building on the concept of 'effectiveness' of international institutions (Helm and Sprinz, 2000; Underdal, 1992; Young and Levy, 1999), this section also develops a framework for assessing the extent to which REDD+ countries have adjusted their national forest monitoring practices and rules to align with the UNFCCC technical guidelines and good governance requirements for MRV. Section four presents the results of our analysis. Section five discusses the results and makes some recommendations. Section six concludes the article and highlights its methodological limitations. The article is based on a literature review and document analysis of national and international reports. These include Readiness Preparation Proposals, UN REDD+ National Program Documents, National REDD+ Strategies, MRV Framework Documents, CIFOR Country Profiles, Norwegian International Climate and Forest Initiative Evaluation Reports, among others (Appendix A). The research was performed in 2014. The study is part of the CIFOR-led Global Comparative Study on REDD+ (GCS) and thus focuses on thirteen countries under study within the GCS: Bolivia, Brazil, Peru, Burkina Faso, Cameroon, Democratic Republic of Congo (DRC), Mozambique, Tanzania, Indonesia, Laos, Nepal, Papua New Guinea (PNG) and Vietnam. 


\subsection{UNFCCC Decisions on REDD+ MRV}

The UNFCCC explicitly states that REDD+ countries wishing to receive results-based payments should measure, report and verify (MRV) REDD+ impacts (UNFCCC, 2014b); and outlines guidelines on how REDD+ MRV should be conducted. Firstly, the UNFCCC requires REDD+ countries to '... establish robust and transparent national forest monitoring systems...' (UNFCCC, 2009, pg. 12) to perform MRV. Secondly, the established NFMS should follow the Intergovernmental Panel on Climate Change's (IPCC) methodological guidance and guidelines for estimating anthropogenic forest-related greenhouse gas emissions by sources, and removals by sinks, forest carbon stocks, and forest carbon stock and forest-area changes (UNFCCC, 2009, 2014b). Thirdly, in performing MRV, the NFMS should:

1) 'Use a combination of remote sensing and ground-based forest carbon inventory approaches ...' (UNFCCC, 2009, pg. 12)

2) Provide estimates that are as far as possible accurate and that reduce uncertainties (UNFCCC, 2009).

3) 'Enable the assessment of different types of forest in the country, including natural forests' (UNFCCC, 2014, pg. 31)

4) Provide estimates that 'are transparent and their results are available and suitable for review' (UNFCCC 2009, Pg. 12).

5 ) ' $\ldots$ the need for full and effective engagement of indigenous peoples and local communities in [...] monitoring and reporting...' (UNFCCC, 2009, pg. 11).

The first guideline outlines technical methods for REDD+ MRV while the second requires that these methods be accurate. The third guideline outlines the scope of REDD+ MRV, namely that it should cover all forests in a country. The fourth and fifth can be interpreted, respectively, as the need for transparency and accountability, and participation in MRV. Since transparency, accountability and participation are key principles of good governance (Secco et al., 2014; Woods, 2000), these guidelines can also be interpreted as the need for 'good' governance in MRV. While these guidelines are determined and agreed upon in an international negotiation process, they need to be translated and implemented in highly diverse country-specific contexts, with country-specific distinct actors, ideas, interests, information and knowledge and existing institutions. 


\section{3. 'Institutions' and UNFCCC Guidelines on REDD+ MRV}

Institutional theory explains order, stability and change in society by locating 'institutions' at the centre of human action and behaviour. The key assumption is that human agencies, in making their decisions and choosing their action trajectories, follow institutionalized values, norms and rules of societies and organizations they are part of, rather than economic incentives per se, such as expected costs and benefits (March and Olson, 1989). However, such institutiondriven behaviour should not be interpreted too mechanistic or functionalist, since agencies have certain degrees of autonomy, the capacity to improvise and, sometimes, the will do things otherwise than expected, although most will remain within the range of appropriate, socially defined boundaries (Bourdieu, 1990; Giddens, 1984). 'Institutions' can be conceptualized from different perspectives (Hall and Taylor, 1996; North, 1991; Schmidt, 2005; Young, 1993), but here we refer to the phrasing that they comprise of the 'rules of the game' ordering social fields, including politics, economics and international relations (March and Olsen, 1998; North, 1991). From an International Relations perspective, however, 'institutions', or 'regimes', are the internationally agreed-upon principles, norms, rules and decision-making procedures around which actors' expectations converge in a given issue area of international cooperation (Krasner, 1982; Rittberger, 1993a). From this perspective, the UNFCCC and its various provisions such as technical guidelines and good governance requirements for REDD+ MRV constitute an 'institution' that shapes and converges the expectations of state Parties on international cooperation on the issue area of climate change, and especially the sub issue-area of REDD + .

A major question addressed by scholars of international institutions centres around 'effectiveness' of such institutions. A number of authors have developed conceptual approaches for examining effectiveness of international regimes (Helm and Sprinz, 2000; Sprinz, 2000; Underdal, 1992; Young and Levy, 1999). Here, we follow the approach proposed by Young and Levy (1999). The authors identify five approaches from which effectiveness of international institutions can be conceptualized and evaluated. The (1) problem-solving approach examines the degree to which the institution has alleviated the problem that led to its creation. The (2) legal approach examines the degree to which the contractual obligations of the institution are met: rules are complied with, policies changed, programs initiated, et cetera, by the Parties. The (3) economic approach incorporates elements of the legal approach but add economic efficiency criteria. The (4) normative approach examines effectiveness in terms of normative principles such as fairness, stewardship, and participation. The (5) political approach, lastly, examines changes in the behaviour and interests of the actors, or in the policies and 
performance of the institution in ways that may contribute to the positive management of the targeted problem (Young and Levy, 1999, p. 4-7). The first and third approaches will be less useful here because it is still too early to assess the extent to which UNFCCC guidelines have contributed to resolving problems with forest measurements in REDD+ countries, and data on costs/benefits of MRV is lacking. The fifth approach will also be less useful for our purpose, especially the perspective on change in behaviour and interests of actors, since it is too early to examine such behavioural and interest changes.

The framework that follows therefore blends aspects of the legal and normative approaches as well as the political approach. The framework (Table 2.1) specifically examines the extent to which the UNFCCC technical guidelines for REDD+ MRV, i.e. the technical methods for estimating forest area, area changes and carbon emissions/removals, are being complied with, and whether the scope of MRV covers all forests, land uses and carbon pools in a country. In addition, it examines REDD+ countries' progress in developing the administrative capacity to implement MRV, for example through hiring skilled experts, formulating new forest measurements protocols, et cetera. Development of such administrative capacity constitute part of implementing technical guidelines for MRV. Lastly, the framework examines the extent to which REDD+ countries complies with norms of 'good' governance - participation, transparency, accountability and coordination - as introduced and further elaborated below. Overall, the framework allows for an assessment of countries' performance with regard to the UNFCCC decisions on REDD+ MRV at the national level. In developing the framework, we follow Keohane et al. (1993) advise to 'focus on observable political effects of institutions rather than directly on environmental impacts' when examining effectiveness of international institutions. The framework also aligns with Helm and Sprinz (2000) observation that such an evaluation of an international institution along its outputs may take place either at the level of the regime itself, analysing its norms, principles and rules, or at the national level in terms of the regulations, decisions and measures implemented by state Parties to implement the provisions of the institution in question (see also Underdal, 1992). 
Table 2.1: Framework for assessing REDD+ countries progress in implementing technical guidelines and good governance requirements for MRV

\begin{tabular}{|c|c|c|}
\hline Approach & Variable & Operationalization \\
\hline Legal/ Political & $\begin{array}{l}\text { Acquiring and } \\
\text { owning technical } \\
\text { methods of MRV }\end{array}$ & $\begin{array}{l}\text { - Ownership of methods for area change measuring } \\
\text { - Ownership of methods for estimating forest carbon } \\
\text { stocks } \\
\text { - Scope of MRV: whether it covers all forests, land uses } \\
\text { and carbon pools }\end{array}$ \\
\hline Legal/ Political & $\begin{array}{l}\text { - Developing } \\
\text { administrative } \\
\text { capacity }\end{array}$ & $\begin{array}{l}\text { - } \text { Clarity of MRV procedures } \\
\text { - } \quad \text { Linkage of REDD+ MRV with other GHG MRV } \\
\text { systems } \\
\text { - } \quad \text { Recruitment and development of expertise } \\
\text { - } \quad \text { Development of strategic partnerships }\end{array}$ \\
\hline Normative & $\begin{array}{l}\text { - Exercising good } \\
\text { governance in MRV }\end{array}$ & $\begin{array}{l}\text { - } \quad \text { Participation } \\
\text { - } \quad \text { Transparency } \\
\text { - Accountability } \\
\text { - } \quad \text { Coordination }\end{array}$ \\
\hline
\end{tabular}

Below, we delve into the IPCC methodological guidelines for Land Use, Land Use Change and Forestry (LULUCF), and good governance literature to develop criterial and indicators for assessing progress in implementing UNFCCC REDD+ MRV decisions at the national level along the three dimensions, and summarized in Table 2.2.

\subsubsection{Ownership of technical methods}

The IPCC provides two factors for estimating GHG emissions/removals: Activity Data and Emission Factors; and identifies six land use categories: forestland, cropland, grassland, wetland, settlement and other land (IPCC 2006). While the concept of land use categories applies to GHG inventories in the Agriculture, Forestry and Other Land Uses sector in general, for REDD+, interest is in 'estimating anthropogenic forest-related greenhouse gas emissions by sources and removals by sinks, forest carbon stocks and forest area changes' (UNFCCC, 2009, p. 11). REDD+ encompasses five activities: (i) reducing emissions from deforestation, (ii) reducing emissions from forest degradation, (iii) conservation of forest carbon stocks, (iv) sustainable management of forests and (v) enhancement of forest carbon stocks (UNFCCC, 2010). Activities $i$ and $v$ not only causes changes in forest carbon stocks, but also changes in forest areas. The rest causes changes in forest carbon stocks but not necessarily in forest areas (see also GOFC-GOLD (2013)). Activity Data refers to area changes between forest and other land use categories, and is needed to precisely estimate forest-related GHG emissions/removals, 
hence the need to measure all forest types in a country. The different forest types have various carbon pools: above-ground biomass, below-ground biomass, dead wood, litter and soil organic matter (IPCC, 2006). These pools have varying carbon emission/removal potentials per unit area. For the LULUCF sector, Emission Factors refers to emission/removal potentials of the various carbon pools.

In estimating their forest-related GHG emissions/removals, REDD+ countries therefore need Activity Data (AD) and Emission Factors (EF). The technical methods for estimating AD correspond with the methods for measuring forest areas and area changes while those for estimating EF correspond to methods for estimating carbon stocks. Traditionally, forest area and area changes (AD) has been estimated using ground-based field inventories (Mohren et al., 2012). However, since the 1980 s, ground-based methods have been complimented by Remote Sensing (RS), since RS offers a more cost-efficient method for measuring large tracks of forests. To estimate AD, the UNFCCC therefore requires REDD+ countries to use RS. Nonetheless, RS needs to be complimented by ground-based methods - so-called 'ground-truth' data because of challenges associated with RS (haze, cloud cover, etc., see Joseph et al. (2013a)). While there are RS methods for estimating Emission Factors, in most developing countries EFs are estimated using ground-based methods. The accuracy (second guideline) of methods for estimating $\mathrm{AD}$ and EF is indicated by the 'Tier' used. The IPCC identifies three Tiers. Tier 1 refers to default $\mathrm{AD}$ and $\mathrm{EF}$ values as provided by the IPCC. Tier 2 involves use of country/region-specific methods for EF and AD. Tier 3 involves use of higher-order, country-specific methods including models and repeated inventory measurements, and provides estimates of greater accuracy (IPCC, 2006).

In this article, we make a distinction between technical methods for estimating AD and those for estimating EFs. Since in most REDD+ countries EFs are estimated using ground-based methods, we further distinguish between ground-based methods for ground-truthing RS data and those for estimating EF. In line with these distinctions, we examine REDD+ countries' progress in: (1) acquiring and owning technical methods for estimating AD, i.e. RS data and ground-based methods for verifying RS data; and (2) developing higher-tier EFs. The former is indicated by acquisition of RS data (satellite images, aerial photos, etc.) and implementation of National Forest Inventories (NFI), including establishment of Permanent and or Temporary Sample Plots (PSP/TSP). The latter is used to access accuracy of the technical methods. Where 
a REDD+ country has acquired RS data, implemented NFI and developed higher-tier EF, for example, 'ownership of technical methods' is rated 'very high'.

The MRV system should cover all types of forests (third guideline). This is necessary to minimize double counting and leakage. MRVying all forests is also necessary to address political issues associated with measuring deforestation/ degradation. As Gupta et al. (2012) and Visseren-Hamakers et al. (2012) convincingly argue, measuring deforestation/ degradation is not an apolitical, neutral, scientific activity. Questions such as what is measured and reported are largely political (Lövbrand and Stripple, 2011; Wertz-Kanounnikoff and McNeill, 2012). This political nature of MRV means that while a country may own RS data, implement NFI and develop higher-tier EFs, it may have little political will to measure certain forests, land uses and carbon pools. To address this political nature of MRV, we examine whether countries intend to MRV all forests, land uses and carbon pools.

\subsubsection{Administrative capacity to implement MRV}

Young and Levy (1999) identify developing administrative capacity of national authorities to implement international institutions as one of the conditions essential for effective action on environmental problems. Therefore, development of administrative capacity of national authorities to implement the provisions of an international institution in itself constitute a measure of effectiveness of such institutions. Cornell (2002) conceptualizes developing administrative capacity to include developing clear procedures, hiring skilled labour and developing expertise, and building cooperative partnerships. Accordingly, we examine REDD+ countries' progress in: (1) clarifying MRV procedures, which encompass methods, guidelines and best practices to follow while conducting MRV; (2) linking REDD+ MRV with other GHG measuring systems. The UNFCCC encourages developing countries to implement Nationally Appropriate Mitigation Actions (NAMAS) and to report on GHG emission reductions resulting from implementation of these actions (UNFCCC, 2010). This implies that REDD+ MRV should fit within a broader national GHG accounting framework for NAMAS; (3) recruiting and developing expertise to conduct MRV. This is necessary especially given the often low technical expertise to measure forests in REDD+ countries (Korhonen-Kurki et al., 2013; Romijn et al., 2012); and (4) developing strategic partnerships with national and international academic, research and development partners to support MRV and capacity building activities. 


\subsubsection{Exercising 'good' governance in MRV}

As argued in section 2, the fourth and fifth guidelines call for transparency, accountability, and participation in MRV, which are key principles of "good" governance (see Secco et al., 2013). Although good governance is itself a contested concept and include many principles (Cashore and Visseren-Hamakers, Forthcoming; Nthiga, 2014), we focus on participation, transparency and accountability as these are the ones that UNFCCC has explicitly called for in MRV. However, we add a fourth - coordination - for reasons explained below. Participation implies that all actors have an opportunity to be heard and influence decisions (Kishor and Rosenbaum, 2012; Secco et al., 2013). This requires that the institutional arrangements expressly provide for their participation in decision-making on, implementation and evaluation of relevant policies. Developing mechanisms for actor participation is a necessary condition for effective participation. Here, we examine participation based on whether countries aim to: (a) involve different actors - state (both forestry and non-forestry), civil society, private and local communities - in MRV, (b) develop mechanisms for actor participation in MRV, and (c) conflict resolution mechanisms.

The UNFCCC also requires NFMS to be transparent and accountable (fourth guideline). Transparency implies that information about a resource and its governance be available to all actors (Gupta and Mason, 2014; Kishor and Rosenbaum, 2012). Transparency is indicated by the extent to which institutional arrangements allow access to and use of information by all actors. This entails availability of documentation procedures, timely provision of information and in a form understandable by all actors and availability of feedback mechanisms (Kishor and Rosenbaum, 2012; Secco et al., 2013). Here, we examine transparency in MRV based on: (a) developing mechanisms for making MRV results public, and for (b) making datasets, methods, approaches etc. public, and (c) provision of MRV results in a timely manner.

Accountability means that those in authority can be held accountable for their actions and decisions (Biermann and Gupta, 2011; Kishor and Rosenbaum, 2012). Indicators of accountability include clarity of roles, clear reporting, frequent monitoring and clear rationales for decision making (Secco et al., 2013). Here, we assess accountability based on clarity of (a) roles of the different actors involved in MRV, and (b) reporting channels. Availability of external evaluation mechanisms, and periodic reporting are not considered since it is assumed that the reported emission reductions/removals will be independently verified under the UNFCCC (see UNFCCC (2014b)). 
While the UNFCCC does not explicitly call for coordination, we add it for four reasons. First, deforestation and degradation stem from several causes, many of which arise outside the forestry sector. Second, in most REDD+ countries, forests fall under multiple jurisdictional levels or non-forestry state agencies. Third, in many countries, several REDD + pilot projects have been initiated. Fourth, the UNFCCC has called on REDD+ countries to nominate National Entities to serve as liaisons between them and the UNFCCC (UNFCCC, 2014b) on REDD+related issues (e.g. receiving results-based payments). A coordination mechanism is therefore necessary to coordinate MRV between different levels and agencies of government, the forest agency and REDD+ pilots, and among different sectors. We therefore examine whether REDD + countries have developed mechanisms to coordinate MRV between agencies and levels of government, REDD+ pilots, and different sectors. 


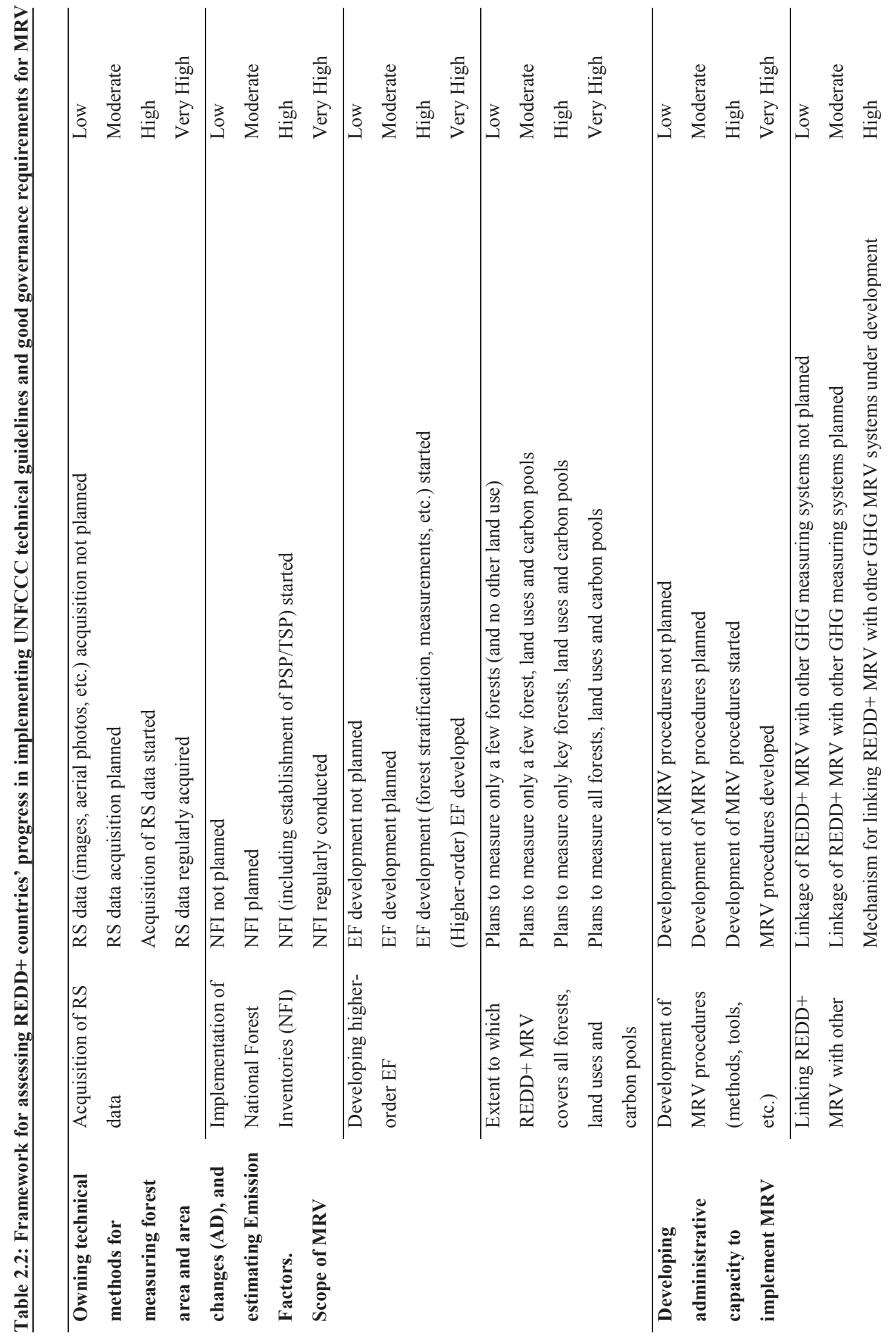




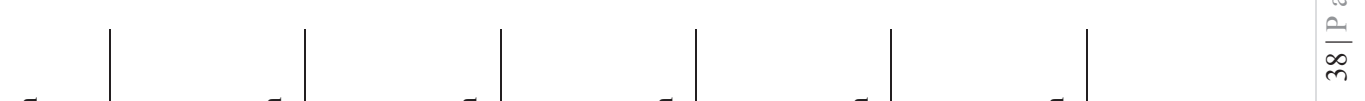

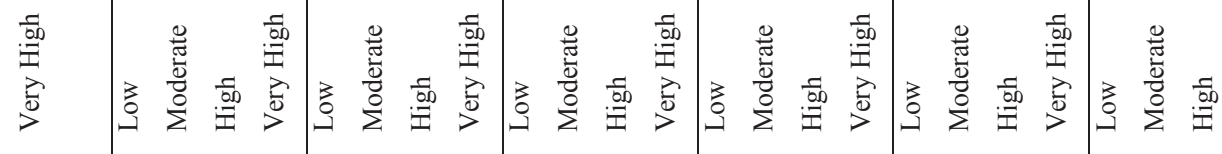

高

t.

$\lambda$

葡

馬

㝵

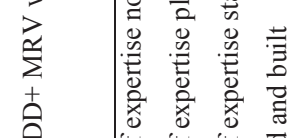

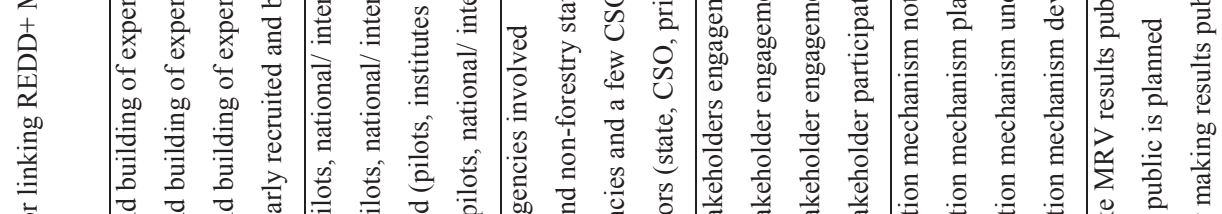

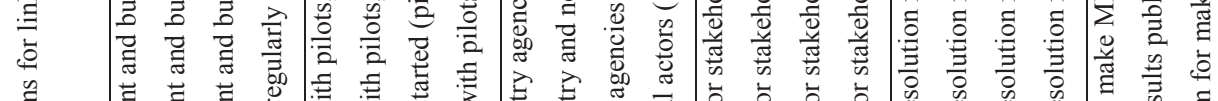

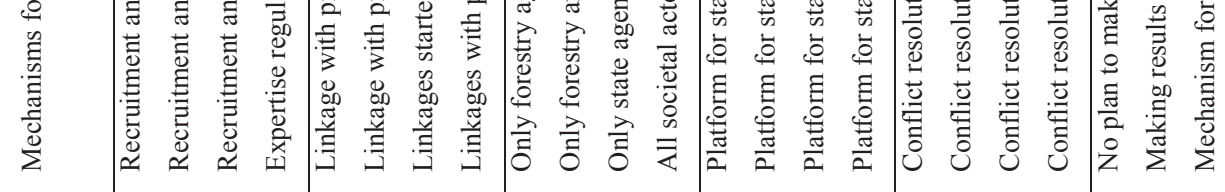

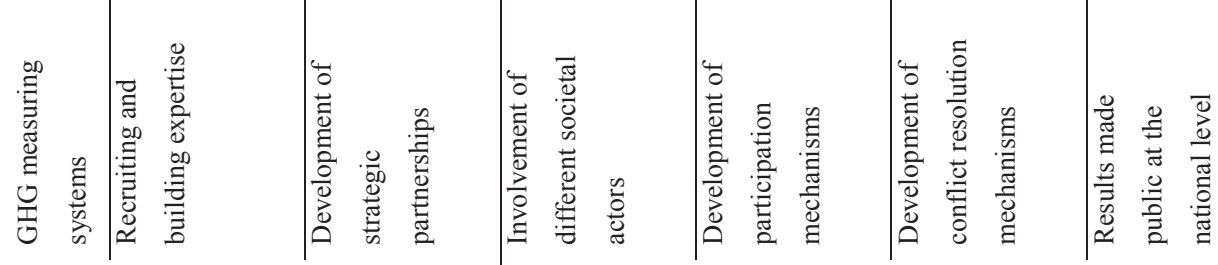




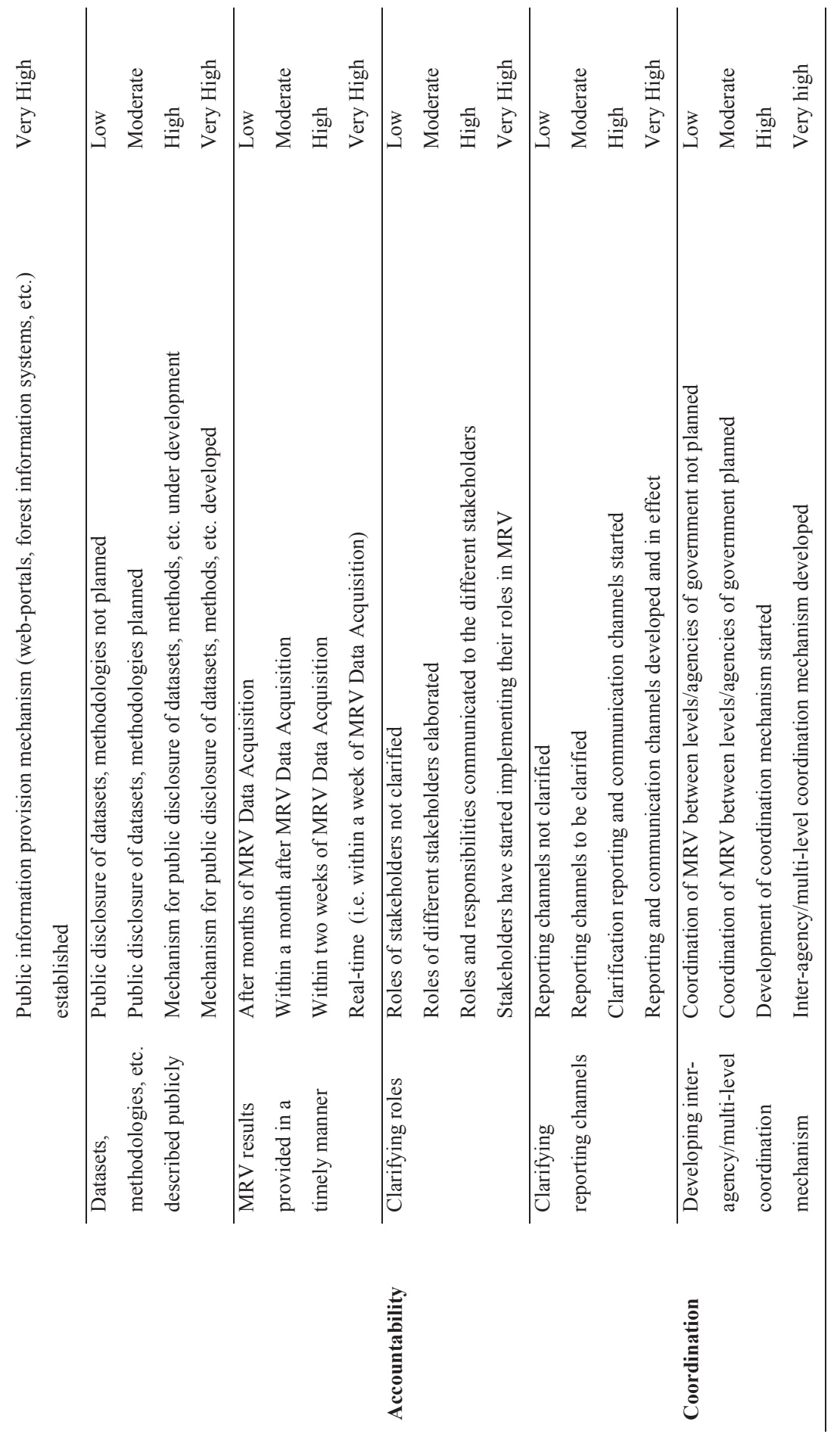




\subsection{REDD+ countries progress in implementing technical guidelines and good governance requirements for MRV}

\subsubsection{Owning technical methods for MRV}

Table 2.3 shows countries' progress in acquiring and owning technical methods for MRV. Mozambique, Tanzania and PNG have started acquiring and owning RS data while the rest have done so. Also, Peru, Tanzania and PNG have started implementing their NFIs while the rest have done this. However, no country has developed higher-order/country-specific Emission Factors; while all aim to develop higher-order EF, only six have started doing so. In terms of scope of MRV, DRC and Nepal aim to MRV only a few forests, land uses and carbon pools while Tanzania aims to MRV only key forests, land uses and carbon pools. The rest aim to MRV all forests, land uses and carbon pools.

Table 2.3: Progress in owning technical methods for MRV

\begin{tabular}{|c|c|c|c|c|c|}
\hline & Owning metho & or estimating $\mathrm{AD}$ & Owning methods for estimating EF & Scope of MRV & Aggregate \\
\hline & $\begin{array}{l}\text { Acquiring RS } \\
\text { data }\end{array}$ & $\begin{array}{l}\text { Implementing } \\
\text { NFI }\end{array}$ & Developing higher-order EFs & & $\begin{array}{l}\text { Score on } \\
\text { ownership }\end{array}$ \\
\hline Bolivia & Very High & Very High & High & Very High & $\begin{array}{l}\text { Very } \\
\text { High }\end{array}$ \\
\hline Brazil & Very High & Very High & High & Very High & $\begin{array}{l}\text { Very } \\
\text { High }\end{array}$ \\
\hline Peru & Very High & High & Moderate & Very High & Moderate \\
\hline Burkina Faso & Very High & Very High & Moderate & Very High & High \\
\hline Cameroon & Very High & Very High & Moderate & Very High & High \\
\hline DRC & Very High & Very High & High & Moderate & Moderate \\
\hline Tanzania & High & High & High & High & Low \\
\hline Mozambique & High & Very High & Moderate & Very High & Moderate \\
\hline Indonesia & Very High & Very High & High & Very High & $\begin{array}{l}\text { Very } \\
\text { High }\end{array}$ \\
\hline Laos & Very High & Very High & Moderate & Very High & High \\
\hline Nepal & Very High & Very High & Moderate & Moderate & Low \\
\hline PNG & High & High & Moderate & Very High & Low \\
\hline Vietnam & Very High & Very High & High & Very High & $\begin{array}{l}\text { Very } \\
\text { High }\end{array}$ \\
\hline
\end{tabular}




\subsubsection{Developing administrative capacity to implement REDD+ MRV}

Table 2.4 shows that six countries have developed MRV procedures (i.e. methods, protocols, approaches) while five are in the process of doing so. The remaining two plans to do so. Although all countries (except Mozambique and Nepal) plan to link REDD+ MRV with other GHG measuring systems, only Brazil and Indonesia have developed mechanisms for doing so. The rest are still in the planning stage. In terms of expertise, seven countries have recruited and built expertise for measuring forests while five have started doing so. Only Nepal is still in the planning stage. Eight countries have developed strategic partnerships with national and international research institutes and development agencies to support them in measuring forests. The rest have started developing such partnerships except Nepal, which is in the planning stage.

Table 2.4: Countries' progress in developing administrative capacity for MRV

\begin{tabular}{|c|c|c|c|c|c|}
\hline & $\begin{array}{l}\text { Developing MRV } \\
\text { procedures }\end{array}$ & $\begin{array}{l}\text { Linking REDD+ } \\
\text { MRV with other } \\
\text { GHG measuring } \\
\text { systems }\end{array}$ & $\begin{array}{l}\text { Recruiting \& } \\
\text { building } \\
\text { expertise }\end{array}$ & $\begin{array}{l}\text { Developing } \\
\text { strategic } \\
\text { partnerships }\end{array}$ & $\begin{array}{l}\text { Aggregate } \\
\text { score on } \\
\text { administrative } \\
\text { capacity }\end{array}$ \\
\hline Bolivia & High & Moderate & Very High & Very High & High \\
\hline Brazil & Very High & Very High & Very High & Very High & Very High \\
\hline Peru & High & Moderate & Very High & Very High & High \\
\hline Burkina Faso & High & Moderate & High & High & Moderate \\
\hline Cameroon & Moderate & Moderate & High & Very High & Moderate \\
\hline DRC & Very High & Moderate & Very High & Very High & Very High \\
\hline Tanzania & High & Moderate & High & High & Moderate \\
\hline Mozambique & Very High & Low & Very High & High & Low \\
\hline Indonesia & Very High & Very High & Very High & Very High & Very High \\
\hline Laos & Moderate & Moderate & Very High & Very High & Low \\
\hline Nepal & Very High & Low & Moderate & Moderate & Low \\
\hline PNG & High & Moderate & High & High & Low \\
\hline Vietnam & Very High & Moderate & High & Very High & High \\
\hline
\end{tabular}

\subsubsection{Exercising good governance in MRV}

Table 2.5 shows countries' progress in building 'good' governance in MRV. In terms of participation, all countries aim to involve both forestry and non-forestry state agencies, civil society, private sector and local communities in MRV. However, only Brazil, DRC, Tanzania, Nepal and Vietnam have developed mechanisms for involving these actors in MRV. Three others have started developing such mechanisms while another three are in the planning stage. 
Mozambique and Laos have, however, not considered developing such mechanisms. None of the countries have developed mechanisms for resolving conflicts in MRV specifically, although seven plan to develop mechanisms for resolving REDD+-related conflicts more generally (not shown in the Table).

In terms of transparency, all countries except Tanzania plan to make MRV results public. However, only Brazil, DRC, Mozambique and Indonesia have developed mechanisms for making MRV results public. Three others have started developing such mechanisms. Although nine countries plan to make MRV datasets, methods, etc. public, only Brazil and DRC have developed mechanisms for doing so. Burkina Faso, Cameroon, Tanzania and Laos have, however, not considered making these public. Only Brazil, Peru and DRC will provide MRV results in timely manner. In terms of accountability, Brazil and Vietnam have clarified the roles/responsibilities of the actors who will participate in MRV. Six other countries have started doing so while four are in the planning stage. Only Laos has not considered this aspect. Brazil and Vietnam have clarified reporting channels between actors who will participate in MRV while Tanzania and Peru have started doing so. The rest are in the planning stage except Bolivia, Burkina Faso and Laos that have not considered this aspect. On coordination, Brazil has developed mechanisms for coordinating MRV among involved actors while Peru, Tanzania and Indonesia have started doing so. The rest are in the planning stage except Burkina Faso, DRC and Laos that have not considered this aspect. 


\subsubsection{Countries' overall progress in implementing UNFCCC technical and good governance guidelines for MRV}

Table 2.6 shows REDD+ countries' aggregate score on each dimension of, and overall performance in implementing technical guidelines and good governance requirements for $\mathrm{MRV}{ }^{2}$ Bolivia, Brazil, Indonesia and Vietnam score very high on 'ownership of technical methods' for MRV. The rest fall within the high and moderate categories except Tanzania, Nepal and PNG, which rank low. In terms of developing 'administrative capacity' to implement MRV, Brazil, DRC and Indonesia rank very high while Bolivia, Peru and Vietnam rank high. Burkina Faso, Cameroon and Tanzania rank moderate while the rest rank low. Finally, on exercising 'good governance' in MRV, only Brazil ranks very high. The rest fall within the high and moderate categories except Burkina Faso and Laos, which rank low. Overall, only Brazil score very high in implementing the technical guidelines and good governance requirements for MRV, followed by DRC, Indonesia and Vietnam. Bolivia, Peru, Cameroon, Tanzania ranks moderate while Burkina Faso, Mozambique, Nepal, Laos and PNG ranks low.

Several potential explanations for these scores can be found in the literature. Brazil's very high overall score on implementing technical and good governance requirements for MRV reflects its long experience in forest measurements in general and deforestation in particular (May et al., 2011). Laos' low overall score is due to its low aggregate score on 'administrative capacity' and 'good governance', which can both be attributed to the limited participation of local population in land-use planning and access to forest information as well as the absence of a fully-developed civil society (Lestrelin et al., 2013). For Nepal, the low overall score is due to its low aggregate score on 'ownership of technical methods' and on 'good governance'. The latter can be attributed to lack of meaningful consultation on REDD+ (Paudel et al., 2013) and dominance of the REDD+ policy arena by governmental actors (Bushley, 2014), and the former to the mountainous nature of the

\footnotetext{
${ }^{2}$ Eleven criteria and 17 indicators were developed (Table 2.2). Each indicator received a score of 0-3 depending on progress in its implementation. Overall, the maximum points that a country could score was 51 (17X3). REDD+ country's overall progress in implementing UNFCCC decisions on MRV was rated very high for a score of $>40$, high for a score of 33-40, medium for a score of 26-32 and low for a score of $<26$. This scale was defined after analysing the relative distribution of score across the 13 countries. The same procedures was used to calculate aggregate score for each dimension. For example, the maximum possible score for 'ownership of technical methods' is 12 (4X3). Aggregate score on ownership of technical methods was rated very high for a score of $>10.25$, high for a score of $9.5-<10.25$, medium for a score of $8.75-<9.5$ and low for a score of $<8.75$.
} 
country, which poses RS challenges and limits large-scale ground-based measurements. PNG's low overall score reflects its slow development of REDD+ policies and institutional arrangements (Brockhaus and Di Gregorio, 2014).

Table 2.6: Countries' aggregate score on each dimension of and overall effectiveness of REDD+ MRV

\begin{tabular}{|c|c|c|c|c|}
\hline & $\begin{array}{l}\text { Owning technical } \\
\text { methods }\end{array}$ & $\begin{array}{l}\text { Developing } \\
\text { administrative } \\
\text { capacity }\end{array}$ & $\begin{array}{l}\text { Exercising } \\
\text { Good } \\
\text { governance }\end{array}$ & $\begin{array}{l}\text { Overall } \\
\text { Effectiveness of } \\
\text { REDD+ MRV }\end{array}$ \\
\hline Bolivia & Very High & High & Moderate & Moderate \\
\hline Brazil & Very High & Very High & Very High & Very High \\
\hline Peru & Moderate & High & High & Moderate \\
\hline Burkina Faso & High & Moderate & Low & Low \\
\hline Cameroon & High & Moderate & Moderate & Moderate \\
\hline DRC & Moderate & Very High & High & High \\
\hline Tanzania & Low & Moderate & Moderate & Moderate \\
\hline Mozambique & Moderate & Low & Moderate & Low \\
\hline Indonesia & Very High & Very High & High & High \\
\hline Laos & High & Low & Low & Low \\
\hline Nepal & Low & Low & Moderate & Low \\
\hline PNG & Low & Low & Moderate & Low \\
\hline Vietnam & Very High & High & High & High \\
\hline
\end{tabular}

\subsection{Discussion and recommendations}

\subsubsection{Owning technical methods}

The findings show that REDD+ countries have either started acquiring or have acquired and own technical methods for forest area and area change measuring (i.e. have RS data and implemented NFI). This finding supports those of other authors (Bernard et al., 2014; Romijn et al., 2015). Virtually all REDD+ countries have implemented some form of forest measurements using both RS and ground-based methods, often supported by bilateral, multilateral and international agencies, especially the FAO (Saket et al., 2010). Moreover, since 2008, Landsat images have been available free of cost thereby improving access to RS data. The challenge for most REDD+ countries is to both assemble RS data within their jurisdictions and/or acquire new ones and 
regularly implement NFIs. International support in both areas is still needed since most high-end RS data are not yet freely available (Wulder et al., 2014) and regular implementation of NFI remains a challenge in many countries (Romijn et al., 2015).

It is remarkable that all 13 countries (except DRC and Nepal) plan to measure and report on at least key forest types, land uses and carbon pools. While this is probably driven by countries' desire to generate large emission reductions in order to earn higher result-based payments, it will help minimize leakage and double counting. A major weakness in countries' progress in owning and controlling technical methods for MRV is the fact that none has developed higher-order Emission Factors, as Romijn et al. (2012) also highlighted. This weakness is due to the very large amounts of financial resources involved in estimating higher-order Emission Factors (see Hardcastle and Baird (2008) for country-specific estimates), which most REDD+ countries currently lack. REDD+ donors should therefore support countries with the necessary resources to enable them develop higher-order EFs.

\subsubsection{Developing administrative capacity}

The vast majority of the countries ranked only low to moderate on developing administrative capacity to implement MRV (Table 6), which represents a major weakness in their overall progress in implementing technical guidelines and good governance requirements for MRV. This low score on administrative capacity for MRV stems from the fact most countries have not developed mechanisms for linking REDD+ MRV with other GHG measuring systems (Table 5). Yet, as noted in section 3.2, REDD+ MRV should be developed within the broader context of MRV for NAMAS. Moreover, in many countries, REDD + falls under jurisdictions of forest or related authorities, while authorities responsible for climate change (so-called UNFCCC focal points) and who are responsible for preparing National Communications and reporting on national GHG emissions, are found in the ministries of environment. REDD+ countries should therefore develop clear channels on how information/data from REDD+ MRV will flow to these UNFCCC focal points, and vice versa.

Although our findings show that most countries have started recruiting and building expertise for REDD+ MRV, this involved recruiting just a few persons and ad hoc training of a handful of people. As Bernard et al. (2014) and Ochieng et al. (2016a) observe, REDD+ countries have not 
yet developed systematic capacity building programs. Given the tremendous task involved in measuring deforestation and degradation, and the lack of adequate expertise for MRV in many REDD+ countries (Korhonen-Kurki et al., 2013), REDD+ donors should support countries to recruit and train a critical mass of national actors if MRV is to be durable.

\subsubsection{Exercising good governance in MRV}

Like with 'administrative capacity', the vast majority of countries ranked only low to moderate in terms of exercising good governance in MRV, which represents another major weakness in their overall progress in implementing technical guidelines and good governance requirements for MRV. While all countries aim to involve different actors in MRV, including local communities, as Pratihast et al. (2013) also show, only five countries have developed mechanisms for their participation in MRV (Table 5). These included Nepal, Tanzania and PNG where donor-driven programs have developed such mechanisms (Verplanke and Zahabu, 2009), highlighting the need for increased donor/international investments in developing such mechanisms. Moreover, in many REDD + countries there are conflicts among different levels and agencies of government on MRVrelated issues such as responsibilities for data (Korhonen-Kurki et al., 2013; Ochieng et al., 2015; Ochieng et al., 2016b; Robiglio et al., 2014). However, our findings show that no country has developed mechanisms for resolving these MRV-related conflicts. While this attests to the current assumption that MRV is a technical activity, free of political contestations, these conflicts point to the political character of MRV especially as regards distribution of roles and potential benefits associated with assuming such roles. Countries should therefore develop mechanisms specifically aimed at resolving MRV-related conflicts. Clarifying the roles of each actor involved in MRV and the reporting channels among them could also help alleviate conflicts. This will have the added advantage of improving accountability in MRV that is wanting in most countries.

The purpose of REDD+ MRV is not only to measure emission reductions/removals but also to ensure timely response to threats of deforestation and degradation. This requires that MRV results be communicated to relevant authorities to enable them to take appropriate action. Such communication will be effective only if done in a timely manner. However, our findings show that only Brazil has developed mechanisms for coordinating and communicating MRV results between different levels and agencies of government (Table 4). Although Peru, DRC, Mozambique, Indonesia, Nepal and PNG have either started or developed mechanisms for making MRV results 
public, the rest are yet to do so. Moreover, besides Brazil, only Peru and DRC will provide MRV results in a timely manner. Given its long experience in near-real time deforestation measuring and in coordinating forest measurement results between different levels and agencies of government (see May et al., 2011), Brazil could help other countries build similar capacities within the framework of south-south cooperation. Empowering local-level actors, especially local communities, to not only report but also to act on identified threats should also be considered. This can be done by both allocating communities clear roles in MRV and providing them with tools such as mobile hand-held devices (Pratihast et al., 2012) to enable them record and report identified threats.

\subsection{Conclusion and limitations}

In conclusion, this study highlights that there is low to moderate progress in implementing the UNFCCC technical guidelines and good governance requirements for MRV in majority of REDD+ countries, and that this slow progress is because while REDD+ countries rank high in terms of 'ownership of technical methods' for MRV, the vast majority ranks only low to moderate in terms of 'administrative capacity' and 'good governance'. This means that although REDD+ countries have started developing technical methods for MRV (acquiring RS data, implementing NFIs, establishing sampling plots), they have not paid adequate attention to building the capacity to administer MRV and to propagating good governance in MRV. This is problematic, since building administrative competence (including technical expertise of the multiple actors who will participate in MRV) and propagating good governance in MRV are indispensable if the measured and reported REDD+ carbon impacts are to be credible and legitimate in the eyes of both national and international actors. Moreover, participation, transparency, accountability and coordination in MRV are necessary to ensure equitable distribution of REDD+ payments. Therefore, besides developing technical methods for MRV, countries should also pay attention to building administrative capacity for, and propagating good governance in MRV. International vigilance and support in these areas is needed.

While our study has developed new insights on REDD+ countries' progress in implementing technical guidelines and good governance requirements for MRV, it also has several limitations. For one, we have relied on only secondary data. While the coverage of the documents reviewed is extensive (see Annex A), it is also possible that many of the countries have already implemented 
some of the items indicated in the documents since their publication. In addition, in some countries (e.g. Cameroon), there were contradictions in information provided in the documents. We addressed this by taking the position indicated in the most recent document. Moreover, while the document analysis has allowed us to develop a "bird's eye view" of REDD+ countries' progress in implementing UNFCCC decisions on REDD+ MRV, subsequent analyses should combine document analysis with primary data sources such as interviews and focus group discussions with national-level actors and international experts, as this would provide a more up-to-date and contextualized account of REDD+ countries' progress in implementing MRV. Lastly, the criteria used to assess good governance in MRV do not cover the whole set of principles of good governance, as discussed in section 3.3. Additional good governance principles and indicators could be included in future analyses, as maybe appropriate. Despite these limitations, our study has advanced the assessment of technical MRV capacity by adding an institutional dimension along the lines of 'ownership of technical methods', 'administrative capacity' and 'good governance'. 


\section{Appendix A: National and International Documents Reviewed by Country}

\begin{tabular}{|c|c|c|c|c|c|c|c|c|}
\hline & $\begin{array}{l}\text { Readines } \\
\text { s } \\
\text { Preparati } \\
\text { on Idea } \\
\text { Note }\end{array}$ & $\begin{array}{l}\text { Readines } \\
\text { s } \\
\text { Preparati } \\
\text { on } \\
\text { Proposal }\end{array}$ & $\begin{array}{l}\text { Emission } \\
\text { Reductio } \\
\text { n } \\
\text { Program } \\
\text { Idea } \\
\text { Note }\end{array}$ & $\begin{array}{l}\text { UN } \\
\text { REDD } \\
\text { National } \\
\text { Program } \\
\text { Docume } \\
\text { nt }\end{array}$ & $\begin{array}{l}\text { Country } \\
\text { REDD+ } \\
\text { Strategy }\end{array}$ & $\begin{array}{l}\text { MRV } \\
\text { Framewo } \\
\text { rk } \\
\text { Documen } \\
\text { t }\end{array}$ & $\begin{array}{l}\text { CIFO } \\
\text { R } \\
\text { Count } \\
\text { ry } \\
\text { Profile }\end{array}$ & $\begin{array}{l}\text { Norwegian } \\
\text { Internation } \\
\text { al Climate } \\
\text { and Forest } \\
\text { Initiative } \\
\text { Evaluation } \\
\text { Reports }\end{array}$ \\
\hline $\begin{array}{l}\text { Burkina } \\
\text { Faso }\end{array}$ & & Oct. 2013 & & & & & & \\
\hline Cameroon & July 2008 & Jan. 2013 & & & & & 2011 & \\
\hline DRC & $\begin{array}{l}\text { March } \\
2008\end{array}$ & $\begin{array}{l}\text { March } \\
2010\end{array}$ & $\begin{array}{l}\text { March } \\
2014 \\
\end{array}$ & $\begin{array}{l}\text { March } \\
2010\end{array}$ & No Date & & 2013 & $\begin{array}{l}2010 ; \text { Sep. } \\
2013\end{array}$ \\
\hline $\begin{array}{l}\text { Mozambiq } \\
\text { ue }\end{array}$ & $\begin{array}{l}\text { March } \\
2008\end{array}$ & Dec. 2010 & & & & & 2012 & \\
\hline Tanzania & Feb. 2009 & Oct. 2010 & & Oct. 2009 & $\begin{array}{l}\text { March } \\
2013\end{array}$ & & 2015 & $\begin{array}{l}2010 \\
\text { Sep.2013 }\end{array}$ \\
\hline Indonesia & & May 2009 & Oct. 2014 & Oct. 2009 & $\begin{array}{l}\text { Sep. } \\
2012\end{array}$ & $\begin{array}{l}\text { Nov. } \\
2012\end{array}$ & 2012 & $\begin{array}{l}2010 \text {; Sep. } \\
2013\end{array}$ \\
\hline Laos & June 2008 & Dec. 2010 & & & & & 2013 & \\
\hline Nepal & $\begin{array}{l}\text { April } \\
2008\end{array}$ & Sep. 2010 & $\begin{array}{l}\text { March } \\
2014 \\
\end{array}$ & & & & 2013 & \\
\hline PNG & July 2008 & Dec. 2013 & & Jan. 2011 & & & 2013 & \\
\hline Vietnam & $\begin{array}{l}\text { March } \\
2008 \\
\end{array}$ & $\begin{array}{l}\text { Nov. } \\
2011 \\
\end{array}$ & $\begin{array}{l}\text { May } \\
2014 \\
\end{array}$ & $\begin{array}{l}\text { Feb. } \\
2011 \\
\end{array}$ & $\begin{array}{l}\text { Feb. } \\
2011 \\
\end{array}$ & Sep. 2011 & 2012 & \\
\hline Bolivia & $\begin{array}{l}\text { March } \\
2008\end{array}$ & & & $\begin{array}{l}\text { March } \\
2010\end{array}$ & & & 2014 & \\
\hline Brazil & & & & & $\begin{array}{l}\text { Dec. } \\
2009\end{array}$ & & 2011 & 2010 \\
\hline Peru & June 2008 & $\begin{array}{l}\text { March } \\
2011\end{array}$ & $\begin{array}{l}\text { May } \\
2014\end{array}$ & & & $\begin{array}{l}\text { March } \\
2014\end{array}$ & 2014 & \\
\hline
\end{tabular}


Chapter 3 - Historical development of institutional arrangements for forest monitoring and REDD+ MRV in Peru: Discursive-institutionalist perspectives

Published as: Ochieng R.M., Visseren-Hamakers, I.J., Brockhaus, M., Kowler, L.F., Herold, M. \& Arts, B., 2016. Historical development of institutional arrangements for forest monitoring and REDD + MRV in Peru: Discursive-institutionalist perspectives. Forest Policy and Economics 71, 52-59. 


\begin{abstract}
The goal of reducing emissions from deforestation and forest degradation, and the roles of conservation, sustainable management of forests and enhancement of forest carbon stocks in developing countries (REDD+) under UNFCCC has triggered a new discussion on forest resource assessments in these countries. The international process on measurement, reporting and verification of REDD+ outcomes (REDD+ MRV) expands the scope of forest inventories to include quantification of forest carbon stocks and their changes for results-based REDD+ payments. UNFCCC decisions also specify methods to be used, and actors to be involved. Although forest management in developing countries has clearly been influenced by international processes in the past, exactly how and to what extent REDD+ MRV has affected institutional arrangements for forest assessments in developing countries remains unknown. Using as a theoretical framework Discursive-Institutionalism, a concept derived from political science, this paper examines (1) the historical evolution of institutional arrangements for forest inventories in Peru; and (2) how and to what extent their development has been shaped by international processes on forests, and, more recently, specifically by REDD+ MRV. The findings show that the international REDD+ MRV discussion has expanded the objectives of forest assessments in Peru, inspired the mobilization of new actors and resources, and spawned the development of new protocols for forest assessments. However, the 'depth' of these changes is not yet extensive, since the new rules for forest inventories have not yet been formally adopted, and the institutes envisaged to implement forest inventories, including measurement of carbon stocks and their changes, have not been established.
\end{abstract}

Keywords: National forest resource assessments, REDD+ MRV, Discursive Institutionalism, Peru, Policy Arrangement Approach 


\subsection{Introduction}

Forest resource assessment in developing countries is becoming a concern for the international community. This is driven by the increasing recognition of the role that forests could play in mitigating global environmental challenges such as climate change, and the attendant need for information on developing countries' forests at the national and international level. This need has sparked investments in national forest monitoring systems in several developing countries (Joseph et al., 2013b; Korhonen-Kurki et al., 2013; Minang et al., 2014; Romijn et al., 2015). Studies show that these investments have improved technical and institutional capacity for forest resource assessments in some countries. However, unlike in some developed countries where some forms of national forest inventories have been conducted, sometimes already for several centuries (Holmgren and Persson, 2002a, b; Lund, no.date; Tomppo et al., 2010a); Xie et al. (2011), national forest surveys in developing countries started only recently (see FAO, 1993; Janz and Persson, 2002). Nevertheless, early national forest inventories mainly quantified forest area, growing stock and, rarely, changes over a time period (Holmgren et al., 2007; Holmgren and Persson, 2002a, b; Mohren et al., 2012; Tomppo et al., 2010a). Over time, however, the range of variables included forest cover change, forest biodiversity, socio-economic uses of forests, and non-timber forest products (NTFPs), among others (Holmgren et al., 2007; Holmgren and Persson, 2002b; Lei et al., 2009; Mohren et al., 2012).

Although the variables included in national forest surveys have been influenced by international developments (Holmgren and Persson, 2002a, b; Lei et al., 2009), the recent United Nations Framework Convention on Climate Change (UNFCCC) decision on reducing emissions from deforestation and forest degradation, and the role of conservation, sustainable management of forests and enhancement of forest carbon stocks in developing countries (REDD+) (see UNFCCC, 2013a; UNFCCC, 2013b) has triggered new national discourses on forest inventories in developing countries. Specifically, the international process on REDD + measurement, reporting and verification (REDD+ MRV) has introduced new elements into forest inventories. First, REDD+ MRV expands the scope to include forest carbon stocks and their changes for possible resultsbased REDD+ payments. Second, it specifies techniques, such as remote sensing (RS) and groundbased methods (UNFCCC, 2009). Third, it advocates new participants, including state actors from and beyond the forestry sector, as well as the private sector and indigenous and local communities (Brockhaus and Angelsen, 2012a; UNFCCC, 2009). UNFCCC decisions on REDD+ MRV are 
likely to spawn new or restructuring of existing institutions for quantifying forest carbon, and, possibly, other forest attributes of national or international interest. The UNFCCC explicitly calls on developing countries wishing to receive results-based REDD+ payments 'to establish national forest measurement systems' (UNFCCC, 2009) to measure and report their forest emission reductions/ removals.

Although the development of forest inventories in developing countries has been examined in terms of technical aspects, such as sampling strategies, plot designs, use of RS and information technologies, et cetera (Hansen et al., 2008; Holmgren and Persson, 2002a; Joseph et al., 2013a; Lei et al., 2010; McRoberts and Tomppo, 2007; Romijn et al., 2012; Tomppo et al., 2010a; Xie et al., 2011), exactly how and to what extent the international discussion on REDD+ MRV has shaped institutional arrangements for forest measurements in developing countries is unknown. This paper aims to bridge this knowledge gap by examining: (1) the historical development of institutional arrangements for forest assessments in Peru; and (2) how and to what extent the evolution of these institutional arrangements have been shaped by international processes on forests, especially REDD+ MRV. The next section outlines the analytical framework, including Discursive Institutionalism (DI) and the Policy Arrangement Approach (PAA), used for the analysis. Section three justifies selecting Peru as a case study, and describes study methods. Section four discusses the development and evolution of institutional arrangements for forest inventories in Peru before REDD + from the 1950 s to the early 2000 s, followed by institutional changes caused by the international REDD + MRV process. Section five discusses the results from our research on the case study of Peru in a broader context.

\subsection{Discursive Institutionalism and the Policy Arrangement Approach}

Although forest resource assessments for REDD are often regarded as technical and apolitical, the REDD+ MRV concept is not entirely an apolitical, neutral scientific phenomenon (Gupta et al., 2012; Visseren-Hamakers et al., 2012). What is to be measured, reported and verified, who is to be involved and what methods are to be used is determined in a political process (Lövbrand and Stripple, 2011; Wertz-Kanounnikoff and McNeill, 2012), which involves negotiations and potentially conflicts and power games. As such, an analysis of REDD+ MRV at national and international levels require a political theoretical perspective. 
We use Discursive Institutionalism (DI), a framework from political science, to analyse REDD+ MRV in Peru in this paper (Arts and Buizer, 2009; Schmidt, 2008). Discursive institutionalism is a new strand of institutional theory distinct from rational choice, historical and sociological institutionalism. It emphasizes the role of ideas and discourses in politics and in explaining institutional change (Hay, 2006; Schmidt, 2002, 2008). The main assumption is that new ideas and the discourses they spawn may undermine or re-shape existing institutional arrangements and thereby cause institutional change (Arts and Buizer, 2009; Schmidt, 2008).

DI identifies discourses and institutions as its two main key concepts (Arts and Buizer, 2009). Here, following Schmidt (2005, 2008), we conceptualize a discourses as a 'double faced' phenomenon: as the shared - and at the same time contested - ideas about policymaking on the one hand, and as the interactive process through which these ideas are exchanged and deliberated among policy actors and the general public on the other. The first face of discourse as ideas conform to Hajer and Versteeg (2005) view of discourses as an ensemble of ideas through which meaning is given to social and physical phenomena. The second face of discourse as interactive processes of policymaking conforms to Habermas' conception of deliberative democracy (Habermas, 1994, 1996, 2006). As an interactive process, policymaking involves two types of policy discourses: communicative and coordinative policy discourses. The latter involves discussions among policy actors within the state bureaucracies, while the former involves discussions between political actors and the general public (Schmidt, 2008). In both policy discourses, DI conceptualizes actors as possessing 'background ideational abilities' and 'foreground discursive abilities', which enable them to re-think the institutional arrangements within which they act, communicate and deliberate their ideas about these institutional arrangements in a critical way, and take action to change or maintain them (Schmidt, 2010).

Institutions, the second key concept in DI, are 'materialized discourses' in that the latter have become transformed and anchored into rules of the game, such as laws and standards (Schmidt, 2008). In our view, however, DI does not comprehensively conceptualize institutions, because it only addresses 'rules of the game', while institutional arrangements consists of more elements than just rules (see for example Van Tatenhove et al., 2000). Therefore, to thoroughly and comprehensively operationalize DI, including institutional arrangements, we use the Policy Arrangement Approach (PAA), (compare Arts and Buizer, 2009, who consider the PAA as an 
operationalization of DI at policy level). A policy arrangement refers to the way a certain policy domain (here national forest measurement) is 'temporarily' shaped in terms of policy discourses, actors, resources and rules (Arts and van Tatenhove, 2006; Liefferink, 2006a; Wiering and Arts, 2006). Below, we elaborate on each PAA dimension more in-depth.

A policy discourse, first of all, is the interactive process of idea formation in public deliberation and policy making (same conceptualization as in DI). However, it may contain three types of ideas: policy, programmatic and philosophical ideas (Mehta, 2011; Schmidt, 2008). Policy ideas are the strategies proposed by different policy actors to achieve given policy aims. Programmatic ideas encompass the definition of the policy problem at hand and the policy aims to be achieved (Mehta, 2011; Schmidt, 2008; Schmidt and Radaelli, 2004; see also Wiering and Arts, 2006). Philosophical ideas are the taken-for-granted underlying ideals and values in a given policy domain that rarely contested, except in times of crisis (Campbell, 1998; Campbell, 2004; Mehta, 2011; Schmidt, 2008). Actors, secondly, are the stakeholders involved in policy formulation and implementation. They interact with one another during policymaking and deliberations and may form coalitions to advocate common policy ideas and or contest competing ones. Thirdly, resources are the tools, technologies, budgets and skills that actors can mobilize to achieve their policy aims. Rules, finally, are the laws and procedures that define the way a policy issue should be conducted. While laws are the codes enacted to implement selected policy ideas, procedures are routines that delineate division of roles and authority between the actors (Arnouts et al., 2012; Wiering and Arts, 2006). Following the PAA, we operationalize national institutional arrangements for forest monitoring as encompassing policy discourses, actors, resources and rules, and examine how these have been affected by international processes.

To gauge the extent to which any particular international process has affected national institutional arrangements for forest inventories in Peru, we distinguish between 'shallow' and 'deep' institutional change. Following Wiering and Arts (2006), we define 'shallow' institutional change as change in policy discourse only - often expressed in speeches and statements to the wider public or in expert debates -, and 'deep' institutional change as change not only in policy discourses but also in actor constellations, resources and rules. Often, when there is pressure for change in a policy sector, or when there is an institutional crisis, 'deep' institutional change is necessary to accommodate the new situation. In such cases, a shallow change is insufficient. Table 3.1 presents 
indicators for assessing extent of institutional change and further operationalizes the key terminologies.

Table 3.1: Framework for assessing extent of institutional change (Adapted from Wiering and Arts, 2006)

\begin{tabular}{lcl}
\hline PAA Element & Change Indicators in Institutional Arrangements \\
\hline Discourses & Change in: \\
& - & Policy ideas: strategies for forest assessments \\
& - & Phogrammatic ideas: Aims and scope of forest assessments \\
& - & assessments \\
Actors & Interactions: nature of interactions among the actors (increased/ decreased, cooperative/ \\
& - & Resourlictual) \\
\hline Resources & - & Resource distribution across actors \\
& - & Laws that codify forest assessments \\
\hline Rules & &
\end{tabular}

\subsection{Methods}

Peru is a major forested country, with over 67 million ha of forests (Organización para Estudios Tropicales, 2011). The country has a large number of REDD+ pilot projects (Piu and Menton, 2014b; Simonet et al., 2014), and is involved in several international initiatives on REDD+, namely the World Bank's Forest Carbon Partnership Facility (FCPF) and Forest Investment Program (FIP), and the United Nations Collaborative Programme on Reducing Emissions from Deforestation and Forest Degradation in Developing Countries (UN REDD) (de la Plaza Esteban et al., 2014; Robiglio et al., 2014).

Primary data were obtained through 42 in-depth interviews and two focus group discussions (FGDs) with representatives of various forestry-related actors (Table 3.2), which were selected because they had been involved in forest inventories in Peru over the last several decades, and/or in the more recent deliberations on REDD+ MRV. Secondary data were obtained through analyses of relevant past and present national forest policy documents, and other scientific and grey literature. 
Table 3.2: Number of interviews by category

\begin{tabular}{lll}
\hline Categories of Interviewees & Number & Interviewees \\
\hline Government: National & 11 & $4,5,10,12,32,33,34,35,36,37,38$ \\
Government: Regional & 9 & $3,17,18,20,24,27,30,41,42$ \\
International Development Agencies & 5 & $6,13,23,25,26$, \\
NGO and Indigenous Community Organizations & 6 & $11,14,19,22,39,40$ \\
Research/ Educational Institutes & 8 & $2,8,9,15,21,28,29,31$ \\
Private Actors & 3 & $1,7,16$ \\
\hline Total & 42 & \\
\hline
\end{tabular}

The interviews and document analysis attempted to reconstruct how and to what extent international processes have affected past and present aims, scope and strategies of forest assessments, the actors involved, resources used and their distribution among actors, and the laws and procedures governing forest surveys. Changes in aims, scope and strategies of forest assessments were deduced from interviews and FGDs. This was so because, being in the 'foreground', strategies, aims and scope are often discussed publicly and can thus easily be deduced from interviews and FGDs (Campbell, 1998). Changes in ideals and values underlying forest assessments were deduced from analysis of policy documents, and scientific and grey literature (e.g. Cossio-Solano, 2009; and Malleux, 1975). This was so because, being in the 'background', such ideals and values are rarely discussed publicly and are thus difficult to deduce from interviews and FDGs (Schmidt, 2008).

From our data, it was not possible to recreate national discussions since there was very limited coordinative and hardly any communicative discourse on MRV in Peru. This is probably so because of the perceived technical nature of REDD+ MRV that makes debates on it limited to a closed group of experts. During field visit, the meetings focussed mainly on training and technical discussions on REDD+ MRV and not on policy development per se, and hence did not, in our view, qualify as coordinative policy discourse but rather 'expert' discussions.

\subsection{Evolution of institutional arrangements for forest assessments in Peru}

Below, we identify the international processes that have shaped institutional arrangements for forest inventories in Peru, and comment on the extent to which they have shaped national policy discourses, actors and their interactions, resources, and rules. Three distinct time periods were dominated by different international processes on forests. These are productivist forest philosophy (1950s - early 1980s), sustainable forest management and multiple-use forest philosophies (1980s - early 2000s), and REDD+ MRV (since 2005). Table 3.3 summarizes the results. 


\subsubsection{0s - 1980: Early attempts to institutionalize forest inventory}

The overriding goal of forest management during this early period was timber extraction. Given this 'productivist' forest (Mather, 2001) philosophy, the main aim of forest measurements was to determine the potential for timber extraction (Malleux, 1975) and issuance of logging permits and concessions. Actors involved in forest mensuration were mainly governmental agencies: the Forest and Wildlife Service, the National Office for Natural Resource Evaluation ${ }^{3}$, and the Forestry Department of the National University of Agriculture, La Molina. These organizations operated independently, and interacted only ad hoc (Interview 8, 9, 15, 16). Other actors involved in forest measurements were the concessionaires, whose participation was limited to commercial species within concession boundaries. In the 1970s, the National Aeronautical Service, the Peruvian National Geographic Institute and the National Cadastral Office participated. The public actors formed a committee that conducted the First National Forest Inventory in the early 1970s and produced the first forest map of Peru (Malleux, 1975). They also engaged local communities to help with tree identification (Interview 29). Thus, although interactions were infrequent, they became less ad hoc and more coordinated.

Nearly all the interviewees reported that forest resource assessments in Peru during this period relied only on aerial photos, suuntos, callipers, and Bitterlich's relascope as mensuration tools. Moreover, national forest assessments were not institutionalized in any legislation. The country's first forest law (Decree Law No. 14552), promulgated in the early 1960s (Cossio-Solano, 2009), omitted forest measurements. This situation only changed in 1975 when Peru enacted a new Forest and Wildlife Law (Decree Law No. 21147, FWL) to better regulate forestry activities (CossioSolano, 2009; Sears and Pinedo-Vasquez, 2011). Unlike the previous law, the FWL obligated contractors with over 100,000 ha of forest to present technical-economic feasibility studies, including inventory details of all commercial trees to be harvested. However, this attempt to institutionalize commercial forest inventories in law did not materialize in practice as the large contractors circumvented the law by sub-contracting 1,000 ha parcels. This enabled the large contractors to harvest much larger tracts of forest without providing any feasibility studies or inventories of harvestable trees (Cossio-Solano, 2009; Sears and Pinedo-Vasquez, 2011).

Procedurally, it was not clear what the roles of the actors were and which actor had the lead role. The actors were not well organized and interacted only infrequently. Furthermore, resources for

${ }^{3}$ It should be noted that the work of Office for Natural Resource Evaluation covered measurement of all natural resources and not just forests. 
forest measurements were limited and the legal provisions were often not followed.

Institutionalization of forest inventories in Peru during this early period was, at best, very 'shallow'.

\subsection{2. $1980 \mathrm{~s}$ - early 2000s: Broadening the scope of forest assessments}

At the beginning of the 1980s two sets of challenges gained attention in the wider (global) public, and led to two new international discourses. The first encompassed loss of intact forests through cultivation of illegal crops, especially coca (Boucher, 1991; Fjeldså et al., 2005; Young, 1996) and illegal logging. The second encompassed global environmental challenges from persistent tropical deforestation, loss of biodiversity and climate change. These challenges culminated in the 'sustainable forest management' and the shift from 'mono-functional' to 'multiple-use' forestry philosophy, concepts established much earlier, but gaining traction in developing countries only from the 1980s onwards (McDermott, 2014). Forest assessments now needed to include growing stock and forest area losses as well as other products and services of forests, such as non-timber forest products (NTFPs) ${ }^{4}$, biodiversity and carbon stores.

New strategies were developed to expand the scope of forest assessments. First, the Peruvian government and the UN Office on Drugs and Crime formulated a strategy to examine the extent of and address illegal coca cultivation (Interviews 1, 12, 16). Second, in 1994, a workshop was organised to deliberate and identify priority areas for biodiversity conservation (Schulman et al., 2007), followed by a national study on biodiversity in 1997 (Anonymous, 1997). Third, in 2000, the National Institute for Natural Resources and the National Environment Council (NEC) developed the 'Program for the Strengthening of National Capacities to Manage the Impact of Climate Change and Air Pollution' to examine the extent of deforestation and associated $\mathrm{CO}_{2}$ emissions. Fourth, in 2002, the Andean Council of Ministers - Peru included - adopted Decision 523 on the Regional Biodiversity Strategy for the Tropical Andean Countries (Comunidad Andina, 2002), to comply with the UN Convention on Biological Diversity. The Strategy promoted national studies on biodiversity. Fifth, in 2003, Peru formed the National Multi-sectorial Commission

\footnotetext{
${ }^{4}$ Non-timber forest product or non-wood forest product is any product other than timber that is obtained from the forest. It is restricted to tradable material products and their processed derivatives Arnold, J.E.M., Pérez, M.R., 2001. Can non-timber forest products match tropical forest conservation and development objectives? Ecological Economics 39, 437-447. NTFPs do not include services derived from forests such as carbon.
} 
Against Illegal Logging (CMLTI) to assess the extent of and address illegal logging (Interview 1). These deliberations culminated in a strategy to eradicate illegal logging (CMLTI, 2003).

The 'sustainable forest management' and 'multiple-use' philosophies also broadened the range of actors involved in forest assessments. Besides CMLTI, special offices were established to assess the extent of illegal deforestation for timber and coca cultivation. International agencies, especially the UN Food and Agriculture Organization (FAO) also started to engage in forest assessments in Peru, mainly through technical assistance and training. In 1993, Peru formed the National Environmental Council (NEC) - the predecessor of the Ministry of Environment - to deal with environmental issues. Both CMLTI and NEC were multi-actor in nature and comprised government, indigenous community and civil society representatives. These representatives interacted frequently and coordinated their forest assessment activities in a more structured manner.

The need to measure more forests variables from the 1980s onwards rendered use of only traditional mensuration tools inadequate. More advanced tools and techniques such as satellite images and automated image analysis increased efficiency. Thus, the $2^{\text {nd }}$ National Forest Inventory, conducted in the 1980s, and assessments of extent of deforestation in 1995 and 2000, used Landsat images (Piu and Menton, 2014b). Images were analysed digitally. However, more modern tools were mainly held by governmental agencies and a few large concessionaires. Because these tools required new skills, Peru invested in its human resources by sending staff abroad for training (Interview 16). However, mainly public employees received such training.

In terms of legislation and procedures, the Peruvian government promulgated a New Forestry and Wildlife Law in 2000 (Decree Law No. 27308, henceforth NFWL) (Cossio-Solano, 2009). The NFWL re-affirmed the role of large contractors in forest inventories in their respective concessions. Like its predecessor, the new law provided that the large contractors present forest management plans including inventory details of commercial species. It further directed that forest management plans be prepared at two levels: (i) a General Forest Management Plan (GFMP), detailing the general planning for the 40 years of the concession contract, updated every five years; and (ii) an Annual Operating Plan (AOP), detailing the activities to be undertaken in any given year. Importantly, it stipulated that the AOPs must provide a census of all commercial tree species 
with diameters above the minimum merchantable diameter. However, this second attempt to institutionalize the role of concessions in forest monitoring also failed. Again, concessionaires either did not conduct or falsified forest inventories (Finer et al., 2014; Sears and Pinedo-Vasquez, 2011; Smith et al., 2006). Moreover, the law remained silent on forest monitoring in areas outside concessions. It was not clear which organization had the lead on forest assessments and what the responsibilities of other actors were. Thus forest resource assessments were institutionalized in, at the very most, a very 'shallow' manner.

\subsubsection{Since 2005: Institutional change instigated by REDD+ MRV}

Since 2005, the international discussion on REDD+ MRV has taken on a prominent position in the area of forests and climate change. Accordingly, the discourse on national forest inventories has also shifted, with new emphasis on quantification of forest cover change and associated emissions/ removals for potential results-based REDD+ payments. The Ministry of Environment, has produced several deforestation statistics since 2011 (Interview 33, 34; FGDs 1, 2) that can be used for computing emission reductions/ removals resulting from REDD+ (Herold and Skutsch, 2011; IPCC, 2006). Over a third of the interviewees saw the current re-focus on forest inventories as a consequence of the REDD+ MRV discussions under the UNFCCC. However, the new aim only complements previous policy aims of forest assessments. Sustainable production of timber and forest services and forest conservation remain a major goals of forest management and a prerequisite for carbon management. Since 2011, the DGFFS, with the support of the FAO, has been developing the design and guidelines for systematic national forest resource assessments.

The expanded scope of forest assessments is to be realized by new plans to establishing new bodies and agencies, mobilizing new resources, and introducing new legislations and guidelines. In terms of actors, REDD+ MRV has seen new governmental and non-governmental actors gain foothold in forest assessments. On the governmental side, the Ministry of Environment and its various departments and programs (Directorate of Land Use Planning, the National Program on Forest Conservation for Climate Change Mitigation, and the Ministry's REDD+ Project) have since 2011 been measuring forest cover and carbon stock changes. Additionally, the newly developed Draft National Action Plan for Forest Monitoring envisages the formation of several bodies to perform forest assessments for REDD+. These include the Technical Task Force for Forest Monitoring to be succeeded by a National Forest Monitoring Agency in 2017 - comprising representatives 
from the Ministry of Environment, DGFSS and the local office of the Amazon Cooperation Treaty Organization (OTCA). A six-member team comprising two representatives from each of the agencies has been constituted as the Interim Task Force.

Other envisaged agencies include the Executive Steering Committee comprising senior representatives of the Ministry of Environment and DGFFS; an Intergovernmental Group, comprising government and donor representatives; the High-level Advisory Group comprising research and academic representatives; and the National Forest Monitoring Group, comprising regional governments, civil society organizations (CSOs) and local and indigenous community groups. While the first three bodies will bring new governmental and inter-governmental (e.g. UN agencies) actors into forest assessments for REDD+, the last two will enable regional governments, indigenous communities and CSOs engage in forest assessments.

By bringing together different governmental and non-governmental actors, these bodies could increase interaction among actors and enhance cooperation or address potential conflicts. Signs of enhanced cooperation are already evident. For example, as opposed to the hitherto conflictual relationship between the Ministry of Environment and DGFFS, there is today increased interaction and cooperation between the two (Interview 17, 30, 39; FDGs 1, 2). Nevertheless, as noted by a third of the interviewees and during FGDs, the regional governments and CSOs are not satisfied with the roles allocated to them. There are also disagreements between different departments and programs of the Ministry of Environment on appropriate forest cover mapping methods.

To meet the expanded aim of measuring deforestation and $\mathrm{CO} 2$ emissions/ reductions, new resources are being mobilized. Since 2010, Peru has been acquiring and developing new tools and technologies. Higher-resolution satellite images (Landsat, RapidEye, etc.) and technologies for image analysis such as CLASlite (Asner et al., 2009) and the University of Maryland methodology (described in Hansen et al., 2013) are increasingly being used (FGDs 1, 2). Peru is also developing its own country-specific Emission Factors in the form of allometric equations and biomass expansion/ conversion factors. The Ministry of Environment's REDD+ Project has developed allometric equations and biomass expansion factors for above-ground biomass for the Amazon region (FGD 2). 
International funding for forest assessments has also increased. The FCPF, the Gordon and Betty Moore Foundation and the German Development Bank have committed over USD 12 million for the development of REDD+ in Peru and $10 \%$ of this budget is for the design of the REDD+ MRV system (MINAM, 2011). Other donors are funding the technical, legal and institutional capacity building for REDD+ MRV within the National Program on Forest Conservation for Climate Change Mitigation framework (Menton et al., 2014; Robiglio et al., 2014). Skills for forest assessments have also increased. The Ministry's REDD+ Project has trained representatives of the Ministry of Environment, DGFFS, regional governments and CSOs on forest cover mapping and carbon stocks estimation (FGDs 1,2). Additionally, many NGOs, international institutes and regional government organizations have provided funds for or organized trainings for indigenous community organizations and regional governments (FGDs 1,2). This suggests that unlike in the earlier periods, when resources and skills for forest measurements were held only by governmental actors and a few concessionaires, resources and skills are spreading to new actors.

To institutionalize forest assessments in general, and REDD+ MRV in particular, in law, new legislations and procedures are being developed. First, a new Forest Law (Decree Law No. 29763), formulated in 2011, created the National Forest and Wildlife Service as the agency responsible for the performance and periodic updates of national forest assessments. This law states that the Service will perform this function in coordination with regional and local governments and other public and private organizations, thereby formalizing the role of these actors in forest assessments. Moreover, the new law stipulates that assessment of forest biodiversity will be conducted in accordance with regulations set by the Ministry of Environment. Thus, unlike its predecessors, this new law clearly identifies the National Forest and Wildlife Service and the Ministry of Environment as lead agencies on forest assessments.

Second, the Draft National Action Plan for Forest Monitoring identifies the bodies that will be created to conduct forest assessment for REDD+ and outlines their roles and authority.

Overall, we conclude that while REDD+ MRV has caused discursive change (i.e. change in aims, scope and strategies), the extent of change is not yet 'deep' for four reasons. First, although REDD+ MRV has added a new aim of forest assessments - measurement of forest cover change and associated $\mathrm{CO}_{2}$ emission reductions/ removals for REDD+ payments - and indeed this new aim, and strategies to achieve it, have been translated into new legislations and procedures, only 
the Forest Law and its regulations have been formally adopted. The Draft National Action Plan for Forest Monitoring that envisages the formation of new bodies to institutionalize the roles of different governmental and non-governmental actors in forests assessments for REDD+ has not been adopted. Second, the plan to have members of the Interim Task Force drawn from the Ministry of Environment, DGFFS and OTCA to work under 'one roof' has not (yet) materialized.

Third, although new actors are entering the national forest assessment arena, the platforms through which they are to engage in forest assessments, such as the National Forest Monitoring Group and the High-level Advisory Group, have not been constituted. Moreover, conflicts already exist over the roles of regional governments and indigenous communities in REDD+ MRV. As Menton et al. (2014) and Robiglio et al. (2014) also observe, there are also conflicts between different departments and programs of the Ministry of Environment on appropriate methods to use. Fourth, while there seems to be some dispersion of resources and skills across actors, most of these resources and skills rest with the Ministry of Environment. Given these observations, it can be concluded that REDD+ MRV has until today caused, if any, only 'shallow' change in institutional arrangements for forest assessments in Peru. 


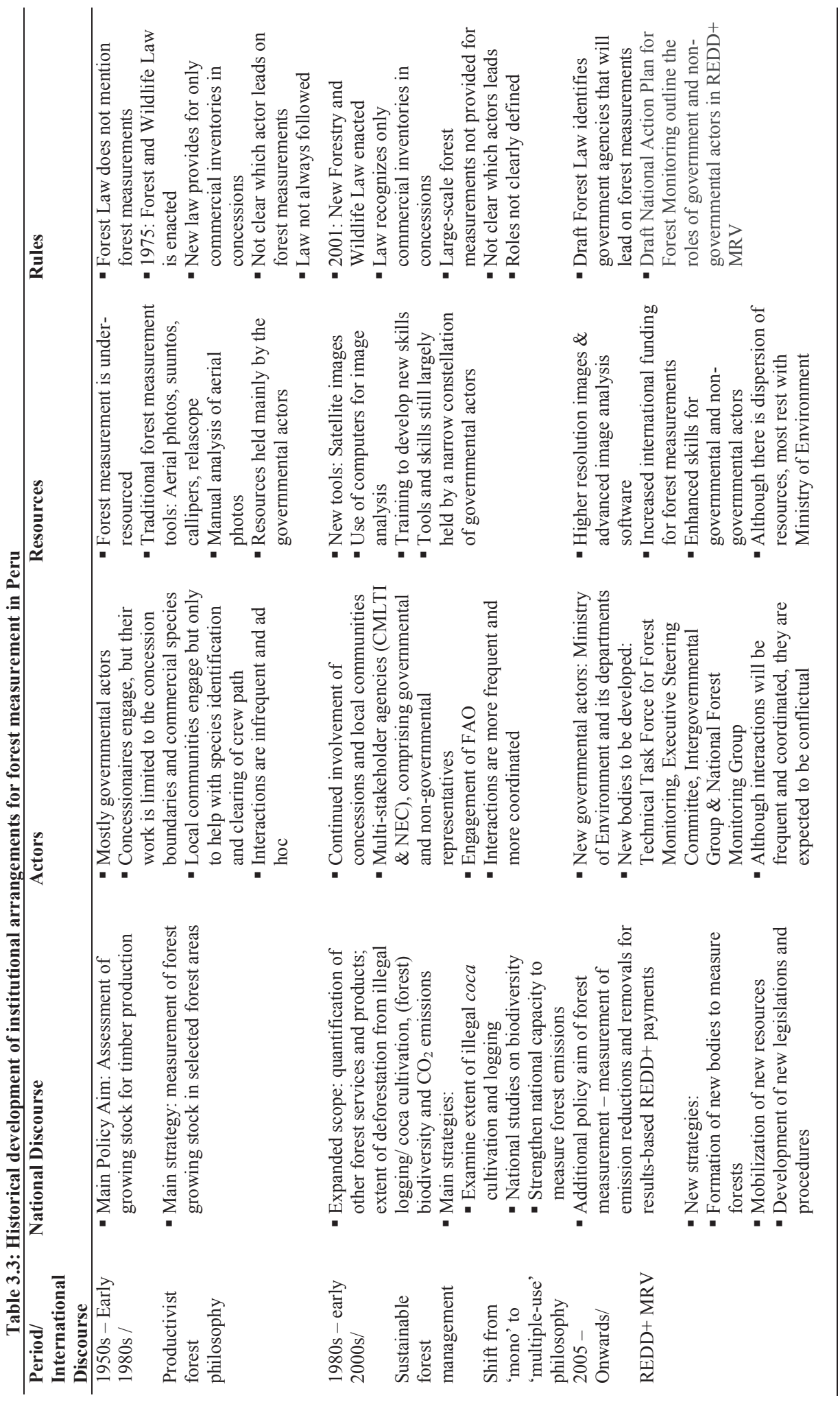




\subsection{Conclusions and discussion}

This paper aimed to examine how institutional arrangements for forest assessments in Peru have evolved, and how their evolution has been shaped by international discourses on forests, recently especially by REDD+ MRV. The analyses showed that REDD+ MRV has resulted in an expanded aim and scope and new strategies for forest assessments. New legislations and procedures, which respectively codify forest assessments in law and outline the roles of the different actors, have tentatively been formulated. Moreover, establishment of new bodies to perform forest measurements has been proposed, which creates opportunities for new governmental and nongovernmental actors to engage in the process. A important question that emerges from this analysis is what lessons can be learned from the Peruvian experience in developing institutions to implement REDD+ MRV.

The first lesson is whether the changes brought by REDD+ MRV have also challenged ideals and values underlying forest management in Peru. Although our analysis shows that both the aims and strategies of forest assessments have changed, the predominant 'productivist' (Mather, 2001; see also Rientjes, 2002) philosophy of most players in Peru's forest sector, especially the timber industry and DGFFS, regarding forests as timber first and everything else second (see CossioSolano, 2009), remains deeply entrenched. This suggests that the 'multiple-use' and 'sustainable forest management' philosophy that encompasses both carbon and biodiversity aspects, is yet to be entrenched in Peru. While a complete shift from productivist to multiple-use and sustainable forest management philosophies is unlikely in the near future, given that timber will remain a major source of revenue, and carbon still has a low value, efforts should be made to convince key interest groups of the appropriateness of forest assessments for SFM, including for REDD+. Indeed, managing forest carbon for climate change adaptation and mitigation provides a new storyline to advocate for multiple-use and sustainable forest management. To realize this, a broader political and societal discussion is needed. However, such a communicative discourse on REDD+ MRV is currently lacking in Peru. It is suggested that Peruvian authorities engage the broader public in a discussion on REDD+ MRV. In this public discussion, policy actors should explain to the various publics (REDD+ project developers, and local and indigenous communities implementing REDD+, the timber industry and regional governments) the appropriateness of 
REDD+ MRV for both production and conservation, while soliciting their views on the proposed strategies.

Although the productivist philosophy remain deeply entrenched and has been used by the state and industry to legitimize their focus on production, Medina et al. (2009), show how communities, NGOs and loggers in Peru used various international processes to legitimate their respective ideas while delegitimizing competing ones. While it was not possible to examine the 'coordinative' policy discourse on REDD+ MRV, since such a discourse is currently lacking, it can be concluded that it is mainly the Ministry of Environment's ideas that have been served, for three reasons. First, most of the resources for REDD+ MRV rest with this ministry. Second, the Draft National Action Plan for Forest Monitoring vests tremendous authority on the Ministry regarding forest assessments for REDD+. Third, the Ministry's position as both the governmental focal point for the UNFCCC and executing agency for REDD+ gives it considerable institutional authority over REDD+ MRV. As Robiglio et al. (2014) shows, the Ministry has used REDD+ resources and its institutional authority to not only carve out for itself a dominant role in REDD+ MRV but also to instil its preferred methodological approach to forest assessments.

But what hinders a central actor such as the Ministry of Environment from using REDD+ resources and institutional authority to foster 'deep' change in institutions for forest assessments in Peru? We identified two factors. The first are the highlighted discursive conflicts. As DI posits, such conflicts are inevitable given the many bodies and actors envisaged to participate in forest assessments for REDD+. This observation leads to the second lesson that can be learned from the Peruvian case, namely that instead of formulating new agencies and bodies to implement REDD+ $\mathrm{MRV}$, it would perhaps be better to strengthen existing institutes for forest assessments. It is suggested that countries developing their national forest monitoring systems for REDD + and their international/ donor partners consider strengthening existing institutes for forest assessments instead of developing entirely new ones. Where entirely new arrangements are needed, as is expected in countries without a tradition in forest resource assessments, caution should be taken to avoid luxuriant growth of too many bodies. Developing many new agencies seems a prescription for failure due to the inevitable discursive conflicts and turf-wars as already visible in Peru. 
The second hindrance is the lack of a true 'coordinative' policy discourse on REDD+ MRV in Peru, as discussions on REDD+ MRV seem to be taking place in a closed group of a few technical experts. This observation leads to the third lesson that can be learned from this case. To realize 'deep' change in institutions for forest monitoring in Peru, and ensure that the reforms achieved so far do not remain 'paper reforms' (Rudel, 2008), investments in REDD+ MRV would need to go beyond equipping the country with technologies and skills. To be clear, Peruvian authorities and their international partners need to also invest in organizing a coordinative policy discourse on REDD+ MRV. This discourse should bring policy actors from relevant sectors and interest groups to debate both the key challenges that REDD+ MRV should address and come up with consensual strategies to address these challenges and implement REDD+ MRV. We believe that giving policy actors from different sectors and interest groups a seat in REDD+ MRV policy discussions will not only enable them to provide input, but also have a better grasp of the strategies proposed so far, and will hopefully stem the mushrooming conflicts. A way forward here could be for the Ministry of Environment to use REDD+ resources at its disposal and its institutional authority to mobilize the interest groups into a true policy discourse on REDD+ MRV, alongside the on-going 'expert' discussion.

A final lesson that can be learned from the Peruvian experience is that 'deep' institutional change does not come over-night. It takes time and effort to convince key policy actors and the general public of the need for and benefits of change. This calls for concerted efforts and long-term commitment by both Peruvian authorities and their international partners and donors. While obstacles are inevitable in any clamour for institutional change, we believe that REDD+, and the material resources that come with it, provide the necessary incentives to organize the suggested coordinative and communicative policy discussions and institute the 'deep' institutional change, required to respond to emerging global needs. The donor community is called upon to renew their commitment to support countries such as Peru in their efforts to implement the institutional changes required to implement REDD+ in general and REDD+ MRV in particular. 
Chapter 4 - Institutionalization of REDD+ MRV in Indonesia, Peru and Tanzania:

Progress and implications

This chapter has been accepted for publication with moderate revision in Ecology and Society as: Ochieng, R.M., Arts, B., Brockhaus, M. \& Visseren-Hamakers, I.J. Institutionalization of the REDD+ MRV in Indonesia, Peru and Tanzania: Progress and implications. 


\begin{abstract}
Reducing emissions from deforestation and forest degradation in developing countries (REDD+) has opened up a new global discussion on forest monitoring and carbon accounting (FMCA) in developing countries. This paper analyses and compares the extent to which the concept of measurement, reporting and verification (MRV) for REDD+ has institutionalized in terms of new policy discourses, actors, resources and rules in Indonesia, Peru and Tanzania. To do so, the paper draws on Discursive Institutionalism and the Policy Arrangement Approach. A qualitative scale that distinguishes between 'shallow' institutionalization on the one end, and 'deep' institutionalization on the other, is developed to structure the analysis and comparison. Results show that in all countries MRV has institutionalized in new or revised aims, scope and strategies for forest monitoring, and development of new agencies and mobilization of new actors and resources. New legislations to anchor forest monitoring in law and procedures to institutionalize the roles of the various agencies are being developed. Nevertheless, the extent to which MRV has been institutionalized varies across countries, with Indonesia experiencing 'deep' institutionalization, Peru 'shallow-intermediate' institutionalization, and Tanzania 'intermediatedeep' institutionalization. We explore possible reasons for and consequences of differences in extent of institutionalization of MRV across countries.
\end{abstract}

Keywords: REDD+ MRV; Discursive institutionalism; Institutionalization; Policy arrangement approach; Indonesia; Peru; Tanzania 


\subsection{Introduction}

National forest monitoring is becoming an established activity in developing countries. Since the post-colonial era, many developing countries have monitored and reported on the status and extent of their forests (FAO, 1993; Freitas et al., 2010; Lei et al., 2010; Lund, no.date; McRoberts and Tomppo, 2007; Tomppo et al., 2010a). Although initially focused on timber stocks, forest monitoring in both developed and developing countries have evolved to include measurement of other variables such as forest health and vitality (Lund, no.date; Mohren et al., 2012), largely in response to the paradigm shift from 'mono-functional' to 'multi-functional' forestry. While these changing demands have provided challenges for both developed and developing countries, the United Nations Framework Convention on Climate Change (UNFCCC) decision on reducing emissions from deforestation and forest degradation, and the role of conservation, sustainable management of forests and enhancement of forest carbon stocks in developing countries (REDD+) has opened up new discussions on forest monitoring in developing countries. Specifically, discussions on monitoring, reporting and verification (MRV) of REDD+ outcomes introduces new ideas on forest monitoring in developing countries regarding 'what' to measure, by 'whom' and using 'which' technologies (UNFCCC, 2009).

The emergence of international discussions on MRV not only presuppose that existing institutions for forest monitoring in developing countries are inadequate but also present challenges on how to develop new or strengthen existing institutions for forest monitoring in these countries. Indeed, several studies have highlighted that majority of REDD+ countries have low technical and institutional capacity to measure and report on their forests in a manner that meets international standards (Grainger and Obersteiner, 2011; Holmgren and Marklund, 2007; Holmgren et al., 2007; Ochieng et al., 2016a; Romijn et al., 2012; Romijn et al., 2015). Others, while pointing at the large and varying technical capacity gaps (Romijn et al. 2012), also show that progress is being made in some countries (Korhonen-Kurki et al., 2013; Minang et al., 2014; Ochieng et al., 2015; Robiglio et al., 2014), suggesting that institutions for forest monitoring in developing countries are adapting to accommodate the new demands. These studies thus provide arguments for an emerging discourse that highlight the need for institutional change while indicating countries capacity to do. 
To date, however, few studies have examined how the demands presented by international discussions on MRV have re-shaped institutions for forest monitoring in REDD+ countries. Although some studies (Korhonen-Kurki et al., 2013; Minang et al., 2014; Ochieng et al., 2015; Robiglio et al., 2014) have examined the development of strategies and agencies to implement MRV in selected REDD+ countries, a comprehensive comparative analysis of the extent of institutionalization of MRV across countries is lacking. This paper aims to fill this gap by comparing the extent of institutionalization of MRV in Indonesia, Peru and Tanzania. To do so, the paper addresses two questions: (1) how and to what extent has MRV materialized in new or reformed institutions for forest monitoring in Indonesia, Peru and Tanzania; and (2) how can differences in extent of institutionalization of MRV in these countries be explained?

Drawing on the theoretical claims of Discursive Institutionalism (Arts and Buizer, 2009; Schmidt, 2008), namely that new ideas, and the discourses through which they are generated and deliberated may re-shape and materialize in institutions, we address the first question by examining the strategies that have been developed to implement MRV, the actors and resources that have been mobilized, and the rules that have been developed to anchor MRV in regulatory arrangements in each country. We address the second question by reflecting on the factors that must be present for any discourse to institutionalize, and their manifestation in each country to explain any differences across the countries. We begin by introducing the theoretical framework of discursive institutionalism and, explain how discourse institutionalization can be examined using the Policy Arrangement Approach. After describing the study methods, we present the results in two steps. We first examine the extent of institutionalization of MRV in each country; and then explore the factors for the varied extent of institutionalization. We conclude by discussing the results and drawing lessons to inform institutionalization of MRV in other countries.

\subsection{Theoretical framework: Discursive institutionalism}

We use discursive institutionalism (DI) as our theoretical framework. DI's main assumption is that new discourses and the ideas they represent may undermine or re-shape existing institutions and thereby cause institutional change (Arts and Buizer, 2009; Schmidt, 2008; Schmidt, 2010). DI has been used in various fields to analyse how new ideas and the discourses through which they are generated and exchanged influence institutions. Buijs et al. (2014), for example, show how counter discourses and ideas on Dutch nature policy undermined existing institutions and materialized in 
new ones for nature conservation in the Netherlands. At a global level, Arts and Buizer (2009) show how new discourses and ideas, for example on sustainability and biodiversity, have emerged and materialized in several new institutions for global forest governance over the last decades. On REDD+ specifically, den Besten et al. (2014) show how new discourses and ideas on deforestation and forest degradation shaped international policy discussions and strategies to reduce greenhouse gas (GHG) emissions and mitigate climate change, and materialized in several institutions to implement REDD+.

Analytically, DI distinguishes between discourses and institutions. Discourses are conceived as shared and at the same time contested ideas about public aims and policies, and as the interactive processes of politics and policymaking. Given its double-view of discourses, a discursive institutionalist allows us to simultaneously indicate the ideas represented in a discourse and the interactive processes by which these ideas are discussed during public deliberations and policymaking. Institutions on the other hand are seen as discourses and ideas that have become anchored in regulatory arrangements such as laws and standards. However, following Giddens (1984) definition of institutions as not just rules but also resources, we believe that DI does not sufficiently conceptualize institutions. Therefore to comprehensively conceptualize institutions, we use the Policy Arrangement Approach (Arts and van Tatenhove, 2006; Van Tatenhove et al., 2000).

A policy arrangement refers to the way a certain policy domain such as national forest monitoring is shaped in terms of policy discourses, actors, resources and rules (Arts and van Tatenhove, 2006; Liefferink, 2006a; Wiering and Arts, 2006). Policy discourses are the discursive processes of policymaking as discussed above. Such policy discourses can contain different types of ideas, including policies and programs (Mehta, 2011; Schmidt, 2008). Policy ideas are the strategies proposed by policy makers to achieve public aims. Programmatic ideas encompass the definition of the policy problem at hand and the aims to be achieved (Mehta, 2011; Schmidt, 2008; Schmidt and Radaelli, 2004; see also Wiering and Arts, 2006). Programmatic and policy ideas are here operationalized as aims and scope, and strategies for forest monitoring, respectively. Actors are the stakeholders involved in formulating and implementing policies or influenced by such policies. Resources are the tools, technologies, budgets and skills that actors can mobilize to achieve their 
policy aims. Rules, finally, are the legislations and procedures that define the way a policy issue should be conducted. Whereas legislations are the laws enacted to implement policies, procedures delineate division of roles and authority among the actors (Arnouts et al., 2012; Wiering and Arts, 2006). The PAA considers 'institutionalization' as the materialization of a new/revised discourse in new/revised actor coalitions, rules of the game and resource allocations (Arts and Buizer, 2009; Buijs et al., 2014).

Thus, 'institutionalization' is considered to occur when MRV and its ideas are (1) formed into policy discourses at the national level in terms of new aims, scope and strategies for forest monitoring, (2) new actors mobilized, (3) additional resources made available, and (4) new legislations developed to formally anchor MRV and the role of different actors in law (cf. Alemayehu et al., 2013). To compare the extent of institutionalization of MRV across the three countries, we apply a qualitative scale (Figure 4.1) that distinguishes between shallow institutionalization (i.e. discourse materialization in only new or revised aims and strategies) on one end, and deep institutionalizations (i.e. discourse materialization in all the elements of the policy arrangement, namely aims and strategies, actors, resources, and rules) on the other (see Wiering and Arts, 2006 for more on shallow and deep institutionalization).

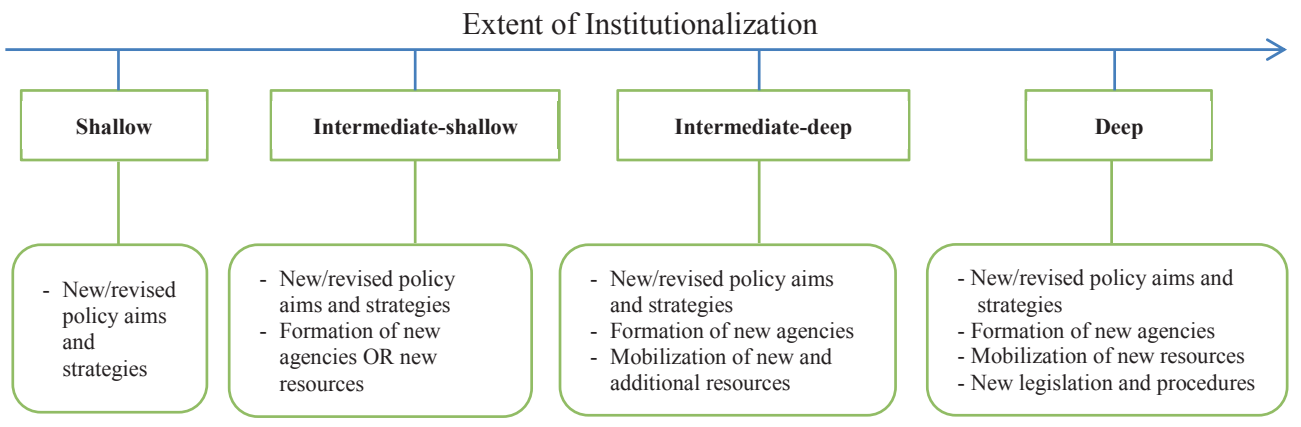

Figure 4.-1: Historical development of institutional arrangements for forest measurement in Peru

Of course, not all (new) ideas and discourses subsequently institutionalize during policymaking (Arts and Buizer, 2009; Crespy and Schmidt, 2014; Phillips et al., 2004; Schmidt, 2008; Schmidt, 2010; Schmidt and Radaelli, 2004). This observation has led discursive institutionalists to examine the factors necessary for discourse institutionalization. Phillips et al. (2004), for instance, highlight 
seven factors that must hold in order for new discourses and ideas to institutionalize. Building on the work of Phillips et al. (2004) and others (Arts and Buizer, 2009; Schmidt, 2008; Schmidt, 2010), Buijs et al. (2014) have condensed these factors into five. These authors hold that for new discourses and ideas to materialize in new institutions: (a) the new discourse and ideas must cover 'existential' and 'timely' topic, and resonate with a larger and concerned audience; (b) they must be credible and coherent to that audience; (c) they must be carried and advocated by authoritative and sentient agents; (d) they must take the form of popular genres or storylines i.e. transcend the language of specific individuals or organizations; and (e) the legitimacy of existing discourse and ideas, and related institutions must be under pressure. We will examine the extent to which each of these factors manifested in the three countries in order to explain any differences in extent of institutionalization of MRV.

\subsection{Methods}

The study was conducted in Indonesia, Peru and Tanzania, which were selected for two reasons. First, compared to Peru, Indonesia and Tanzania started their REDD+ policy processes at a relatively early stage. Additionally, both countries have been receiving support from Norway's International Forest and Climate Initiative and the UN REDD Program and the Forest Carbon Partnership Facility (Brockhaus and Di Gregorio, 2014) including on issues regarding establishing forest monitoring systems for REDD+ (LTS International, 2013). Thus, both can be expected to be well advanced in implementing the different REDD+ elements including MRV. Peru, on the other hand, became actively engaged in REDD+ only after 2012 (Piu and Menton, 2014a). Second and most importantly, despite the early engagement of Indonesia and Tanzania in REDD+ compared to Peru, recent studies (Korhonen-Kurki et al., 2013; LTS International, 2013; Minang et al., 2014; Ochieng et al., 2016a) show that they are at different stages in developing technical and institutional capacities for MRV.

Primary data were obtained through interviews with representatives of different state and non-state agencies (Table 4.1). These representatives were selected because they have been involved in forest monitoring and or in MRV discussions in the respective country, and were selected 'judgementally' and through snowball sampling (Punch, 2005). Field work was conducted between October and December 2015 and August and September 2015 in Indonesia and Tanzania 
respectively, and between May and June 2014 in Peru. Secondary data were obtained through analyses of national REDD+ policy documents, and other scientific and grey literature.

Table 4.1: Number of respondents by category

\begin{tabular}{llll}
\hline Respondent of category & Indonesia & Peru & Tanzania \\
\hline Governmental agencies (National/ sub-national) & 8 & 20 & 9 \\
Domestic NGOs/ CSOs & 7 & 6 & 5 \\
International/ Intergovernmental organizations & 14 & 5 & 2 \\
Others (private, consultants, university) & 5 & 11 & 7 \\
Total & 34 & 42 & 23 \\
\hline
\end{tabular}

\subsection{Results}

\subsubsection{Institutionalization of MRV in Indonesia, Peru and Tanzania}

\subsubsection{Deep institutionalization of MRV in Indonesia}

In Indonesia, the extent of institutionalization of MRV can be assessed as 'deep', since changes can be detected in all the four dimensions of the PAA. The aims and scope of forest monitoring have been reviewed and expanded to include measurement of forest carbon stocks and its changes (see Sugardiman, 2012). To realize these expanded aims and scope of forest monitoring, Indonesia has developed and implemented several strategies. One such strategy is the implementation of the Indonesian Carbon Accounting System (INCAS) (INCAS FACTSHEET, 2013; Krisnawati et al., 2015a). Through INCAS, Indonesia has developed region-specific allometric equations (Krisnawati et al., 2012), and methodologies for estimating GHG emissions from forests and peatlands (Krisnawati et al., 2015b, c), forest carbon monitoring and calculations (SNI, 2011), and for processing satellite images (LAPAN, 2014). Other strategies included piloting provincial/district-level forest monitoring in several provinces and districts across Indonesia (FORCLIME, 2013a, b; Republic of Indonesia, 2014; RoI, 2014; UN REDD Programme, 2013).

To implement forest monitoring for forest management in general and for REDD+ in particular, several national and sub-national agencies have been (re-)constituted. At the national Directorate General of Forestry Planning and Environmental Management (henceforth DG Forest Planning), the Directorate of Forest Resources Inventory and Monitoring has been strengthened through technical capacity and infrastructure development (UN REDD Programme, 2013). Additionally, a National Forest Monitoring System (NFMS) (RoI, 2014; Sugardiman, 2012) has been developed. 
At the newly established Directorate General of Climate Change, a Directorate of GHG Inventory and MRV has been established. Within this directorate, a sub-directorate of GHG Inventory and MRV of the land-based sector in general, and a section on GHG Inventory of the Forestry Sector in particular have been established (MoEF, 2015; RoI, 2015). Interviews consider this new directorate and its sub-directorates as the 'MRV Institution' of Indonesia. At the sub-national level, interviews and document analyses show that District MRV Task Forces have been established in several districts and provinces (UN REDD Programme, 2013).

Indonesia has strengthened its technical and human resource capacity for forest monitoring. Through INCAS, a geo-data infrastructure has been installed at the National Institute of Aeronautics and Space (LAPAN) to facilitate downloading and processing of satellite images (INCAS FACTSHEET, 2013). Through recruitment and training, INCAS has built technical capacity within LAPAN to process satellite data. Interviews show that the DG Forest Planning has also developed software to support analyses of forest inventory data collected over the past 20 years. Through the UN REDD Programme support, a specialized data management system for national forest inventories was installed in 18 computers at the DG Forest Planning, and four national and eighteen provincial forest officers trained (UN REDD Programme, 2013). Additionally, the DG Forest Planning has recruited ten image interpreters at the national level and 22 at provincial technical units to fast-track land cover classification. At the sub-national level, key agencies such as the Provincial Forest Service, Provincial Environment Service, Provincial Development Planning Agency, local universities, and local NGOs and REDD+ Project Developers have been trained on MRV (FORCLIME, 2013a, b; Korhonen-Kurki et al., 2013; Republic of Indonesia, 2014; RoI, 2014; UN REDD Programme, 2013).

To institutionalize GHG inventories and reporting in general and monitoring and reporting of GHG emission reductions from REDD+ in particular, Indonesia has since 2005 enacted several pieces of legislation including presidential and ministerial regulations and procedures. The Presidential Degree No 71 on Implementation of National Greenhouse Gas Inventories (RoI, 2011) outlines its aims as follows: provide information on emissions/ reductions resulting from mitigation activities; and outlines the actors to be involved in GHG inventories. The Ministry of Forest Regulation No 67 on criteria and standards for forest inventory (Ministry of Forestry, 2006) also outlines which 
actors are responsible for forest inventories in which areas. Presidential Regulation No. 16 (2015) that establishes the Ministry of Environment and Forestry (MoEF) (RoI, 2015) and MoEF Regulation No. P. 18 (2015) on organization of work of the MoEF (MoEF, 2015) further clarifies which directorates and sub-directories are responsible for what activities with regard to GHG Inventory in general and REDD+ MRV in particular. Additionally, key government agencies such as MoEF, National Institute of Aeronautics and Space and Geospatial Information Agency have signed memoranda of understanding (MoU), which spells out the responsibility of each on issues of forest monitoring for REDD+.

However, assessment of institutionalization of MRV in Indonesia as 'deep' needs to be put into perspective and nuanced in several ways. First, although new strategies have been developed, several interviews showed that some of these strategies, especially INCAS, are strongly contested. Arguments concerns the methodologies and algorithms used in INCAS and their suitability to Indonesian conditions. Second, although Indonesia has built a considerable technical and human resource base for forest monitoring, these are not yet sufficient. Most interviewees observed that while there could be enough human capacity at the national level, this is still scattered across different agencies (see also Sugardiman (2012); UN REDD 2013). Majority also note that technical capacity for forest carbon monitoring at the sub-national level is very low. Third, issues of coordination among national agencies and between national and sub-national agencies and nongovernmental actors remain problematic (see also Korhonen-Kurki et al., 2013; Steininger, 2014) as some agencies are not open to sharing data. Finally, there is also what can be characterized as 'rule density'. As shown above, there are many regulations on GHG inventories in general and forest monitoring in particular. Many of the interviews noted that the inconsistencies among these regulations and procedures creates confusion.

\subsubsection{Intermediate-shallow institutionalization of MRV in Peru}

In Peru, the extent of institutionalization of MRV can be assessed as 'shallow-intermediate', for different reasons. Institutionalization of MRV has evidently gone beyond 'shallow' since MRV has materialized in an additional aim of forest monitoring: quantification of forest-cover change and associated $\mathrm{CO}_{2}$ emissions/ removals. To realize this additional aim of forest monitoring, Peru has developed new strategies. These include implementation of a multi-purpose national forest inventory (NFI) (Ministerio de Agricultura and Ministerio del Ambiente, 2011) and development 
of deforestation statistics for the entire country (MINAM, 2014b; Potapov et al., 2014; Vargas et al., 2014), region-specific emission factors (MINAM, 2014a), and methodologies for forest cover change mapping (MINAM and MINAGRI, 2014a) and classifying satellite images (MINAM and MINAGRI, 2014b). However, implementation of these strategies especially the NFI is yet to be completed, and emission factors for other regions have not been developed.

In terms of actors, new agencies to implement forest monitoring for REDD+ have been proposed (RoP, 2014). The Draft National Action Plan for Forest Monitoring envisages the formation of several bodies to perform forest monitoring for REDD+. These include the Technical Task Force for Forest Monitoring comprising representatives from the Ministry of Environment, the National Forest and Wildlife Service (SERFOR) and the local office of the Amazon Cooperation Treaty Organization (OTCA). A six-member team comprising two representatives from each of these agencies has been constituted as the Interim Task Force. Additionally, the Ministry of Environment has assigned two staff members to oversee forest cover change analysis (Steininger, 2014). Other envisaged bodies include the Executive Steering Committee, an Intergovernmental Group, a Highlevel Advisory Group, and the National Forest Monitoring Group (see RoP, 2014). A new Directorate of Inventory and Evaluation has been established within SERFOR to institutionalize the on-going NFI (MINAM, 2015). However, except for the new Directorate of Inventory and Evaluation and the Interim Task Force, all other envisaged bodies are yet to be constituted.

However, in terms of resources, Peru has mobilized new and additional resources for forest monitoring. At the Ministry of Environment, the Global Land Analysis and Dynamics system (Potapov et al., 2014; Potapov et al., 2015) and technologies for image analysis such as CLASlite (Asner et al., 2009) have been installed to facilitate forest cover change monitoring. Several development cooperation agencies have committed over USD 12 million for the development of REDD+ in Peru, and 10\% of this budget is for the design of the REDD+ MRV system (Ministerio de Agricultura and Ministerio del Ambiente, 2011). The FAO-Finland cooperation has also committed USD 6 million for the NFI (Ministerio de Agricultura and Ministerio del Ambiente, 2011). Training sessions have also been held to build capacity of local communities, regional and national government agencies, and NGOs on forest carbon monitoring (Robiglio et al., 2014; 
Steininger, 2014). Some of the regional governments have also been equipped with technologies for forest cover change monitoring and analysis.

In terms of rules, Peru is formulating new legislations and procedures to institutionalize forest monitoring in general and MRV in particular in law. The newly adopted Forest and Wildlife Law (Law Decree No. 29763) and its recently approved Regulations (Supreme Decree No. 21-2015) (MINAM, 2015) identify the National Forest and Wildlife Service (SERFOR) and the Ministry of Environment as the government agencies responsible for the performance and periodic update of national forest monitoring. Additionally, the Draft National Action Plan for Forest Monitoring identifies the bodies that will be created to conduct forest monitoring for REDD + and outlines their roles and their relation with one another. However, except for the Forest and Wildlife Law and its Regulations that have been adopted (MINAM, 2015), the Draft National Action Plan for Forest Monitoring has not been adopted. Yet, it is this Plan that outlines the additional aim of measuring forest carbon stocks and its changes, and the roles of different actors in MRV.

\subsubsection{Intermediate-deep institutionalization of MRV in Tanzania}

In Tanzania, institutionalization of MRV can be assessed as 'intermediate-deep', for several reasons. Like in the other countries, MRV has materialized in revised aims and scope of forest monitoring. These aims and scope have been reviewed to include measurement of forest carbon stocks and its changes (URT, 2015). To realize these revised aims, Tanzania has implemented several strategies including the National Forest Resource Monitoring and Monitoring (NAFORMA) (URT 2015) and the Zanzibar Wood Biomass Survey (Indufor, 2013b). The other strategy involved implementation of the project 'Enhancing MRV of forests in Tanzania through the application of advanced remote sensing techniques' commonly called 'the LiDAR project' (MFA and URT, 2011) that piloted use of LiDAR and other high-resolution remote sensing technologies for forest carbon monitoring. Other strategies involved piloting community/ participatory forest carbon monitoring under different REDD+ pilot projects (Indufor, 2013a; Mäkelä et al., 2015). Through these strategies, Tanzania has developed background forest cover data and allometric equations (URT, 2015), manuals and methodologies for forest inventories (Tomppo et al., 2010c; URT, 2010b), methodologies for socioeconomic surveys (URT, 2010a) and a list of tree species names (URT, 2010c). 
Like in Indonesia, new agencies have been established to implement MRV. First, at the national level, an MRV Working Group was established to deliberate on technical issues of forest monitoring. These deliberations led, second, to the establishment of the National Carbon Monitoring Centre (NCMC) (MFA and URT, 2015). Third, within the Tanzania Forest Service, a Forest Monitoring and Inventory Section was established to institutionalize periodic national forest inventories. In addition, District and Village Natural Resource and Environmental Committees have been mobilized and strengthened to undertake forest monitoring (see below). This is different than in Peru where most of the bodies envisaged to perform forest monitoring for REDD + are yet to be constituted.

As in Indonesia and Peru, Tanzania has mobilized a significant technical and human resource base for forest monitoring. Through the FAO-Finland and Norwegian cooperation, Tanzania has acquired several RS and ground-based forest measurement equipment (FAO, 2011; MFA and URT, 2011, 2015; URT, 2015). Interviews indicate that Tanzanian universities, especially Sokoine University of Agriculture (SUA), which hosts the NCMC, have been well equipped with GIS laboratories and image analyses software. Financially, the Norwegian Government has committed an equivalent of over USD 4 million to support the NCMC for the next three years (MFA and URT, 2015). The FAO-Finland cooperation has also committed almost USD 20,000 to facilitate institutionalization of NAFORMA within the TFS (FAO, 2011). Also, a government interviewee reported that the Tanzanian government has allocated an equivalent of USD 400,000 for the remeasurement of sample plots established under NAFORMA. Some 170 national and district-level forest officers have been trained and engaged in forest monitoring under NAFORMA (URT, 2015). Local communities and district-level government officers have also been mobilized and trained on forest carbon monitoring.

In terms of rules however, no legislations have been developed to anchor forest monitoring in law. Although the NCMC project documents (NCMC Project Document, 2015) outline the roles of different actors in MRV and how they will relate with the NCMC, no legislations have been enacted to formalize MRV in law. Furthermore, while the NCMC has been formalized in MoUs between the Norwegian Embassy and the Department of Environment (DoE-VPO) and between the DoE-VPO and SUA, this has not been accompanied by a legislation that anchors the NCMC 
in law. This is unlike in Indonesia and Peru, where legislations have been developed to anchor forest monitoring in general and MRV in particular in law. Moreover, although the roles of the various actors in MRV have been clarified, interviews showed that many of these actors are not aware of their roles, and how these will relate with the NCMC. The REDD+ pilot projects - which formed part of Tanzania's readiness activities - have also ended (see Mäkelä et al. (2015)), leading what the interviews characterized as loss of institutional memory (Indufor, 2013a). 


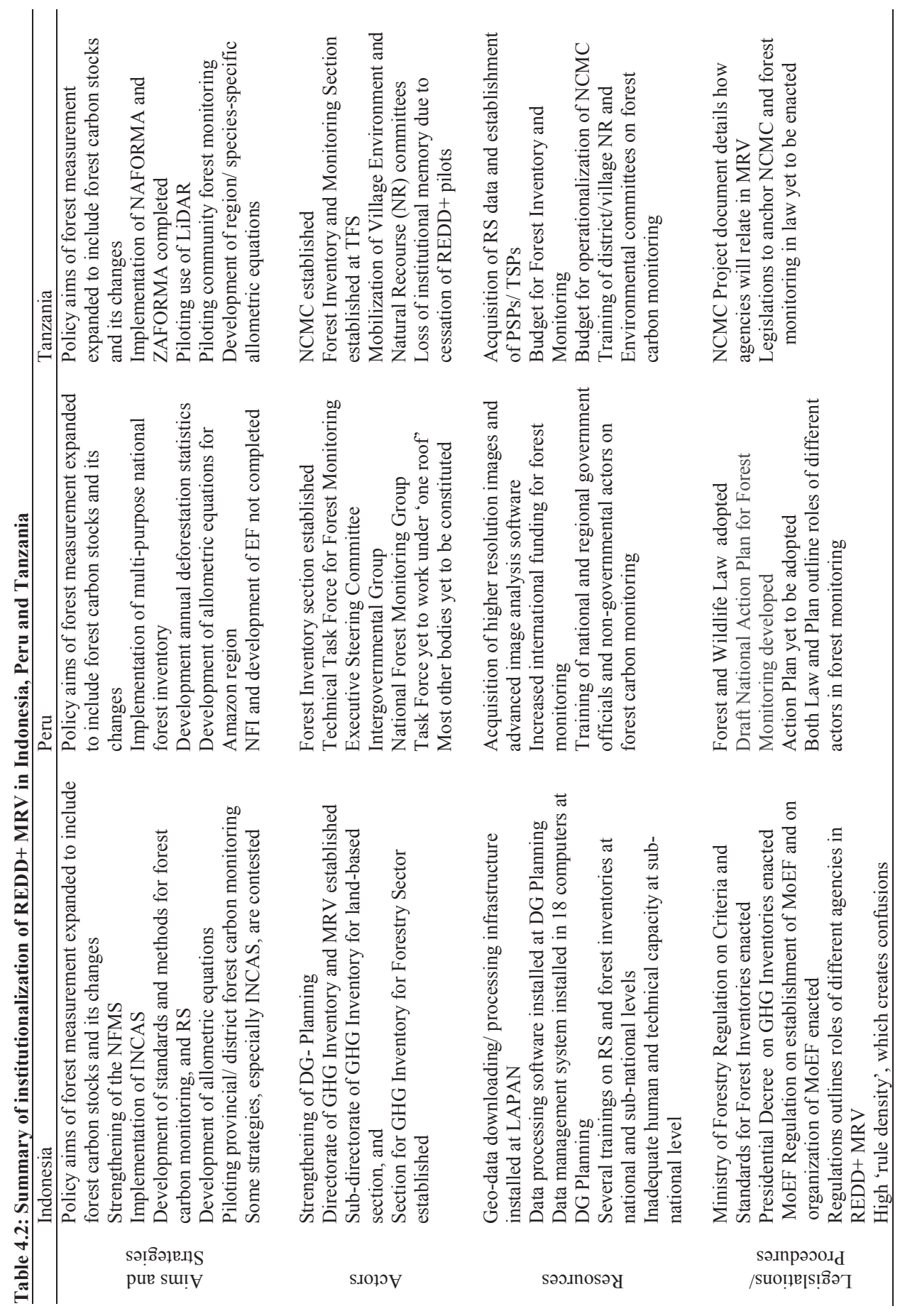




\subsubsection{Exploring reasons for differences in institutionalization of MRV across countries}

The preceding section shows that MRV has re-shaped and materialized in new and reformed institutions for forest monitoring in all three countries. However, it also shows that the extent of institutionalization varies across countries, with Indonesia experiencing 'deep' institutionalization, Peru 'shallow-intermediate' institutionalization, and Tanzania 'intermediate-deep' institutionalization. The question addressed here is what factors could explain the differences across countries.

First, discursive institutionalism identifies the 'existential', 'timeliness' and 'resonance' of a discourse and its ideas as critical for institutionalization. This condition was present in Indonesia and Tanzania, but not in Peru. In both countries, MRV has been a topical national REDD+ policy issue since 2008. Indeed, the need to monitor forests and account for forest carbon has been advocated by a broader audience. This audience comprises national government agencies (the former Ministries of Forestry and Environment and the defunct National Climate Change Council and National REDD+ Agency, for Indonesia; and the Forest and Beekeeping Division (FBD) and Department of Environment of the Vice President's Office (DoE-VPO), for Tanzania), and nongovernmental organizations (NGOs), project developers and local communities implementing REDD + pilot projects. Interviews showed that this audience has been concerned with how they could measure and account for the carbon stored in their forests or the carbon impacts of their REDD+ projects. Consequently, in Indonesia, several REDD+ pilot projects incorporated MRV in their activities and piloted sub-national and project-level MRV implementation (UN REDD Programme, 2013). In addition, several national and regional government agencies, NGOs, project developers and the academia were represented in national REDD+ MRV policy discussions (Indonesian REDD+ Task Force, 2012). Thus, despite some differences on strategic aspects such as the methods to use, interviews show that there was broad consensus on the need to reform the existing national forest inventory and create new agencies to specifically deal with GHG inventories in the land use (forests and peatlands) sector.

Similarly, in Tanzania, most of the REDD+ pilot projects incorporated MRV in their activities (Indufor, 2013a). Additionally, the NGOs implementing these pilots were well represented in 
national MRV policy discussions (Rantala, 2012) and introduced their ideas of how MRV should be conducted and how the different constituencies they represent could be engaged in the process (see Rantala and Di Gregorio, 2014; REDD Pilot Projects, 2011). In Peru, by contrast, although MRV has been a key REDD+ policy issue, national-level discussions on REDD+ in general (Piu and Menton, 2014a) and MRV in particular began only recently. Although the regional governments of the five regions that spans the Peruvian Amazon, NGOs, project developers and local communities had been discussing MRV in so-called REDD+ Roundtables (CIF, 2013; RoP, 2011) and piloting sub-national and project level implementation of MRV since 2008 (see also Joseph et al., 2013b), interviews show that national-level policy discussions on MRV remained limited until after 2012 (Kowler and Larson, 2016; Piu and Menton, 2014a; RoP, 2014). This suggests that for quite some time, MRV was not a topical policy issue at the national level in Peru.

Second, DI emphasizes the importance of credibility and coherence of a discourse in enabling institutionalization. The importance of this factor was particularly evidenced in Indonesia and Tanzania. In both countries, the interviews showed that MRV and the ideas it represents, especially that of involving local communities and other non-state actors was well received by and appealing to a broader audience including national and sub-national government agencies and nongovernmental actors. Consequently, inclusion of governmental and non-governmental actors in forest monitoring for REDD+ was widely discussed and the roles of both in MRV agreed upon in a consensual manner. In Peru, by contrast, the idea of involving regional governments, local communities and NGOs in MRV, while advocated by the latter (Robiglio et al., 2014), has not been appealing to national government agencies especially the Ministry of Environment. This can be seen in the fact that the Ministry has allocated only a 'verification' role to regional governments, NGOs and local communities (RoP, 2014), a proposal that has not been well-received by the latter. Conversely, according to confidential interviews, there has been limited credibility of the proposed institutional changes among regional governments, NGOs, project developers and local communities. Some interviews argued that this explains why agencies proposed to implement MRV have not been constituted as their establishment does not enjoy the support of this group.

Third, DI also emphasizes the importance of authoritative and sentient agencies in promoting discourse institutionalization. The importance of this factor was manifested in Indonesia and 
Tanzania. In both countries, the revision of the aims of forest monitoring and development of new strategies to implement MRV was advocated and supported by authoritative governmental and non-governmental agencies. In Tanzania, all the key policy actors agreed on the need to establish the NCMC (Rantala and Di Gregorio, 2014). Despite initial disagreements on where the NCMC should be hosted, a host institution was not only selected in a consensual manner, but interviews also show that its establishment was advocated and supported by authoritative actors such as the Norwegian Embassy in Dar es Salaam, national government agencies such as FBD and DoE-VPO, and influential NGOs such as the Tanzania Forest Conservation Group (for authority and influence of these actors see Rantala and Di Gregorio (2014) and Rantala (2012)). Similarly, in Indonesia, interviews indicate the need to reform the existing national forest monitoring system and create new agencies was advocated and spearheaded by the authoritative former Ministry of Forestry and the defunct National Climate Change Council and National REDD+ Agency (Brockhaus and Di Gregorio, 2014; see Moeliono et al., 2014 for the relative authority and influence of these actors), and more recently by the newly established Directorate General of Climate Change. The establishment of the Directorate of GHG Inventory and MRV was also advocated for and supported by authoritative national government agencies including the Presidency and the powerful National Planning Agency (Indonesian REDD+ Task Force, 2012). By contrast, in Peru, the various strategies proposed to implement REDD+ MRV have not enjoyed the support of some authoritative actors especially the regional governments who are the authorities in charge of forests in their respective regions, as well as non-governmental actors. These actors have not only contested the limited verification role allocated to them in MRV, but also other aspects of REDD+ in general (AIDESEP, 2012; AIDESEP and FPP, 2011; Friends of the Amazon, 2011).

Fourth, DI emphasizes the (political) popularity and encompassing nature of discourse as a critical factor for institutionalization. This factor was present in Indonesia and Tanzania but not in Peru. In both Indonesia and Tanzania, interviews show that MRV has been presented as an all-inclusive activity that requires involvement of actors with different kinds of expertise, and both governmental and non-governmental organizations. Consequently, both state agencies (including forestry and non-forestry agencies) as well as non-governmental actors have been represented in national MRV policy discussions. This indicates that in both countries MRV has been considered to transcend the sphere of any specific actor. By contrast, in Peru, interviews show that MRV has 
been presented as a technical issue that can be discussed and performed by only a certain calibre of experts. As a result, national discussions on MRV have been restricted to a closed group of experts comprising the Ministries of Environment and Agriculture, OTCA and a select group of a few academicians and international agencies. This has meant that there is neither a broad-based national policy nor a broader societal discussion on MRV in Peru. Thus, the ideas presented in these technical expert discussions do not represent the views of a broader audience, but can be characterized as representing the language and sphere of only a small group of experts.

Lastly, discursive institutionalism also holds that for any new or counter discourse to institutionalize, the existing discourse and related institutions must be under pressure. Our findings show, however, that this is not as critical a condition as the first four already discussed. In all the three countries, national policy discourses on and institutions for forest monitoring have been under pressure to reform and accommodate emerging international demands for information and data on national forests. Indeed, as indicated in the preceding section, in all the three countries, the aims of forest monitoring were reviewed to accommodate issues of carbon accounting and new strategies to implement the revised aims developed. However, since the other four conditions have not been met in Peru, institutionalization of MRV has not gone beyond 'shallow-intermediate'. This is in contrast to Indonesia and Tanzania where all the other four factors were present to a considerable degree.

\subsection{Discussion and conclusions}

This paper sought to analyse and compare the extent of institutionalization of MRV in Indonesia, Peru and Tanzania, and to explain any differences across the countries. The results showed that MRV has materialized in new and reformed institutions for forest monitoring in all countries. This finding puts into perspective the cynicism of many commentators on the willingness and capacity of (developing) countries to implement international agreements. Too often, developing countries are portrayed as signing international agreements to please donors without any intention of implementing such agreements (Dimitrov, 2005; Humphreys, 2006; Young, 1999b). However, as the findings of this study show, (some) developing countries take efforts to implement the international (environmental) agreements they sign. We do not claim that all REDD+ elements have been institutionalized in the three countries. On the contrary, when the findings of this study are cast in the broader debates on progress with REDD+ implementation, it can be concluded that 
MRV is the only REDD+ element that has progressed (cf. Korhonen-Kurki et al., 2013). Although all the countries have developed REDD+ strategies and are in the process of developing reference emission levels and safeguards, which are the other three elements of REDD+ (UNFCCC, 2010), the REDD+ literature (e.g. Angelsen et al., 2012; Brockhaus et al., 2016; Minang et al., 2014) shows that none of the studied countries has addressed the drivers of deforestation and forest degradation that should be the main focus of REDD+.

However, our point here is that international agreements have influence on national institutions. As DI posits, these international agreements and the discourses and ideas associated with them influence national institutions in two steps. First, the discourses and ideas arising from the international agreements trigger national policy discussions on how to implement their provisions. Through these national discursive processes, second, policy actors develop new or revised strategies to implement the provisions of the agreements, mobilize new actors and resources, and formulate new or revised rules. This is exactly what we have seen in the three countries. Our findings therefore confirm the analytical potential of discursive institutionalism in examining the nexus between global discourses and ideas and national institutions.

However, national level institutionalization of discourses and ideas arising from the international level does not follow a neat, linear policy process. As exemplified by the 'shallow-intermediate' institutionalization of MRV in Peru, developing national strategies to implement discourses and ideas arising from international agreements involve discursive struggles among different policy actors and interest groups. Such struggles, as DI posits, can effectively hinder institutionalization. In Peru, it is precisely the discursive struggles among different levels and agencies of government that militates against 'deep' institutionalization of MRV (see also Robiglio et al 2014). While not the explicit focus of this paper, such struggles show that analysing the interactive policy process as suggested by discursive institutionalism could point out the actors involved in such policy processes and their ideas and identify their ideational points of convergence and divergence. It is suggested that for a better understanding of discourse institutionalization, a study of the discursive process could be undertaken. This would not only highlight which actors and ideas win or lose in a given policy process but could provide a starting point for mediating the ideational points of contest that hinder 'deep' institutionalization. By conceiving discourse as both the interactive 
process by which policy actors exchange ideas during policymaking and public deliberation and as the ideas represented in such discursive exchanges (Schmidt, 2008; Schmidt, 2010), DI therefore offers a powerful analytical framework for disentangling and mediating the struggles involved in policy processes.

The varied extent of institutionalization of MRV and the manifestation of factors for discourse institutionalization in Indonesia and Tanzania and not Peru not only affirms the centrality of these factors in facilitating discourse institutionalization as DI claims (Buijs et al., 2014; Phillips et al., 2004; Schmidt, 2008) but also offers useful lessons for other countries grappling with how to implement MRV. First, as the Indonesian and Tanzanian cases indicate, it is imperative that national policy discussions on MRV are initiated when the issue is not only existential and timely but also resonates with a larger and concerned audience. Kingdon (1995) has coined the term 'policy window' to describe the time when a policy issue is existential, timely and resonates with a majority of policy actors and interest groups. The findings of this study suggest that national policy actors would be successful in pushing for 'deep' institutionalization if they could identify or create such policy windows. Second, in developing any new strategies to implement MRV, countries could consider formulating an all-inclusive policy process (see also Brockhaus et al., 2014) that involves all the authoritative actors. Our findings suggest that when authoritative actors are absent from calls for change and not behind it, new demands such as MRV might not be institutionalized at all.

A third related lesson relates to the use of an inclusive and appealing storyline (Buijs et al., 2014; Phillips et al., 2004; Schmidt, 2001). In Indonesia and Tanzania, lead government agencies used the popular and attractive ideas in MRV such as that of involving local communities and NGOs strategically to generate broader acceptance of proposed strategies. In Peru, by contrast, the allocation of a less appealing 'verification' role to regional governments, local communities and NGOs/ projects developers has diminished the appeal of the proposed strategies. Cox and Béland (2013) have coined the term 'valence' to conceptualize ideas and storylines that have high level of emotional appeal and resonance. The emotional attractiveness of the idea of involving sub-national governments, local communities and NGOs, as the Indonesian and Tanzanian cases demonstrates, have indeed proved a valent storyline to advocate for change in institutions for forest monitoring. 
Overall, the study highlights that DI provides a powerful theoretical framework for analysing how ideas and discourses from the international level shape national policy processes and institutions. Additionally, it shows that the extent of discourse institutionalization can be explained by examining the theoretical factors for discourse institutionalization and their manifestation in a given policy process. This also suggests that taking these factors into account could enhance deep institutional change. However, though discursive institutionalism considers the credibility of existing discourses and related institutions as crucial for discourse institutionalization, our study shows that this is not always the case. This is not surprising as there are many cases in which existing discourses and related institutions are under pressure, but institutionalization of new or counter discourses and realization of institutional change remains elusive. This suggests that for deep institutional change to occur, the legitimacy of existing discourses and related institutions must not only be under pressure, but the new or counter discourses and ideas must also meet the other theoretical factors for discourse institutionalization. We do not claim to identify through the DI lens all factors that can explain and provide insights into why or why not a particular country makes progress with MRV. However, we believe that taking a DI perspective provides a useful tool to structure national MRV policy discussions ex ante, and highlight constraints and opportunities for countries aiming to implement MRV ex post. 
Chapter 5 - Does discourse matter in institutionalization? The case of REDD+ MRV in Indonesia, Peru and Tanzania

Submitted for publication as Ochieng, R.M., Visseren-Hamakers, I.J., Brockhaus, M. \& Arts, B. (forthcoming) Does discourse matter in institutionalization? The case of REDD+ MRV in Indonesia, Peru and Tanzania. Global Environmental Change. The Chapter was awarded the Oran R Young Prize at the 2016 Nairobi Conference on Earth System Governance 


\begin{abstract}
Reducing emissions from deforestation and forest degradation in developing countries (REDD+) has opened up new deliberative spaces in the forest policy arena of many developing countries. One such deliberative space deals with developing strategies to implement a national monitoring, reporting and verification (MRV) system. Although MRV is often regarded a technical activity, we argue here that it is in essence political. We examine (1) the actors involved in developing policies to implement MRV, and the ideas they brought into the discussions and the ones they contested, and (2) how political contestation inherent in these deliberative processes have enabled or constrained institutionalization of MRV in Indonesia, Peru and Tanzania. Results show that while different stakeholders had different ideas on best methodologies and strategies to implement MRV in Indonesia and Tanzania, the discursive process enabled the stakeholders to forge common ground on conflicting ideas, leading to institutionalization of MRV in several strategies. In Peru by contrast, the stakeholders are yet to agree on the methodologies and strategies to implement MRV, largely due to the exclusive and constraining nature the discursive process. We conclude that inasmuch as the carbon figures generated through MRV will have different socio-economic implications for different stakeholders, the methodologies and strategies to implement MRV will remain subject to political contestation. This implies that stakeholders involved in developing MRV systems and their donors should invest in mediating these potential conflicts, if the resulting methodologies and strategies are to be viewed as legitimate.
\end{abstract}

Keywords: REDD+ MRV; Coordinative discourse; Institutionalization; Indonesia; Peru; Tanzania 


\subsection{Introduction}

Since the emergence of Reducing Emissions from Deforestation and forest Degradation in developing countries; and the role of conservation, sustainable management of forests and enhancement of forest carbon stocks in developing countries (REDD+) under the United Nations Framework on Climate Change (UNFCCC), new deliberative spaces have opened up in the national forest policy arena of many developing countries. Within these spaces, stakeholders are discussing ideas on the key problems that REDD+ should address, the goals that REDD+ should achieve, and the best policy options to achieve those goals (Brockhaus and Angelsen, 2012b; Brockhaus and Di Gregorio, 2014; Brockhaus et al., 2014). Implementing REDD+ involves developing four elements: national REDD+ strategies and action plans; reference emission levels; monitoring, reporting and verification (MRV) systems; and REDD+ safeguards (UNFCCC, 2010). Each deliberative space is therefore concerned with developing policies to implement a specific REDD+ element.

REDD + is a climate change mitigation strategy that aims to provide financial incentives (REDD+ payments) to developing countries to reduce emissions from deforestation and forest degradation. Since it is a results-based payment mechanism, developing countries must have in place systems to monitor and report on how their activities have contributed to emission reductions in order to access payments, which is done by developing national MRV systems. MRV systems are thus national mechanisms for 'Monitoring' emission reductions from REDD+ activities, 'Reporting' the measured reductions to the UNFCCC, and facilitating 'Verification' of the reported reductions by third parties (McRoberts et al., 2013).

This paper is concerned with the deliberative space where strategies to implement a national MRV system are being discussed and developed. Although MRV is arguably a technical activity that requires technical knowhow, the carbon data it generates will have different economic and social implications for different groups of REDD+ implementers. For example, the amount of carbon reductions estimated at the national, subnational or project level has implications on the amount of REDD+ payments that will accrue to any particular group of REDD+ stakeholders. This makes non-experts interested not only in the technical methodologies used for MRV, but also in the development and implementation of methodologies for forest carbon assessments (Kowler and 
Larson, 2016; Vijge, 2016). It is precisely these potential socio-economic implications of MRV on different stakeholders that implicate MRV as political. The politics of MRV policy development involve contestation and argumentation among diverse stakeholders with different and often conflicting ideas (cf. Brockhaus and Di Gregorio, 2014; Brockhaus et al., 2014). The diversity of stakeholders and their conflicting ideas generally produce political conflicts over the policy problems that a MRV system should address, the goals that the MRV system should achieve, and the appropriate policy options to achieve those goals. In these political processes of deliberation and contestation, policy stakeholders use argumentation, negotiation and persuasion (Habermas, 1996; Risse, 2000; Schmidt, 2008; Schmidt, 2010) to advance their preferred policy options while de-legitimating competing ones.

This paper examines (1) the actors involved in the interactive processes of deliberating and developing policies to implement MRV, and the ideas they brought into the discussions and the ones they contested, and (2) the effect of these deliberative processes on political conflicts, and how they have enabled or constrained institutionalization of MRV in Indonesia, Peru and Tanzania. Analysing the discursive process of MRV policymaking is especially relevant since analyses of discursive processes of policymaking have received little empirical attention in the discursive-institutionalist literature, as others (Mehta, 2011; Schmidt, 2010) have also acknowledged. The paper proceeds as follows. Section 2 introduces Discursive Institutionalism, while section 3 describes the study methods. Section 4 presents the results, while section 5 discusses and concludes the paper by explaining how discourse matters in instances of institutionalization of ideas.

\subsection{Discursive Institutionalism: coordinative policy discourse}

We use Discursive Institutionalism (DI) to examine how the interactive discourse among policy actors has enabled or hindered institutionalization of MRV policies in Indonesia, Peru and Tanzania. DI conceives of discourse as the shared - and at the same time contested - ideas about policymaking on the one hand, and as the interactive process by which these ideas are exchanged, deliberated and (de)legitimized during policymaking and public deliberations (Schmidt, 2002, 2008; Schmidt, 2010; Schmidt and Radaelli, 2004), on the other. A discourse can contain three types of ideas: policy, programmatic, philosophical ideas (Schmidt, 2008). Policy ideas are the different strategies proposed by policymakers to solve given policy problems (Mehta, 2011; 
Schmidt, 2008). Programmatic ideas encompass the definition of the policy problem at hand, the aims to be achieved, the actors to be involved, and the methods and instruments to be used (Mehta, 2011; Schmidt, 2008). Philosophical ideas are the underlying values in a given policy domain that are rarely contested, except in times of crisis (Campbell, 2004; Mehta, 2011). Since philosophical ideas are rarely contested in policy processes (Campbell, 1998; Schmidt, 2008), they are not examined in this paper.

Although a number preconditions are considered necessary for materialization and institutionalization of any new idea (Buijs et al., 2014; Kingdon, 2003; Phillips et al., 2004; Schmidt, 2008), DI also posits that the discursive processes of policymaking and public deliberations are critical determinants of institutionalization. With this proposition, Schmidt observes that '.. tracing discursive processes of policy coordination and communication is a way of showing why ideas may succeed or fail. But discourse, like ideas, sometimes matters to that success and sometimes does not ...' (Schmidt, 2008 p. 311, emphasis added). She distinguishes between communicative political and coordinative policy discourses. The latter involves discussions among policy actors within the state bureaucracies, while the former involves discussions between political actors and the general public (Schmidt, 2008; Schmidt, 2010). Communicative political discourse will be less useful for our purpose here since our analysis is concerned with deliberations among MRV policy actors (i.e. coordinative discourse).

In this paper, we analyze which programmatic and policy ideas were introduced and adopted by policy actors during MRV policymaking in the respective countries. This MRV coordinative policy discourse involves negotiation, contestation and persuasion among different policy actors about the policy problems to be solved, the goals to be realized, the methods to be used, and the actors to be involved (i.e. programmatic ideas), and the appropriate policy solutions (i.e. policy ideas) to implement MRV. For discursive institutionalists (Dryzek, 2000; Hajer, 2006; Hajer, 1995; Schmidt, 2008; Schmidt, 2010), these processes of negotiation, argumentation, and contestation constitute discursive politics. The processes and outcomes of this discursive politics can enable or constrain institutionalization of certain MRV policy options (Brockhaus et al., 2014; den Besten et al., 2014; Gallemore et al., 2014). Analysing the interactive discourse involved in 
MRV policy development can therefore reveal why certain programmatic and policy ideas on MRV and the concept of MRV in general have been institutionalized in a given REDD+ country.

\subsection{Methods}

The study was conducted in Indonesia, Peru and Tanzania, which were selected for one main reason. Indonesia and Tanzania started their MRV policy processes as early as 2008 (Indrarto et al., 2012; Kweka et al., 2015), while the MRV process in Peru began only after 2012 (Piu and Menton, 2014a). Despite the relatively early engagement of Indonesia and Tanzania in MRV, however, studies show that they are at different stages in developing technical and institutional capacities for MRV (Korhonen-Kurki et al., 2013; Minang et al., 2014; Ochieng et al., 2016a). The three countries thus provide interesting cases to study and compare.

Data were obtained through 34 semi-structured interviews in Indonesia, 23 in Tanzania, and 42 interviews and two focus group discussions (FGDs) in Peru (Table 5.1). The interviews were conducted with representatives of different state and non-state actors as well as forest monitoring and MRV experts in each country. The representatives and experts were selected because they have been involved in forest monitoring or in MRV discussions in the respective countries, and were selected 'purposefully' from contacts found in publicly available REDD + documents (Creswell, 2014; Punch, 2005). Additional interviewees were identified using snowball sampling (Punch, 2005). Field work was conducted during October - December 2015, and August September 2015 in Indonesia and Tanzania respectively, and May - June 2014 in Peru. These were complimented with selected 'follow-up' Skype/ telephone interviews in 2016 in each of the countries. In Peru, additional primary data was obtained through participant observation of MRV processes in 2014. This primary data was triangulated with secondary data obtained through analyses of national REDD+ policy documents and other scientific and grey literature. 
Table 5.1: Respondents by country

\begin{tabular}{|c|c|c|c|c|c|c|}
\hline \multirow{2}{*}{$\begin{array}{l}\text { Category of } \\
\text { respondent }\end{array}$} & \multicolumn{2}{|c|}{ Indonesia } & \multicolumn{2}{|c|}{ Peru } & \multicolumn{2}{|c|}{ Tanzania } \\
\hline & No. & Interviewees & No. & Interviewees & No. & Interviewees \\
\hline $\begin{array}{l}\text { National/sub- } \\
\text { national } \\
\text { government } \\
\text { agencies }\end{array}$ & 12 & $\begin{array}{l}\text { I1,I3,I4,I6,I7,I10, } \\
\text { I11,I16,I21,I22, } \\
\text { I23,I26 }\end{array}$ & 22 & $\begin{array}{l}\text { P3,P4,P5,P6,P10,P12,P18,P20, } \\
\text { P21,P24,P25,P27,P31,P32,P33, } \\
\text { P34,P35,P36,P37,P38,P41,P42 }\end{array}$ & 8 & $\begin{array}{l}\text { T2,T4,T6, } \\
\text { T12,T13, } \\
\text { T17,T21,T23 }\end{array}$ \\
\hline $\begin{array}{l}\text { Non-governmental } \\
\text { organizations }\end{array}$ & 8 & $\begin{array}{l}\text { I2,I8,I13,I14,I31, } \\
\text { I32,I33,I34 }\end{array}$ & 9 & $\begin{array}{l}\text { P11,P14,P17,P19,P22,P23,P30,P3 } \\
\text { 9, } \\
\text { P40, }\end{array}$ & 5 & $\begin{array}{l}\mathrm{T} 3, \mathrm{~T} 11, \mathrm{~T} 14, \\
\mathrm{~T} 16, \mathrm{~T} 22\end{array}$ \\
\hline $\begin{array}{l}\text { Intergovernmental } \\
\text { organizations }\end{array}$ & 9 & $\begin{array}{l}\mathrm{I9}, \mathrm{I} 12, \mathrm{I} 15, \mathrm{I} 17, \mathrm{I} 18, \\
\mathrm{I} 19, \mathrm{I} 20, \mathrm{I} 25, \mathrm{I} 29\end{array}$ & 3 & $\mathrm{P} 13, \mathrm{P} 26, \mathrm{P} 28$ & 2 & $\mathrm{~T} 1, \mathrm{~T} 20$ \\
\hline $\begin{array}{l}\text { Private actors } \\
\text { (Consultants, } \\
\text { academics) }\end{array}$ & 5 & $\mathrm{I} 5, \mathrm{I} 24, \mathrm{I} 27, \mathrm{I} 28, \mathrm{I} 30$ & 8 & $\begin{array}{l}\text { P1,P2,P7,P8,P9,P16, } \\
\text { P16,P29 }\end{array}$ & 8 & $\begin{array}{l}\text { T5,T7,T8,T9, } \\
\text { T10,T15,T18, } \\
\text { T19 }\end{array}$ \\
\hline Total & 34 & & 42 & & 23 & \\
\hline
\end{tabular}

\subsection{Discursive politics of MRV policymaking: actors, ideas and institutionalization}

Across the analysed countries, discussions on programmatic ideas about MRV centred on the appropriate methodologies for forest monitoring, whether there is enough in-country technical capacity to conduct MRV and where this capacity exists, and the actors to be involved in MRV and their roles. Discussions on strategies to implement MRV (policy ideas) centred on whether to establish new agencies or strengthen existing ones to lead on MRV. In all countries, discussions focused on the Monitoring (M) component of MRV. There was consensus among stakeholders in all countries that Reporting $(\mathrm{R})$ is the prerogative of the government body that serves as the focal point for the UNFCCC, and that Verification (V) would be conducted by independent third parties, appointed by the UNFCCC. Below, we examine the actors that were involved in MRV discussions in each country, the specific programmatic and policy ideas they introduced or contested, and how the discursive process (argumentation and contestation, or lack thereof) has enabled or constrained institutionalization of MRV.

\subsubsection{Inclusive and enabling MRV discourse in Indonesia}

In Indonesia, REDD+ processes in general and MRV discussions in particular started as early as 2008, and have been influenced by the presidential elections of July 2014 that brought in a new government. In May 2010, before the elections, the Indonesian government had signed a Letter of Intent with Norway in which both countries committed to cooperate on REDD+ (Seymour et al., 2015). The incumbent President at the time established the REDD+ Task Force to lead REDD+ policy development in the country. The Task Force was to prepare for the establishment of a more 
permanent, ministerial body - the REDD+ Agency - which would then lead the Indonesian REDD+ policy development and implementation processes. In 2013, the REDD+ Task Force established, and was succeeded by, the National REDD+ Agency. During this early stage (20092013) of REDD+ in Indonesia, different working groups were established to deliberate different elements of REDD+. For MRV, an MRV Working Group (MRV WG) was established as a national forum to coordinate MRV policy discussions (REDD+ Task Force MRV Working Group, 2012). Several stakeholders were represented in the MRV WG, including national and sub-national government agencies, research and educational institutes, non-governmental organizations (NGOs) and private actors (Indonesian REDD+ Task Force, 2012).

Between 2010 and 2012, the MRV WG held several meetings, during which different stakeholder groups introduced and supported or contested different ideas either individually or in coalition with others. Two issues were particularly contentious. The first issue concerned the question whether an entirely new body should be established to conduct MRV or whether existing agencies should be strengthened to assume this task. In the early stages of MRV policy development, the National REDD+ Agency (and its predecessor the REDD+ Task Force), the Ministry of Environment, the National Council on Climate Change and several NGOs and research institutes had proposed the idea of establishing a new agency - the 'MRV Institution' (REDD+ Task Force MRV Working Group, 2012) - to oversee national forest monitoring and carbon accounting for REDD+. According to $70 \%$ of Indonesian respondents, during this period all stakeholders were in agreement that the existing national forest inventory system based at the Directorate General of Forest Planning of the then Ministry of Forestry was inadequate for the MRV task. NGOs, academic and research institutes, and non-forestry government agencies argued that the data and methods used by the Directorate General of Forest Planning were not only obsolete, but were also not transparent (Interview I6, I27, I30, I32, I33, I34). Given this lack of transparency, they argued that any carbon figures generated by the Directorate would not be trusted. Half of the Indonesian respondents reported that, as a coalition, the actors also argued that the then Ministry of Forestry in general lacked the technical capacity to implement MRV in a manner that would meet the stringent levels of accuracy and precision required under REDD + . They therefore proposed the establishment of a new independent 'MRV Institution' that would generate new methods and data in a transparent manner. 
However, the idea of establishing a new MRV Institution was contested by the then Ministry of Forestry (Interview I1,I5,I16,I27). This Ministry is reported to have argued that it has technical capacity for forest monitoring, and that its Directorate General of Forest Planning has been conducting national forest inventories since the 1980s (Interview I4,I5,I7,I11,I26,I27). It argued that it has generated large amounts of forestry inventory data over 20 years that should not simply be discarded (Interview 4,11,26). While the Ministry acknowledged that its data had not been collected in regular intervals, it argued that the volume of data it has collected over the years is sufficient for not only developing baseline forest carbon emissions, but also for calculating regionspecific carbon emissions (Interview I4,I7,I21,I26). It noted that establishing the 'MRV Institution' would duplicate the same data collection effort it has conducted over the years, and argued that for efficiency, it was better to strengthen and build on the data it has generated so far (Interview I4,I7,I26). However, in these early stages of MRV policy development, the Ministry's arguments were less convincing to the other policy actors, and it was outnumbered in the MRV discussions. Subsequently, the idea of establishing a new 'MRV Institution' was institutionalized in the National REDD+ Strategy (Indonesian REDD+ Task Force, 2012) and the National MRV Framework Document (REDD+ Task Force MRV Working Group, 2012).

Things took a turn in 2014 when a new government was elected in Indonesia, which disbanded the REDD + Agency and the National Council on Climate Change. This re-organization also meant that the activities of the MRV WG were terminated and the Group dissolved. As a shift in policy, the new government in 2015 merged the Ministries of Forestry and Environment into a new Ministry of Environment and Forestry (RoI, 2015). A new Directorate General of Climate Change was created, and has since absorbed the functions of the REDD+ Agency and the National Council on Climate Change (Seymour et al., 2015). In the ministerial restructuring that followed, the Directorate General of Forest Planning was restructured and renamed the Directorate General of Forest Planning and Environmental Management (MoEF, 2015). In deliberating how to continue implementing REDD+ elements and specifically MRV, the new Ministry, through its Directorates General of Forest Planning and Environmental Management and Climate Change, have recently argued that creating a new MRV Institution as was previously proposed would not provide an efficient MRV system (Interview I7,I16,I21,I26). Instead, they argue that this would create new centres of power, and escalate existing interagency competition and conflict (Interview 
I2,I7,I16,I21,I26). In this argument, they have been supported by several NGOs and research institutes. Although these NGOs and research institutes previously advocated for a new MRV Institution, they have recently argued that from previous experiences, creating new agencies has not improved efficiencies in government operations (Interview I1,I5,I27,I32,I33,I34). They proposed that instead of creating a new body, the existing forest monitoring system of the Directorate of Forest Resource Inventory and Monitoring under DG Forest Planning and Environmental Management be strengthened with technologies and skills to conduct REDD+ MRV (Interview I4,I11,I26,I27). They argue that this is necessary since this Directorate has been collecting data over the last 20 years and has the requisite experience and only needs additional strengthening of technical skills and technologies (Interview I4,I7,I21,I26).

At the time of the fieldwork, according to the majority $(>60 \%)$ of the respondents the idea of establishing a new MRV Institution has disappeared. Instead, at the restructured Directorate General of Forestry Planning and Environmental Management, the Directorate of Forest Resources Inventory and Monitoring has been strengthened through technical capacity and infrastructure development (UN REDD Programme, 2013), and development of a National Forest Monitoring System (RoI, 2014; Sugardiman, 2012). Some of the interviewees argued, however, that the MRV Institution has been institutionalized in the new Directorate General of Climate Change (Interview I4,I7,I26). They noted that within this Directorate General, a Directorate of GHG Inventory and MRV has been established, complete with a sub-directorate for GHG Inventory and MRV of the land-based sector in general and a section on GHG Inventory of the Forestry Sector in particular (MoEF, 2015; RoI, 2015). All non-governmental and some governmental interviewees consider the Directorate of GHG Inventory and MRV to represent the 'MRV Institution'. Interviewees from bilateral/ multilateral development cooperation agencies (Interview I12,I17,I20) also view this Directorate as the MRV Institution, arguing that its functions are the very ones that the MRV Institution was to perform.

The second contentious issue concerned the best methodological approach to deliver a technically sound MRV system. In the early stages (2009-2012) of MRV development in Indonesia, the Australian Government - through the Indonesia-Australia Carbon Partnership (IAFCP, 2015) and the Forest Research and Development Agency (FORDA) - proposed the development and 
implementation of the so-called Indonesian National Carbon Accounting System (INCAS). INCAS is an approach to forest carbon monitoring that enables carbon emissions to be monitored and reported at any time period. It is designed to develop greenhouse gas (GHG) inventories for the land-use (forests, peat land and agriculture) sector (IAFCP, 2015; INCAS Roadmap, 2015). It is modelled on the Australian national carbon accounting system for land-based emissions (Davies, 2015). In the early stages, the main proponents of INCAS included the Australian Agency for International Development, Australia's Department of Climate Change, and FORDA (Interview I1,I5,I6,I8,I11,I31). These actors agreed and noted that the existing forest monitoring system and its methods and data were not rigorous enough for the MRV task (Interview I6,I11). They therefore proposed the development of INCAS and new algorithms and datasets to provide a methodologically robust MRV system (Interview I1,I5,I11,I27,I31). This proposal was supported by key government agencies such as National Institute for Aeronautics and Space (abbreviated LAPAN in Indonesian), National Planning Agency (abbrev. BAPPENAS, Indonesian), Geospatial Information Agency (abbrev. BIG, Indonesian) and the former Ministry of Environment (Interview I10,I11,I22,I23)

However, several other policy actors, especially NGOs, research and educational institutes, and the then Ministry of Forestry (later the Directorates General of Climate and Forest Planning and Environmental Management), initially contested this methodological proposal, arguing that the algorithms and assumptions of INCAS do not reflect the conditions of Indonesia but rather those of Australia (Interview I1,I4,I13,I26,I27). According to some interviewees (Interview I4,I7,I21,I22,I23,I26), governmental actors in particular questioned why Indonesia had to adopt INCAS, while the existing system run by the Directorate General of Forest Planning and Environmental Management can also deliver region-specific (so-called Tier 2, IPCC (2006)) carbon data. Some indicated that the Directorates General of Forest Planning and Environmental Management and Climate Change in particular questioned why Indonesia had to use such a stringent methodology as INCAS, when it is not clear at the international level whether there will be REDD+ payments (Interview I4,I26). Interviewees also showed that the former Ministry of Forestry feared that adopting INCAS methodologies would render several positions redundant thus leading to loss of jobs (Interview I11,I16,I22,I23,I31). Others (Interview I7,I13,I31) noted that the government was also not open to INCAS because of sovereignty issues, since it was seen as mainly 
driven by Australia's interest to show to the world its capacity in forest carbon monitoring and not necessarily to enable Indonesia to engage in carbon trade (cf. Seymour et al., 2015 p. 6). NGOs and local researchers on their part argued that the INCAS methodology and its underlying algorithms were just as not transparent as those of the existing forest monitoring system (Interview $\mathrm{I} 22, \mathrm{I} 23, \mathrm{I} 27, \mathrm{I} 30, \mathrm{I} 34)$.

Concerned by these counter-arguments against INCAS, interviewees (Interview I11,I31) reported that the INCAS formulation team led by FORDA convened several meetings with all stakeholders to address their concerns. In these meetings, the formulation team explained the algorithms and assumptions underlying INCAS. Interviewees reported that this allayed the fears and led to a softening of position by NGOs and research institutes (Interview I11,I27,I31,I32). It was also discussed and agreed that although the methodologies of INCAS are stringent, it will in essence use data generated by recognized national agencies, including the Directorate General of Forest Planning and Environmental Management and LAPAN. This, according to some interviewees led to softening of position by the critical governmental stakeholders (Interview I11,I31). These stakeholders are also reported to have been convinced that they could still exert their influence in MRV, as they would be in charge of data generation (Interview I7,I11,I21,I31). The compromises resulting from these discussions enabled the institutionalization of INCAS methodologies and the use of data of DG Forest Planning and Environmental Management. INCAS and its methodologies have been institutionalized in the installation of new hardware and software for downloading and processing satellite images at LAPAN and at FORDA (Interview I11,I27,I31). According to interviewees, this has been accompanied by recruitment of staff to run the geo-data infrastructure and their subsequent absorption as permanent staff of LAPAN (Interview I11,I22,I23,I31). Additionally, a new institutional arrangement for implementing INCAS has been proposed (INCAS Roadmap, 2015) that also institutionalizes the role of the DG Forest Planning and Environmental Management as the official source and custodian of data to be used by INCAS.

\subsubsection{Inclusive and facilitative $M R V$ discourse in Tanzania}

Like in Indonesia, REDD+ processes in Tanzania started as early as 2008 with the signing of a Letter of Intent with Norway (Kweka et al., 2015). A REDD+ Task Force was established to lead on REDD+ policy development, including the country's MRV system. The Task Force comprised representatives of government agencies, NGOs, universities and donor agencies (Rantala, 2012). 
In addition to the discussions of the Task Force, an MRV Working Group (MRV WG) was established as a forum to coordinate national discussions on MRV specifically (Tanzania R-PP 2010). The MRV WG comprised representatives of government agencies, NGOs, research and academic institutes and donors. All Tanzanian interviewees observed that in the discussions of both the Task Force and MRV WG, all stakeholders were unanimous that the existing national forest monitoring system operated by the Tanzania Forest Service (TFS) was inadequate for the MRV task. Interviewees reported that the stakeholders noted that data generated by the TFS was not only fragmented, but had also not been collected systematically (Interview T3,T9,T17,T19, T20,T21). All interviewees reported that policy actors agreed on the need to develop a new system - the National Carbon Monitoring Centre (NCMC) - to oversee REDD+ MRV. This idea was subsequently institutionalized in the REDD+ Strategy (URT, 2013). In discussing how to establish the NCMC, the stakeholders had two issues to consider: (1) whether to establish the NCMC as a stand-alone executive agency of the government under the Executive Agencies Act 1997, or to anchor it to an existing agency, and in this case, (2) which national agency was best suited to host the Centre (Interview T6,T8,T11,T12,T19).

Regarding the first issue, all respondents indicated that there was unanimous agreement among stakeholders that the NCMC should be established as a stand-alone executive agency. A major point of discussion was how such as an executive agency could be established. Respondents reported that the stakeholders considered that for an executive agency to be established, its establishment must be provided in law, and that such an agency must be able to sustain itself financially (Interview T6,T8,T9,T11,T12). Stakeholders grappled with how to surmount these legal and financial hurdles in order to establish the NCMC as an executive agency. The actors consulted the Public Service Management Office of the President's office, an agency that approves establishment of executive agencies (Interview T6,T8,T12). According to interviewees, this Office advised that given financial sustainability concerns and the fact that establishment of the NCMC is not provided in any Tanzanian law, the NCMC can only be established and hosted within an existing agency (Interview T6,T8). The stakeholders thus concluded that the NCMC would not be established as a stand-alone agency but would be hosted within an existing institute. 
With the first issue settled, deliberations shifted to where the NCMC should be hosted. Interviewees showed that various agencies including the TFS, Department of Environment of the Vice President's Office (VPO-DoE), Institute of Resource Assessment of the University of Dar es Salaam (IRA-UDSM) and Sokoine University of Agriculture (SUA) all jockeyed to host the Centre for different reasons (Interview T3,T6,T9,T10,T11,T19). The TFS argued that since it is the custodian of forests and has been conducting national forest monitoring, including the just concluded National Forest Monitoring and Assessment (NAFORMA, see below), its existing Forest Resource Assessment Unit should be strengthened and transformed into the NCMC (Interview T4,T8,T13,T17,T23). The DoE-VPO on the other hand argued that since it is the national authority of climate change issues, including REDD+, and the focal point for the UNFCCC, it had a duty to host the Centre (Interview T6,T8,T11,T12). The TFS and DoE-VPO proposals and arguments were countered and dismissed by the other policy actors on several grounds. These other actors comprised representatives from Tanzanian universities, NGOs, and donor agencies. Together, they argued that TFS is the custodian of forests in Tanzania, and as such cannot be charged with monitoring and verifying itself, observing that this would amount to 'selfpolicing' (Interview T3,T8,T9,T19,T20). They offered that although TFS would play a key role in collecting forest data, it would not be justified if it again played the role of verifying its own data. They observed that doing so would undermine the credibility of the generated carbon data. For the DoE-VPO, the actors argued that it did not have the technical infrastructure and capacity to conduct forest monitoring (Interview T4,T9,T13,T17,T19). They further argued that forest monitoring for REDD+ should be overseen by an independent agency that is not under direct government control. University and NGO representatives also pointed out that the Royal Norwegian Embassy - as the donor that would support establishment of the NCMC - had provided establishment of the NCMC outside direct government control as one of the conditions for its support (Interview $\mathrm{T} 1, \mathrm{~T} 3, \mathrm{~T} 8, \mathrm{~T} 9, \mathrm{~T} 1, \mathrm{~T} 17, \mathrm{~T} 20)$. These counter-arguments by university, NGOs and donor representatives are reported to have been convincing, and soon the TFS and DoE-VPO dropped their proposals (Interview T3,T17).

Subsequent deliberations shifted to whether SUA or IRA-UDSM was best suited to host the Centre, and soon two coalitions emerged. A coalition comprising SUA, the Royal Norwegian Embassy, several NGOs, and later the VPO-DoE, advocated for hosting the NCMC at SUA 
(Interview T8,T9,T19). In their arguments they offered that SUA has the best expertise, experience and resources for forest assessments in the country. They further argued that most of the forest resource assessments that have been conducted in the country so far, including NAFORMA, had been facilitated by SUA experts (Interview T3,T9,T13,T14T19,T20). To buttress its suitability to host the Centre, SUA representatives argued that the university could mobilize resources to sustain the Centre when the Norwegian funding ceases (Interview T9,T19). To bolster this argument, SUA cited instances where it had successfully mobilized resources to continue projects after cessation of donor funding (Interview T9,T19). The powerful Norwegian Embassy is reported to have had a preference for SUA, and was convinced that SUA has the technical infrastructure and capacity to host the Centre, and exerted pressure on the VPO-DoE to support SUA (Interview T3,T9,T19). However, IRA-UDSM and the REDD+ Secretariat argued that since IRA-UDSM had been hosting the REDD+ Secretariat, it should also host the NCMC (Interview T8,T10,T11). They argued that this would enable IRA-UDSM to build on and continue the institutional development work that had been started by the REDD+ Secretariat (Interview T3,T8,T19,T20). They also argued that IRA-UDSM has expertise and is an authority in resource assessments in the country (Interview T1,T8). However, these arguments were countered by the other actors, who were particularly concerned that IRA-UDSM lacks the technical and infrastructural capacity for forest assessments (Interview T3,T9,T11,T19).

However, IRA-UDSM and REDD+ Secretariat refused to change their position. To resolve the deadlock, the actors agreed to commission a consultancy study to assess the capacities of the two agencies and others, and recommend the most suitable one (Interview T6,T10,T12). The study developed criteria for ranking agencies and presented its findings, in which they recommended SUA as the most suitable agency to host the NCMC (Interview T10). Today, the NCMC has been established at SUA through memoranda of understanding between the Royal Norwegian Embassy and the VPO-DoE, and between the VPO-DoE and SUA (see MFA and URT, 2015).

The second strategy for implementing MRV in Tanzania was the implementation of the National Forest Monitoring and Assessment (NAFORMA). The NAFORMA idea had been introduced much earlier in the National Forest Program (NFP 2001-2010, see FAO/ GoT, 2009) before issues of REDD+ gained traction in Tanzania. During the NFP formulation, stakeholders noted that the 
existing forest information was fragmented and outdated, and that there was need to conduct a national-level forest assessment to determine the extent and status of forest resources. However, with REDD+, key stakeholders, especially the TFS, VPO-DoE and REDD+ Task Force proposed, and it was agreed, that the objectives and methodologies of NAFORMA be revised to incorporate issues of forest carbon and provide baseline data for MRV (FAO/ GoT, 2009; URT, 2015). Although implementing NAFORMA appeared a simple technical issue on the surface, the appropriate field methodologies to be used were fiercely contested (Interview T13,T17,T19), mainly by a national consultant on the one hand, and the FAO Technical Team on the other (Interview T9,T17,T19). Disagreement focused on the most suitable sampling designs and plot layout, given the available human and technological resources. Interviewees indicated that the FAO Team had advocated for the conventional FAO National Forest Monitoring and Assessment (NFMA) sampling design and methodologies (Interview T9,T13,T17,T19,T20). In this NFMA method, sampling plots are systematically located at the intersection of latitudes and longitudes, with stratification conducted on basis of known strata areas (for details on NFMA see Tomppo and Andersson, 2008; Tomppo and Katila, 2008). However, the local consultant argued the NFMA sampling design was not suitable for Tanzania conditions and the purposes of NAFORMA (Interview T9,T13,T17,T19,T20). He specifically argued that the NFMA sampling design would not be the most cost-efficient methodology for estimating forest biophysical parameters compared to other alternatives (Interview T19). He also highlighted that national stakeholders had agreed that data from NAFORMA should be of a resolution that would produce sufficiently detailed information at the sub-national (district) level, and noted that the NFMA sampling design could not produce such detailed information. He proposed that the NFMA methodology be revised and adapted to meet local conditions and information needs, taking into account available resources (Interview T13,T17,T19,T20). Initially, the local consultant's proposal was very unpopular (Interview T17,T19), but he got a boost in these discussions when an international forest monitoring consultant not only voiced misgivings about the NFMA, but also supported this alternative proposal (Interview T19). This international consultant had previously reviewed and recommended changes to the classical NFMA methodologies (Tomppo and Andersson, 2008; Tomppo and Katila, 2008). To reinforce their argument, the two are reported to have organized a field visit to demonstrate why the NFMA sampling design would not be most efficient design for Tanzania (Interview T17,T19). As the parties could not resolve the methodological disagreements, 
the FAO commissioned a study (Tomppo et al., 2010c) to assess suitability of different methodologies and recommend a suitable one. Following the results of this study, the parties agreed to develop a tailored methodology (descrided in Tomppo et al., 2010c) for NAFORMA (Interview T17,T19). This tailored methodology and NAFORMA in general have been institutionalized through the newly establishment of a Forest Monitoring and Inventory Section at TFS (Interview T4,T13,T17,T20).

\subsubsection{Exclusionary and constraining MRV discourse in Peru}

In Peru, REDD+ processes, including discussions on MRV, began at the sub-national level as early as 2008. During this early period (2008-2011), the national government was not actively engaged in REDD+ in general and MRV specifically. The Ministry of Environment (abbreviated MINAM in Spanish) had chosen the so-called 'nested' approach to REDD+ (for a description see VCS, 2013), and supported development of REDD+ projects at the sub-national level (Piu and Menton, 2014a). Accordingly, early discussions on MRV took place mainly at the sub-national level under the auspices of the Regional REDD+ Roundtables (de la Plaza Esteban et al., 2014; Kowler and Larson, 2016). These Roundtables bring together regional governments, local/indigenous communities, REDD+ project developers and regional-level NGOs. It was not until late 2011 when MINAM started to take a lead role in REDD+ policy development. Since 2012 national level discussions on MRV have been taking place in three main forums. The first comprises the ad hoc discussions taking place in the so-called National REDD Group (CIF, 2013; RoP, 2011). However, all interviewees from regional governments and NGOs considered this Group rather small, in terms of the number and range of NGOs represented, which are mostly those operating in the capital Lima. The second arena where MRV is discussed is in meetings organized by MINAM's REDD+ Project. A quarter of the interviewees, however, consider this as a closed sectoral system that comprises technical experts of MINAM, and occasionally invitees from the National Forest Service (SERFOR) and the local office of the Amazon Cooperation Treaty Organization. A final forum where national discussions take place is in meetings organized by MINAM through the Inter-regional Amazonian Council (CIAM). However, according to interviewees (Interview P3,P11,P18,P20,P24,P27) and our own observations of these meetings, they are largely information and training sessions. All regional government and NGOs interviewees considered discussions organized by the REDD + Project, CIAM or the REDD Group as training and 
consultation sessions and not policy coordination processes. It can thus be concluded that until 2016 there was no national forum for discussing MRV in Peru.

Notwithstanding the lack of a national forum for coordinating MRV policy development, some ideas have been proposed that have generated conflicts among different stakeholders. The first concerns the appropriate level for forest monitoring for REDD+. MINAM has proposed a national forest monitoring system with sub-national verification (Kowler and Larson, 2016; RoP, 2014). However, $35 \%$ of the Peruvian interviewees noted that this proposal has been contested by regional governments, NGOs, REDD+ project developers and local/indigenous community organizations. Interviewees (Interview P1,P3,P6,P24) reported that these stakeholders have argued that they have already developed subnational and project (i.e. jurisdictional) level forest monitoring systems that should simply be 'nested' within the national MRV system. For them, sub-national forest monitoring systems are most suitable, given the unique forest conditions of the different regions and projects. $40 \%$ of the interviewees reported that the regional governments, NGOs, REDD+ project developers and local communities argue that they are closest to the forests, and should therefore be fully involved in forest monitoring for REDD+. Specifically, interviewees from the regional governments of Madre de Dios and San Martin argued that they are already well-advanced in developing their 'jurisdictional' MRV systems that they cannot simply abandon and adopt the national one (Interview P3,P6,P24). To date, the stakeholders are yet to agree on the appropriate level for forest monitoring.

The second issue concerns the role of the different actors in MRV. As mentioned, MINAM has proposed a 'verification' role for regional governments, NGOs and REDD+ project developers (RoP, 2014). However, $80 \%$ of the interviewees reported that these stakeholders have contested this proposal. These actors argue that they are better placed to monitor the conditions of forest in their respective jurisdictions (Interview P3,P11,P18,P20,P24,P27). Some interviewees reported that the regional governments are particularly concerned that the numbers generated by the national government may be too low, resulting in very small if any emissions reductions, since the methodologies developed at the national level are not as detailed and region-specific (Interview P3,P6,P24). They fear this would lower REDD+ payments, and therefore they prefer to have a hand in how MRV is conducted. Indigenous community organizations, however, are reported to 
have protested against any attempts that aim to value forests for their carbon (Interview $\mathrm{P} 1, \mathrm{P} 11, \mathrm{P} 14, \mathrm{P} 22)$. Instead, they argue for considering the totality of environmental, social and economic functions of forests. Still, some actors within MINAM have contested even the limited 'verification' role allocated to regional governments, NGOs and indigenous community organizations (Interview P1,P5). These actors have argued that 'field verification' is not needed as 'validation' can easily and efficiently be done using high-resolution satellite images (Interview $\mathrm{P} 1, \mathrm{P} 4, \mathrm{P} 5)$. To date, the stakeholders are yet to agree on the role of regional governments, NGOs, REDD+ projects and local communities in MRV vis-à-vis that of the national government.

The last point of conflict concerns the appropriate methods for forest monitoring. This methodological conflict is mainly between the national government, specifically MINAM's REDD+ project and the regional governments (Interview P1,P16,P30). As noted, some regional governments had started developing sub-national MRV systems as early as 2008, when the national government was not active on REDD+. These regions, specifically Madre de Dios and San Martin had invested resources, and, with the blessings of MINAM (Kowler and Larson, 2016), developed methodologies for establishing forest reference levels and for MRV. Later, in 2011, however, MINAM started to develop a national MRV system, including methodologies for developing reference levels and forest monitoring. These national methodologies are different from those already developed by the regional governments (Interview P1,P16,P30). Regional governments argue that their methodologies and datasets are of higher quality than those of the national government, and that their land-cover maps reflect the diverse vegetation types more accurately (Interview P3,P6,P24). It was reported that due to discrepancies in the methodologies used, regional governments are particularly concerned that adopting national methodologies and datasets might have adverse effects on their carbon emissions and ultimately payments (Interview P1,P3,P6,P16,P24,P30). As such, they are not willing to accept data generated at the national level. MINAM, on the other hand, argues that as the national authority, it has the duty to develop methodologies to be used for forest monitoring to ensure comparability and consistency of methods as required under the UNFCCC (Interview P4,P4,P16,P30). CIAM has organized three meetings for the stakeholders to discuss and consolidate the two methodologies (Interview P16,P30). However, these meetings have not produced any positive results. According to interviews with NGOs, regional governments and MINAM, discussions on how to reconcile 
regional and national datasets remain a challenge. Although the region of San Martin has agreed to align their methodologies with those of the national government (Interview P24), others, such as Loreto, have adopted a 'wait and see' attitude (Interview P18,P20,P25,P27), while Madre de Dios has remained resistant (Interview P3,P6). Interviews with MINAM, regional governments and NGOs showed that these methodological disagreements have stalled progress in negotiations about how to implement MRV in Peru. Regional government interviewees observed that the situation has been made worse by MINAM's 'unilateral' decision to insist on nationally-generated data for MRV (Interview P3,P6,P24). This decision, as Kowler and Larson (2016) reported, has upset and disenfranchised the regional governments, NGOs and REDD+ project developers, leading to a breakdown in negotiations.

\subsection{Discussion and conclusion: the relevance of discourse}

This paper aimed to examine the actors involved in MRV policy development in Indonesia, Peru and Tanzania, and the ideas they introduced or contested; and how the argumentation and contestation inherent in the discussions enabled or constrained institutionalization of MRV. Findings show that several actors were involved and introduced different and often conflicting ideas in MRV policy discussions in all three countries. In Indonesia, stakeholders had different ideas on the appropriate methods for forest monitoring and the best strategy to implement MRV. Despite the differences, however, MRV has been institutionalized in Indonesia through the establishment of the Directorate of GHG Inventory and MRV, strengthening of the existing Directorate of Forest Resource Inventory and Monitoring, and through the adoption of INCAS and methodologies and datasets of the Directorate Forest Resources Inventory and Monitoring. Similarly, in Tanzania, although stakeholders had different ideas on the appropriate methods to implement NAFORMA and where the NCMC should be hosted, MRV has been institutionalized through the establishment of the NCMC at SUA, and a Forest Monitoring and Inventory Section at TFS. In Peru, by contrast, no strategies have been developed to implement MRV. Although MINAM has proposed an institutional architecture for implementing MRV, this has not been operationalized as stakeholders are yet to agree on the level, methods and the roles of different actors in MRV.

So, does discourse matter in institutionalization? The further institutionalization of MRV in Indonesia and Tanzania as compared to Peru suggests that discourse indeed does matter. In both 
Indonesia and Tanzania, the discursive process enabled institutionalization of MRV in two ways. First, in both countries, there were national forums dedicated to discussing MRV, which enabled a variety of actors representing different REDD+ stakeholders to engage in MRV policy development. In Peru, by contrast, there has not been a national forum dedicated to deliberating MRV. The three existing national-level forums (see 4.3) began only recently, and have not been as inclusive. With a lack of space for stakeholders to organize themselves into a coordinative MRV discourse, exchange, deliberation and contestation (discursive politics!) has largely been absent in Peru.

Also, in both Indonesia and Peru, the discursive process enabled the stakeholders to 'agree to disagree' and make compromises on the methodologies and strategies to implement MRV. While policy actors in all countries agreed that existing institutions for forest monitoring were inadequate and new ones were needed, only in Indonesia and Tanzania have the stakeholders agreed on the strategies to implement MRV. In both countries, the methods and strategies to implement MRV were contentious, with different policy actors and coalitions proposing different ideas. However, the discursive process in both countries allowed the stakeholders to forge common ground on issues of conflict. Also, stakeholders in these countries were often willing to consider the ideas of their opponents, and soften their own position whenever their opponents' ideas proved convincing. By contrast in Peru, stakeholders have not been able to agree on the appropriate methods and levels for forest monitoring, and the role of the different actors. This had made 'agreeing to disagree' on strategies to implement MRV problematic.

Although the discursive processes in Indonesia and Tanzania were largely enabling, the compromises leading to institutionalization of MRV in both countries were also achieved because of strong argumentation for particular policy proposals. For example, the need to adopt a countryspecific methodology for NAFORMA in Tanzania was accepted only because the actors were convinced by the arguments of those who proposed the idea. Similarly, in Indonesia, INCAS was adopted because actors were convinced that its methodologies were more robust compared to those used by the former Ministry of Forestry. These cases lend credence to the proposition that ‘communicative action' (Habermas, 1994, 1996, 2006) and ‘argumentative rationality’ (Risse, 2000) are powerful characteristics of reaching political agreement. The two cases also affirm 
Mehta's assertion that a given idea can become policy simply because of its properties, including the property that Hall (1989) refers to as 'policy viability'; i.e. the ability of the policy idea to solve given policy problems. In Peru, by contrast, the conflicting parties have not been willing to listen and consider the merits of their rival's ideas and counter arguments. This is partly due to a lack of a forum to discuss MRV that would enable the actors to consider the views of one another.

The Tanzanian case demonstrates the usefulness of (independent) studies in depoliticizing ideas and unlocking political gridlock in policy discussions. In many policy processes, 'science' is often called upon to demystify political conflict. This is exactly what happened in Tanzania. When conflicting parties held to their ideas on the appropriate methods for NAFORMA and where the NCMC should be hosted, the disagreements were resolved through independent reports. This observation exemplifies the role of independent studies in enhancing 'political viability' (Hall, 1989) of a policy idea. However, as Mehta (2011) observes, the 'political viability' of an idea can also be enhanced by increasing the number of stakeholders backing that particular idea in policy discussions. The Indonesian case demonstrates how the number and power of stakeholders backing a given idea can lead to its institutionalization. As shown in 4.2, seemingly conflicting ideas have simultaneously been institutionalized. The simultaneous institutionalization of these ideas can be explained by the relative power of their proponents and the number of actors backing them. The lack of institutionalization of MRV in Peru is conversely due to the large number of stakeholders resisting the proposed institutional architecture, which has limited its legitimacy (Kowler and Larson, 2016).

Our study also confirms that deliberations on policy ideas involves consideration of the administrative and cost viability (Hall, 1989; Mehta, 2011). In Indonesia and Tanzania, stakeholders also considered and debated the administrative and financial viability of proposed policy solutions. In Tanzania, stakeholders abandoned the idea of establishing the NCMC as a stand-alone agency because of concerns over its financial sustainability. In Indonesia, key policy actors argued that the Directorate of Forest Planning and Environmental Management already has the man-power and budget for its forest resource inventory and monitoring section, and that it is more sustainable to use this existing system than to invent new ones. However, contrary to assertion that only discussions on policy ideas are wrought with considerations of administrative 
and cost viability, the Tanzania case demonstrate that discussions on programmatic ideas can also be subjected to administrative and cost considerations. As mentioned, one of the issues on which the NFMA methodology and that proposed by the local consultant were evaluated was their relative cost-efficiency (Tomppo et al., 2010b).

The literature on policy ideas asserts that most politics is played at the level of programmatic ideas (Kingdon, 2003; Mehta, 2011); i.e. about what the problem is, what methods are to be used, and which actors should be involved. Our findings suggest that when policy actors are able to overcome conflicts over programmatic ideas, developing strategies to address given policy problems may become easier. This implies that stakeholders involved in MRV policy construction could be successful in pushing for reforms if they can first develop consensus on the policy problem that MRV should address, the goals it should achieve, methods to use, and which actors to be involved, before moving on to consider the strategies to implement MRV.

Overall, our study attests that MRV is in essence political - it can no longer be maintained that MRV presents only a technical challenge. As long as the carbon figures generated through MRV will have different impacts for different actors, discussions on the methods to be used, the actors to be involved, etc. will be subject to political contestation. This has implications for current (inter)national debates on REDD+ MRV. For one, discussion on MRV especially at the UNFCCC and within multilateral donor agencies focus mainly on developing guidelines for high-tech methods for monitoring forest carbon and technical capacity building (Gupta et al., 2014). Although such high-tech methods and capacity development are certainly needed, our findings urge national stakeholders and donors involved in developing MRV systems to also invest in mediating potential conflicts on the methods, the actors to be involved in, and best strategies to implement MRV. This is especially necessary if the resulting strategies to implement MRV, including the high-tech methodologies, are to be regarded as legitimate and can enjoy the support of all REDD+ stakeholders in a country. 
Chapter 6 - Conclusions and Reflections 


\subsection{Introduction}

As argued in Chapter 1, the UNFCCC and its decisions on REDD+ MRV constitute an international institution. Moreover, discussions within the UNFCCC on REDD+ MRV constitute a new discourse on forest monitoring in developing countries. This discourse has introduced new ideas on the scope and objectives of forest monitoring, the actors to be involved and resources to be used, and the rules governing forest monitoring. I argued in Chapter 1 that taken together, the emergence of this discourse and associated ideas call for change in the institutional arrangements for forest monitoring in developing countries. I argued, furthermore, that translating such ideas into national institutional arrangements involves argumentation and contestation among national stakeholders over the goals that a national REDD+ MRV system should achieve, the actors to be involved and methods to be used, and the best strategies to implement MRV. These essentially constitute what I labelled discursive politics, with strong implications for assessment of the actual outcomes and impact of REDD+, since what is assessed is what is counted (Cameron, 1963), which inevitably raises the question of 'who' counts and 'how'. Thus, the institutionalisation of what is monitored, how it is monitored and by whom affect what becomes visible at the outcome stage of a particular policy, in this case REDD+.

The objectives of this dissertation have been three-fold: To examine (1) the institutional effectiveness of REDD+ MRV; (2) how the concept of REDD+ MRV and associated ideas have materialized in new institutional arrangements for forest monitoring in developing countries; and (3) how discursive processes of policymaking and the argumentation and contestation inherent in such processes enable or constrain institutionalization of MRV in developing countries. To achieve these three objectives, four research questions were formulated.

1. What is the institutional effectiveness of REDD+ MRV in terms of its implementation in developing countries?

2. How have institutional arrangements for forest monitoring in Peru evolved, and how and to what extent has their evolution been shaped by international discourses on forests, especially REDD+ MRV?

3. How and to what extent has the concept of MRV become institutionalized in new or reformed institutional arrangements for forest monitoring in Indonesia, Peru and Tanzania, 
and how can differences in this extent of institutionalization across the countries be explained?

4. How has discursive politics enabled or constrained institutionalization of MRV in Indonesia, Peru and Tanzania?

This final chapter contains the conclusions of and reflection on the dissertation as a whole. It is organized into nine sections. Sections 6.2-6.5 draw on the empirical chapters to answer the research questions. Section 6.6 reflects on the empirical findings and conclusions of the study. Section 6.7 reflects on the theoretical framework while section 6.8 reflects on the study methods. Section 6.9 ends by outlining policy recommendations.

\subsection{Varying institutional effectiveness of REDD+ MRV across 13 countries}

The first research question dealt with the institutional effectiveness of REDD+ MRV. This question was addressed in Chapter 2. The chapter built on Young and Levy's (1999) framework for assessing effectiveness of international institutions. Based on this framework, and drawing on the IPCC's methodological guidance and good practice guidelines for forest monitoring, and good governance literature, three dimensions along which the institutional effectiveness of REDD+ MRV can be evaluated were developed. The 'Ownership of technical methods' dimension examined REDD+ countries' progress in acquiring technical methods to conduct MRV. The 'Administrative capacity' dimension evaluated countries' progress in developing the capacity to administer MRV system, and the 'Good governance' dimension examined REDD+ countries' progress in integrating principles of 'good' governance - namely participation, transparency, accountability and coordination, in their MRV systems.

The results showed that 10 of the 13 studied countries have moderate to very high 'ownership of technical methods' for MRV (Table 6.1). That is to say, these 10 countries have acquired remote sensing (RS) data, have either implemented or are in the process of implementing National Forest Inventories (NFIs), and plan to monitor most if not all forests. However, as others have also reported (Romijn et al 2012; Romijn et al 2015), this study confirmed that progress in 'owning technical methods' for MRV is constrained by the fact that the vast majority of the countries are yet to develop higher-tier Emission Factors (EF) (Chapter 2). This can be attributed to the high initial costs and poor access to technologies for developing such higher-tier EF (Böttcher et al., 
2009; Hardcastle and Baird, 2008). Another explanatory factor is the decline in state funding and official development assistance to the forestry sector over the years (see Dobransky, 2014; Humphreys, 2006; Humphreys, 2014), which has meant that most countries do not have the budget to conduct routine forest inventories that would enable then develop such higher-tier EFs.

Table 6.1: Summary of countries' institutional effectiveness ${ }^{5}$

\begin{tabular}{|c|c|c|c|c|}
\hline \multirow{2}{*}{$\begin{array}{l}\text { Level of } \\
\text { Effectiveness }\end{array}$} & \multicolumn{3}{|c|}{ Dimension of institutional effectiveness } & \multirow{2}{*}{$\begin{array}{l}\text { Overall } \\
\text { institutional } \\
\text { effectiveness }\end{array}$} \\
\hline & $\begin{array}{l}\text { Ownership of } \\
\text { methods }\end{array}$ & $\begin{array}{l}\text { Administrative } \\
\text { capacity }\end{array}$ & Good governance & \\
\hline Very high & $\begin{array}{l}\text { Bolivia, Brazil, } \\
\text { Indonesia, Vietnam }\end{array}$ & $\begin{array}{l}\text { Brazil, DRC, } \\
\text { Indonesia }\end{array}$ & Brazil & Brazil \\
\hline High & $\begin{array}{l}\text { B. Faso, Cameroon, } \\
\text { Laos }\end{array}$ & $\begin{array}{l}\text { Bolivia, Peru, } \\
\text { Vietnam }\end{array}$ & $\begin{array}{l}\text { Peru, DRC, } \\
\text { Indonesia, Vietnam }\end{array}$ & $\begin{array}{l}\text { DRC, Indonesia, } \\
\text { Vietnam }\end{array}$ \\
\hline Moderate & $\begin{array}{l}\text { Peru, DRC, } \\
\text { Mozambique }\end{array}$ & $\begin{array}{l}\text { B. Faso, Cameroon, } \\
\text { Tanzania, }\end{array}$ & $\begin{array}{l}\text { Bolivia, Cameroon, } \\
\text { Mozambique, } \\
\text { Tanzania, Nepal, } \\
\text { PNG }\end{array}$ & $\begin{array}{l}\text { Bolivia, Peru, } \\
\text { Cameroon, } \\
\text { Tanzania }\end{array}$ \\
\hline Low & $\begin{array}{l}\text { Tanzania, Nepal, } \\
\text { PNG }\end{array}$ & $\begin{array}{l}\text { Mozambique, Laos, } \\
\text { Nepal, PNG }\end{array}$ & B. Faso, Laos & $\begin{array}{l}\text { B. Faso, } \\
\text { Mozambique, } \\
\text { Laos, Nepal, PNG }\end{array}$ \\
\hline
\end{tabular}

Only Brazil, DRC and Indonesia scored very high on 'administrative capacity' while the rest of the studied countries scored low to high. Specifically, the evidence showed that while the majority of the countries has put in place the technical and data infrastructure to implement MRV, they are yet to build sufficient human capacity to administer this infrastructure. With the exception of Brazil and Indonesia, the studied countries also have not developed mechanisms to link REDD+ MRV with other GHG monitoring systems. However, the majority of the countries has developed strategic partnerships that could enable them to build technical and administrative capacity for forest monitoring going forward. Except for Brazil, none of the studied countries have integrated aspects of 'good governance' into their MRV systems. This suggests that fundamental governance issues such as participation, transparency, accountability and coordination are yet to be built into national MRV systems of the majority of the REDD+ countries. Overall, the 13 countries performed better in 'ownership of technical methods' and 'administrative capacity', compared to 'good governance'.

\footnotetext{
${ }^{5}$ The methodology for calculating the overall institutional effectiveness of REDD+ MRV is explained in Chapter 2.
} 
The observation that the majority of REDD+ countries score at least 'moderate' on ownership of technical methods is in itself not surprising. Most REDD+ countries have invested heavily in building technical capacity to conduct MRV (see e.g. Joseph et al., 2013b; Minang et al., 2014; Romijn et al., 2015). This investment has been facilitated by technical and infrastructural support from bilateral and multi-lateral initiatives. This study thus confirms that these donor investments in development of technical capacity and data infrastructure have paid off in boosting countries' technical capacity to implement REDD+ MRV. However, it is surprising that despite the heavy technical support and capacity building that have been undertaken over the last years (Romijn et al., 2012; Romijn et al., 2015), many of the countries are yet to develop the capacity to administer MRV. One explanation for this may be the fact that expertise for forest monitoring in most REDD+ countries remains spread across different agencies of the government. This situation is exacerbated by the limited coordination of MRV activities in the studied countries. The other explanation is the high turnover of qualified personnel, which has led to a loss of institutional memory, e.g. in the case of Tanzania (see also Chapter 3). The low score on 'good governance' suggests that countries are paying 'lip service' to governance reforms. Yet, as many commentators (KorhonenKurki et al., 2013; Korhonen-Kurki et al., 2014; Loft et al., 2016; Lövbrand and Stripple, 2011) have noted, implementing governance reforms - including ensuring good governance in MRV are most critical for the success of REDD+.

\subsection{Shallow institutionalization of REDD + MRV in Peru}

Given the varied institutional effectiveness of REDD+ MRV across the 13 countries (Chapter 2), the second research question dealt with how the concept of REDD+ MRV and other international discourses have shaped institutional arrangements for forest monitoring in developing countries. This question was addressed in Chapter 3. Chapter 3 sought to develop a detailed understanding of how various international processes, and more recently REDD+ MRV, have shaped institutional arrangements for forest monitoring in developing countries, using Peru as a case study. The chapter documented three distinct international discourses - (1) productivist forest, (2) sustainable forest management and multiple-use forest philosophies and (3) REDD+ MRV - that have shaped forest monitoring in Peru. The Chapter used Discursive Institutionalism (Schmidt, 2008; Schmidt, 2010) to conceptualize REDD+ MRV as constituting a new discourse and ideas on forest monitoring in developing countries, and the Policy Arrangement Approach (PAA) (Arts and van Tatenhove, 2006) to operationalize institutional arrangements as comprising policy discourses, actors, 
resources and rules. Thus operationalized, the Chapter built on the distinction by Wiering and Arts (2006) between 'shallow' and 'deep' institutional change to gauge the extent to which each discourse affected national institutional arrangements. 'Shallow' institutional change refers to change in policy discourse only, while 'deep' institutional change refers to change in policy discourses, actor constellations, resources and rules. Thus, the chapter examined whether and how each of previously mentioned discourses changed national policy discourses on forest monitoring, the actors involved and resources used, as well as rules governing forest assessments.

Results showed that while forest monitoring in Peru has been shaped by international discourses, these discourses have not led to deep institutionalization of forest monitoring (Table 6.2). Between 1950s and early 1980s, forest management in Peru was primarily aimed at timber production. In line with this productivist forest philosophy, the scope and objective of forest monitoring was limited to timber stock assessments. Moreover, such forest assessments were conducted on an ad hoc basis only, and involved only a few governmental agencies. Although concessionaires had a role in forest monitoring, their activities were restricted to census of commercial species within their concession. Resources for forest assessments were limited, with only traditional forest mensuration tools being used. Furthermore, regular forest monitoring was not codified in any law. This situation changed in 1975 when a new forest law was enacted. However, the new law only provided for inventories of commercial species in concessions. Moreover, this attempt to institutionalize commercial forest inventories did not materialize as concessionaires often failed to conduct inventories. As such, forest monitoring was only 'shallowly' institutionalized during this period. 
Table 6.2: Depth of institutional change instigated by different international discourses on forests

\begin{tabular}{|l|l|l|}
\hline Period & Discourse & Depth of institutional change \\
\hline 1950 --early 1980s & Productivist forest philosophy & Shallow \\
\hline 1980s-early 2000s & $\begin{array}{l}\text { Sustainable forest management; multiple-use } \\
\text { forest philosophies }\end{array}$ & Shallow \\
\hline 2005-onwards & REDD+ MRV & Shallow \\
\hline
\end{tabular}

The emergence of the 'sustainable forest management' and 'multiple-use' forest philosophies from the 1980s onwards led to a broadened scope of forest monitoring. Forest assessments now included assessment of growing stock, forest area changes, other products and services of forests, forest biodiversity and carbon stores. New strategies were developed, including formation of new agencies and multi-sectoral committees. This resulted in a broadening of actors involved in forest assessments to include NGOs, local and indigenous communities, as well as inter-governmental agencies such as the FAO. The broadened scope also called for the use of more advanced technologies, and Peru acquired new tools for forest assessments and invested in human capacity development. A new forest law was formulated in 2000 that affirmed the role of concessionaires in forest assessments. However, it remained silent on forest assessments outside concessions and did not clarify the roles of other actors. Furthermore, just as in the previous period, the concessionaires often failed to conduct inventories. As such, forest monitoring was only 'shallowly' institutionalized, also during this second period.

Since 2005, REDD+ and MRV have become dominant in forest and climate change discussions in Peru. This has renewed the focus of forest monitoring on assessments of forest cover change and associated carbon emissions. To realize this objective, a strategy that includes development of new agencies and legislation has been developed. New and additional resources, including highresolution satellite images and technologies for image analysis, have been mobilized. The strategy also envisages establishment of new agencies to enable different governmental and nongovernmental actors to engage in forest monitoring for REDD+ (see also Chapter 3). A draft national action plan for forest monitoring has been developed, which outlines the agencies that will be established to engage in forest monitoring, and their specific roles. Also, a new forest law that provides for periodic nation-wide forest assessments, and that recognizes the roles of different actors, has been enacted. However, it is too early to conclude that REDD+ MRV has caused 'deep' change in institutional arrangements for forest monitoring in Peru. For one, none of the agencies through which the envisaged new actors will engage in forest assessments have been established. 
Secondly, the draft national action plan for forest monitoring, which explicitly provides for assessments of forest carbon stocks and their changes, is yet to be formally adopted. It can thus be concluded that REDD+ MRV has only caused 'shallow' discursive institutional change in forest monitoring in Peru.

\subsection{Varying degrees of institutionalization of MRV in Indonesia, Peru and Tanzania}

The third research question dealt with how institutionalization of REDD+ MRV compares across different developing countries. This question was addressed in Chapter 4. Using Discursive Institutionalism and the Policy Arrangement Approach (see 6.3 above), the chapter specifically examined how and to what extent REDD + MRV as a discourse and set of ideas has materialized in new or reformed institutional arrangements for forest monitoring in Indonesia, Peru and Tanzania. In order to compare the extent of institutionalization of REDD+ MRV across the three countries, the chapter refined the Wiering and Arts (2006) framework (as presented in section 6.3 and Chapters 3 and 4), and developed a qualitative evaluation framework that distinguishes four levels of institutionalization. 'Shallow' institutionalization refers to materialization of REDD+ MRV in new or revised aims and strategies. 'Shallow-intermediate' institutionalization refers to materialization in new or revised aims and strategies, and mobilization of new actors or resources. 'Intermediate-deep' refers to materialization in new or revised aims and strategies, mobilization of new actors, and additional resources, and 'deep' institutionalization refers to materialization in new or revised aims and strategies, mobilization of new actors and additional resources, as well as enactment of new rules.

Results showed that institutionalization of REDD+ MRV varies across the countries, with Indonesia experiencing 'deep' institutionalization, Tanzania 'intermediate-deep' and Peru 'shallow-intermediate' (Table 6.3). There is discursive change in all countries, with each country having revised the scope and aims of forest assessments to include measurement of forest carbon stocks and their changes for possible result-based REDD+ payments (Chapter 4). However, although all three countries have developed new strategies to implement REDD + , in Peru some of these strategies are yet to be implemented. For example, the national forest inventory is not yet complete and the agencies envisaged to conduct REDD+ MRV have not yet been established (Chapter 3 and 4, see also Kowler and Larson, 2016). All countries have also mobilized and trained new actors to engage in forest monitoring for REDD+. These include state actors from within and 
beyond the forestry sector, regional government agencies, research organizations and academia, NGOs and indigenous and local community organizations. However, only in Indonesia and Tanzania have the agencies through which these actors will engage in REDD+ MRV been established.

Table 6.3: Summary of extent of institutionalization of REDD+ MRV in Indonesia, Peru and Tanzania

\begin{tabular}{|c|c|c|c|}
\hline \multirow[t]{2}{*}{ Dimensions of institutionalization } & \multicolumn{3}{|l|}{ Country } \\
\hline & Indonesia & Peru & Tanzania \\
\hline $\begin{array}{l}\text { Aims and scope of forest assessments } \\
\text { revised, and new strategies developed }\end{array}$ & Yes & $\begin{array}{l}\text { Yes, but some strategies (e.g. } \\
\text { NFI) not yet completed }\end{array}$ & Yes \\
\hline New actors mobilized & Yes & $\begin{array}{l}\text { Yes, but agencies through which } \\
\text { new actors are to be engaged in } \\
\text { REDD+ MRV not yet } \\
\text { established }\end{array}$ & Yes \\
\hline Additional resources mobilized & Yes & Yes & Yes \\
\hline $\begin{array}{l}\text { New rules enacted to anchor forest } \\
\text { monitoring and REDD+ MRV in law }\end{array}$ & Yes & $\begin{array}{l}\text { Yes, but the national action plan } \\
\text { for forest monitoring is yet to be } \\
\text { adopted }\end{array}$ & $\begin{array}{l}\text { No, though NCMC } \\
\text { has been formalized } \\
\text { through MoUs }\end{array}$ \\
\hline Extent of institutionalization & Deep & Shallow-intermediate & Intermediate-deep \\
\hline
\end{tabular}

All three countries have mobilized new and additional resources for forest monitoring. As shown in Chapters 2-4, all countries have acquired new technologies and hardware for forest monitoring. Similarly, all countries have trained actors on technologies for forest carbon assessments. To further institutionalize forest assessments in general and REDD+ MRV in particular, Indonesia and Peru have both developed new legislation and procedures that codify forest assessments, and the role of the different actors, in law. In Tanzania, however, no legislation has been developed to anchor forest monitoring in law. Although the National Carbon Monitoring Centre (NCMC, see Chapter 4) project documents outline the roles of different actors in REDD+ MRV, the Centre is yet to be anchored in any legislation. A similar situation exists in Peru (see also Chapter 3).

To explain these observed differences in institutionalization of REDD+ MRV across the three countries, I examined the enabling factors for discourse institutionalization and their manifestation in each country (Chapter 4). The five theoretical factors for discourse institutionalization as condensed by Buijs et al. (2014) are: (a) the new discourse and ideas are 'timely' and 'topical', and resonate with a larger audience; (b) they are credible and coherent to this audience; (c) they are advocated by authoritative agents; (d) they transcend the language of specific individuals or organizations; and (e) the legitimacy of existing discourses, and related institutions are under pressure (see Buijs et al., 2014 and Chapter 4 for a detailed exposition ). 
Results showed that all five factors were present in Indonesia and Tanzania, where there was 'deep' and 'intermediate-deep' institutionalization of REDD+ MRV, respectively (Table 6.4). In Peru, however, only one factor - the legitimacy of existing discourses and related institutions are under pressure - was present. In both Indonesia and Tanzania, MRV has been a topical national REDD+ policy issue since 2008. Stakeholders in both countries have been concerned with how to monitor and report on their emission reductions. In Peru, however, although MRV has been a topical issue at the regional level, it was not until 2012 that it became a topical REDD+ policy issue at the national level (see also Chapter 5). In Indonesia and Tanzania, moreover, MRV and the ideas proposed to implement it have been credible and coherent to all national stakeholders. This has not been the case in Peru. As shown in Chapter 4, for example, the idea of involving regional governments, NGOs and local communities has not been appealing to the Ministry of Environment. Vice versa, the strategy proposed by the Ministry to implement MRV has not resonated with the latter group (cf. Robiglio et al., 2014).

In addition, strategies to implement MRV have been promoted by authoritative and influential national actors in both Indonesia and Tanzania. In Tanzania, for example, the establishment of the NCMC was advocated by authoritative national actors, such as the Department of Environment of the Vice President's Office (VPO-DoE), the Tanzania Forest Service (TFS), Norwegian Embassy, and several influential NGOs. In Indonesia, similarly, strategies to implement GHG inventories and REDD+ MRV were advocated by authoritative actors such as the National Planning Agency and the REDD+ Agency. Here, the President promoted formulation of new legislation to anchor GHG inventories in general and MRV in particular in law. Examples include the Presidential Regulation on Greenhouse Gas Inventories and the MoEF Regulation that established the DG of Climate Change and the Directorate of GHG Inventory and MRV (see Chapter 4). This Presidential involvement can explain why there is 'deep' institutionalization in Indonesia and only 'intermediate-deep' in Tanzania. As noted above, no legislation has been developed to anchor forest monitoring and REDD+ MRV in law in Tanzania. In Peru, by contrast, the strategies to implement MRV have been contested by authoritative actors, such as the regional governments and several influential indigenous community organizations (see also Chapter 3). 
Also, in both Indonesia and Tanzania, MRV has been represented as an activity that requires involvement of both governmental and non-governmental agencies. Thus both governmental and non-governmental actors have been involved in MRV deliberations, suggesting that MRV has transcended the sphere of any specific actor in both countries. In Peru, however, MRV has been represented as a technical issue that can be discussed by only experts and in national discussions restricted to a small group of experts (see also Kowler and Larson 2016). In all three countries, however, existing discourses on forest assessments and related institutional arrangements have been under pressure. Thus, the more 'deep' institutionalization of REDD+ MRV in Indonesia and Tanzania, as compared to Peru, can be attributed to presence of the first four factors discussed above.

Table 6.4: Manifestation of enabling factors for discourse institutionalization across countries

\begin{tabular}{|c|c|c|c|}
\hline \multirow{2}{*}{$\begin{array}{l}\text { Factor for discourse } \\
\text { institutionalization }\end{array}$} & \multicolumn{3}{|c|}{ Manifestation per country } \\
\hline & Indonesia & Peru & Tanzania \\
\hline $\begin{array}{l}\text { MRV topical national REDD+ } \\
\text { policy issue }\end{array}$ & Yes, since 2008 & Not until after 2012 & Yes, since 2008 \\
\hline $\begin{array}{l}\text { MRV and associated ideas } \\
\text { credible to a larger audience }\end{array}$ & Yes & $\begin{array}{l}\text { The idea of engaging local } \\
\text { communities does not appeal to } \\
\text { MINAM }\end{array}$ & Yes \\
\hline $\begin{array}{l}\text { MRV, and strategies to } \\
\text { implement it, advocated by } \\
\text { authoritative actors }\end{array}$ & $\begin{array}{l}\text { Yes, including } \\
\text { high level } \\
\text { officials }\end{array}$ & $\begin{array}{l}\text { No, some authoritative actors contest } \\
\text { proposed strategies }\end{array}$ & $\begin{array}{l}\text { Yes, but by mostly } \\
\text { middle-level } \\
\text { officials }\end{array}$ \\
\hline $\begin{array}{l}\text { MRV presented as } \\
\text { transcending the sphere one } \\
\text { particular actor }\end{array}$ & Yes & $\begin{array}{l}\text { No, presented as activity that can be } \\
\text { discussed by technical experts only }\end{array}$ & Yes \\
\hline $\begin{array}{l}\text { Existing discourses and } \\
\text { institutions under pressure }\end{array}$ & Yes & Yes & Yes \\
\hline
\end{tabular}

\subsection{Discursive politics in MRV policymaking}

The fourth research question dealt with how the argumentation and contestation in the process of developing strategies to implement MRV has enabled or constrained its institutionalization. This question was dealt with in Chapter 5. Specifically, Chapter 5 deployed the concept of coordinative discourse (see Chapter 1, but also Schmidt, 2008; and Schmidt, 2010 for a detailed exposition) to examine the actors involved in REDD+ MRV policy discussions in Indonesia, Peru and Tanzania, the ideas they introduced or contested in these discussions, and how argumentation and contestation among them - in other words, discursive politics - enabled or constrained institutionalization. 
Results showed that in all three countries, stakeholders had different ideas on various aspects of MRV. Two issues were particularly contentious across all the countries (Table 6.5). First, in all countries, policy stakeholders had different ideas on the appropriate methodologies to deliver a technically robust MRV system (Chapter 5). In Indonesia, for example, while some stakeholders preferred developing new methodologies, datasets and algorithms - the so-called Indonesian National Carbon Accounting System (INCAS), others preferred using the methodologies and datasets of the existing Directorate of Forest Resource Inventory and Monitoring. In Peru, similarly, while the Ministry of Environment (MINAM) proposed use of methodologies and datasets developed at the national level, regional governments, NGOs and REDD+ project developers preferred region- and project-specific methodologies (see also Kowler and Larson, 2016). In Tanzania, too, stakeholders differed on the methodology to implement the National Forest Monitoring and Assessment (NAFORMA) that would provide baseline data for MRV. While the FAO technical team preferred use of the conventional National Forest Monitoring and Assessment methodology and sampling design, (inter)national consultants preferred a tailored methodology and sampling design that would reflect the unique conditions in Tanzania.

A second point of conflict across all countries concerned the best strategy to implement MRV. While some actors preferred establishing new agencies to take the lead on MRV, others preferred strengthening existing agencies. In Indonesia, for instance, some actors (e.g. the defunct REDD+ Agency, former Ministry of Environment, and the National Climate Change Council, among others) proposed the establishment of a new agency - the so-called MRV Institution - to oversee forest monitoring for REDD+. However, this idea was contested by other actors, who argued that a new agency would not deliver an efficient system, but would instead escalate existing interagency competition. These actors (especially the former Ministry of Forestry, and more recently the DGs of Climate Change and Forest Planning and Environmental Management, and NGOs) therefore preferred strengthening of existing agencies, especially the DG Forest Planning to take the lead on REDD+ MRV (Global Witness, 2011; Loft et al., 2016; NORAD, 2013). In Tanzania, while policy stakeholders agreed in principle that a new agency - the NCMC - should be established (see also Chapter 4), they had different ideas on where this agency should be hosted. In Peru, MINAM proposed an institutional infrastructure for MRV that would give it and the Forest Service (SERFOR) a lead role in national forest monitoring for REDD+. However, while this 
framework provides for the creation of several other peripheral agencies to enable actors such as regional governments, NGOs and indigenous communities to engage in the MRV process, these actors have contested this proposition. Instead, they advocate a system that would enable them to play an active role in forest monitoring, and not just in 'verifying' data generated by national government agencies. Because of this disagreement, the proposed infrastructure has not been adopted, as the latter group is not satisfied with the roles allocated to them, and prefers for forest monitoring to be conducted at the sub-national level (see also Chapter 3 and 4).

Table 6.5: Major points of conflict and their resolution

\begin{tabular}{|c|c|c|}
\hline Country & Points of conflict & Resolution \\
\hline \multirow[t]{2}{*}{ Indonesia } & $\begin{array}{l}\text { Whether to establish a new agency } \\
\text { (MRV Institution) or strengthen } \\
\text { existing Directorate of Forest Resource } \\
\text { Monitoring }\end{array}$ & $\begin{array}{l}\text { Common solution found } \\
\text { Stakeholders agreed that a new agency - } \\
\text { Directorate of GHG Inventory and MRV - be } \\
\text { established and the existing forest monitoring be } \\
\text { strengthened to provide forest inventory data }\end{array}$ \\
\hline & $\begin{array}{l}\text { Whether to develop a new methodology } \\
\text { (INCAS) or use existing methods and } \\
\text { datasets }\end{array}$ & $\begin{array}{l}\text { Common solution found } \\
\text { Policy stakeholders agreed that INCAS provides a } \\
\text { more robust system, but also agreed that DG Forest } \\
\text { Planning has generated large amount of data that } \\
\text { should be used }\end{array}$ \\
\hline \multirow[t]{2}{*}{ Peru } & $\begin{array}{l}\text { Whether MRV should be done using } \\
\text { nationally generated methods and data } \\
\text { sets or region- and project-specific } \\
\text { method and datasets }\end{array}$ & Not yet resolved \\
\hline & $\begin{array}{l}\text { Whether MRV should be implemented } \\
\text { by national level experts, with others } \\
\text { playing a verification role, or whether } \\
\text { MRV is to be conducted at the regional } \\
\text { level with active roles for regional } \\
\text { governments, NGOs, etc. }\end{array}$ & Not yet resolved \\
\hline \multirow[t]{2}{*}{ Tanzania } & $\begin{array}{l}\text { Whether to use conventional FAO } \\
\text { NFMA methodology for NAFORMA or } \\
\text { use a tailored methodology suited for } \\
\text { Tanzanian conditions }\end{array}$ & $\begin{array}{l}\text { Common solution found } \\
\text { Resolved through an independent study that } \\
\text { compared the merits of both proposals and } \\
\text { suggested the most suitable, namely an adapted } \\
\text { NFMA methodology }\end{array}$ \\
\hline & $\begin{array}{l}\text { Stakeholders agreed on the need to } \\
\text { establish NCMC, but differed on where } \\
\text { it should be hosted }\end{array}$ & $\begin{array}{l}\text { Common solution found } \\
\text { Resolved through a study that compared SUA and } \\
\text { IRA-UDSM, and recommended SUA as most } \\
\text { suitable }\end{array}$ \\
\hline
\end{tabular}

Despite the differences in ideas on appropriate methodologies, the actors to be involved and their roles and best strategies to implement MRV in Indonesia and Tanzania, the discursive process enabled the stakeholders to forge common ground on all issues of conflict. This has enabled institutionalization of MRV in both countries (see Chapters 4 and 5). In both of these countries, the discursive process enabled institutionalization in two ways. First, there were national forums 
dedicated to MRV policy coordination. In Indonesia, national discussions on MRV were conducted under the auspices of the REDD Task Force MRV Working Group, which enabled stakeholders representing different constituencies to engage in the MRV policy debate. In Tanzania, MRV policy discussions were conducted through the MRV Working Group, which brought together representatives from governmental agencies and non-governmental organizations. Second, in both countries, stakeholders were often willing to change their position whenever their opponents' points proved convincing. For instance in Indonesia, opponents of INCAS in the end agreed that despite their misgivings, INCAS provides a more robust system. However, the actors also agreed that the Directorate of Forest Planning has generated large volumes of data that cannot simply be discarded. Thus, both ideas have institutionalized (see Chapter 4). In Tanzania, the opponents were able to agree on the methodologies to implement NAFORMA and resolve conflicts on where the NCMC should be hosted.

In Peru, on the other hand, the actors have not been able to agree on the methods to implement MRV, the actors to be involved and their roles, and the best strategies to implement MRV (Chapter 5, see also Chapters 3 and 4). This is largely due to the less inclusive and less facilitative discursive process. This less inclusive and facilitative discourse has constrained institutionalization of MRV in two ways. First, until 2012, there were no national forums dedicated to MRV policy coordination. The forums that emerged after 2012 (see Chapter 4) have been less inclusive in terms of the variety and number of actors involved. This has meant that only a few actors from the national government have been involved in MRV discussions, something I have referred to as 'expert' discourse (Chapter 3). Second, with such a lack of inclusive national forums to coordinate MRV policy development, stakeholders have not been able to forge common ground on conflicting issues. Thus, stakeholders are still 'talking at each other' on the methodologies and strategies to implement MRV, instead of finding common solutions.

The 'deeper' institutionalization of MRV in Indonesia and Tanzania, compared to Peru, suggests that how discursive politics is conducted matters in institutionalization. Especially when discursive politics is inclusive, in terms of bringing together different stakeholders, and enabling, in terms of facilitating the actors to make compromises on conflicting issues, institutionalization is high. The findings also suggest that while in essence, MRV can be regarded as a technical activity, decisions 
on methodologies for forest monitoring for REDD+, the actors to be involved and their roles, and strategies to implement MRV are highly political, as others have also suggested (Gupta et al., 2012; Lovbrand and Stripple, 2011; Vijge, 2016). Lastly, the findings suggest that political conflicts over these issues can be resolved through an inclusive and enabling coordinative policy discourse, as was done in Indonesia and Tanzania.

\subsection{Empirical synthesis and reflections}

This study aimed to examine the institutional effectiveness of REDD+ MRV; how the concept of REDD+ MRV has materialized in new institutional arrangements for forest monitoring in developing countries; and how discursive politics enabled or constrained institutionalization. The findings showed that the majority $(60 \%$, Table 4$)$ of analysed REDD + countries has achieved at least a 'moderate' institutional effectiveness of MRV. This means that the majority of the analysed REDD + countries has started developing the data infrastructure and methodologies to implement MRV and the capacity to administer MRV. However, most of the countries have not made progress in integrating good governance principles in their MRV systems. The 'moderate' institutional effectiveness of REDD+ MRV in the majority of the countries was further confirmed by in-depth analysis of the performance of REDD+ MRV in Indonesia, Peru and Tanzania, which showed that institutionalization is at least 'shallow-intermediate' in Peru. Thus, from this study, it can be concluded that although institutional capacity to implement REDD+ MRV varies across countries, the majority of analysed REDD+ countries has built the technical and infrastructural capacity for forest monitoring in general, and REDD + MRV in particular. Further, it can also be concluded that REDD+ MRV has materialized in reformed institutional arrangements for forest monitoring in all the three studied countries, albeit to varying degrees.

The varying overall institutional effectiveness and institutionalization of REDD+ MRV has implications for debates on effectiveness of international environmental institutions, not in the least the UNFCCC. Most accounts of effectiveness of environmental institutions, especially the forest and climate regimes of which REDD+ is a part (Giessen, 2013; Humphreys, 2006; Rayner et al., 2010; Smouts, 2008), are mostly pessimistic (Dimitrov, 2006; Dimitrov, 2005; Dimitrov et al., 2007; Humphreys, 1996, 2006; Humphreys, 2014; Young, 1999a; Young, 2011). This pessimism about the potential of environmental regimes to address the deforestation and climate change problems is indeed understandable, given that the rate of global deforestation remains high 
(FAO, 2015) and that there is an increase in GHG emissions (IPCC, 2014). This limited effectiveness of forest and climate regimes can perhaps be attributed to two factors. The first is political economy and global trade and investment patterns, whereby developed country investments and investors fuel deforestation in the tropics (Anderson et al., 2016; De Sy, 2016; Hosonuma et al., 2012; Kanninen et al., 2007; Kissinger et al., 2012), while their governments engage in environmental agreements like REDD+. The second is a lack of political will on both developed and developing countries to tackle drivers of deforestation and the main cause of global warming.

However, with regard to REDD+ MRV, the findings of this study paint a somewhat different picture of the institutional effectiveness and institutionalization of international regimes, and the mechanisms through which they work at the national level. First, the findings suggest that international institutions do have effect, thereby confirming the conclusion of recent evaluations that environmental regimes do make a difference (Arts and Babili, 2013; Arts et al., 2016; Breitmeier et al., 2011; Young, 2011). Specifically, the findings of this study show that some developing countries do make an effort to implement the provisions of the agreements they sign. This is not to suggest that all countries strive to fully implement the agreements they sign. On the contrary, the varying institutional effectiveness of REDD+ MRV across the 13 studied countries suggests that some countries indeed struggle to implement international agreements. Lack of or inadequate technical and administrative capacity is one major reason why some countries struggle to implement the provisions of international agreements, as Brockhaus and Di Gregorio (2014) show in the case of Cameroon, for example.

Second, the empirical chapters (especially chapters 3-4) suggest that international regimes produce effect on the ground through a different working mechanism than predicted by the conventional top-down hierarchical model of assessing performance of global environmental governance. This hierarchical model is rooted in regime literature (Arts et al., 2016; Bernstein and Cashore, 2012; Breitmeier et al., 2011), and examines effectiveness of environmental regimes by looking at whether the contractual obligations of the regime are being adhered to by state parties (as done in Chapter 2), and whether its objectives (e.g. halting deforestation, reducing GHG emissions) are being realized. However, taking a discursive institutionalist perspective on the performance of 
international regimes - as applied in Chapters 3-5 - paints a different picture of how these agreements perform at the national level, and on the working mechanisms through which they shape national institutions and practices. This discursive institutionalist approach emphasises how ideas and discourses that emerge from the international level (UNFCCC COPs, etcetera), such as the concept of REDD+ MRV, travel to and influence national institutions (cf. Arts and Babili, 2013; Arts et al., 2016; Bernstein and Cashore, 2012; Turnhout et al., 2015).

At the national level, ideas and discourses from international regimes shape national institutions foremost by influencing national policy discourses (Chapters 3 and 4). As shown in Chapters 3-4, this takes places when existing aims and strategies are reviewed in light of the demands imposed by international agreements. This reformulation of aims and strategies may lead to mobilization of new actors and coalitions. This mobilization of new actors and coalitions may be done to bring in new or missing expertise and resources (Arts and Buizer, 2009; Bernstein and Cashore, 2012), to engage hitherto excluded actors, and/or to amass a broader coalition for reform against entrenched interests (Mehta, 2011; Schmidt, 2008; Schmidt, 2010). New and additional resources (including finance, technologies, skills, etcetera) may also be mobilized to implement the new or revised strategies and realize new policy aims. Such changes may be accompanied by revision of existing laws or development of entirely new sets of laws to formalize new aims and strategies and domesticate the provisions of the international agreements into national laws.

From this discursive institutionalist perspective, therefore, it is difficult to conclude that the forest and climate change regimes are failing or fading away, as some literature suggests in the case of REDD+ (Fletcher et al., 2016). Rather, it can be concluded that the forest and climate regimes have effect and perform in various ways at the national level. The empirical chapters showed that the scope and aims of forest monitoring have been revised to accommodate forest carbon stocks and their changes in all the three countries. New actors and coalitions and resources are being mobilized to build the technical capacity and data infrastructure to implement forest monitoring for REDD+. In Indonesia and Peru, new laws have been enacted to formalize regular forest assessments in general, and for REDD+ MRV in particular, in law. Chapter 2 also showed that all 13 analysed countries are taking steps to implement MRV. However, it is still too early to talk of absolute success (or effectiveness), since REDD + MRV is a relatively new policy, and because 
institutional effectiveness of REDD+ MRV is low in the majority of countries (Chapter 2), and the concept of MRV is yet to be 'deeply' institutionalized in Peru and Tanzania (Chapters 2-5). Thus, while there is change in institutional arrangements, and what could be considered technical improvements, there are also reasons to be sceptical, since many of these changes can be regarded as easy to implement, low hanging fruit for the countries, and all this progress might be related to the no-regret character of investments in MRV. And, although some might consider MRV the most neutral, no-regret investment, this study documents clearly the politics within MRV (Chapter 5, see also Chapter 3).

Third, as shown in Chapter 5, ideas and discourses from the international level do not start with a national clean slate, where they are simply implemented (see also Turnhout et al., 2015). Rather, when global discourses and ideas such as REDD+ MRV enter national policy arenas, they are (re)negotiated among a variety of national policy actors, with different and often conflicting interests. As shown in this study, national processes for developing policies to implement provisions of international agreements such as REDD+ MRV thus become sites of discursive politics and contestation. Here, stakeholders battle over what exactly is to be monitored, the methodologies to be used, the actors to be involved, and the best strategies to realize MRV. Thus, the study highlights that REDD+ MRV is indeed political. In particular, the methodologies to be used for MRV, the actors to be involved and their roles, and the appropriate strategies to implement MRV are decided through political negotiations. But the findings also suggest that the ensuing political conflict can be mediated through inclusive and enabling policy processes. The findings of this study thus suggest that those involved in REDD+ MRV development in particular, and REDD+ in general, need to embrace the politics, since politics can neither be ignored nor removed, but is present in all spheres of social life.

\subsection{Theoretical reflections}

I have used discursive institutionalism (DI) and the Policy Arrangement Approach (PAA) to study how ideas and discourses from the international level, such as REDD+ MRV, reshape and materialize in national institutional arrangements. In this section, I present five main theoretical reflections on how DI could be improved using the PAA, and how it can be used to enrich the latter. First, DI proved useful in conceptualizing REDD+ MRV as a discourse, and illuminating the ideas it represents. However, as I indicated in Chapter 1, there were problems in using DI to 
conceptualize and elaborate how discourses shape institutional arrangements. Although proponents of DI emphasize the constitutive role of ideas and discourses in politics, policymaking and institutional change (Hay, 2006; Schmidt, 2002, 2008), they hardly specify what exactly discourse institutionalization, institutionalization and institutional change entail. To address this lacuna, I used the Policy Arrangement Approach (PAA) to conceptualize institutionalization and institutional change.

The PAA was originally developed to conceptualize and study the substance and organization of specific policy domains. It does so by analysing how a given policy domain is shaped in terms of policy discourses, actors, resources, and rules (Arts and van Tatenhove, 2006; Liefferink, 2006a; Wiering and Arts, 2006). The analytical concepts of policy discourses, actors, resources and rules proved useful in conceptualizing national institutional arrangements, and what institutionalization and institutional change entail. Thus, these analytical concepts enabled me to analyse how REDD+ MRV has materialized in national institutional arrangements by (re)shaping national policy discourses (in terms of policy and programmatic ideas), the actors involved and resources used, as well as the rules governing forest assessments. The PAA can thus also be used in future analyses to conceptualize institutionalization and institutional change, and in analyses of how discourses and ideas from the international level shape national institutional arrangements (see also Arts, 2006; Arts and Buizer, 2009).

Second, although the PAA proved useful in operationalizing institutionalization, institutional change and institutional arrangements, it could not account for the political processes by which institutionalization and institutional change take place. While the PAA conceives of institutional change as triggered by the interplay of day-to-day interactions among actors on the one hand, and as the macro-processes of social and political change on the other, it fails to account for and illuminate the contestation and argumentation inherent in day-to-day interactions and macroprocesses of institutional change. Thus, to account for day-to-day interactions among policy actors and the discursive politics involved in developing strategies to implement REDD+ MRV, I drew on the concepts of coordinative policy and communicative political discourse as elucidated in DI. In particular, I deployed the concept of coordinative policy discourse to examine the actors involved in MRV policy development, the ideas they introduced or contested, and how 
argumentation and contestation among them enabled or constrained institutionalization (Chapter 5). With this, PAA enthusiasts can account for day-to-day interactions and macro-processes of political and institutional change, as constituted by discursive politics, and this discursive politics can further be specified as being constituted by coordinative policy and communicative political discourse, as elaborated in DI.

Third, the definition of 'substance' of policymaking as the 'dominant interpretative schemes, ranging from formal policy concepts and texts to popular story lines, by which meaning is given to a policy domain' (Arts and Tatenhove, 2004, p. 343), as defined in PAA, is limiting in the sense that it does not specify in detail what 'substance' is. Drawing on DI, PAA analysts can better specify the substance of politics and policymaking as constituted by policy, programmatic and philosophical ideas. In short, by adopting the double-faced conception of discourse - i.e. both as ideas and as the interactive processes by which these ideas are generated and exchanged during policymaking and public deliberations, as done in DI, PAA analysists can simultaneously account for discursive politics and the substance of politics and policymaking. Specifically, discursive politics can be viewed to entail coordinative and communicative political discourse, while the substance of politics and policymaking can be teased out by specifying and analysing the policy, programmatic and philosophical ideas that are the subject of contestation and argumentation.

Fourth, in chapter 4 I drew on the theoretical factors for discourse institutionalization (Table 3), as elaborated by several authors (Kingdon, 2003; Phillips et al., 2004; Schmidt, 2008), and condensed by Buijs et al. (2014). While these factors enabled me to explain differences in the extent of institutionalization of REDD+ MRV across the studied countries, it was clear that these factors alone cannot account for the observed differences. It was for this reason that Chapter 5 specifically examined - using the concept of coordinative discourse - the actors involved in MRV policy development, and how discursive politics among them have enabled or constrained institutionalization. In general, the concept of coordinative discourse proved useful in illuminating the actors involved in MRV policy development and how discursive politics enabled or constrained institutionalization. Although I am convinced that both the theoretical factors for discourse institutionalization and discursive politics are useful in explaining differences in institutionalization of REDD+ MRV across countries, the conclusion that MRV is in essence 
political (Chapter 5) suggests that other perspectives on politics may also be useful in explaining the observed differences. Especially factors such as bureaucratic politics (Allison and Halperin, 1972) also play a role in efforts to institutionalize international discourses and ideas such as REDD + MRV. Future analysis of REDD + MRV could explore how bureaucratic politics affect institutionalization of REDD+ MRV and other international discourses.

Lastly, DI is a relatively new strand in the neo-institutionalist literature. Although theoretical debates among discursive institutionalists have concluded that discourse - understood as ideas and the discursive processes by which these ideas are generated and deliberated during policymaking - shape institutions and may cause institutional change (Hay, 2006; Mehta, 2011; Schmidt, 2008; Schmidt, 2010), empirical analysis of instances where discourses have shaped institutions remain minimal. Calls have thus been made for discursive institutionalists to empirically show instances where new and counter-discourses have (re)shaped and materialized in institutions. This research, along with others (Arts and Buizer, 2009; Buijs et al., 2014; den Besten et al., 2014), has contributed to addressing this empirical lacuna. It has done so by not only using the PAA to conceptualize institutionalization and institutional change, but also by analysing these phenomena empirically. Furthermore, the research has empirically shown how discursive processes of policymaking matter in institutionalization. With this, the research has contributed both theoretically and empirically in this nascent theoretical debate.

\subsection{Methodological reflections}

Methodologically, I deployed the nested case study design (Lotz-Sisitka and Raven, 2004) in this research endeavour. First, to study institutional effectiveness of REDD+ MRV, I analysed 13 country cases (Chapter 2). While these countries include tropical countries with the largest forest cover and forest-related emissions (e.g. Brazil and Indonesia, Korhonen-Kurki et al., 2014), they represent only $18 \%$ of all REDD+ countries. The two major multilateral REDD+ initiatives (UN REDD and the FCPF) work with 71 tropical countries (REDD+ Countries Website; UN REDD Programme Website). Future analysis could thus be extended to cover the 58 remaining REDD+ countries. Second, to examine the extent to which REDD+ MRV has shaped national institutional arrangements, I analysed Indonesia, Peru and Tanzania. While these countries are representative of the universe of REDD+ countries, as argued in Chapter 1, an examination of other country cases could yield new insights on how institutionalization of REDD+ MRV and discursive politics of 
institutionalization play out in a larger sample. Such analysis could identify also the countries and conditions under which interactive discourse among policy actors produces positive or negative results in efforts to institutionalize REDD+ MRV. Going forward, this analysis should cover not only the initial institutionalization of REDD + MRV, but also the effectiveness of REDD+ in general, including its MRV systems, in solving the problem that led to their establishment. This is to suggest that future analysis should examine the institutional effectiveness and institutionalization of REDD+ and MRV in a larger sample of countries. This could yield relevant insights that would enable REDD+ stakeholders, policy makers and negotiators devise more effective strategies.

In addition to limitations in the number of cases studied, case studies as study designs are prone to low external validity (Flyvbjerg, 2006; Yin, 2009). In cognisance if this, I deployed a number of strategies to guarantee external validity of the research findings. External validity was enhanced, first, through triangulation of data methods and sources, member validation (through follow-up interviews (see Chapter 5)), and combining both primary (in-depth interviews, observation) and secondary data (analysis of national REDD+ policy documents) (Chapter 1). Second, external validity of the findings from the country case studies (Chapters 3-5) was enhanced through the cross-country comparative analysis (Chapters 2, 4 and 5).

There were other limitations in the study methods, especially regarding instruments for data collection. First of all, I relied on in-depth interviews, expert interviews, FGDs and participant observation as sources of primary data (see Chapter 1). The breadth of the types of actors interviewed and participating in the FDGs spanned representatives of both governmental and nongovernmental agencies. To analyse a policy process, however, the research should ideally be conducted ex nunc, i.e. when the policy process is on-going (Kumar, 2005; Punch, 2005). This would involve interviewing the actors involved in the policy process and observation of the processes in 'real time'. However, especially in Indonesia and Tanzania, it was not possible to study the REDD+ MRV policy process as, by the time of field work, MRV policy discussions had been (nearly) finalized in both countries. Similarly, although document analysis of media publications, petitions etc. would have also been ideal instruments, such sources of data were not available, as there was hardly coverage of REDD + MRV policy processes in the media in all 
analysed countries (Alvarez et al., 2014; Cronin and Santoso, 2010; Kweka, 2014). These methodological challenges were addressed by interviewing actors that were or had been involved in REDD+ MRV policy discussion in the respective countries, and by observing the 'expert' MRV discussions in Peru. Interviewing these actors enabled them to recall their experience in the MRV policy deliberation process, which is a valid retrospective data collection method (see Kumar, 2005). Furthermore, interviewing actors from different stakeholder groups enabled triangulation of data sources. Combining interviews with analysis of national REDD + policy documents and international evaluation reports also enabled triangulation of data methods. Additional follow-up interviews enabled corroboration and validation of data (see Chapter 1 and 5). These strategies, as noted above, enhanced the validity of the data collected. Future analysis of REDD + MRV policy process could, however, be conducted by interviewing the actors when the policy process is ongoing and observing the policy discussions as they unfold.

\subsection{Policy recommendations}

This chapter has presented the main findings of the study, thereby answering the research questions. In addition, it has reflected on the theoretical framework and methodology of the study. Based on the findings and conclusions of the study, the following policy recommendations emerge.

- This study showed that there is visible change in institutional arrangements and technical capacity for forest monitoring in all studied countries. However, the quality and extent of institutionalisation of new approaches to forest monitoring, reporting and verification (MRV) induced by REDD+ might be dependent on donor financing. Such donor investments should thus be sustained and extended to cover more REDD+ countries needing support in order for REDD + to be effective. However, the study also suggests that for middle-income countries, such as Indonesia, technical and human capacity may not be a major constraint. Although Indonesia does not have an advanced forest monitoring system such as that in Brazil, it can be argued that it has qualified technical staff for forest monitoring that, however, remains scattered across different agencies of government. It can also be argued that Indonesia can internally mobilize resources for forest monitoring. What perhaps especially constrains institutionalization of MRV and developing the capacity for forest monitoring for REDD+ in Indonesia is the discursive politics among the different agencies. For this type of countries, therefore, investments should be directed to instituting administrative reform and professionalizing existing agencies. Similarly, 
investments should be directed to organizing a coordinative policy process to bring key national agencies and stakeholders together, to develop a way forward on the best strategy to implement MRV.

For low-income countries, however, investment in building the initial technical and human capacity remains paramount. This is necessary to build enough in-country capacity for forest monitoring, as most of these countries lack the technical and human resources to conduct routine forest assessments. This technical capacity development should then be accompanied by investments in discursive processes of MRV policy making, to enable different constituencies to provide input into the policy process and achieve broader stakeholder buy-in of the policies and reforms proposed to implement and institutionalize forest monitoring for REDD+.

- The study has shown that in all the three case study countries, new agencies are being developed to implement REDD+ MRV. However, for the most part, these new agencies are unlikely to deliver an efficient and effective MRV system. As the study has shown, such new agencies are likely to create new centres of power and escalate inter-agency conflicts. The study thus suggest that countries developing their national forest monitoring systems for REDD+, and their donors, should consider strengthening existing agencies for forest assessments instead of developing entirely new ones. Working with and strengthening existing agencies would also guarantee durability of forest monitoring for REDD+, as existing agencies already have staff and budgets for their routine forest assessment functions. Nevertheless, in some cases, entirely new agencies would still be needed, especially in countries without a tradition for forest monitoring. In such countries, the study suggests that caution should be taken to avoid luxuriant growth of too many agencies to avoid the potential of inter-agency conflict and competition.

- This study showed that monitoring, reporting and verifying REDD+ outcomes is a highly political activity. Specifically, decisions on what exactly is to be measured, what methodologies to use, and the actors to be involved and their roles are made through national political processes. However, discursive politics in these processes has 
implications on whether MRV is institutionalized or not. As such, more investment in MRV policy coordination is needed to ensure broader stakeholder participation in MRV policy development and acceptance of the strategies to implement MRV. Thus, negotiators need to be aware of the domestic policy processes involved in implementing international agreements, as they inevitably create winners and losers, which leads to political conflicts. Such conflicts, if not well managed, as shown in the case of Peru, can hinder the development of the institutional changes required to implement provisions of agreements made at the international level. Vice versa, national policy makers and implementers need to be aware of international negotiations, and ensure that their negotiators are aware of the potential domestic implications of the outcomes of international negotiations.

- Lastly, this study has shown that while there is a coordinative discourse on MRV in the three countries, communicative political discourse is largely absent. Further, the coordinative discourse on MRV seems to be dominated by experts from national government agencies (Khatri et al., 2012). Because of the limited range and number of stakeholders involved in national MRV policy processes in Peru, for example, the strategies proposed to implement MRV do not enjoy the support of key REDD+ stakeholders. The credibility and resonance of these strategies is, hence, low and has limited institutionalization of MRV. This suggests that countries should organize a more inclusive MRV policy discourse. In addition, countries should also invest in a broader MRV communicative discourse. This should be done to enlighten all key stakeholders on MRV policy processes and strategies being proposed, while seeking the views of and feedback from these constituencies on the proposed strategies. Such communicative discourse can be done through regular press briefings and holding consultative meetings with key stakeholder groups (e.g. REDD+ project developers, NGOs, national experts, etc.).

With the insights generated through this research endeavour and the recommendations above, REDD+ in general, and MRV more specifically, can be further institutionalized into national policy contexts, thereby better ensuring that developing countries can more effectively address, monitor, report and account for carbon emissions from deforestation and forest degradation. 


\section{References}

AIDESEP, 2012. Construyendo REDD+ indígena. Adecuación intercultural del REDD+ Perú a los derechos territoriales y colectivos de los pueblos indígenas, In: AIDESEP (Ed.), Lima, Peru.

AIDESEP, FPP, 2011. La realidad de REDD+ en Perú: Entre el dicho y el hecho... Análisis y alternativas de los pueblos indígenas Amazónicos, In: AIDESEP, F., CARE and FPP (Ed.), Lima, Peru.

Alemayehu, N.A., Arts, B., Wiersum, F.K., 2013. Historical development of forest policy in Ethiopia: Trends of institutionalization and deinstitutionalization. Land Use Policy 32, 186-196.

Allison, G.T., Halperin, M.H., 1972. Bureaucratic politics: A paradigm and some policy implications. World politics 24, 40-79.

Alvarez, J.P., Montero, D.F., Barrantes, E.B., Takahashi, T.P., Menton, M., 2014. REDD+ politics in the media: A case study from Peru. CIFOR.

Angelsen, A., Brockhaus, M., Sunderlin, W.D., Verchot, L.V., 2012. Analysing REDD+: Challenges and choices. Cifor.

Angelsen, A., Brown, S., Loisel, C., 2009. Reducing emissions from deforestation and forest degradation (REDD): an options assessment report.

Anonymous, 1997. Estudio Nacional de la Diversidad Biológica. Volumen II, Sistema Nacional de Áreas Protegidas por el Estado - SINANPE. Ministerio de Agricultura and Instituto Nacional de Recursos Naturales, Lima.

Arnold, J.E.M., Pérez, M.R., 2001. Can non-timber forest products match tropical forest conservation and development objectives? Ecological Economics 39, 437-447.

Arnouts, R., van der Zouwen, M., Arts, B., 2012. Analysing governance modes and shifts - Governance arrangements in Dutch nature policy. Forest Policy and Economics 16, 43-50.

Arts, B., 1998. The political influence of global NGOs: case studies on the climate and biodiversity conventions. Jan van Arkel (International Books).

Arts, B., 2000. Regimes, Non-State Actors and the State System: AStructurational'Regime Model. European Journal of International Relations 6, 513-542.

Arts, B., 2006. Forests, institutions, discourses: a discursive-institutional analysis of global forest politics. Inaugural address, In: University, W. (Ed.).

Arts, B., 2012. Forests policy analysis and theory use: Overview and trends. Forest Policy and Economics $16,7-13$.

Arts, B., Babili, I., 2013. Global Forest Governance: Multiple Practices of Policy Performance, In: Art, B., Behagel, J., van Bommel, S., de Koning, J., Turnhout, E. (Eds.), Forest and nature governance: a practice based approach. Springer Science+Business Media, Dordrecht.

Arts, B., Buizer, M., 2009. Forests, discourses, institutions: A discursive-institutional analysis of global forest governance. Forest Policy and Economics 11, 340-347.

Arts, B., Kleinschmit, D., Pulzl, H., 2016. Forest governance: connecting global to local practices, In: Spaargaren, G., Weenink, D., Lamers, M. (Eds.), Practice Theory and Research: Exploring the dynamics of social life. Routledge, London and New York.

Arts, B., Tatenhove, J., 2004. Policy and power: A conceptual framework between the 'old' and 'new' policy idioms. 37, 339-356.

Arts, B., van Tatenhove, J., 2006. Institutional Dynamics in Environmental Governance. Springer, Dordrecht.

Asner, G.P., Knapp, D.E., Balaji, A., Páez-Acosta, G., 2009. Automated mapping of tropical deforestation and forest degradation: CLASlite. Journal of Applied Remote Sensing 3, 033543-033543-033524.

Bernard, F., Minang, P.A., Adkins, B., Freund, J.T., 2014. REDD+ projects and national-level Readiness processes: a case study from Kenya. Climate Policy 14, 788-800.

Bernstein, S., Cashore, B., 2012. Complex global governance and domestic policies: four pathways of influence. International Affairs 88, 585-604. 
Bevir, M., Rhodes, R.A., 2005. Interpretation and its Others. Australian Journal of Political Science 40, 169-187.

Biermann, F., Gupta, A., 2011. Accountability and legitimacy in earth system governance: A research framework. Ecological Economics 70, 1856-1864.

Böttcher, H., Eisbrenner, K., Fritz, S., Kindermann, G., Kraxner, F., McCallum, I., Obersteiner, M., 2009. An assessment of monitoring requirements and costs of'Reduced Emissions from Deforestation and Degradation'. Carbon Balance and Management 4, 7.

Boucher, D.H., 1991. Cocaine and the Coca Plant. BioScience 41, 72-76.

Bourdieu, P., 1990. The logic of practice. Stanford University Press.

Breitmeier, H., Underdal, A., Young, O.R., 2011. The Effectiveness of International Environmental Regimes: Comparing and Contrasting Findings from Quantitative Research1. International Studies Review 13, 579-605.

Brockhaus, M., Angelsen, A., 2012a. Seeing REDD+ through 4Is: a political economy framework. Analysing REDD+: challenges and choices. Center for International Forestry Research, Bogor, Indonesia, 15-30.

Brockhaus, M., Angelsen, A., 2012b. Seeing REDD+ through 4Is: A political economy framework, In: Angelsen, A., Brockhaus, M., Sunderlin, W.D., Verchot, L.V. (Eds.), Analysing REDD+: Challenges and choices. CIFOR, Bogor, Indonesia.

Brockhaus, M., Di Gregorio, M., 2014. National REDD+ policy networks: from cooperation to conflict. Ecology and Society 19.

Brockhaus, M., Di Gregorio, M., Carmenta, R., 2014. REDD+ policy networks: exploring actors and power structures in an emerging policy domain. Ecology and Society 19.

Brockhaus, M., Korhonen-Kurki, K., Sehring, J., Di Gregorio, M., Assembe-Mvondo, S., Babon, A., Bekele, M., Gebara, M.F., Khatri, D.B., Kambire, H., 2016. REDD+, transformational change and the promise of performance-based payments: a qualitative comparative analysis. Climate Policy, 123.

Buijs, A., Mattijssen, T., Arts, B., 2014. "The man, the administration and the counter-discourse": An analysis of the sudden turn in Dutch nature conservation policy. Land Use Policy 38, 676-684.

Bushley, B.R., 2014. REDD+ policy making in Nepal: toward state-centric, polycentric, or marketoriented governance? Ecology and Society 19.

Cameron, W.B., 1963. Informal sociology: A casual introduction to sociological thinking. Random House New York.

Campbell, J.L., 1998. Institutional analysis and the role of ideas in political economy. Theory and society $27,377-409$.

Campbell, J.L., 2004. Institutional Change and Globalization. Princeton Univ. Press, Princeton, NJ.

Cashore, B., Visseren-Hamakers, I.J., Forthcoming. Making good forest governance matter.

CIF, 2013. Forest Investment Plan for Peru, Climate Investment Funds. FIP/SC.11/4/Rev.1. Washington DC, October 18, 2013.

Comunidad Andina, 2002. Decision 523 and the Annex. Regional biodiversity strategy for the tropical Andean Countries.

Cornell, S.E., 2002. What is institutional capacity and how can it help American Indian nations meet the welfare challenge. University of Arizona.

Cossio-Solano, R.E., 2009. Capacity for Timber Management among Private Small-Medium Forest Enterprises in Madre de Dios, Peru University of Florida.

Cox, R.H., Béland, D., 2013. Valence, policy ideas, and the rise of sustainability. Governance 26, 307328.

Crespy, A., Schmidt, V., 2014. The clash of Titans: France, Germany and the discursive double game of EMU reform. Journal of European Public Policy 21, 1085-1101.

Creswell, J., 2014. W.(2009). Research design: Qualitative, quantitative, and mixed methods approaches, 91359-99702. 
Cronin, T., Santoso, L., 2010. REDD+ politics in the media: a case study from Indonesia. Center for International Forestry Research (CIFOR), Bogor, Indonesia.

Davies, R., 2015. The Indonesia-Australia Forest Carbon Partnership: A Murder Mystery, In: (CGD), C.f.G.D. (Ed.). CGD Policy Paper 060 April 2015.

de la Plaza Esteban, C., Visseren-Hamakers, I.J., de Jong, W., 2014. The Legitimacy of Certification Standards in Climate Change Governance. Sust. Dev. 22, 420-432.

De Sy, V., Herold, M., Achard, F., Asner, G.P., Held, A., Kellndorfer, J., Verbesselt, J., 2012. Synergies of multiple remote sensing data sources for REDD+ monitoring. Current Opinion in Environmental Sustainability 4, 696-706.

den Besten, J.W., Arts, B., Verkooijen, P., 2014. The evolution of REDD+: An analysis of discursiveinstitutional dynamics. Environmental Science \& Policy 35, 40-48.

Denman, K.L., Brasseur, G.P., Chidthaisong, A., Ciais, P., Cox, P.M., Dickinson, R.E., Hauglustaine, D.A., Heinze, C., Holland, E.A., Jacob, D.J., 2007. Couplings between changes in the climate system and biogeochemistry. Climate change 2007: The physical science basis.

Dimitrov, R., 2006. Science and international environmental policy: regimes and nonregimes in global governance. Rowman \& Littlefield.

Dimitrov, R.S., 2005. Hostage to norms: states, institutions and global forest politics. Global environmental politics 5, 1-24.

Dimitrov, R.S., Sprinz, D.F., DiGiusto, G.M., Kelle, A., 2007. International Nonregimes: A Research Agenda1. International Studies Review 9, 230-258.

Dobransky, S., 2014. Violators amongst us: international regimes and the role of compliance, a case study on official development assistance. Politics \& Policy 42, 593-634.

Dryzek, J.S., 2000. Deliberative democracy and beyond: Liberals, critics, contestations. Oxford University Press on Demand.

FAO, 1993. Forest Resources Assessment 1990. Tropical Countries, Rome, Italy.

FAO, 2011. National Forest Monitoring and Assessment of Tanzania (NAFORMA)GCP/GLO/194/MUL: Mid-Term Evaluation Report, In: Evaluation, O.o. (Ed.). FAO, Rome, Italy.

FAO, 2015. Global Forest Resources Assessment 2015: How are the world's forests changing. Second Edition, In: FAO (Ed.), Rome, Italy.

FAO/ GoT, 2009. TRUST FUND AGREEMENT BETWEEN THE GOVERNMENT OF TANZANIA AND THE FOOD AND AGRICULTURE ORGANIZATION OF THE UNITED NATIONS: NATIONAL FORESTRY RESOURCES MONITORING AND ASSESSMENT.

Finer, M., Jenkins, C.N., Sky, M.A.B., Pine, J., 2014. Logging Concessions Enable Illegal Logging Crisis in the Peruvian Amazon. 4.

Fjeldså, J., Álvarez, M.D., Lazcano, J.M., León, B., 2005. Illicit Crops and Armed Conflict as Constraints on Biodiversity Conservation in the Andes Region. AMBIO: A Journal of the Human Environment 34, 205-211.

Fletcher, R., Dressler, W., Büscher, B., Anderson, Z.R., 2016. Questioning REDD+ and the future of market-based conservation. Conservation Biology.

Flyvbjerg, B., 2006. Five Misunderstandings About Case-Study Research. Qualitative Inquiry 12, 219245.

FORCLIME, 2013a. Support for Reduced Emissions from Deforestation and Forest Degradation (REDD), In: 2013, F.T.M.B.N.N.F. (Ed.), Jakarta.

FORCLIME, 2013b. Support for the Setup of a District Forest Management Information System

(DFMIS), In: version), F.T.M.B.N.N.F.u. (Ed.), Jakarta.

Freitas, J., de Oliveira, Y.M., Rosot, M.A., Gomide, G., Mattos, P., 2010. Development of the National Forest Inventory of Brazil, In: Tomppo, E., Gschwantner, T., Lawrence, M., McRoberts, R.E. (Eds.), National forest inventories. Pathways for Common Reporting. Springer.

Friends of the Amazon, 2011. Declaration of Iquitos: There is no Redd+ without Territories, Rights and Autonomy for Indigenous People (English Translation), Iquitos, April 27, 2011. 
Gallemore, C.T., Prasti H, R.D., Moeliono, M., 2014. Discursive barriers and cross-scale forest governance in Central Kalimantan, Indonesia. Ecology and Society 19.

George, A.L., Bennett, A., 2005. Case Studies and Theory Development in the Social Sciences. MIT Press, Harvard.

Giddens, A., 1984. The constitution of society: Outline of the theory of structuration. Univ of California Press.

Giessen, L., 2013. Reviewing the main characteristics of the international forest regime complex and partial explanations for its fragmentation. International Forestry Review 15, 60-70.

Global Witness, 2011. Forest Carbon, Cash \& Crime: The Risk of Criminal Engagement in REDD+. Global Witness, London, UK.

GOFC-GOLD, 2010. A sourcebook of methods and procedures for monitoring and reporting anthropogenic greenhouse gas emissions and removals caused by deforestation, gains and losses of carbon stocks in forest remaining forests, and forestation. GOFC-GOLD Report version COP15-1 edition.

GOFC-GOLD, 2013. A sourcebook of methods and procedures for monitoring and reporting anthropogenic greenhouse gas emissions and removals associated with deforestation, gains and losses of carbon stocks in forests remaining forests, and forestation, GOFC-GOLD Report version COP19-1 ed. GOFC-GOLD Land Cover Project Office, Wageningen University, The Netherlands.

Grainger, A., Obersteiner, M., 2011. A framework for structuring the global forest monitoring landscape in the REDD+ era. Environmental Science \& Policy 14, 127-139.

Gupta, A., Lövbrand, E., Turnhout, E., Vijge, M.J., 2012. In pursuit of carbon accountability: the politics of REDD+ measuring, reporting and verification systems. Current Opinion in Environmental Sustainability 4, 726-731.

Gupta, A., Mason, M., 2014. Transparency in Global Environmental Governance: Critical Perspectives. MIT Press.

Gupta, A., vijge, M.J., Turnhout, E., Pistorius, T., 2014. Making REDD+ Transparent: The politics of measuring, reporting and verification systems, In: Gupta, A., Mason, M. (Eds.), Transparency in Global Environmental Governance: critical perspectives MIT Press, Cambridge, pp. 181-201.

Haas, E.B., 1982. Words can hurt you; or, who said what to whom about regimes. International Organization 36, 207-243.

Haas, P.M., Keohane, R.O., Levy, M.A., 1993. Institutions for the earth: sources of effective international environmental protection. Mit Press.

Habermas, J., 1994. THREE NORMATIVE MODELS OF DEMOCRACY. Constellations 1, 1-10.

Habermas, J., 1996. Between facts and norms, trans. William Rehg. Polity, Oxford, 274-328.

Habermas, J., 2006. Political Communication in Media Society: Does Democracy Still Enjoy an Epistemic Dimension? The Impact of Normative Theory on Empirical Research1. Communication Theory 16, 411-426.

Hajer, M., 2006. Doing discourse analysis: coalitions, practices, meaning, In: van den Brink, M., Metze, T. (Eds.), Words matter in policy and planning: Discourse theory and method in the social sciences. Netherlands Graduate School of Urban and Regional Research, Utrecht, pp. 65 - 76. .

Hajer, M., Versteeg, W., 2005. A decade of discourse analysis of environmental politics: achievements, challenges, perspectives. Journal of environmental policy \& planning 7, 175-184.

Hajer, M.A., 1995. The politics of environmental discourse: ecological modernization and the policy process. Clarendon Press Oxford.

Hall, P., Taylor, R., 1996. Political science and the three new institutionalisms. . Political Studies 44, 952-973.

Hall, P.A., 1989. The political power of economic ideas: Keynesianism across nations. Princeton University Press, Princeton, N.J.

Hansen, M.C., Potapov, P.V., Moore, R., Hancher, M., Turubanova, S., Tyukavina, A., Thau, D., Stehman, S., Goetz, S., Loveland, T., 2013. High-resolution global maps of 21st-century forest cover change. science $342,850-853$. 
Hansen, M.C., Roy, D.P., Lindquist, E., Adusei, B., Justice, C.O., Altstatt, A., 2008. A method for integrating MODIS and Landsat data for systematic monitoring of forest cover and change in the Congo Basin. Remote Sensing of Environment 112, 2495-2513.

Hardcastle, P.D., Baird, D., 2008. Capability and cost assessment of the major forest nations to measure and monitor their forest carbon. Report Prepared for the Office of Climate Change. LTS International Ltd, Penicuik.

Hasenclever, A., Mayer, P., Rittberger, V., 1996. Interests, power, knowledge: the study of international regimes. Mershon International Studies Review 40, 177-228.

Hasenclever, A., Mayer, P., Rittberger, V., 1997. Theories of international regimes. Cambridge university press.

Hay, C., 2006. "Constructivist Institutionalism: Or, Why Interests into Ideas Don't Go", Paper presented at the annual meeting of the American Political Science Association, Marriott, Loews Philadelphia, and the Pennsylvania Convention Center, Philadelphia, PA. .

Helm, C., Sprinz, D., 2000. Measuring the effectiveness of international environmental regimes. Journal of Conflict Resolution 44, 630-652.

Herold, M., 2009. An assessment of national forest monitoring capabilities in tropical non-Annex I countries: Recommendations for capacity building.

Herold, M., Johns, T., 2007. Linking requirements with capabilities for deforestation monitoring in the context of the UNFCCC-REDD process. Environmental Research Letters 2, 045025.

Herold, M., Roman-Cuesta, R., Mollicone, D., Hirata, Y., Van Laake, P., Asner, G., Souza, C., Skutsch, M., Avitabile, V., MacDicken, K., 2011. Options for monitoring and estimating historical carbon emissions from forest degradation in the context of REDD+. Carbon Balance and Management 6, 13 .

Herold, M., Skutsch, M., 2011. Monitoring, reporting and verification for national REDD + programmes: Two proposals. Environmental Research Letters 6, 014002.

Holly, K.G., Martin, H., 2007. Tropical deforestation and greenhouse gas emissions. Environmental Research Letters 2, 045021.

Holmgren, P., Marklund, L.-G., 2007. National Forest Monitoring Systems - purposes, options and status, In: Freer-Smith, P.H., Broadmeadow, M.S.J., Lynch, J.M. (Eds.), Forestry \& Climate Change. CAB International.

Holmgren, P., Marklund, L.-G., Saket, M., Wilkie, M.L., 2007. Forest Monitoring and Assessment for Climate Change Reporting: Partnerships, Capacity Building and Delivery, Forest Resources Assessment Working Paper 142. FAO, Rome.

Holmgren, P., Persson, R., 2002a. Evolution and prospects of global forest assessments. Unasylva 210, 39.

Holmgren, P., Persson, R., 2002b. Why did we end up here? The evolution of global forest assessments, Kotka IV: Expert Consultation on Global Forest Resources Assessments - Linking National and International efforts, Kotka, Finland, 1-5 July 2002. Background Paper 5.3.

Hosonuma, N., Martin, H., Veronique De, S., Ruth, S.D.F., Maria, B., Louis, V., Arild, A., Erika, R., 2012. An assessment of deforestation and forest degradation drivers in developing countries.

Environmental Research Letters 7, 044009.

Humphreys, D., 1996. Forest Politics: The Evolution of International Cooperation. Earthscan London. Humphreys, D., 2006. Logjam; Deforestation and the Crisis of Global Governance. Earthscan, London. Humphreys, D., 2014. Forest politics: the evolution of international cooperation. Routledge.

IAFCP, 2015. Measuring, Reporting and Verifying Emissions Reductions at The National Scale. , In: Partnership, I.-A.F.C. (Ed.).

INCAS FACTSHEET, 2013. Indonesian National Carbon Accounting System (INCAS) Program.

INCAS Roadmap, 2015. Research, Development and Innovation Agency of the Ministry of Environment and Forestry, Bogor, Indonesia.

Indonesian REDD+ Task Force, 2012. REDD+ National Strategy, September 2012, Jakarta, Indonesia. 
Indrarto, G.B., Murharjanti, P., Khatarina, J., Pulungan, I., Ivalerina, F., Rahman, J., Prana, M.N., Resosudarmo, I.A.P., Muharrom, E., 2012. The context of REDD+ in Indonesia. Center for International Forestry Research (CIFOR), Bogor, Indonesia.

Indufor, 2013a. Mid-Term Review of the Norwegian Funded MRV Research Project in Tanzania. Indufor Asia Pacific, Auckland City, New Zealand.

Indufor, 2013b. Zanzibar woody biomass survey: Preparedness for REDD+ Phase: Biophysical inventory report, RGZ, Zanzibar Town

IPCC, 2003. Good Practice Guidance for Land Use, Land-Use Change and Forestry, Prepared by the National Greenhouse Gas Inventories Programme. IGES, Japan.

IPCC, 2006. IPCC Guidelines for National Greenhouse Gas Inventories vol 4.

IPCC, 2014. Climate Change 2014: Mitigation of Climate Change. Contribution of Working Group III to the Fifth Assessment Report of the Intergovernmental Panel on Climate Change [Edenhofer, O., R. Pichs-Madruga, Y. Sokona, E. Farahani, S. Kadner, K. Seyboth, A. Adler, I. Baum, S. Brunner, P. Eickemeier, B. Kriemann, J. Savolainen, S. Schlömer, C. von Stechow, T. Zwickel and J.C. Minx (eds.)], Cambridge University Press, Cambridge, UK and New York, NY.

Janz, K., Persson, R., 2002. How to Know More about Forests? Supply and Use of Information for Forest Policy. CIFOR Occasional Paper No. 36. Bogor, Indonesia.

Johnson, R.B., Onwuegbuzie, L.A., 2004. Mixed Methods Research: A Research Paradigm Whose Time Has Come. Educational Researcher 33, 14-26.

Joseph, S., Herold, M., Sunderlin, W.D., Verchot, L.V., 2013a. Challenges in operationalizing remote sensing in climate change mitigation projects in developing countries, Geoscience and Remote Sensing Symposium (IGARSS), 2013 IEEE International, pp. 2752-2755.

Joseph, S., Herold, M., Sunderlin, W.D., Verchot, L.V., 2013b. REDD+ readiness: Early insights on monitoring, reporting and verification systems of project developers. Environmental Research Letters 8 .

Keohane, R.O., Haas, P.M., Levy, M.A., 1993. The Effectiveness of International Environmental Institutions, In: Haas, P.M., Keohane, R.O., Levy, M.A. (Eds.), Institutions for the Earth - Sources of Effective International Environmental Protection. MIT Press, Cambridge, MA, pp. 3-24.

Khatri, D., Bhushal, R.P., Paudel, N.S., Gurung, N., 2012. REDD+ politics in the media: A case study from Nepal. Center for International Forestry Research (CIFOR), Bogor, Indonesia.

Kingdon, J., 2003. Agendas, alternatives, and public policies. Longman classics in political science Show all parts in this series.

Kingdon, J.W., 1995. Agendas, Alternatives, and Public Policies, 2nd ed. HarperCollins, New York.

Kishor, N., Rosenbaum, K., 2012. Assessing and Monitoring Forest Governance: A user's guide to a diagnostic tool. Program on Forests (PROFOR), Washington DC.

Korhonen-Kurki, K., Brockhaus, M., Duchelle, A., Atmadja, S., Thuy, P.T., Schofield, L., 2013. Multiple levels and multiple challenges for measurement, reporting and verification of REDD + . International Journal of the Commons 7.

Korhonen-Kurki, K., Sehring, J., Brockhaus, M., Di Gregorio, M., 2014. Enabling factors for establishing REDD+ in a context of weak governance. Climate Policy 14, 167-186.

Kowler, L.F., Larson, A.M., 2016. Beyond the technical: The politics of developing the MRV system in Peru. Center for International Forestry Research (CIFOR), Bogor, Indonesia.

Krasner, S.D., 1982. Structural Causes and Regime Consequences: Regimes as Intervening Variables. International Organization 36, 185-205.

Kratochwil, F., Ruggie, J.G., 1986. International Organization: A State of the Art on an Art of the State. International organization 40, 753-775.

Krisnawati, H., Adinugroho, W.C., Imanuddin, R., 2012. Monograph: Allometric Models for Estimating Tree Biomass at Various Forest Ecosystem Types in Indonesia, In: Research and Development Center for Conservation and Rehabilitation, F.R.a.D.A. (Ed.), Bogor, Indonesia. 
Krisnawati, H., Imanuddin, R., Adinugroho, W.C., Hutabarat, S., 2015a. National Inventory of Greenhouse Gas Emissions and Removals on Indonesia's Forests and Peatlands, In: Research, D.a.I.A.o.t.M.o.E.a.F. (Ed.), Bogor, Indonesia.

Krisnawati, H., Imanuddin, R., Adinugroho, W.C., Hutabarat, S., 2015b. Standard Methods for Estimating Greenhouse Gas Emissions for the Forestry Sector in Indonesia, Version 1, In: Research and Development Center for Conservation and Rehabilitation, F.R.a.D.A. (Ed.), Bogor, Indonesia.

Krisnawati, H., Imanuddin, R., Adinugroho, W.C., Hutabarat, S., 2015c. Standard Methods for Estimating Greenhouse Gas Emissions from Forests and Peatlands in Indonesia, Version 2, In: Research and Development Center for Conservation and Rehabilitation, F.R.a.D.A. (Ed.), Bogor, Indonesia.

Kumar, R., 2005. Research Methodology: A Step-by-Step Guide for Beginners, 2nd ed. Sage Publications, London.

Kweka, D., 2014. REDD+ politics in the media: a case study from Tanzania. CIFOR.

Kweka, D., Carmenta, R., Hyle, M., Mustalahti, I., Dokken, T., Brockhaus, M., 2015. The context of REDD+ in Tanzania: Drivers, agents and institutions. Center for International Forestry Research (CIFOR), Bogor, Indonesia.

LAPAN, 2014. The Remote Sensing Monitoring Program of Indonesia's National Carbon Accounting System: Methodology and Products, Version 1, In: LAPAN-IAFCP (Ed.), Jakarta.

Lasswell, H.D., 1950. Politics: Who gets what, when, how. P. Smith New York.

Lei, X., Tang, M., Hong, L., Lu, Y., 2010. Development of China's National Forest Inventory, In: Tomppo, E., Gschwantner, T., Lawrence, M., McRoberts, R.E. (Eds.), National forest inventories. Pathways for Common Reporting. Springer.

Lei, X.D., Tang, M.P., Lu, Y.C., Hong, L.X., Tian, D.L., 2009. Forest inventory in China: status and challenges. International Forestry Review 11, 52-63.

Leroy, P., Arts, B., 2006. Institutional dynamics in environmental governance, Institutional dynamics in environmental governance. Springer, pp. 1-19.

Lestrelin, G., Trockenbrodt, M., Phanvilay, K., Thongmanivong, S., Vongvisouk, T., Pham, T.T., Castella, J.C., 2013. The context of REDD+ in the Lao People's Democratic Republic: Drivers, agents and institutions. Center for International Forestry Research (CIFOR), Bogor, Indonesia.

Liefferink, D., 2006a. The dynamics of policy arrangements: turning round the tetrahedron, In: Arts, B., van Tatenhove, J. (Eds.), Institutional Dynamics in environmental Governance. Springer, Dordrecht.

Liefferink, D., 2006b. The dynamics of policy arrangements: turning round the tetrahedron, In: Arts, B.a.L., Pieter (Ed.), Institutional Dynamics in Environmental Governance. Springer, Dordrecht, pp. $45-68$.

Loft, L., Pham, T., Wong, G., Brockhaus, M., Le, D.N., Tjajadi, J.S., Luttrell, C., 2016. Risks to REDD+: potential pitfalls for policy design and implementation. Environmental Conservation, 12p.

Lotz-Sisitka, H., Raven, G., 2004. Learning through cases: adopting a nested approach to case-study work in the Gold Fields participatory course initiative. Environmental Education Research 10, 67-87.

Lovbrand, E., Stripple, J., 2011. Making climate change governable: accounting for carbon as sinks, credits and personal budgets, . Critical Policy Studies 5, 187-200.

Lövbrand, E., Stripple, J., 2011. Making climate change governable: accounting for carbon as sinks, credits and personal budgets, . Critical Policy Studies 5, 187-200.

LTS International, 2013. Real-Time Evaluation of Norway's International Climate and Forest Initiative Contribution to Measurement, Reporting and Verification. Report 5/2013, Norad, Norwegian.

Lund, H.G., no.date. National Forest Inventories and Global Resource Assessments. Forests and Forest Plants-Vol. I.

Mäkelä, M., Blomley, T., Edwards, K., Lukumbuzya, K., Kingazi, S., Vesa, L., Martin, J., 2015. Lessons learned from the implementation of REDD pilot projects in Tanzania. A report prepared for the Royal Norwegian Embassy in Tanzania, In: Oy, N.F. (Ed.), Vantaa, Finland.

Malleux, J.O., 1975. Mapa Forestal Del Peru: Memoria Explicativa, Departamento de Menejo Forestal, Universidad Nacional Agraria Lan Molina. 
March, J.G., Olsen, J.P., 1983. The New Institutionalism: Organizational Factors in Political Life. American Political Science Review 78, 734-749.

March, J.G., Olsen, J.P., 1998. The institutional dynamics of international political orders. International organization 52, 943-969.

Mather, A.S., 1992. The forest transition. Area, 367-379.

Mather, A.S., 2001. Forests of consumption: postproductivism, postmaterialism, and the postindustrial forest. Environment and Planning C: Government and Policy 19, 249-268.

May, P.H., Millikan, B., Gebara, M.F., 2011. The context of REDD+ in Brazil: Drivers, agents, and institutions. Center for International Forestry Research (CIFOR), Bogor, Indonesia.

McDermott, C.L., 2014. REDDuced: From sustainability to legality to units of carbon-The search for common interests in international forest governance. Environmental Science \& Policy 35, 12-19.

McRoberts, R.E., Tomppo, E.O., 2007. Remote sensing support for national forest inventories. Remote Sensing of Environment 110, 412-419.

McRoberts, R.E., Tomppo, E.O., Vibrans, A.C., de Freitas, J.V., 2013. Design considerations for tropical forest inventories.

Medina, G., Pokorny, B., Weigelt, J., 2009. The power of discourse: Hard lessons for traditional forest communities in the Amazon. Forest Policy and Economics 11, 392-397.

Mehta, J., 2011. The Varied Roles of Ideas in Politics : From "Whether" to "How", In: Béland, D., Cox, R.H. (Eds.), Ideas and Politics in Social Science Research. Oxford University Press.

Menton, M., Perla, J., Sotes, J., Fatorelli, L., 2014. Analysis of REDD+ policy networks in Peru. Center for International Forestry Research (CIFOR), Bogor, Indonesia.

Meridian Institute, 2009. Reducing Emissions from Deforestation and Forest Degradation (REDD): An Options Assessment Report. Prepared for The Government of Norway.

Metz, B., Davidson, O., Bosch, P., Dave, R., Meyer, L., 2007. Climate Change 2007: Mitigation: Contribution of Working Group III to the Fourth Assessment Report of the Intergovernmental Panel on Climate Change: Summary for Policymakers and Technical Summary. Cambridge University Press.

MFA, URT, 2011. Agreement between the Government of the United Republic of Tanzania and the Norwegian Ministry of Foreign Affairs regarding development cooperation concerning 'Enhancing the Measuring, Reporting and Verification (MRV) of forests in Tanzania through the application of advanced remote sensing techniques'.

MFA, URT, 2015. Agreement between the Government of the United Republic of Tanzania and the Norwegian Ministry of Foreign Affairs regarding development cooperation concerning 'Establishing a National Carbon Monitoring Center in Tanzania'.

MINAM, 2014a. Estimación de los contenidos de carbono de la biomasa 1240 aérea en los bosques de Perú, In: Ministerio del Ambiente (NINAM), P.N.d.C.d.B.p.l.M.d.C.C. (Ed.), Lima, Perú.

MINAM, 2014b. Mapeo de Pérdida de Cobertura de Bosques Húmedos Amazónicos del Perú entre los años 2000-2011, In: Ambiente, M.d. (Ed.), Lima, Perú.

MINAM, 2015. Peru's submission of a Forest Reference Emission Level (FREL) for reducing emissions from deforestation in the Peruvian Amazon. Submission of the Republic of Peru to the United Nations Framework Convention on Climate Change, In: Ambiente, M.d. (Ed.), Lima, Peru.

MINAM, MINAGRI, 2014a. Memoria Descriptiva del Mapa de Bosque/No Bosque año 2000 y Mapa de pérdida de los Bosques Húmedos Amazónicos del Perú 2000-2011, In: (MINAM), M.d.A. (Ed.), Lima, Perú.

MINAM, MINAGRI, 2014b. Protocolo de clasificación de pérdida de cobertura en los bosques húmedos amazónicos 1250 entre los años 2000 y 2011, In: (MINAM), M.d.A. (Ed.), Lima, Perú.

Minang, P.A., Van Noordwijk, M., Duguma, L.A., Alemagi, D., Do, T.H., Bernard, F., Agung, P., Robiglio, V., Catacutan, D., Suyanto, S., Armas, A., Silva Aguad, C., Feudjio, M., Galudra, G., Maryani, R., White, D., Widayati, A., Kahurani, E., Namirembe, S., Leimona, B., 2014. REDD+ Readiness progress across countries: time for reconsideration. Climate Policy 14, 685-708. 
Ministerio de Agricultura, Ministerio del Ambiente, 2011. Inventario Nacional Forestal y Manejo Forestal Sostenible del Perú ante el Cambio Climático, Lima - Perú.

Ministry of Forestry, 2006. Ministry of Forestry Regulation No. P.67/Menhut-II/2006 on Standard and Criteria for Forest Inventory (English Translation), In: Forestry, M.o. (Ed.), Jakarta, Indonesia.

MoEF, 2015. Ministry of Environment and Forestry Regulation No. P.18/Menlhk-II/2015 on Organization and Work Procedures of Ministry of Environment and Forestry (English Translation), In: Forestry, M.o.E.a. (Ed.), Jakarta, Indonesia.

Moeliono, M., Gallemore, C., Santoso, L., Brockhaus, M., Di Gregorio, M., 2014. Information networks and power: confronting the "wicked problem" of REDD+ in Indonesia. Ecology and Society 19.

Mohren, G.M.J., Hasenauer, H., Köhl, M., Nabuurs, G.J., 2012. Forest inventories for carbon change assessments. Current Opinion in Environmental Sustainability 4, 686-695.

NCMC Project Document, 2015. Establishing a National Carbon Monitoring Centre in Tanzania: A proposal presented to Royal Norwegian Embassy, Dar es Salaam, Tanzania. May 2015.

NORAD, 2013. Real-time Evaluation of Norway's International Climate and Forest Initiative: Contribution toMeasurement, Reporting and Verification. Norwegian Agency for Development Cooperation (NORAD), Oslo, Norway.

North, D., 1991. Institutions, Institutional Change and Economic Performance. Cambridge University Press.

Nthiga, R.W., 2014. Governance of Tourism Conservation Partnerships: Lessons from Kenya. Wageningen University, NL, PhD Thesis.

Ochieng, R.M., Art, B., Visseren-Hamakers, I.J., Brockhaus, M., Herold, M., 2015. Influence of REDD+ MRV rules on institutional arrangements for forest measurements in developing countries: Insights from Peru, XIV WORLD FORESTRY CONGRESS. FAO, Durban, South Africa.

Ochieng, R.M., Visseren-Hamakers, I.J., Arts, B., Brockhaus, M., Herold, M., 2016a. Institutional effectiveness of REDD+ MRV: Countries progress in implementing technical guidelines and good governance requirements. Environmental Science \& Policy 61, 42-52.

Ochieng, R.M., Visseren-Hamakers, I.J., Brockhaus, M., Kowler, L.F., Herold, M., Arts, B., 2016b. Historical development of institutional arrangements for forest monitoring and REDD + MRV in Peru: Discursive-institutionalist perspectives. Forest Policy and Economics 71, 52-59.

Organización para Estudios Tropicales, 2011. Diagnóstico de las Necesidades de Capacitación de las Organizaciones Públicas y Privadas para el Desarrollo del Mecanismo REDD en el Perú, Lima, Peru.

Palmer Fry, B., 2011. Community forest monitoring in REDD+: the 'M' in MRV? Environmental Science \& Policy 14, 181-187.

Paudel, N.S., Khatri, D.B., Khanal, D.R., Karki, R., 2013. The context of REDD+ in Nepal: Drivers, agents, and institutions. Center for International Forestry Research (CIFOR), Bogor, Indonesia.

Phillips, N., Lawrence, T.B., Hardy, C., 2004. Discourse and institutions. Academy of management review 29, 635-652.

Piu, H.C., Menton, M., 2014a. The context of REDD+ in Peru: Drivers, agents and institutions. Center for International Forestry Research (CIFOR), Bogor, Indonesia.

Piu, H.C., Menton, M., 2014b. The context of REDD+ in Peru: Drivers, agents and institutions. . CIFOR, Bogor, Indonesia.

Potapov, P.V., Dempewolf, J., Talero, Y., Hansen, M.C., Stehman, S.V., Vargas, C., Rojas, E.J., Castillo, D., Mendoza, E., Calderón, A., Giudice, R., Malaga, N., Zutta, B.R., 2014. National satellite-based humid tropical forest change assessment in Peru in support of REDD+ implementation.

Environmental Research Letters 9, 124012.

Potapov, P.V., Turubanova, S.A., Tyukavina, A., Krylov, A.M., McCarty, J.L., Radeloff, V.C., Hansen, M.C., 2015. Eastern Europe's forest cover dynamics from 1985 to 2012 quantified from the full Landsat archive. Remote Sensing of Environment 159, 28-43.

Pratihast, A., Herold, M., Avitabile, V., de Bruin, S., Bartholomeus, H., Jr., C., Ribbe, L., 2012. Mobile Devices for Community-Based REDD+ Monitoring: A Case Study for Central Vietnam. Sensors 13, 21-38. 
Pratihast, A.K., Herold, M., De Sy, V., Murdiyarso, D., Skutsch, M., 2013. Linking community-based and national REDD+ monitoring: a review of the potential. Carbon Management 4, 91-104.

Punch, K.F., 2005. Introduction to Social Research: Quantitative and Qualitative Approaches, Second Edition ed. Sage Publications, London.

Rantala, S., 2012. Knowledge and brokerage in REDD+ policy making: A Policy Networks Analysis of the case of Tanzania, In: Sustainability Science Program Working Paper No. 2012-03. Sustainability Science Program, K.S.o.G., Harvard University, Cambridge, MA, USA, and Center for International Forestry Research (CIFOR) (Ed.), Bogor, Indonesia.

Rantala, S., Di Gregorio, M., 2014. Multistakeholder environmental governance in action: REDD+ discourse coalitions in Tanzania. Ecology and Society 19.

Rayner, J., Buck, A., Katila, P., 2010. Embracing complexity: meeting the challenges of international forest governance. A global assessment report. IUFRO (International Union of Forestry Research Organizations) Secretariat.

REDD Pilot Projects, 2011. Feedback on National REDD Strategy by TZ REDD Pilot Projects.

REDD+ Countries Website, REDD+ Countries." REDD+ Countries | The Forest Carbon Partnership Facility. N.p., n.d. Web. 30 Jan. 2017. .

REDD+ Task Force MRV Working Group, 2012. Strategy and Implementation Plan for REDD+ Measurement, Monitoring, Reporting, and Verification (MRV) in Indonesia, In: Force, R.T. (Ed.), Jakarta.

Republic of Indonesia, 2014. Indonesia District Level REDD+ Emission Reductions Program, Jakarta.

Rientjes, S., 2002. Making nature conservation modern: an analysis of developments in nature conservation policy in relation to macro-social changes - the Netherlands as a case study. J. Environ. Policy Plann. 4, 1-21.

Risse, T., 2000. “Let's argue!”: communicative action in world politics. International organization 54, 139.

Rittberger, V., 1993a. Regime Theory and International Relations. Clarendon Press, Oxford.

Rittberger, V., 1993b. Research on International Regimes in Germany: The Adaptive Internalization of an American Social Science Concept. Regime Theory and International Relations, Oxford, 3-22.

Rittberger, V., Mayer, P., 1993. Regime theory and international relations. Oxford University Press, USA.

Robiglio, V., Armas, A.D., Silva Aguad, C., White, D., 2014. Beyond REDD+ readiness: land-use governance to reduce deforestation in Peru. Climate Policy 14, 734-747.

RoI, 2011. Presidential Regulation No 71/2011 on Implementation of National Greenhouse Gases Inventory (English Translation), In: Indonesia, R.o. (Ed.), Jakarta, Indonesia.

RoI, 2014. UPDATED MID-TERM PROGRESS REPORT OF THE REPUBLIC OF INDONESIA AND REQUEST FOR ADDITIONAL FUNDING FROM THE FOREST CARBON PARTNERSHIP FACILITY (FCPF), In: Indonesia, R.o. (Ed.), Jakarta.

RoI, 2015. Presidential Regulation Number 16 (2015) on Establishment the Ministry of Environment and Forestry (English Translation), In: Indonesia, R.o. (Ed.), Jakarta, Indonesia.

Romijn, E., Herold, M., Kooistra, L., Murdiyarso, D., Verchot, L., 2012. Assessing capacities of nonAnnex I countries for national forest monitoring in the context of REDD+. Environmental Science \& Policy 19-20, 33-48.

Romijn, E., Lantican, C.B., Herold, M., Lindquist, E., Ochieng, R., Wijaya, A., Murdiyarso, D., Verchot, L., 2015. Assessing change in national forest monitoring capacities of 99 tropical countries. Forest Ecology and Management 352, 109-123.

RoP, 2011. Readiness Prepararion Proposal (R-PP), In: Ministry of Environment (MINAM), R.o.P. (Ed.), Lima, Peru.

RoP, 2014. Emission Reductions from Deforestation Fronts in the Peruvian Amazon, In: National Forest Conservation And Climate Change Mitigation Program (PNCBMCC) - Ministry of Environment (MINAM), R.o.P. (Ed.), Lima, Peru.

Rudel, T., 2008. Forest policy changes in the tropics: an emerging research priority. 18, 253-255. 
Saket, M., Branthomme, A., Piazza, M., 2010. FAO NFMA—Support to developing countries on national forest monitoring and assessment, In: Tomppo, E., Gschwantner, T., Lawrence, M., McRoberts, R.E. (Eds.), National forest inventories-Pathways for common reporting. Springer, New York.

Santilli, M., Moutinho, P., Schwartzman, S., Nepstad, D., Curran, L., Nobre, C., 2005. Tropical deforestation and the Kyoto Protocol. Climatic Change 71, 267-276.

Schmidt, V., 2005. Institutionalism and the state, In: Hay, C., Marsh, D., Lister, M. (Eds.), The State: Theories and Issues. Basingstoke, Palgrave.

Schmidt, V.A., 2001. The politics of economic adjustment in France and Britain: when does discourse matter? Journal of European Public Policy 8, 247-264.

Schmidt, V.A., 2002. Does Discourse Matter in the Politics of Welfare State Adjustment? Comparative Political Studies 35, 168-193.

Schmidt, V.A., 2006. Procedural democracy in the EU: the Europeanization of national and sectoral policy-making processes. Journal of European Public Policy 13, 670-691.

Schmidt, V.A., 2008. Discursive Institutionalism: The Explanatory Power of Ideas and Discourse. Annual Review of Political Science 11, 303-326.

Schmidt, V.A., 2010. Taking ideas and discourse seriously: explaining change through discursive institutionalism as the fourth 'new institutionalism'. European political science review 2, 1-25.

Schmidt, V.A., 2013. Democracy and legitimacy in the European Union revisited: input, output and 'throughput'. Political Studies 61, 2-22.

Schmidt, V.A., Radaelli, C.M., 2004. Policy Change and Discourse in Europe: Conceptual and Methodological Issues. West European Politics 27, 183-210.

Schrope, M., 2009. When money grows on trees. 101-103.

Schulman, L., Ruokolainen, K., Junikka, L., Sääksjärvi, I., Salo, M., Juvonen, S.-K., Salo, J., Higgins, M., 2007. Amazonian biodiversity and protected areas: do they meet? Biodiversity Conservation 16, 3011-3051.

Scott, W.R., 2001. Institutions and organizations. Sage.

Scott, W.R., 2014. Institutions and Organizations: Ideas, Interests, and Identities. Fourth Edition. Sage.

Sears, R.R., Pinedo-Vasquez, M., 2011. Forest Policy Reform and the Organization of Logging in Peruvian Amazonia. Development and Change 42, 609-631.

Secco, L., Da Re, R., Pettenella, D.M., Gatto, P., 2013. Why and how to measure forest governance at local level: A set of indicators. Forest Policy and Economics.

Secco, L., Da Re, R., Pettenella, D.M., Gatto, P., 2014. Why and how to measure forest governance at local level: A set of indicators. Forest Policy and Economics 49, 57-71.

Seymour, F., Birdsall, N., Savedoff, W., 2015. The Indonesia-Norway REDD+ Agreement: A Glass HalfFull. CGD Policy Paper 56. Washington DC: Center for Global Development.

Simonet, G., Karsenty, A., de Perthuis, C., Newton, P., Schaap, B., 2014. REDD+ projects in 2014: an overview based on a new database and typology. Information and debates Series No. 32. June 2014.

Skutsch, M., McCall, M., 2010. Reassessing REDD: governance, markets and the hype cycle. 100, 395402.

Smith, J., Colan, V., Sabogal, C., Snook, L., 2006. Why policy reforms fail to improve logging practices: The role of governance and norms in Peru. Forest Policy and Economics 8, 458-469.

Smouts, M.-C., 2008. The issue of an international forest regime. International Forestry Review 10, 429432.

SNI, 2011. Pengukuran dan penghitungan cadangan karbon -Pengukuran lapangan untuk penaksiran cadangan karbon hutan (ground based forest carbon accounting), In: (SNI), S.N.I. (Ed.), Jakarta.

Sprinz, D.F., 2000. Research on the effectiveness of international environmental regimes: a review of the state of the art. Potsdam Institute for Climate Impact Research \& University of Potsdam (PIK).

Steininger, M., 2014. Experiences in Capacity Building on Forest Monitoring at the National Level: The FCMC Peru MRV Activity. USAID-supported Forest Carbon, Markets and Communities Program, Washington, DC, USA.

Stern, N.H., 2007. The economics of climate change: the Stern review. cambridge University press. 
Sugardiman, R.A., 2012. Stepwise approaches to developing REDD+ MRV capacity in Indonesia, In: Mora, B., Herold, M., De Sy, V., Wijaya, A., Verchot, L., Penman, J. (Eds.), Capacity development in national forest monitoring: Experiences and progress for REDD+, Joint report by CIFOR and GOFC-GOLD. Bogor, Indonesia.

Tomppo, E., Andersson, K., 2008. Technical review of FAO's approach and methods for National Forest Monitoring and Assessment (NFMA). Forestry Department, FAO.

Tomppo, E., Gschwantner, T., Lawrence, M., McRoberts, R.E., 2010a. National Forest Inventories: Pathways for Common Reporting. Springer.

Tomppo, E., Katila, M., 2008. Comparing alternative sampling designs for national and regional forest monitoring. Technical review of FAO's approach and methods for National Forest Monitoring and Assessment (NFMA)/Ed. Tomppo, E. \& Andersson, K.

Tomppo, E., Katila, M., Mäkisara, K., Peräsaari, J., Malimbwi, R., Chamuya, N., Otieno, J., Dalsgaard, S., Leppänen, M., 2010b. Report to the Food and Agriculture Organization of the United Nations (FAO) in Support of Sampling Study for National Forestry Resources Monitoring and Assessment (NAFORMA) in Tanzania. Dar es Salaam, Tanzania: NAFORMA.

Tomppo, E., Katila, M., Mäkisara, K., Peräsaari, J., Malimbwi, R., Chamuya, N., Otieno, J., Dalsgaard, S., Leppänen, M., 2010c. Report to the Food and Agriculture Organization of the United Nations (FAO) in Support of Sampling Study for National Forestry Resources Monitoring and Assessment (NAFORMA) in Tanzania. FAO: Rome, Italy 10.

Turnhout, E., Skutsch, M., De Koning, J., 2015. Carbon accounting, In: Bäckstrand, K., Lövbrand, E. (Eds.), RESEARCH HANDBOOK ON CLIMATE GOVERNANCE. Edward Elgar Publising, pp. 366-376.

UN REDD Programme, 2013. FINAL EVALUATION OF THE UN-REDD PROGRAMME IN INDONESIA, Jakarta.

UN REDD Programme Website, "UN-REDD Programme." UN-REDD Programme. N.p., n.d. Web. 30 Jan. 2017. .

Underdal, A., 1992. The Concept of RegimeEffectiveness'. Cooperation and conflict 27, 227-240.

UNFCCC, 2009. Methodological guidance for activities relating to reducing emissions from deforestation and forest degradation and the role of conservation, sustainable management of forests and enhancement of forest carbon stocks in developing countries, Decision COP 15/4.

UNFCCC, 2010. Outcome of the work of the Ad Hoc Working Group on long-term Cooperative Action under the Convention - Policy approaches and positive incentives on issues relating to reducing emissions from deforestation and forest degradation in developing countries; and the role of conservation, sustainable management of forests and enhancement of forest carbon stocks in developing countries. UNFCCC COP 16 Cancun.

UNFCCC, 2013a. Report of the Conference of the Parties on its nineteenth session, held in Warsaw from 11 to 23 November 2013.

UNFCCC, 2013b. Work programme on results-based finance to progress the full implementation of the activities referred to in decision 1/CP.16, paragraph 70 .

UNFCCC, 2014a. key decisions relevant for reducing emissions from deforestation and forest degradation in developing countries (REDD+)' Decision booklet REDD+. UNFCCC Secretariat.

UNFCCC, 2014b. Report of the Conference of the Parties on its nineteenth session, held in Warsaw from 11 to 23 November 2013.

URT, 2010a. NATIONAL FORESTRY RESOURCES MONITORING AND ASSESSMENT OF TANZANIA (NAFORMA): Field Manual Socioeconomic survey, In: Division, F.a.B. (Ed.), Dar es Salaam, Tanzania.

URT, 2010b. NATIONAL FORESTRY RESOURCES MONITORING AND ASSESSMENT OF TANZANIA (NAFORMA): Field Manual, Biophysical survey, In: Division, F.a.B. (Ed.), Dar es Salaam, Tanzania. 
URT, 2010c. NATIONAL FORESTRY RESOURCES MONITORING AND ASSESSMENT OF TANZANIA (NAFORMA): Species List sorted by Latin names, In: Division, F.a.B. (Ed.), Dar es Salaam, Tanzania.

URT, 2013. National Strategy for Reduced Emissions from Deforestation and Forest Degradation (REDD+), In: Department of Environment, V.P.s.O. (Ed.).

URT, 2015. National Forest Monitoring and Assessment of Tanzania: Main Results, In: Agency, T.F.S. (Ed.). Ministry of Natural Resources and Tourism, United Republic of Tanzania, Dar es Salam.

Van Tatenhove, J., Arts, B., Leroy, P., 2000. Political Modernisation and the Environment. The Renewal of Environmental Policy Arrangements. Kluwer Academic Publishers, Dordrecht.

Vargas, G.C., B.E., R., S.D., C., Mendoza, E.V., C.A., C.n.-U., Giudice, G.R., Malaga, D.N., 2014. Protocolo de Clasificación de Pérdida de Cobertura en los Bosques Húmedos Amazónicos entre los años 2000-2011, In: Riego, M.d.A.y.M.d.A.y. (Ed.), Lima-Perú.

VCS, 2013. Jurisdictional and Nested REDD+ (JNR) Requirements, Version 3. , In: Standards, V.C. (Ed.).

Verbesselt, J., Kalomenopoulos, M., Souza, C., Herold, M., 2012. Near real-time deforestation monitoring in tropical ecosystems using satellite image time series, Geoscience and Remote Sensing Symposium (IGARSS), 2012 IEEE International, pp. 2020-2023.

Verplanke, J.J., Zahabu, E., 2009. A Field Guide for Assessing and Monitoring Reduced Forest Degradation and Carbon Sequestration by Local Communities.

Victor, D.G., 2006. Toward effective international cooperation on climate change: Numbers, interests and institutions. Global environmental politics 6, 90-103.

Vijge, M.J., 2016. Carbonizing forest governance: Analysing the consequences of REDD+ for multilevel forest governance, Environmental Policy Group. Wageningen University and Research Centre, Wageningen, p. 178.

Visseren-Hamakers, I.J., Gupta, A., Herold, M., Peña-Claros, M., Vijge, M.J., 2012. Will REDD+ work? The need for interdisciplinary research to address key challenges. Current Opinion in Environmental Sustainability 4, 590-596.

Visseren-Hamakers, I.J., 2013. Partnerships and sustainable development: the lessons learned from international biodiversity governance. Environmental Policy and Governance 23, 145-160.

Wertz-Kanounnikoff, S., McNeill, D., 2012. Performance indicators and REDD+ implementation, In: Angelsen, A., Brockhaus, M., Sunderlin, W.D., Verchot, L.V. (Eds.), Analysing REDD+: Challenges and choices. CIFOR, Bogor, Indonesia, pp. 233 - 246.

Westoby, J., 1989. Introduction to world forestry: people and their trees. Basil Blackwell.

Wiering, M.A., Arts, B.J.M., 2006. Discursive shifts in Dutch river management: "deep" institutional change or adaptation strategy? Hydrobiologia 565, 327-338.

Wiersum, K.F., 1995. 200 years of sustainability in forestry: lessons from history. Environmental management 19, 321-329.

Wiersum, K.F., Arts, B., van Laar, J., 2012. From Practical Science to a Practice Based Approach: A Short History of Forest Policy Studies, Forest and Nature Governance. Springer, pp. 23-46.

Woods, N., 2000. The Challenge of Good Governance for the IMF and the World Bank Themselves. World Development 28, 823-841.

Wulder, M.A., Coops, N.C., , 2014. Satellites: Make Earth observations open access. Nature 513.

Xie, X., Wang, Q., Dai, L., Su, D., Wang, X., Qi, G., Ye, Y., 2011. Application of China's National Forest Continuous Inventory Database. 48, 1095-1106.

Yin, R.K., 1994. Case Study Research. Design and Methods, 2 ed. Sage Publications, Thousand Oaks, CA.

Yin, R.K., 2009. Case study research: Design and methods 4th ed, United States: Library of Congress Cataloguing-in-Publication Data.

Young, K.R., 1996. Threats to biological diversity caused by coca/cocaine deforestation in Peru. Environmental Conservation 23, 7-15.

Young, O.R., 1980. International regimes: Problems of concept formation. World Politics 32, 331-356. 
Young, O.R., 1993. International organizations and international institutions: Lessons learned from environmental regimes. Environmental politics in the international arena, 145-164.

Young, O.R., 1999a. Chapter 5: Regime Effectiveness: Taking Stock, In: Young, O.R., Levy, M.A. (Eds.), The Effectiveness of International Environmental Regimes: The Causal Connections and Behavioral Mechanisms. The MIT Press, Cambridge, MA, pp. 249-279.

Young, O.R., 1999b. The effectiveness of international environmental regimes: Causal connections and behavioral mechanisms. MIT Press.

Young, O.R., 2011. Effectiveness of international environmental regimes: Existing knowledge, cuttingedge themes, and research strategies. Proceedings of the National Academy of Sciences 108, 1985319860.

Young, O.R., Levy, M.A., 1999. Chapter 1: The Effectiveness of International Environmental Regimes, In: Young, O.R. (Ed.), The Effectiveness of International Environmental Regimes: The Causal Connections and Behavioral Mechanisms. The MIT Press, Cambridge, MA, pp. 1-32. 


\section{Summary - The role of forests in climate change mitigation: A discursive-institutional analysis of REDD+ MRV}

Since the advent of professional forestry in the $17^{\text {th }}$ century, forest monitoring has been part and parcel of forest management, and has been implemented in different forms in many European countries. The practice of forest monitoring was later exported to the European colonies, and has since been taken over and conducted by post-colonial governments in many developing countries. From an earlier focus on assessment of timber stocks, the practice has evolved to include assessments of other forest variables than timber. Despite this evolution, national forest monitoring has remained largely timber-oriented, and a closed system with little participation of actors outside the state forestry bureaucracy. However, the United Nations Framework Convention on Climate Change (UNFCCC) decision on reducing emissions from deforestation and forest degradation, and the role of conservation, sustainable management of forests and enhancement of forest carbon stocks in developing countries (REDD+) has opened up new discussions on forest monitoring in developing countries. Specifically, the global discourse on monitoring, reporting and verification (MRV) of REDD+ outcomes has introduced new ideas and demands on the scope and objectives of forest monitoring, the actors to be involved, and resources to be used. Taken together, the emergence of the REDD+ MRV discourse and associated ideas calls for change in the institutional arrangements for forest monitoring in developing countries. Furthermore, while these ideas and demands are determined and agreed upon in an international negotiation process, they need to be translated and implemented in highly diverse country-specific contexts, with country-specific actors, ideas, interests, and institutions. Translating the REDD+ MRV discourse and ideas into national institutional arrangements thus involves negotiation and contestation among national stakeholders.

This dissertation examines the performance of REDD+ MRV in terms of its implementation and institutionalization in developing countries, and the political processes by which such institutionalization occurs. Specifically, it examines (1) the institutional effectiveness of REDD+ MRV; (2) how the concept of REDD+ MRV and associated ideas have materialized in new institutional arrangements for forest monitoring in developing countries; and (3) how discursive processes of policymaking and the argumentation and contestation inherent in such processes 
enable or constrain institutionalization. With this, the dissertation contributes to the literature on REDD+ MRV by examining forest monitoring from a social science perspective. While current research on REDD+ MRV remains highly technical, since it is assumed that forest monitoring is a neutral, apolitical activity, this study argues that monitoring deforestation is also political, and contributes by highlighting the political contestation involved in implementing REDD+ MRV at the national level. The dissertation also contributes to scientific debates on the performance of international environment agreements at the national level, and how contestation and negotiation among domestic stakeholders enable or constrain their institutionalization at the national level.

Chapter 1 introduces the research presented in this dissertation. It provides an overview of the emergence of reducing emissions from deforestation and forest degradation in developing countries (REDD+) within the United Nations Convention on Climate Change (UNFCCC) as a climate mitigation strategy, and argues that the UNFCCC's decisions on monitoring, reporting and verification (MRV) for REDD+ pose new ideas and demands for forest monitoring in developing countries. It elucidates the research that has been done on REDD+ MRV so far, identifies gaps in the existing literature on forest monitoring for REDD + , and delineates the objectives of the study. It discusses the theoretical basis and framework for the study, explaining how the main theoretical concept - discursive institutionalism - is combined with the Policy Arrangement Approach (PAA) to examine how REDD+ MRV has been shaped and institutionalized in new or reformed institutional arrangements for forest monitoring in developing countries, and discursive processes by which such institutionalization occurs. After presenting the conceptual framework, four research questions are outlined, namely:

1. What is the institutional effectiveness of REDD+ MRV in terms of its implementation in developing countries?

2. How have institutional arrangements for forest monitoring in Peru evolved, and how and to what extent has their evolution been shaped by international discourses on forests, especially REDD+ MRV?

3. How and to what extent has the concept of MRV become institutionalized in new or reformed institutional arrangements for forest monitoring in Indonesia, Peru and Tanzania, and how can differences in this extent of institutionalization across the countries be explained? 
4. How has discursive politics enabled or constrained institutionalization of MRV in Indonesia, Peru and Tanzania?

The chapter then describes the study's overall research design and methodology, and ends by outlining the structure of the dissertation.

Chapter 2 examines the institutional effectiveness of REDD+ MRV. The chapter draws on regime literature to conceptualize UNFCCC and its decisions on REDD+ MRV as an international institution or regime, and outlines the technical and good governance requirements for MRV. Drawing on Young and Levy's (1999) framework for assessing effectiveness of international institutions, and building on UNFCCC and IPCC methodological guidelines for Land Use, Land Use Change and Forestry (LULUCF), and good governance literature, it develops criteria and indicators for assessing progress in implementing the identified technical and governance requirements for MRV. Three dimensions on which effectiveness of REDD+ MRV can be evaluated are developed: 'owning technical methods for MRV', 'developing administrative competence' and 'integrating good governance' in MRV. The framework is applied to assess and compare institutional effectiveness of REDD+ MRV in 13 REDD+ countries, based on a review of national and international documents. The Chapter shows that REDD+ countries have high to very high ownership of technical methods. However, the majority of the countries rank only low to moderate on administrative capacity and good governance. This means that although countries have started developing technical methods for MRV, they are yet to develop the competence necessary to administer MRV and to incorporate aspects of good governance in MRV. The chapter explains the scores and suggest ways of improving implementation of REDD+ MRV.

Chapter 3 examines how and to what extent global discourses and ideas on forests, especially the concept of REDD+ MRV, have shaped institutional arrangements for forest monitoring in developing countries, using the case of Peru. It draws on discursive institutionalism to conceptualize REDD+ MRV as a discourse and identify the ideas represented in the discourse. It then combines discursive institutionalism with the policy arrangement approach to craft a framework for examining the extent to which REDD+ MRV, and other global discourses, have shaped national institutional arrangements for forest monitoring in Peru. An analytical distinction is made between 'shallow' and 'deep' institutional change. The chapter identifies three distinct 
discourses - productivist forest philosophy, multiple-use and sustainable forest management philosophies and REDD+ MRV - that have shaped forest monitoring in Peru. The chapter shows that while all the three discourses have shaped the scope and objectives of forest monitoring, the actors involved, resources used, and rules governing forest assessments, none of them has led to 'deep' institutionalization of forest monitoring. On REDD+ MRV specifically, the chapter shows that it has expanded the scope and objectives of forest assessments in Peru, inspired the mobilization of new actors and resources, and spawned the development of new rules to govern forest monitoring. However, these institutional changes are not yet 'deep', since the new rules for forest inventories have not yet been formally adopted, and the agencies envisioned to implement forest monitoring have not been established. The chapter concludes that forest monitoring in general, and REDD+ MRV in particular, is only shallowly institutionalized in Peru.

Chapter 4 compares how and to what extent the concept of REDD+ MRV has institutionalized in Indonesia, Peru and Tanzania. To do so, the chapter draws on insights from discursive institutionalism operationalized by means of the policy arrangement approach to develop the analytical categories of 'shallow', 'shallow-intermediate', 'deep-intermediate' and 'deep' institutionalization, and uses these categories to examine the extent of institutionalization across the countries. The chapter shows that in all three countries, REDD+ MRV has institutionalized in new or revised aims, scope and strategies for forest monitoring, and the development of new agencies and mobilization of new actors and resources. New legislation to anchor forest monitoring in law, and procedures to institutionalize the roles of the various agencies, are also being developed. Nevertheless, the extent of institutionalization of MRV varies across the countries, with Indonesia experiencing 'deep' institutionalization, Peru 'shallow-intermediate', and Tanzania 'intermediate-deep' institutionalization. To explain the differences in institutionalization, the chapter examines the theoretical factors for discourse institutionalization and their manifestation in each country. It shows that the relatively 'deep' institutionalization of REDD+ MRV in Indonesia and Tanzania is due to the presence of all five factors for discourse institutionalization. Only one factor is found to be present in Peru, and the 'shallow-intermediate' institutionalization of REDD + is largely due to the absence of other factors. Based on the findings and conclusions, the chapter draws lessons to inform institutionalization of MRV in other countries. 
Chapter 5 examines how the discursive politics of MRV policymaking has enabled or constrained institutionalization of REDD+ MRV in Indonesia, Peru and Tanzania. To do this, it draws on the concept of discourse - understood as ideas and the interactive process of policymaking and public deliberation - to examine the actors involved in MRV policy development in the respective countries, and how the deliberation, argumentation and contestation among them (discursive politics) have enabled or constrained institutionalization. The chapter shows that in all countries, the methodologies to be used for MRV, the actors to be involved and their roles were contentious. However, it shows that in Indonesia and Tanzania, where there was a broad-based national discourse on MRV, and where policy actors agreed on the strategies to implement MRV and the role of different actors in forest monitoring, there is relatively 'deep' institutionalization compared to Peru, where such discourse and agreement were lacking. The chapter discusses how the discursive process facilitated institutionalization of REDD+ MRV in Indonesia and Tanzania and constrained the same in Peru. It concludes that how discursive politics is played matters in institutionalization.

Chapter 6 presents the conclusions on the study. It draws on the empirical chapters to answer the research questions, concluding that majority $(60 \%)$ of the analysed countries has achieved at least a 'moderate' institutional effectiveness for MRV. Further, it concludes that the concept of REDD+ MRV has materialized in reformed institutional arrangements for forest monitoring in Indonesia, Peru and Tanzania, albeit to varying degrees. The chapter also concludes that forest monitoring for REDD+ is not only a technical activity, but is also political. Specifically, it concludes that decisions on what exactly is to be monitored and reported, by whom and using what methods are determined through political negotiations, and that how this political process is managed has a significant influence on how, and the extent to which, MRV is institutionalized. After drawing the conclusions, the chapter reflects on the key theoretical concepts used in the study by outlining how discursive institutionalism and the policy arrangement approach can be used to enrich one another. The chapter ends by outlining several policy recommendations. First, it recommends that while the development of new agencies to implement REDD+ MRV is necessary in some countries, care should be taken to avoid establishment of many agencies. Where possible, policy makers and donors should consider working with and strengthening existing agencies before deciding to 
establish new agencies. Second, it recommends that more investments be directed to organizing inclusive MRV policy coordination processes, since the politics involved in these processes determine the extent to which REDD+ MRV is institutionalized. Lastly, investments in policy coordination should be accompanied with investments in broader communicative political discourse to enlighten all REDD+ stakeholders on MRV policy processes and the strategies being proposed, while seeking the views and feedback these strategies. This is necessary if the proposed strategies are to be legitimate in the eyes of key REDD+ stakeholders. 


\section{Samenvatting - De rol van bossen in de strijd tegen klimaatverandering: een discursief- institutionele analyse van REDD+/MRV}

Al sinds het begin van de professionele bosbouw in de zeventiende eeuw is monitoring van bosontwikkeling een vast onderdeel van Europees bosbeheer geweest. Later werd dit gebruik geëxporteerd naar de Europese koloniën en inmiddels is het ook overgenomen door postkoloniale regeringen in veel ontwikkelingslanden. Waar in eerste instantie de focus lag op het beoordelen van de houtvoorraad, werden later ook andere variabelen opgenomen. Ondanks deze ontwikkeling blijft nationale bosmonitoring hoofdzakelijk gericht op hout en wordt slechts een beperkt aantal actoren van buiten het staatsapparaat betrokken. De beslissing van het Klimaatverdrag (United Nations Framework Convention on Climate Change - UNFCCC) over de vermindering van emissies door ontbossing en bosdegradatie (REDD+) heeft nieuwe discussies op gang gebracht over het monitoring van bos in ontwikkelingslanden. Specifiek heeft het mondiale discours over monitoring, rapportage en verificatie (MRV) van REDD+-resultaten geleid tot nieuwe ideeën en wensen met betrekking tot de reikwijdte en doelstellingen van monitoring, de actoren die daarbij moeten worden betrokken en de middelen die daarvoor moeten worden gebruikt. In het geheel genomen vereist de opkomst van het REDD+/MRV-discours - en de daarmee geassocieerde ideeën en wensen - een verandering van het institutionele arrangement voor het monitoren van bos in ontwikkelingslanden. Bovendien moeten deze ideeën en wensen, hoewel ze in een internationaal onderhandelingsproces zijn overeengekomen, worden vertaald naar sterk uiteenlopende, land-specifieke contexten met uiteenlopende actoren, ideeën, belangen en instellingen. Het vertalen van het REDD+/MRV-discours naar nationale institutionele arrangementen vereist dan ook onderhandeling en debat tussen nationale belanghebbenden.

In dit proefschrift wordt onderzoek gedaan naar de prestaties van REDD+/MRV in termen van implementatie en institutionalisering in ontwikkelingslanden, en naar de achterliggende politieke processen. Specifiek wordt onderzoek gedaan naar (1) de institutionele effectiviteit van REDD+/MRV; (2) de manier waarop het concept REDD+/MRV en de daarmee geassocieerde ideeën worden verwezenlijkt in de vorm van nieuwe institutionele arrangementen voor het monitoren van bos in ontwikkelingslanden; en (3) de manier waarop argumentatie en debat (of te wel 'discursieve processen') dergelijke institutionalisering bevorderen dan wel belemmeren. Als 
zodanig levert dit proefschrift een bijdrage aan de literatuur over REDD+/MRV door het monitoren van bos te onderzoeken vanuit een sociaalwetenschappelijk perspectief. Dit onderzoek naar is vooralsnog zeer technisch gebleven, omdat wordt aangenomen dat monitoren een neutrale, apolitieke activiteit is. Dit onderzoek stelt echter dat het monitoren van ontbossing en bosdegradatie ook een politieke activiteit is en biedt daarmee een politieke analyse van de implementatie van REDD+/MRV op nationaal niveau. Dit proefschrift levert tevens een bijdrage aan wetenschappelijke debatten over de prestaties van internationale milieuverdragen op nationaal niveau, en geeft bovendien inzicht in de mate waarin discursieve processen (debat en onderhandeling) tussen nationale belangengroepen de institutionalisering van internationale afspraken op nationaal niveau bevorderen of belemmeren.

Hoofdstuk 1 introduceert het onderzoek dat in dit proefschrift wordt gepresenteerd. Er wordt een overzicht gegeven van de opkomst van REDD+ binnen de UNFCCC als een strategie in de strijd tegen klimaatverandering, en er wordt gesteld dat de beslissingen van de UNFCCC over monitoring, rapportage en verificatie (MRV) voor REDD+ nieuwe ideeën en wensen hebben opgeleverd voor het monitoren van bos in ontwikkelingslanden. Het onderzoek dat tot nu toe is uitgevoerd naar REDD+/MRV wordt nader toegelicht, leemtes in de huidige literatuur over dit onderwerp worden vastgesteld, en de doelstellingen van de studie worden gepresenteerd. De theoretische basis en het kader voor de studie worden uit de doeken gedaan, waarbij wordt uitgelegd hoe het theoretisch perspectief - discursief-institutionalisme - wordt gecombineerd met de Policy Arrangement Approach (PAA) om na te gaan hoe REDD+/MRV vorm heeft gekregen in nieuwe of hervormde institutionele arrangementen voor het monitoren van bos in ontwikkelingslanden, en welke discursieve processen een dergelijke institutionalisering teweegbrengen. Nadat het conceptuele kader is geschetst, worden vier onderzoeksvragen gesteld, namelijk:

1. Wat is de institutionele effectiviteit van REDD+/MRV in termen van de implementatie in ontwikkelingslanden?

2. Hoe zijn de institutionele arrangementen voor het monitoren van bos in Peru geëvolueerd, en hoe en in welke mate is deze evolutie gevormd door internationale discoursen over bossen, in het bijzonder REDD+/MRV? 
3. Hoe en in welke mate is het concept MRV geïnstitutionaliseerd in nieuwe of hervormde institutionele arrangementen voor het monitoren van bos in Indonesië, Peru en Tanzania, en hoe kunnen de verschillen in de mate van institutionalisering tussen deze landen worden verklaard?

4. Op welke manier heeft discursieve politiek de institutionalisering van MRV in Indonesië, Peru en Tanzania bevorderd of belemmerd?

Hoofdstuk 1 wordt afgesloten met de algemene opzet en methodologie van het onderzoek, gevolgd door de opzet van het proefschrift.

Hoofdstuk 2 gaat in op de institutionele effectiviteit van REDD+/MRV. Aan de hand van literatuur over regimes worden de UNFCCC en zijn beslissingen over REDD+/MRV geconceptualiseerd als een 'internationaal regime', en worden de technische vereisten en de vereisten van goed bestuur voor MRV vastgesteld. Aan de hand van Young en Levy's (1999) kader voor het beoordelen van de effectiviteit van internationale instituties, en voortbouwend op de methodologische richtlijnen voor landgebruik, verandering van landgebruik en bosbouw (LULUCF) van de UNFCCC en IPCC, alsmede gebaseerd op literatuur over goed bestuur, worden criteria en indicatoren ontwikkeld voor het beoordelen van de voortgang van de nationale implementatie van MRV. Er worden drie dimensies ontwikkeld op basis waarvan de effectiviteit van REDD+/MRV kan worden geëvalueerd: 'eigenaarschap van technische methodes voor MRV', 'ontwikkeling van bestuurlijke deskundigheid' en 'integratie van goed bestuur'. Het kader wordt toegepast om de institutionele effectiviteit van REDD+/MRV in dertien REDD+-landen te beoordelen en vergelijken, op basis van een review van nationale en internationale documenten. In dit hoofdstuk blijkt dat REDD+-landen een sterk tot zeer sterk eigenaarschap hebben van technische methodes. De meerderheid van de landen scoort echter matig tot laag op bestuurlijke capaciteit en goed bestuur. Dit houdt in dat landen wel begonnen zijn met het ontwikkelen van technische methodes voor MRV, maar dat ze de capaciteit voor het aansturen van MRV systemen, met inachtneming van aspecten van goed bestuur, nog moeten ontwikkelen. Afsluitend worden in dit hoofdstuk deze bevindingen verklaard en suggesties gedaan voor het verbeteren van de implementatie van REDD+/MRV. 
Hoofdstuk 3 onderzoekt hoe en in welke mate mondiale discoursen en ideeën over bossen, in het bijzonder het concept REDD+/MRV, de institutionele arrangementen voor het monitoren van bos in ontwikkelingslanden hebben gevormd, waarbij Peru als casus wordt gebruikt. Daarbij wordt gebruik gemaakt van het discursief-institutionele perspectief om REDD+/MRV te analyseren. REDD+/MRV kan volgens dit kader worden gezien als een 'discourse', als een set van ideeën die belanghebbenden uitwisselen en zo mogelijk ook veranderen.. Vervolgens wordt dit perspectief gecombineerd met de PAA om een kader te creëren voor het onderzoeken van de mate waarin het REDD+/MRV discourse (en eventueel andere mondiale discoursen) de nationale institutionele arrangementen voor het monitoren van bos in Peru hebben gevormd. Er wordt een analytisch onderscheid gemaakt tussen oppervlakkige en diepgaande institutionele veranderingen. In dit hoofdstuk worden drie aparte discoursen geïdentificeerd - het productivistische discourse, het meervoudig-bosgebruik discourse (in combinatie met het duurzaam-bosbeheer discourse), en het REDD+/MRV discourse - die het monitoren van bos in Peru hebben gevormd. Dit hoofdstuk laat zien dat hoewel elk van de drie discoursen van invloed zijn geweest op de reikwijdte en doelstellingen van monitoring, de betrokken actoren, de gebruikte middelen en de regels voor bosbeoordeling, geen van deze discoursen heeft geleid tot diepgaande institutionalisering van nieuwe vormen van monitoring. Het REDD+/MRV discours heeft weliswaar geleid tot uitbreiding van reikwijdte en doelstellingen van bosmonitoring in Peru, mobilisering van nieuwe actoren en middelen, en ontwikkeling van nieuwe regels, echter deze institutionele veranderingen zijn niet diepgaand, aangezien de nieuwe regels voor bosinventarisaties nog niet formeel zijn aangenomen en de instanties die verantwoordelijk zullen zijn voor de monitoring nog niet zijn opgericht. Tot slot wordt geconcludeerd dat het monitoren van bos in het algemeen en REDD+/MRV in het bijzonder in Peru slechts oppervlakkig zijn geïnstitutionaliseerd.

In hoofdstuk 4 wordt gekeken hoe en in welke mate het concept REDD+/MRV is geïnstitutionaliseerd in Indonesië, Peru en Tanzania. Hierbij wordt opnieuw uitgegaan van het discursief-institutionalisme als perspectief, dat met behulp van de PAA wordt geoperationaliseerd tot de analytische categorieën 'oppervlakkige', 'matig oppervlakkige', 'matig diepgaande' en 'diepgaande institutionalisering'. Deze categorieën worden vervolgens gebruikt om de mate van institutionalisering van REDD+/MRV in de verschillende landen te onderzoeken. In dit hoofdstuk wordt aangetoond dat REDD+/MRV in alle drie de landen is geïnstitutionaliseerd in nieuwe of 
herziene doelen, reikwijdtes en strategieën voor bosmonitoring, en dat er nieuwe instanties worden opgericht voor het mobiliseren van actoren en middelen. Tevens worden nieuwe wetten opgesteld om monitoring institutioneel te verankeren, evenals procedures om de rol van de verschillende instanties vast te leggen. Desondanks varieert de mate van institutionalisering van MRV van land tot land, waarbij het concept diepgaand is geïnstitutionaliseerd in Indonesië, matig oppervlakkig in Peru en matig diepgaand in Tanzania. Om deze verschillen te verklaren, worden in dit hoofdstuk de factoren onderzocht voor institutionalisering van discoursen uit de theoretische literatuur en hun empirische manifestatie in elk land. Hieruit blijkt dat de relatief diepgaande institutionalisering van REDD+/MRV in Indonesië en Tanzania te danken is aan het feit dat alle vijf de factoren voor institutionalisering van discoursen aanwezig zijn. In Peru is slechts een van deze vijf factoren aanwezig. Op basis van deze bevindingen en conclusies worden lessen getrokken om institutionalisering van MRV in andere landen te bevorderen.

In hoofdstuk 5 wordt onderzocht in hoeverre discursieve politiek institutionalisering van REDD+/MRV in Indonesië, Peru en Tanzania heeft bevorderd of belemmerd. Daarbij wordt uitgegaan van het concept discours - begrepen als ideeën in politiek debat en in interactieve beleidsvorming - om onderzoek te doen naar de actoren die betrokken zijn bij de ontwikkeling van MRV in de respectieve landen, en naar de manier waarop onderling debat, argumentatie en beraadslaging (of te wel 'discursieve politiek') institutionalisering hebben bevorderd of belemmerd. In dit hoofdstuk blijkt dat de voor MRV te gebruiken methodologieën, de te betrekken actoren en hun rol in alle landen controversieel zijn. Er blijkt echter sprake te zijn van een relatief diepgaande institutionalisering in Indonesië en Tanzania, waar sprake was van een breed gedragen nationaal discours over MRV en waar beleidsactoren overeenstemming hadden bereikt over de strategieën voor het implementeren van MRV en de rol van verschillende actoren daarbij. In Peru ontbreekt echter zulk een discours en overeenstemming. In dit hoofdstuk wordt daarom geconcludeerd dat bij institutionalisering van beleid discursieve politiek van groot belang is.

In hoofdstuk 6 worden conclusies getrokken. Aan de hand van de empirische hoofdstukken worden de onderzoeksvragen beantwoord. Het blijkt dat de meerderheid $(60 \%)$ van de geanalyseerde landen minimaal een matige institutionele effectiviteit voor MRV heeft bereikt. Daarnaast wordt geconcludeerd dat het concept REDD+/MRV heeft geleid tot hervormde 
institutionele arrangementen voor bosmonitoring in Indonesië, Peru en Tanzania, zij het in verschillende mate. Een andere conclusie is dat het monitoren van bos voor REDD+ niet alleen een technische, maar ook een politieke activiteit is. Meer specifiek wordt geconcludeerd dat er politieke onderhandelingen voorafgaan aan beslissingen over wat precies moet worden bewaakt en gerapporteerd, wie dit moet doen en welke methodes daarbij worden gebruikt, en dat de manier waarop dit politieke proces wordt vorm gegeven een significante invloed heeft op de wijze en mate van institutionalisering van MRV. Na de conclusies volgt een reflectie op de belangrijkste theoretische concepten van de studie, waarbij wordt geschetst hoe het discursief-institutionalisme en de Policy Arrangement Approach elkaar kunnen aanvullen. Tot slot wordt een aantal beleidsaanbevelingen geformuleerd. Ten eerste moet worden vermeden dat te veel instanties zich bemoeien met het implementeren van REDD+/MRV, hoewel het in sommige landen noodzakelijk zal zijn om nieuwe organisaties op te richten. Waar mogelijk moeten beleidsmakers en financiers echter overwegen om samen te werken met bestaande instanties of deze te versterken voordat nieuwe worden opgericht. Een tweede aanbeveling is om meer te investeren in het organiseren van inclusieve beleidsprocessen voor MRV, aangezien de discursieve politiek, die bij zulke processen hoort, bepaalt in welke mate REDD+/MRV wordt geïnstitutionaliseerd. Tot slot moeten investeringen in beleidscoördinatie worden gecombineerd met investeringen in een breder communicatief politiek discours om alle belanghebbenden te informeren over MRVbeleidsprocessen, en om tevens hun mening en feedback te vragen over deze processen. Dit is nodig om te zorgen dat de voorgestelde strategieën in de ogen van de belangrijkste belanghebbenden legitiem zijn. 


\section{List of Publications}

\section{Peer reviewed}

Ochieng R.M., Visseren-Hamakers, I.J., Brockhaus, M., Kowler, L.F., Herold, M. \& Arts, B. (2016). Historical development of institutional arrangements for forest monitoring and REDD + MRV in Peru: Discursive-institutionalist perspectives. Forest Policy and Economics 71, 52-59.

Ochieng, R.M., Visseren-Hamakers, I.J., Arts, B., Brockhaus, M. \& Herold, M., 2016. Institutional effectiveness of REDD+ MRV: Countries progress in implementing technical guidelines and good governance requirements. Environmental Science \& Policy 61, 42-52.

Romijn, E., Lantican, C.B., Herold, M., Lindquist, E., Ochieng, R., Wijaya, A., Murdiyarso, D. \& Verchot, L., 2015. Assessing change in national forest monitoring capacities of 99 tropical countries. Forest Ecology and Management 352, 109-123.

Cheboiwo, J.K., Ochieng, R.M., Mbinga, J. \& Mutiso, F. (2015). Potential Growth, Yields and Socioeconomic Benefits of Four Indigenous Species for Restoration in Moist Forests, Mau Kenya. Journal of Environment and Earth Science 5(6): 72-84.

Tegegne, Y.T., Ochieng, R.M., Visseren-Hamakers, I.J., Lindne, M \& Fobissie, K.B. 2014. Comparative Analysis of the Interactions between FLEGT and REDD+ Regimes in Cameroon and the Republic of Congo. International Forestry Review 16(6): 602-614.

Arevalo, J., Ochieng, R., Mola-Yudego, B. \& D. Gritten. 2014. Understanding bioenergy conflicts: Case of a jatropha project in Kenya's Tana Delta. Land Use Policy 41: 138-148.

Ochieng R.M., Visseren-Hamakers, I.J. \& Nketiah, S. 2013. Interaction between the FLEGTVPA and REDD+ in Ghana: Recommendations for interaction management. Forest Policy and Economics 32: 32-29.

\section{Non-peer reviewed (technical reports and workshop/ conference proceedings)}

Ochieng, R.M. (2016a). Does discourse matter in institutionalization? The case of REDD+ MRV in Indonesia, Peru and Tanzania. In: Proceedings of the 2016 Earth System Governance, Nairobi, Kenya, 7 - 9 Dec 2016.

Ochieng, R.M. (2016b). Institutionalization of the REDD+ MRV in Indonesia, Peru and Tanzania. In: Proceedings of CIFOR GCS Module II Workshop and Outreach, Addis Ababa, Ethiopia, 8 - 10 June 2016.

Ochieng, R.M. et al. (2015a). Influence of REDD+ MRV rules on institutional arrangements for forest measurements in developing countries: Insights from Peru. In: Proceedings of the XIV World Forestry Congress, Durban, South Africa, 7-11 Sept. 2015. 
Ochieng, R.M. (2015b). Influence of global discourse and rules for REDD+ MRV on institutional arrangements for forest measurements: Insights from Peru. In: Proceedings of the WASS PhD Day, Wageningen, the Netherlands, 28 May 2015.

Tegegne, Y.T., Ochieng, R.M., Visseren-Hamakers, I.J., Lindner, M., Fobissie, K.B. \& Kanninen, M. (2014). National-level FLEGT VPA and REDD+ interactions, Congo Basin. In: Broekhoven, Guido and Marieke Wit (eds.). Linking FLEGT and REDD+ to Improve Forest Governance. ETFRN News 55. Tropenbos International. pp. 18-24.

Ochieng, R.M. (2014). A framework for assessing institutional capacity for forest measurements: an illustration from Vietnam. In: Proceedings of the CIFOR GCS Module I Planning Meeting and Outreach Workshop, Ouagadougou, Burkina Faso. 23-36 April 2014. 
Robert M. Ochieng

Wageningen School of Social Sciences (WASS)

Completed Training and Supervision Plan

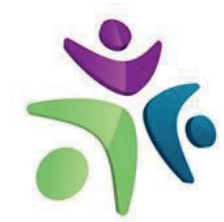

Wageningen School

of Social Sciences

\begin{tabular}{|c|c|c|c|}
\hline Name of Learning Activity & Department/ Institute & Year & ECTS* \\
\hline \multicolumn{4}{|l|}{ Project related competences } \\
\hline Writing PhD Research Proposal & FNP & 2013 & 6 \\
\hline Research Methodology: From Topic to Proposal & WASS & 2013 & 4 \\
\hline Visiting scholar at George Mason University & $\begin{array}{l}\text { George Mason University, } \\
\text { Virginia, USA }\end{array}$ & 2016 & 1 \\
\hline \multicolumn{4}{|l|}{ General research related competences } \\
\hline WASS introductory course & WASS & 2013 & 1 \\
\hline Systematic literature review for social sciences & WASS/ WUR Library & 2013 & 3.7 \\
\hline $\begin{array}{l}\text { FNP Summer school - Governing landscape } \\
\text { restoration: Governance, Restoration, } \\
\text { Privatization }\end{array}$ & $\mathrm{FNP} / \mathrm{CDI} / \mathrm{COMMON} / \mathrm{WASS}$ & 2015 & 3 \\
\hline $\begin{array}{l}\text { 'A framework for assessing institutional capacity } \\
\text { for forest measurements: an illustration from } \\
\text { Vietnam' }\end{array}$ & $\begin{array}{l}\text { CIFOR GCS Module I } \\
\text { Planning Meeting and } \\
\text { Outreach Workshop, } \\
\text { Ouagadougou, Burkina Faso }\end{array}$ & 2014 & 1 \\
\hline $\begin{array}{l}\text { 'Institutional capacity for forest monitoring: } \\
\text { REDD }+ \text { countries' progress towards fulfilling } \\
\text { MRV requirement. }\end{array}$ & $\begin{array}{l}\text { Seminar Presentation, } \\
\text { CIFOR HQs, Bogor, } \\
\text { Indonesia. }\end{array}$ & 2014 & 1 \\
\hline $\begin{array}{l}\text { 'Influence of global discourse and rules for } \\
R E D D+M R V \text { on institutional arrangements for } \\
\text { forest measurements: Insights from Peru' }\end{array}$ & $\begin{array}{l}\text { WASS PhD Day, } \\
\text { Wageningen, the Netherlands }\end{array}$ & 2015 & 1 \\
\hline $\begin{array}{l}\text { 'Influence of REDD+ MRV rules on institutional } \\
\text { arrangements for forest measurements in } \\
\text { developing countries: Insights from Peru' }\end{array}$ & $\begin{array}{l}\text { XIV World Forestry } \\
\text { Congress, Durban, South } \\
\text { Africa }\end{array}$ & 2015 & 1 \\
\hline $\begin{array}{l}\text { 'Institutionalization of the REDD+ MRV in } \\
\text { Indonesia, Peru and Tanzania' }\end{array}$ & $\begin{array}{l}\text { CIFOR GCS Module II } \\
\text { Workshop and Outreach, } \\
\text { Addis Ababa, Ethiopia }\end{array}$ & 2016 & 2 \\
\hline $\begin{array}{l}\text { 'Global discourse on REDD+MRV and national } \\
\text { institutions: Institutional effectiveness, } \\
\text { institutionalization and discursive politics' }\end{array}$ & $\begin{array}{l}\text { Seminar Presentation, } \\
\text { Department of } \\
\text { Environmental Science and } \\
\text { Policy, GMU }\end{array}$ & 2016 & 0.5 \\
\hline $\begin{array}{l}\text { 'Does discourse matter in institutionalization? } \\
\text { The case of REDD+MRV in Indonesia, Peru and } \\
\text { Tanzania' }\end{array}$ & $\begin{array}{l}\text { Nairobi Conference of Earth } \\
\text { System Governance, Nairobi, } \\
\text { Kenya }\end{array}$ & 2016 & 2 \\
\hline
\end{tabular}




\section{Career related competences}

Writing skills

WGS

$2014 \quad 2$

$\mathrm{PhD}$ competence assessment

WGS

$2014 \quad 1$

Presentation skills

WGS

$2015 \quad 1.8$

Information literacy including endnote

WGS/ WUR Library

$2015 \quad 0.6$

introduction

Mobilising your scientific network

WGS

$2015 \quad 1$

Project and time management

WGS

$2015 \quad 1.5$

Lecturer in Forest and Nature Governance: FNP

FNP

2014

1.5

24306

Guest lecturer in Forest and Nature Governance

FNP

2015

0.5

Guest lecturer, REDD+ MRV Processes in

George Mason University

2016

0.5 developing countries

Guest Lecturer, Environmental Policy Making in

George Mason University

2016

0.5

Developing Countries

Total

38.1

* One credit according to ECTS is on average equivalent to 28 hours of study load 


\section{Funding}

This PhD was financially supported by a scholarship from the Centre for International Forestry Research (CIFOR). The research described in this dissertation form part of the CIFOR-led Global Comparative Study on REDD+ (GCS REDD+). Funding for the GCS REDD+ was provided by the Norwegian Agency for Development Cooperation (Grant Nos. QZA-12/0882 and QZA016/0110 nr 1500551); the Australian Agency for International Development (Grant No. 63560); the European Union (Grant No. EUROPEAID/DCI-ENV/2011/269-520); the International Climate Initiative (IKI) of the German Federal Ministry for the Environment, Nature Conservation, Building and Nuclear Safety (BMUB) (Grant No. KI II 7-42206-6/75); the United Kingdom Department for International Development (DFID Component code 203034-103); and the CGIAR Research Program on Forests, Trees and Agroforestry (Grant No. CGIAR Funds TF No. 069018). 


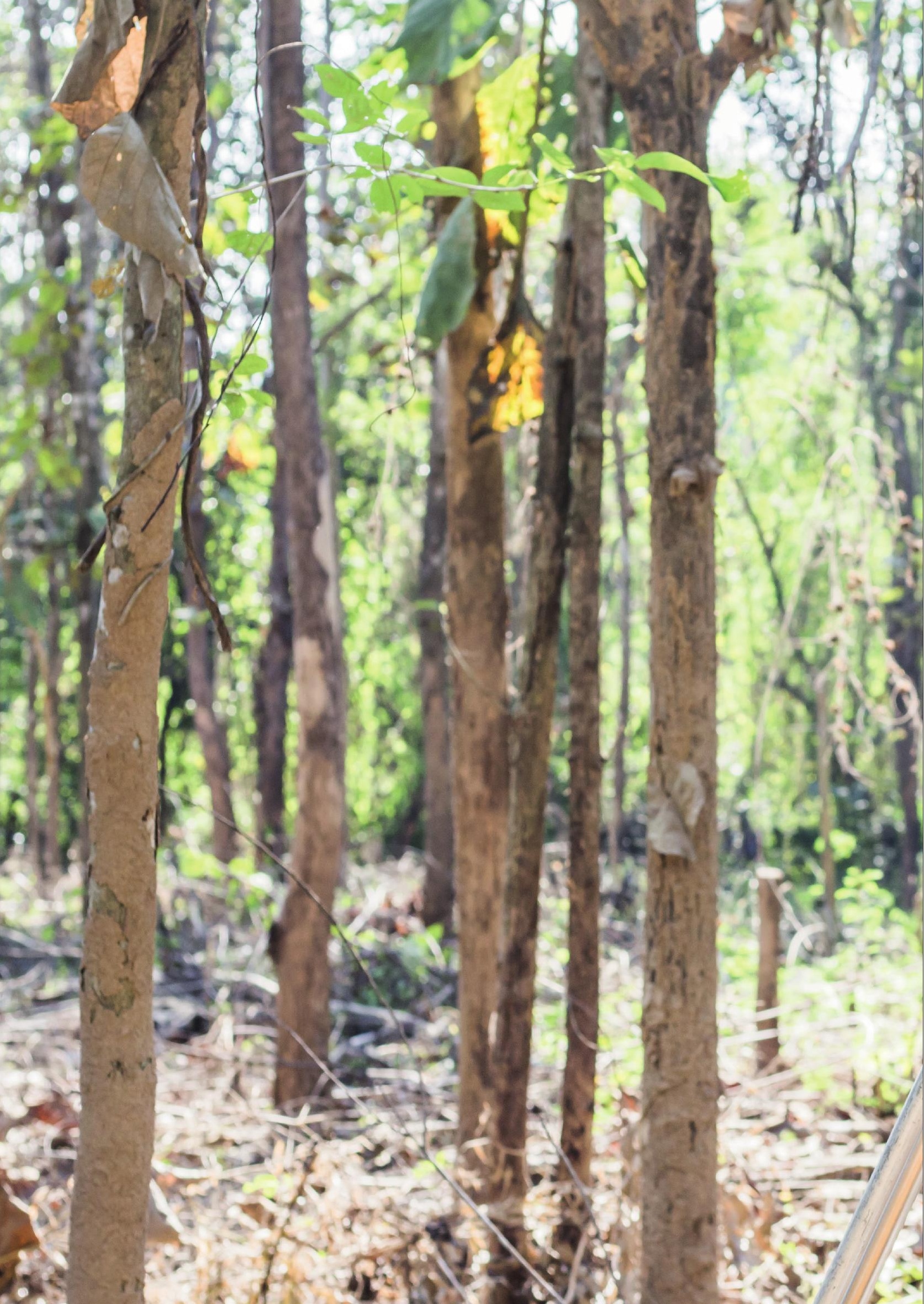

